\title{
Where should I study? \\ International students' perceptions of higher education in the UK, Ireland, and the U.S.
}

\author{
by \\ Cheryl Ann Rounsaville \\ B.Sc., M.Sc.
}

Thesis submitted to the University of Nottingham for the degree of Doctor of Philosophy October 2011 


\begin{abstract}
In the thesis I examine international student decision-making arguing that there is a gap in knowledge about the theoretical frameworks which have been applied to understanding this issue. A comprehensive review of the literature showed that thus far the foremost theory utilised for explaining international student decision-making is the Push-Pull Theory of Migration, a theory which is primarily quantitative. This research innovatively uses a theoretical framework combining three influential capital theories based on a qualitative methodology. Using this theoretical framework, I sought a deeper, and potentially new and different understanding of why international students choose to study abroad and why they select particular host countries - the two questions traditional Push-Pull Theory seeks to answer.
\end{abstract}

The three capital theories used are Human, Cultural and Social Capital. Using these to understand the decision-making of international students begins with the premise that individuals invest in international education in the hope of achieving some aim or reaping some benefit. As these theories originate from two different disciplines, I argue that such an approach provides a more multifaceted perspective for understanding students' decision-making. Each of these theories, including their strengths and weaknesses, is discussed in detail in the thesis.

The context for the study is provided through an examination of the impact of globalisation and neo-liberalism on the political, economic, socio-cultural, and technological trends of recent decades. It also considers the growing internationalisation and marketisation of higher education, including a greater emphasis on and expansion of international student recruitment and mobility.

The research notes that individuals are increasingly responsible for their own success in the global knowledge economy. International education is one way in which students can make themselves competitive in the labour market as well as obtain valuable sociocultural benefits. The research emphasises that higher education is becoming a privately rather than publicly-funded activity in which individual students (and often their families) 
make the decisions about whether or not to study abroad and where. Host country, source country, and student perspectives are considered.

The research focused on international postgraduates originating from five Asian source countries, studying in six disciplines, and enrolled at universities in three different Englishspeaking host countries. Data on why students decided to study abroad and why they selected their host country was gathered using questionnaires and face-to-face interviews. The student participants in the research were already enrolled in their host universities at the time of data collection thus enabling me to investigate post-enrolment the reasons for their decisions.

The combined theoretical framework was used to analyse and categorise the data based on whether students' answers referred primarily to human, cultural or social capital. The analysis revealed that for each form of capital, the decisions made by these students were based on both the capital they possessed and had access to prior to international study (existing capital) and the capital they hoped to gain from going abroad (potential capital). Existing and potential capital were broken down further into relevant themes and subthemes. The analyses also showed that human capital factors were most influential, followed by cultural capital and then social capital factors. In addition there was significant overlap among the forms of capital. Finally, the implications and limitations of the research are considered along with recommendations for further research. 


\section{Acknowledgements}

I have many thanks to give for all the help and support I received during my doctoral journey. First and foremost, to my father, Dr. George A. Rounsaville, for his constant encouragement, love, support, and for providing the resources necessary for me to undertake a PhD. Next, to my mother, husband and sister without whose support and encouragement I would not have completed the thesis. Lastly, to all the people from my days in Washington who encouraged me and helped me with my application, especially Dr. France Pruitt and Dr. Thomas Mitchell.

My sincerest thanks to Professor W. John Morgan for his continued support and patience through what must have seemed like five very long years reading about international students, as well as to Dr. Anne Convery and Professor Simon McGrath for their help in bringing the thesis together. Many thanks to my friends and colleagues at Nottingham for their friendship and advice, especially Musa, Caron, Paola, Fella, Eleanor, Monira, Engin, Rosalind and Filip.

Thanks to the staff of all the universities I targeted in the research for their help in accessing students. Finally, my heartfelt thanks go out to the international students who took time from their busy schedules to complete my survey, and especially to those who consented to be interviewed. I truly enjoyed meeting all of them and hearing their stories. They showed me that while they are often portrayed as numbers grouped according to host or source country, field or level of study, they all have individual stories - and compelling reasons - for how they came to be studying in countries far from their homes and loved ones. 


\section{Table of Contents}

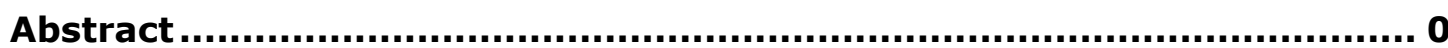

Acknowledgements........................................................................ 3

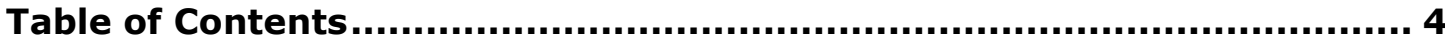

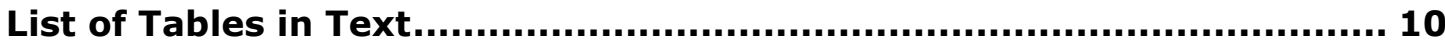

List of Figures ................................................................................... 10

List of Appendices.............................................................................. 11

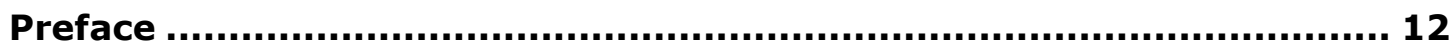

Chapter 1: Introduction ................................................................ 14

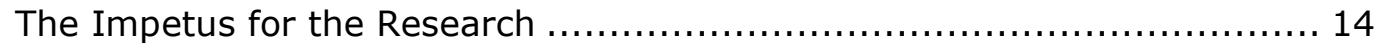

International Students and Terrorism in the U.S. ....................... 14

International Students and Terrorism in the UK ........................ 16

The Importance of International Students.................................. 17

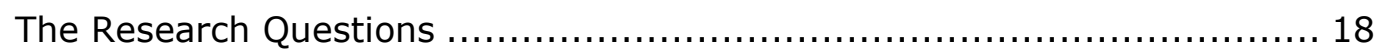

The Research Design........................................................ 20

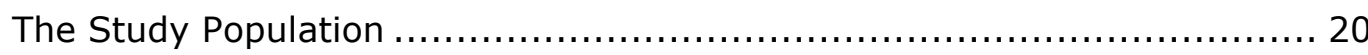

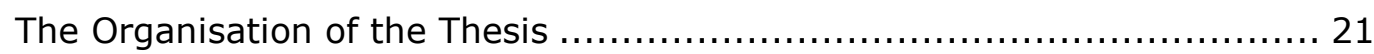

Chapter 2: The Context ......................................................................... 22

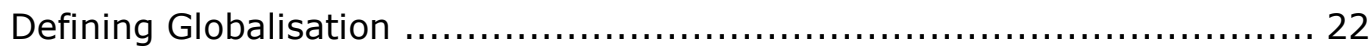

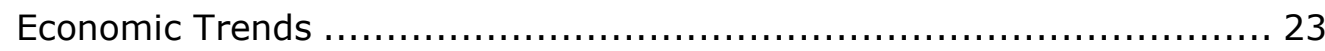

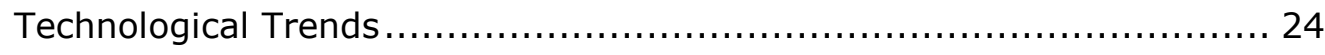

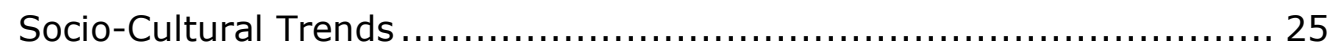

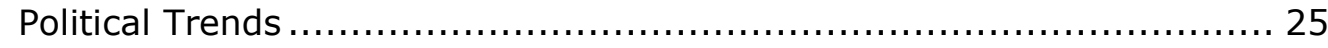

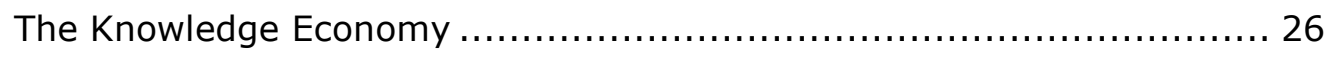

Globalisation and Higher Education ........................................ 27

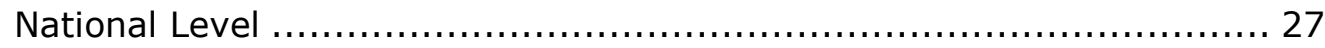

Increasing Demand for Access to Higher Education .................... 28

Decreasing Public Funding of Higher Education......................... 29

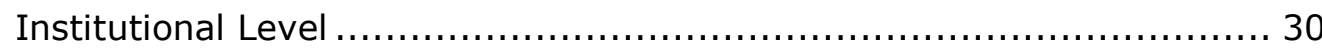

Globalisation, Internationalisation, and Higher Education .................... 31

The Global Market for Higher Education ..................................... 32

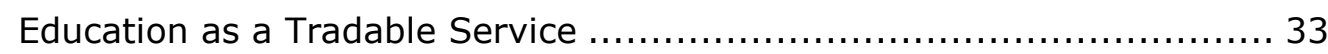

International Higher Education as a Service Export ....................... 33

Branding and Reputation ................................................ 34

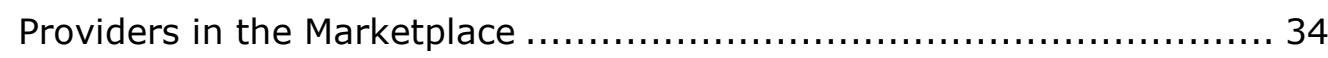


The Competition for International Students ................................ 35

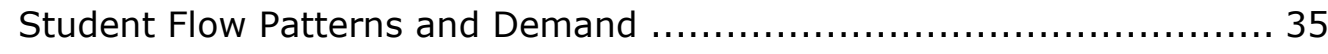

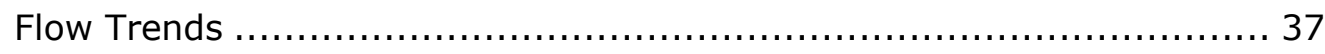

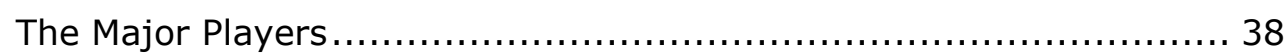

The Middle Powers (and Regionalism) .................................. 39

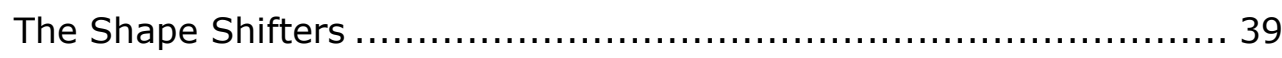

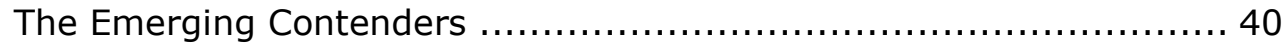

Factors Affecting International Student Mobility in the $21^{\text {st }}$ Century $\ldots \ldots 40$

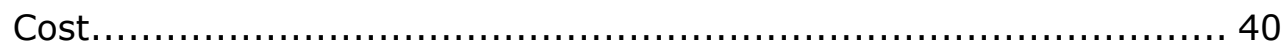

English-Language Provision ......................................... 41

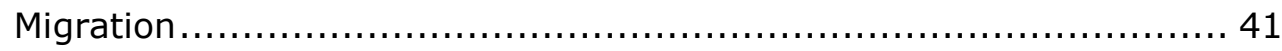

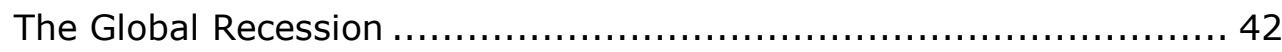

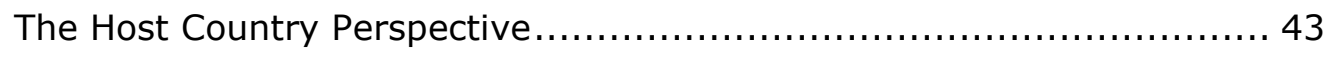

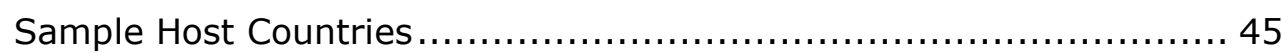

The Source Country Perspective ......................................... 49

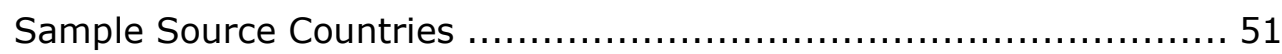

The International Student Perspective .................................. 57

Chapter 3: Review of Previous Research.......................................61 61

The Push-Pull Theory of Migration ...................................... 61

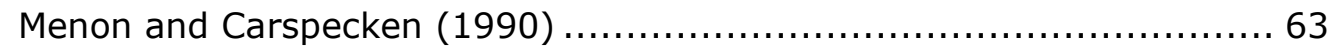

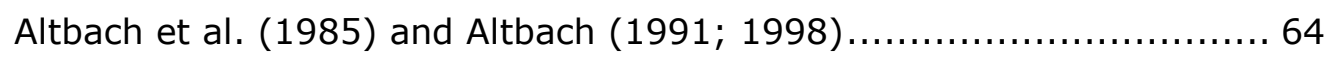

McMahon (1992) ................................................... 65

Mazzarol-led studies: Mazzarol et al. (1996); Mazzarol et al. (2001a);

Mazzarol et al. (2001b); Mazzarol and Soutar $(2001 ; 2002) \ldots \ldots \ldots \ldots \ldots . \ldots 7$

Mazzarol et al. (1996) .............................................. 68

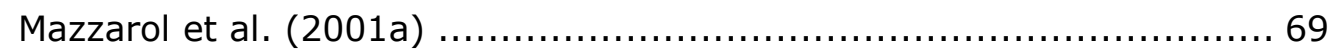

Mazzarol et al. (2001b) .............................................. 71

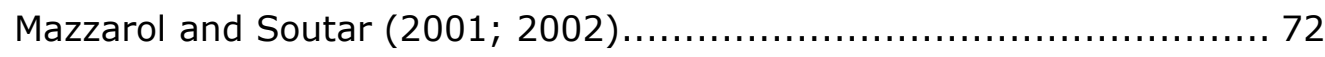

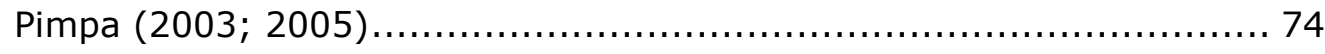

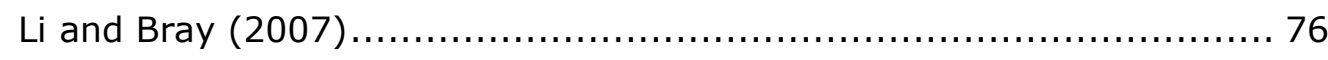

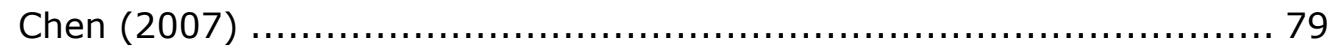

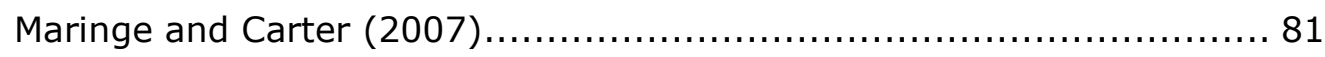

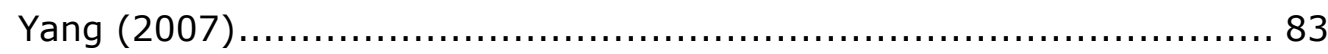

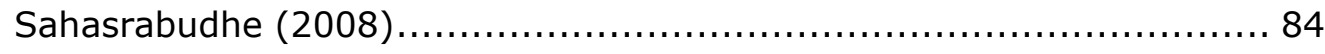

de Wit et al. (2008b) and de Wit and Rumbley (2008).................. 85

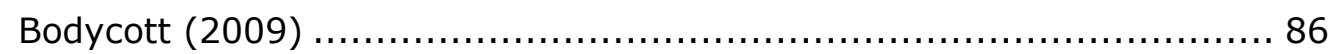

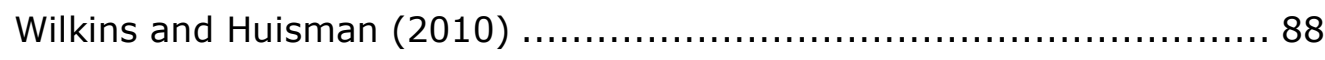

Collective Contribution of the Push-Pull Studies and Influence on the Thesis

Limitations and Gaps in the Existing Research ............................ 92

Chapter 4: The Theoretical Framework ............................................... 96 
What is Capital?

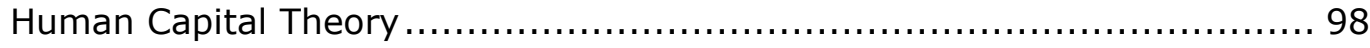

Defining Human Capital .................................................... 99

Human Capital Investments ........................................... 100

Individual Investment in Education ................................... 101

Costs and benefits................................................... 101

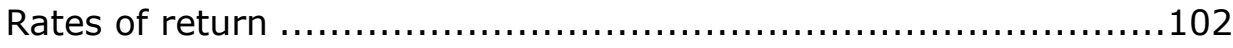

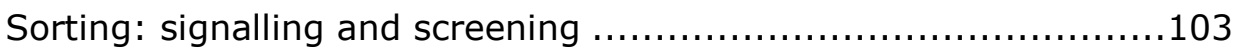

Individual Investment in Migration.................................... 104

International Education and Human Capital .............................105

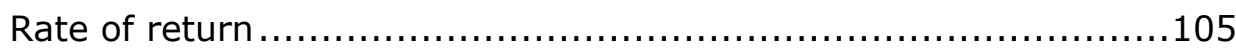

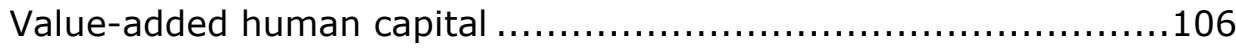

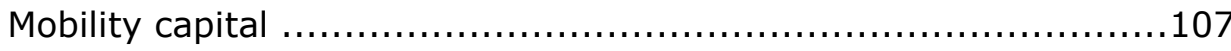

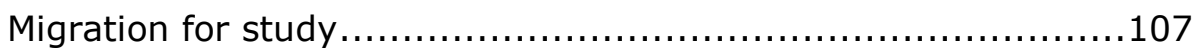

Labour and permanent migration ................................ 108

Critiques of Human Capital Theory ......................................... 108

Public Policy and Human Capital Theory...................................109

Cultural Capital Theory ..................................................... 109

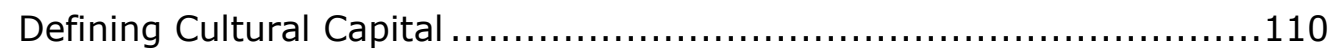

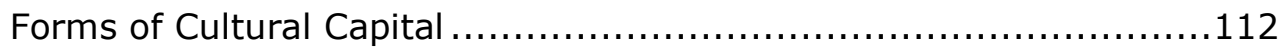

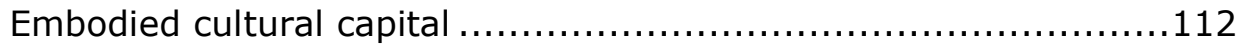

Institutionalised cultural capital ....................................112

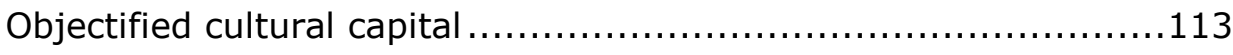

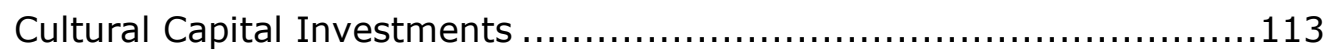

Family Socialisation and Resources .................................114

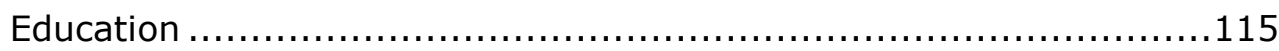

Higher Education and Cultural Capital.....................................116

International Education and Cultural Capital...............................118

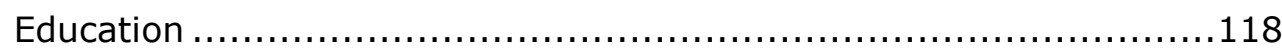

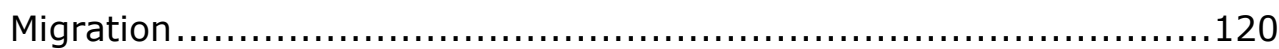

Public Policy and Cultural Capital Theory ...................................121

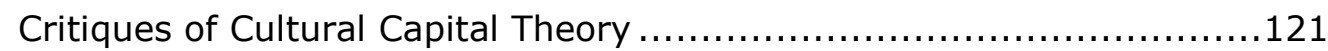

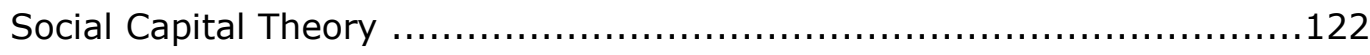

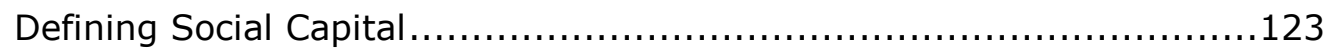

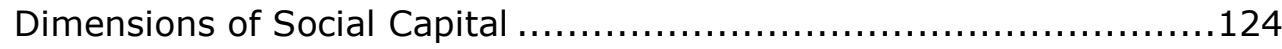

Types of Social Capital ............................................... 125

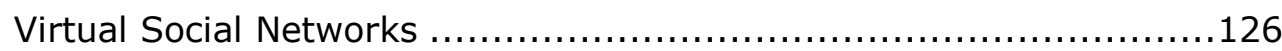

Social and Other Forms of Capital ....................................... 127

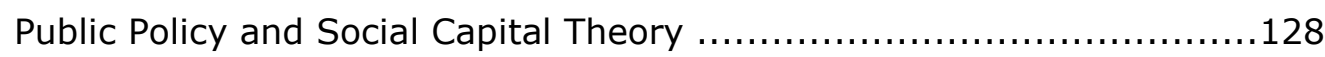

Social Capital Investment ................................................ 129

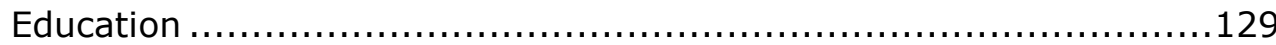




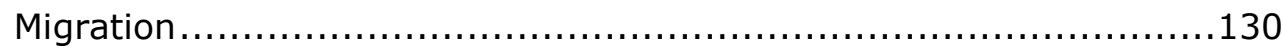

International Education and Social Capital ...............................131

Kinship Networks ................................................... 131

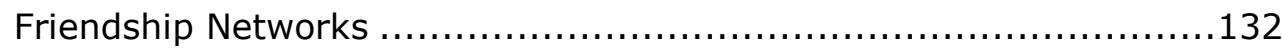

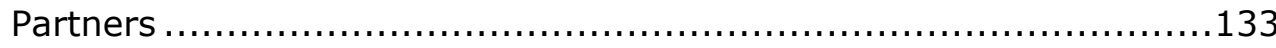

Other Social Capital Resources ...........................................133

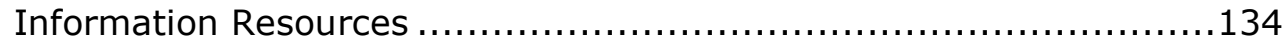

Renewing Social Capital ............................................... 135

Critiques of Social Capital Theory ........................................ 136

Chapter 5: Methodology and Research Design ................................ 137

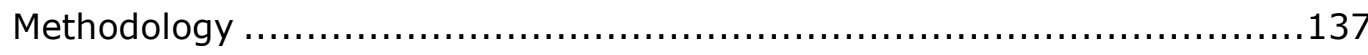

Epistemological and Ontological Considerations ............................138

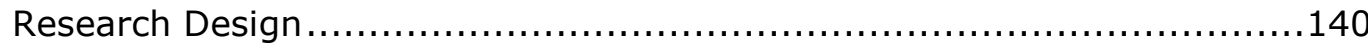

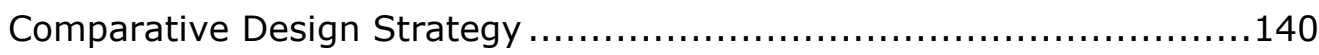

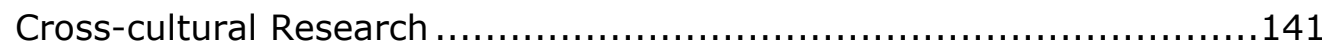

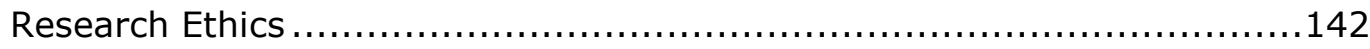

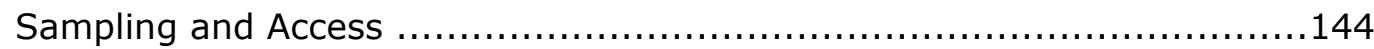

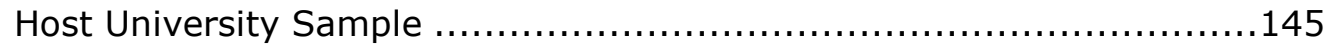

Student Sample.................................................... 145

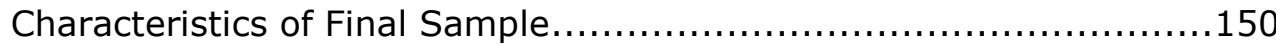

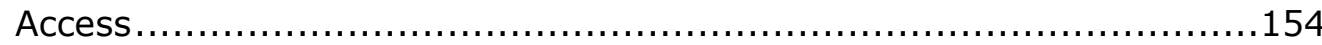

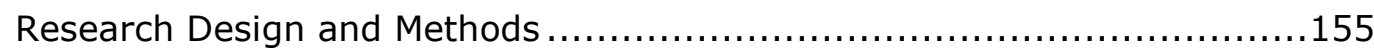

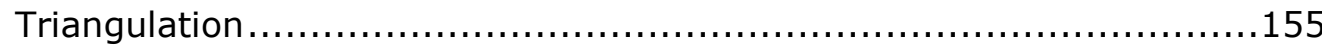

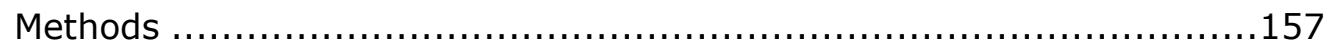

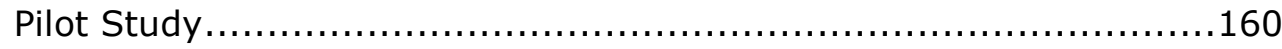

Main Data Collection ................................................. 161

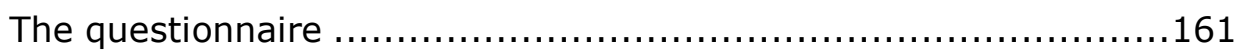

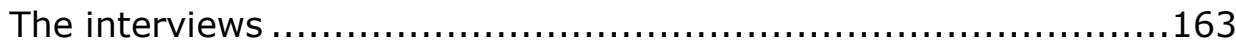

Chapter 6: Presentation and Analyses of Data ................................ 168

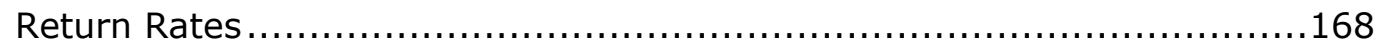

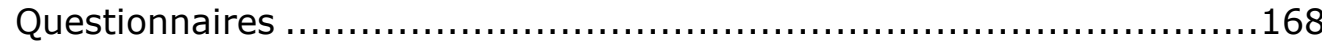

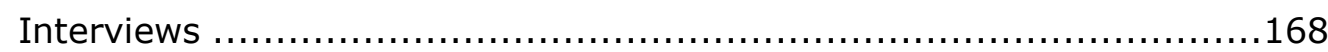

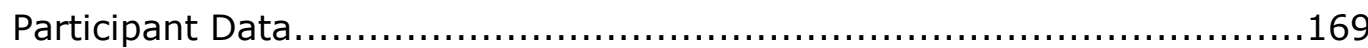

Questionnaires ......................................................... 169

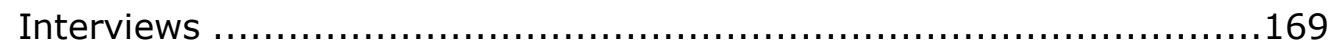

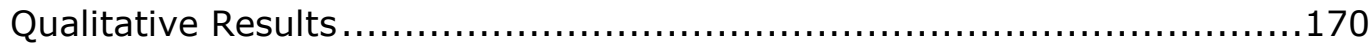

Considering Overall Patterns in the Data...................................172

The Questionnaire and Interview Data ..................................... 183

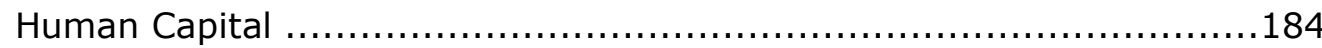

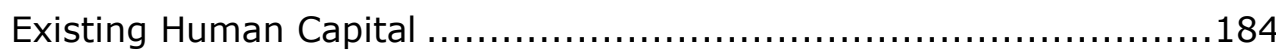


Previous university degree obtained 186

Previous degree/study/work done in the same host country 186

Previous work experience 188

Student's previous academic achievement 188

Potential Human Capital 189

Postgraduate level education 191

High quality education 192

Cost-effective education 196

Better career opportunities 202

Access to better resources for study 208

High standard of living 213

Access to specific course content or specialised programme 215

Exposure to specialisation in the field of study 217

Quick and easy admittance to university 219

Exposure to an economically developed country.... 222

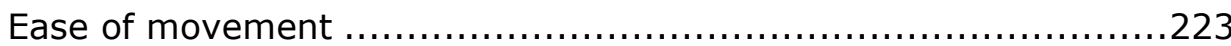

Cultural Capital .224

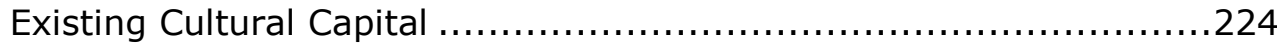

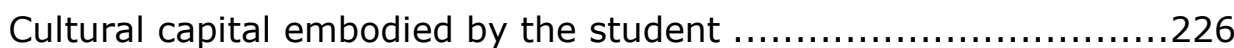

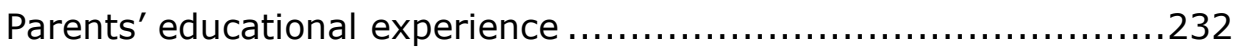

Family tradition of studying/working/living overseas................233

Cultural capital embodied by home country ..........................234

Cultural capital embodied by home country education ...............235

Potential Cultural Capital ...............................................236

Cultural capital of host country ..................................... 238

Cultural capital of host country education.............................239

International and cross-cultural experience .........................244

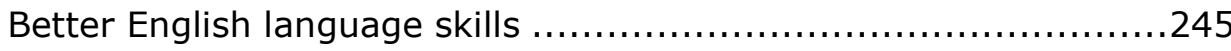

Knowledge of 'Western' values.....................................247

Personal growth ....................................................... 248

Increased status in the mind's of others .............................250

Cultural capital gains for student's family ..........................253

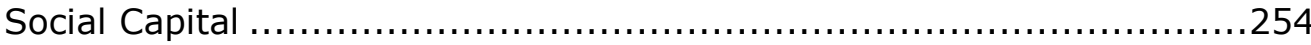

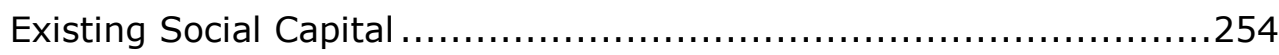

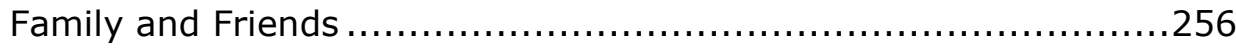

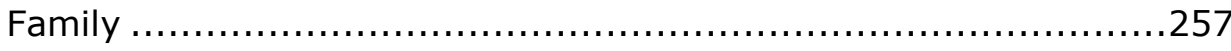

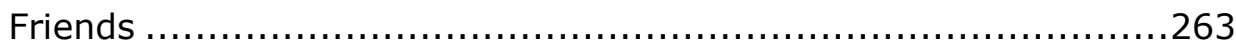

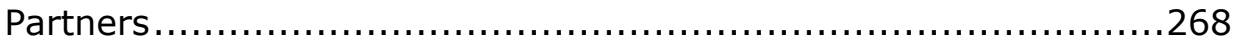

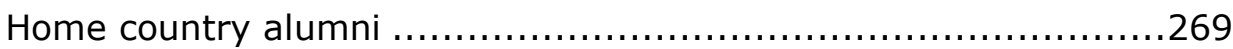

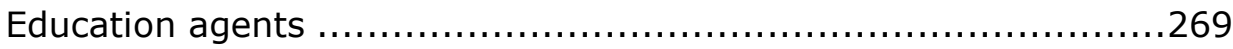

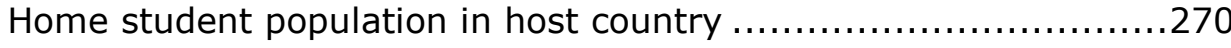


Community of home country nationals in host country 271

Electronic resources/Internet.....................................271

Potential Social Capital...............................................275

Network with new people ........................................277

Network with other international people/students ...................277

Network with academic/professional community .....................278

Chapter 7: What does the data show? ......................................... 280

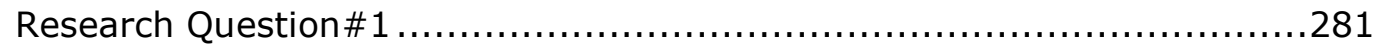

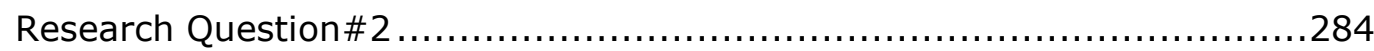

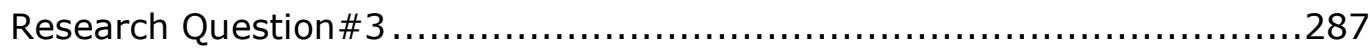

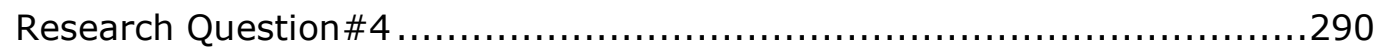

How the Forms of Capital Overlap ........................................ 292

Comparison with Studies using Push-Pull Theory .............................294

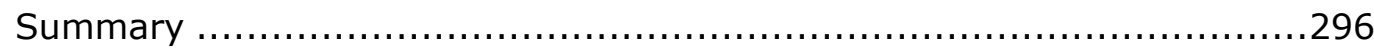

Chapter 8: Conclusion ...................................................................... 298

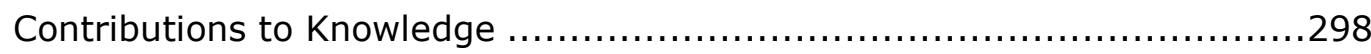

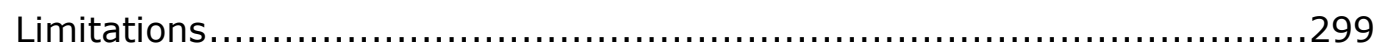

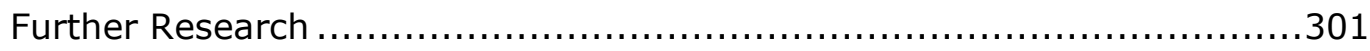

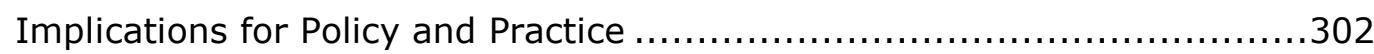

Reflecting on the Research................................................. 305

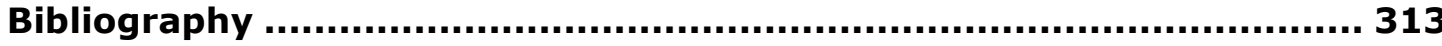

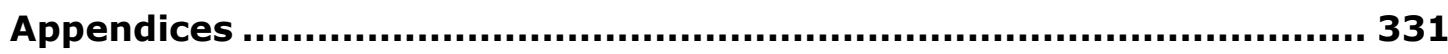




\section{List of Tables in Text}

\section{Chapter 6 tables:}

Table 15a: Reasons by Host Country

Table 15b: Reasons by Host Country

Table 15c: Reasons by Host Country

Table 16a: Reasons by Source Country

Table 16b: Reasons by Source Country

Table 16c: Reasons by Source Country

Table 17a: Reasons by Field of Study

Table 17b: Reasons by Field of Study

Table 17c: Reasons by Field of Study

Table 19: Existing Human Capital

Table 20: Potential Human Capital

Table 21: Existing Cultural Capital

Table 23: Potential Cultural Capital

Table 24: Existing Social Capital

Table 25: Potential Social Capital

\section{List of Figures}

\section{Chapter 2:}

Figure 1. Student flows in the worldwide environment of higher education.

\section{Chapter 3:}

Figure 2. Basic push-pull model.

Figure 3. Multidimensional reverse push-pull model. 


\section{List of Appendices}

Appendix A: Questionnaire Information and Consent Forms

Appendix B: Interview Information and Consent Forms

Appendix C: Questionnaire

Appendix D: Interview Schedule

Appendix E: Return and Response Rates

Table 1: Questionnaires Return Rates

Table 2: Interviewee Response Rates

Appendix F: Participant Demographic Data

Table 3: Questionnaires - Demographic data for University UK

Table 4: Questionnaires - Participant data for University UK

Table 5: Questionnaires - Demographic data for University U.S.

Table 6: Questionnaires - Participant data for University U.S.

Table 7: Questionnaires - Demographic data for University Ireland

Table 8: Questionnaires - Participant data for University Ireland

Table 9: Interviews - Demographic data for University UK

Table 10: Interviews - Participant data for University UK

Table 11: Interviews - Demographic data for University U.S.

Table 12: Interviews - Participant data for University U.S.

Table 13: Interviews - Demographic data for University Ireland

Table 14: Interviews - Participant data for University Ireland

Appendix G: Interviewee Information

Table 18: Interviewee Information

Appendix H: Parents' Education and Occupations

Table 22: Parents' Education/Occupation 


\section{Preface}

No research can be completely value-free so I would like to begin by explaining how I came to be interested in conducting research on international students. My interest in international education was initially sparked by my experience as an English teacher in Japan where I lived and worked from 1996 to 1999. Through this experience I had the privilege of seeing the power of international exchange up close and knew that I had found what I wanted to do. Upon returning to the U.S., I worked as an international education professional for several years, sending American students and young professionals abroad for work or study. Initially, I had only a slight interest in and knowledge of the other side of the international education coin, international students. The events of September 11, $2001(9 / 11)$ however sparked my interest in learning more and the desire to deepen my knowledge prompted me to undertake doctoral research focusing on the decision-making processes of these students.

Another note of significance for the thesis, regarding my position as a researcher on international student issues, is that I am also an international student: an American pursuing a $\mathrm{PhD}$ at a British university. This gives me some personal insight into and sympathy with the motives and choices made by international students. My decision to study in the UK rather than at home was both professional and personal. At the time I was applying for PhD programmes I had worked for over six years in the field of international education. I was eager to move beyond day-to-day programme administration and thought one way to improve my promotion potential would be to obtain a PhD. In an informal review of the credentials of those working as directors and assistant directors of various international education programmes, centres, and organisations I conducted about this time, the majority seemed to possess PhDs or EdDs. I concluded that besides securing a more challenging job, having a doctorate would potentially provide me with a higher salary as well.

On the personal side, it has been a longtime goal of mine to get a PhD. The main reasons are because of the personal sense of accomplishment, as well as the social and academic prestige inherent in having such a high level education. I have been taught the value of higher education and been inspired to pursue it by my uncle who has a PhD, my father 
who obtained the degree of Doctor of Dental Surgery, and my mother who completed a Bachelor's degree in Sociology. My mother and father were the first persons in their families to attend university. Finally, I have been an Anglophile since I was a teenager so I have long dreamed of living in the UK. I was the first person in my family to visit the UK when I was twenty-two and I traveled here numerous times prior to studying at Nottingham so am familiar with the country and culture. Another reason for choosing the UK for study is that I am a native English speaker making study here much easier for me than in a non-English speaking country. I also felt a degree from a British university would be seen as equivalent to a degree from an American university in the U.S. labour market. Unlike many of the international students I surveyed however, I considered only one host country - the UK, and England particularly - for study. 


\section{Chapter 1: Introduction}

The central focus of the thesis is international student decision-making. This chapter details the circumstances which led to the empirical research being conducted, presents the main research questions, describes how the research was carried out, and clarifies the organisation of the thesis.

\section{The Impetus for the Research}

International Students and Terrorism in the U.S.

The terrorist attacks of $9 / 11$ brought the issue of international students to the forefront because an investigation into these attacks showed that at least one of the hijackers involved had entered the U.S. on an international student visa. The suspect, Hani Hanjour, entered the country using a student visa but never attended the English language programme in which he was enrolled in California. As a result of this information, the U.S. government tightened immigration policy for all international students. One U.S. senator even called for a six-month moratorium on all student visas in order to give the government time to fix the holes in the visa system exploited by Hanjour (Curry, 2001). This moratorium was never instituted but there were a number of other reforms put into place to strengthen the system, such as the Student and Exchange Visitor Information System (SEVIS) ${ }^{1}$ and the Visa Mantis programme ${ }^{2}$. In addition, the U.S. government began to require that all visa applicants be interviewed in person at a U.S. embassy or consulate, and biometric data be collected upon entry into the U.S. (Bollag, 2004a; 2004b).

While the need to reform the visa system to strengthen national security seemed necessary at the time, the restrictions and difficulties involved with the implementation of the above reforms caused many problems for international students hoping to study in the U.S. The main complaints of students were about excessive visa delays and denials with

\footnotetext{
${ }^{1}$ SEVIS is an Internet-based system, administered by the U.S. Department of Homeland Security that collects information on non-immigrants who enter the U.S. with student and exchange visitor visas, as well as their dependents (GAO, 2007).

2 The Visa Mantis programme is a security review procedure involving multiple U.S. government agencies, which aims to identify those visa applicants, particularly science students and scholars, who may pose a threat to national security by illegally transferring sensitive technology $(G A O, 2005)$.
} 
some waiting on average sixty-seven days before being notified about whether or not their visas were approved. These visa delays and denials prevented many international students and scholars from beginning their programmes of study on time and from conducting scientific research (ISSS-BU News, 2004; Lee, 2008). Reports of these delays and denials continued even through the early months of 2003, causing important research on such issues as HIV to be hampered or cancelled altogether (Bollag, 2003; Gutterman, 2003).

Visa applicants also complained they were not given valid reasons for visa denial or that their parents were denied visas to visit them during their time in the country (Bollag, 2004a; 2004b). In some cases, U.S. officials demanded that students who left the country undergo new security checks before being allowed to re-enter. Student complaints about SEVIS focused on the onerous reporting requirements, as well as the $\$ 100$ fee required to cover the cost of administration (Bollag, 2004b; Lee, 2008). In addition, paying this fee was no guarantee that if the student was accepted to a university he or she would be issued a visa or would receive it before the start of classes (Kless, 2004). The in-person visa interview was also a cause for complaint from students because they sometimes had to travel a great distance at some expense for a three-minute interview and answer questions often perceived as insulting and rude, while the collection of biometric data was regarded as demeaning (Bollag, 2004a; Johnson, 2009). There were also lingering fears among students (and parents) about safety in the U.S. (Bollag, 2004c; de Wit and Rumbley, 2008).

Studies done in the two to three years immediately after $9 / 11$ showed an alarming decline in the number of international students applying to study in the U.S., with visa delays and the burdensome restrictions of the new system as major reasons for these declines (Bollag, 2004a; Lee, 2008). Although the U.S. government took some measures in 2004 to reduce student visa processing times and restore visa approval rates to pre-9/11 levels, the number of applications from international students continued to fall prompting further investigation into the decline. One of the most worrisome findings of these studies was the perception of potential applicants that international students were no longer welcome in the U.S. (Bollag, 2004a; GAO, 2004; Suter and Jandl, 2008; Johnson, 2009). Although the government made some changes in order to make the process easier for applicants to navigate, after three years of extremely strict visa regulations and numerous "horror- 
stories" concerning the treatment of visa applicants, the U.S. had gained a reputation of being unwelcoming to international students. This caused many to question whether this perception could be overcome or whether the U.S. had truly lost its edge as the leading destination of international students (Bollag, 2004a; GAO, 2009).

The tragedy of 9/11 touched America in many unforeseen ways. Who would have predicted that terrorist acts would cause a major shift in American immigration policy for international students, a decline in the number of international students applying to study in the U.S., and the erosion of America's image of academic freedom and reputation as a welcoming place for students and scholars from around the world?

\section{International Students and Terrorism in the UK}

Terrorism involving international students is unfortunately not unique to the U.S. The UK has also suffered from or been associated with terrorist incidents involving international students. These incidents include attempted bombings in London and Glasgow in 2007 in which two of the four suspects had studied in the UK ("Doctors held in bomb probe", 2007; "Bomb plot: Arrests and releases", 2007). There were two other cases in 2009 and 2010 of former international students who had studied in the UK involved in airplane and suicide bombings ("Profile: Umar Farouk Abdulmutallab, 2010; "Plane bomb suspect 'not radicalised at London's UCL", 2010; "Sweden suicide bombing suspect faces terror charges", 2011).

It is also important to note that the UK, like the U.S., due in part to increased national security concerns (including the threat of further terrorism), has attempted to tighten its immigration system by making changes to its visa requirements and immigration rules (MacDonald, 2008; Newman, 2009). The implementation of a new points-based, fivetiered immigration system (PBS) occurred in 2008, the time this research began (MacDonald, 2008; Somerville et al., 2009). Tier 4, which took effect in March 2009, focused on visa and immigration requirements for all incoming international students (UKBA, 2008; MacDonald, 2008; Cooper, 2009).

New measures under Tier 4 to which international students were subject included the limitation of student visas to a maximum of four years (no matter the length of the 
course); mandatory registration at local police stations within a week of arrival; collection of biometric data and possession of biometric identity cards from an immigration clearance post; and special security clearance from the Foreign Office to study certain subjects (UKBA, 2008; Dyke, 2008; McCracken, 2009). As in the U.S., many of these changes have been accompanied by extra costs for students (UKBA, 2008). PBS also required educational institutions to serve as sponsors for students, gather considerably more documentation from students at the application stage, and track student attendance while at the institution (Cooper, 2009; McCracken, 2009; Somerville et al., 2009).

Higher education experts expressed their concerns about the new system being too complicated and onerous for students as well as institutions. They worried that its similarities to the post-9/11 system in the U.S. would lead to similar problems in the UK, and most worryingly would result in decreases in international student numbers and a reputation for being unwelcoming to international students (McCracken, 2009). A more stringent visa system targeting international students was even more worrisome when coupled with the global economic crisis that began in 2008 (McCracken, 2009; Somerville and Sumption, 2009). In addition, the UK's main competitor for international students, the U.S., having worked out its visa problems was seeing international students numbers increase again, while other competitors, like Australia, were further intensifying and increasing their recruitment activities (MacDonald, 2008; Douglass and Edelstein, 2009; McCracken, 2009).

\section{The Importance of International Students}

The impact of these events on the academic world has been significant and challenging to say the least. While national security is the fundamental responsibility of governments, higher education cannot be naïve about the threat of terrorism. At the same time, higher education must continue to promote academic freedom and mobility, as well as international cooperation. However, the fact that some of these terrorists have been identified as international students in the countries in which the attacks occurred has cast a shadow of suspicion on the actions and motives of all international students (Feller, 2007). 
Concerns about national security have disrupted the free flow of international students and scholars, but have also highlighted the benefits of hosting these individuals at both the national and institutional levels. For example, international students are a source of revenue for higher education institutions and local economies, conduct important research, and bring intellectual and cultural diversity to host nations and host institutions (NAFSA, 2003; Council of Graduate Schools, 2004). They also provide nations with a pool of highly skilled migrants needed to be competitive in the labour market (Suter and Jandl, 2008).

Further, despite the case of Hani Hanjour, international students also play a critical, if indirect, role in strengthening national security. For example, U.S. government officials were so focused on strengthening visa policies and regulations after $9 / 11$ they overlooked that creating goodwill towards the U.S. among citizens of other countries is also a critical factor in promoting U.S. public diplomacy and national security. Providing a welcoming environment and high quality education to international students is one method of generating goodwill and improving foreign relations (NAFSA, 2003; GAO, 2009). During their time studying in the U.S., international students, many of them future leaders in government and industry, gain an appreciation for American culture and values which they take back to their home countries, and American citizens in turn gain an appreciation for the cultures and values of international students (NAFSA, 2003).

The benefits of hosting international students do not, of course, pertain only to the U.S. but are important to most host countries. These countries see the economic, political, cultural, and academic benefits of hosting international students and, in many cases, they compete fiercely with one another to recruit these students to study in their institutions. The global competition for international students is intense and so the motivations of these students and the way in which they make decisions are important for host countries and their institutions to understand.

\section{The Research Questions}

The thesis focuses on the motivations and decision-making processes of international students with the ultimate goal to contribute to the body of knowledge in this area. I intend to do this by applying a unique theoretical framework to the understanding of this issue. 
A comprehensive review of past literature revealed that hitherto the foremost theory utilised for explaining international student decision-making is the Push-Pull Theory of Migration. One of the aims of the research was to take the study of international student decision-making beyond this widely accepted paradigm and examine it using a different (and, I feel, more comprehensive) theoretical framework based on the theories of Human, Social, and Cultural Capital.

The research first attempted to answer the two key questions asked by Push-Pull Theory: 'Why do international students choose to study overseas (push)?' and 'Why do international students choose a certain host country for study (pull)?' The research questions developed from these two key questions were:

1. How do human, social, and cultural capital rank amongst the various reasons international postgraduates pursue international education?

2. What human, cultural, and social capital did students possess prior to their postgraduate programme that:

a. enabled them to study overseas?

b. influenced their choice of a particular host country?

3. What human, cultural, and social capital do they hope to gain from:

a. studying overseas?

b. studying in a particular host country?

4. What sources did students use to help them evaluate the benefits of:

a. studying overseas?

b. studying in a particular host country?

The research next attempted to provide a comparison of international students studying in different host countries in terms of the research questions above, and to explore the reasons these students selected one host country over another. However, after conducting my analysis I realised that for reasons of time, space, and coherence, I would not be able to include a comparative perspective in the thesis but should concentrate on answering 
the fundamental research questions (1-4 above) first. The thesis does provide me with a basis for more detailed comparative work with this data which I hope to do in future. My comparative questions were:

5. For students studying in the UK or Ireland: Did they choose the UK or Ireland because they perceived that a degree from one of these host countries would have greater human, cultural and social capital benefits than one from the U.S.?

6. For students studying in the U.S.: Did they choose the U.S. because they perceived that a degree from the U.S. would have greater human, cultural and social capital benefits than one from the UK or Ireland?

\section{The Research Design}

I began my research by conducting an extensive literature review of issues impacting international student mobility as well as previous research done on international student decision-making. The literature was used to develop my research questions and methods, as well as to identify a sample population.

The field research was conducted in two phases. The first phase involved the dissemination of a questionnaire to international postgraduate students at three universities in the UK, Ireland, and the U.S. Closed questions were used to confirm demographic and educational information. Open-ended questions were used to probe reasons why students left home to study abroad, and why they chose to study in one host country over another. The second phase of the research consisted of individual, face-toface, semi-structured interviews with a self-selected sample of students who had completed a questionnaire. The interview schedule consisted of a combination of (mostly) pre-determined, closed and open-ended questions aimed at clarifying and expanding on questionnaire responses and eliciting new information relevant to the topic.

\section{The Study Population}

For purposes of easier comparability across host countries, the study population targeted in the research was very specific and subject to a sampling process in which they had to 
meet six pre-determined criteria. Based on these criteria, the study population was limited to students who were self-funded international post-graduates studying full-time and pursuing full degrees at the university in which they were enrolled. In addition, the country of origin of students was limited to five Asian source countries (China, India, Korea, Japan, and Taiwan), and seven fields of study, including important STEM subjects (Engineering, Business Management, Physical and Life Sciences, Mathematics, Computer Sciences, Law, and Medicine). The three universities which were used as research sites are all considered to be prestigious universities both domestically and internationally although selecting only prestigious universities was not intentional but rather due primarily to the ease of access to student participants.

\section{The Organisation of the Thesis}

The final purpose of this introductory chapter is to give readers an indication of the structure of the thesis and a general idea of what is discussed in subsequent chapters. Chapter 2 examines the policy context in which the research took place focusing specifically on how international student mobility has been affected by globalisation, internationalisation, the knowledge economy, and the current global economic crisis. This chapter also presents information on each of the three host and five source countries targeted in the research.

Chapter 3 provides a discussion of the previous literature on international student decision-making highlighting important and relevant research that utilised Push-Pull Theory. Chapter 4 explores each of the capital theories used as part of the theoretical framework. Chapter 5 explains the choice of methodology used, together with a review of the ethical issues involved, and an outline of the research design and methods employed. The results of the analyses are presented in Chapter 6 followed by a discussion of the findings in Chapter 7. Finally, Chapter 8 offers concluding remarks about the research including limitations and suggestions for further research.

This introductory chapter has attempted to provide some insight into the impetus and importance of the research, and to explain my position as the researcher. In addition, it has presented the research questions, a brief description of the research design, and the organisation of the thesis. Chapter 2 turns to setting the context of the research. 


\section{Chapter 2: The Context}

Chapter 2 sets the context for the research in two parts. The first part focuses on globalisation, internationalisation, the knowledge economy, and the global higher education market. The second part focuses on the competition for international students, including the characteristics and changing patterns of international student flows over time concluding with a picture of the market at the time of data collection. The chapter also presents the perspectives of the host countries, source countries, and students.

\section{Defining Globalisation}

There is still much debate about how to define globalisation and identify its consequences, and to determine who, if anyone, benefits from it (Rizvi, 2004). Some argue that globalisation is simply the establishment of free markets for products, services and capital via deregulation, decentralisation, and privatisation (Rizvi, 2004; Field and Fegan, 2005). Others argue that globalisation derives from (and is propelled by) America's neo-liberal policy agenda and cultural hegemony, and its push for political democracy and capitalism. Others believe globalisation is simply about power, part of a 'hegemonic project' or new form of colonialism in which the three economic powers, the U.S., the European Union (EU) and Japan continue to grow stronger and richer to the detriment of the poorer countries who cannot keep up with the rapid pace of change associated with globalisation (Rizvi, 2004). Still others argue that globalisation should be defined according to whether it represents a subjective or objective reality for individuals, or constitutes both (Lauder et al., 2006; Marginson, 2010). Field and Fegan (2005) proffer a conciliatory response to these debates by stating "the use of the term globalisation is broad and understanding it depends upon the semantic paradigm applied and the context in which it is used" (p.4).

Most agree, however, that globalisation is creating significant and pervasive changes along economic, technological, socio-cultural, and political dimensions (Coulby and Zambeta, 2005; Olssen, 2006). The most distinctive characteristic of globalisation is the speed at which changes are taking place, due primarily to continuing technological advancement. These changes are not uni-directional and do not occur evenly in every country, but they 
have been significant enough to have an impact on the views, beliefs, behaviour, as well as the material circumstances, of people around the world (Rizvi, 2004; Gunn, 2005; Stiglitz, 2006). These changes have also led to the creation of a global economy consisting of numerous networks, connections, and associations between nations, societies, organisations and individuals (Coulby and Zambeta, 2005).

\section{Economic Trends}

Neo-liberal economic theory, seen as the driving force behind globalisation, promotes the concepts of New Public Management (NPM), and open markets that support the free flow of commodities and capital around the world. Introduced in the 1980s, the aim of NPM was to promote better management of the public budget through a market orientation which would, in turn, make public bodies more accountable, effective, and cost-efficient (Olssen et al., 2004; Gunn, 2005). This has resulted in, for better or worse, greater privatisation of services once provided and funded by the state in many countries, like higher education (Altbach et al., 2009).

Formerly, it was mainly goods traded across national boundaries, but the current state of globalisation has changed the nature of trading to embrace the commodification of all types of human enterprise (Gunn, 2005). The quantity and speed with which these commodities, including capital, labour and information, are moved across national borders is continually increasing. Information, or knowledge, is now one of the most valuable and important commodities traded in the globalised economy (Coulby and Zambeta, 2005; Gunn, 2005).

Globalisation has caused the emphasis in trade, mainly among developed nations, to move from the manufacture of products to the provision and consumption of services, including education services. A nation's ability to be economically competitive and relevant in the global market is highly dependent on being able to produce specialised products and services for consumers making research and development crucial (Mazzarol and Soutar, 2001; Coulby and Zambeta, 2005). 


\section{Technological Trends}

The continuing advances and spread of new developments in science and technology, linked mainly to international communication, transportation, and the sharing of and access to information, are among the major drivers of globalisation (Mazzarol and Soutar, 2001; Coulby and Zambeta, 2005). Four technological developments in particular - the Internet, mobile phones, satellite technology, and airplane travel - have increased the amount and the ways in which people around the world interact (Coulby and Zambeta, 2005; Gunn, 2005; Lauder et al., 2006). These technologies have the ability to virtually shrink time and space making it possible for people around the world to communicate with one another in seconds (Mazzarol and Soutar, 2001; Gunn, 2005; Lauder et al., 2006).

In recent years, the development of information communication technologies (ICTs), particularly the Internet, has resulted in the rapid and unprecedented sharing of knowledge and helped create extensive global networks in all areas of life (Mazzarol and Soutar, 2001; Marginson, 2002; Olssen, 2006). The invention of mobile phones has resulted in changes in both the instruments and manner of communication. Access to transportation, particularly airplane travel, has grown and become cheaper leading to an increased movement of people for business, work, research, and study. This increased movement of people has, in turn, resulted in an unprecedented convergence of cultures, economies, and ideologies around the world (Marginson, 2002).

Technological innovations have also changed the skill requirements needed in the labour market leading to increased demand for more highly educated workers as ICTs are now vital to many work functions (Lauder et al., 2006). In addition, ICTs are important objects of consumption impacting daily life and leisure. They have produced considerable social and cultural changes in societies which have been exposed to them although their digital content reflects primarily the language, cultural attitudes and viewpoints of the Englishspeaking developed world (Coulby and Zambeta, 2005; Gunn, 2005; Robertson et al., 2007). 


\section{Socio-Cultural Trends}

Culture is one of the ways in which people most directly experience globalisation (Robertson et al., 2007). Cultural values and norms are transmitted via such globally marketed products as films, books, magazines, television, media, newspapers, electronic games, and food (Coulby and Zambeta, 2005). The scale of cultural transmission via ICTs and global products has also perpetuated the idea of a global culture that cuts across national boundaries (Yang, 2002; Olssen et al., 2004; Oliver, 2005).

The spread of English throughout the world as a consequence of British colonialism and American hegemony has facilitated its use as the dominant means of global communication. English is currently the lingua franca used in international diplomacy, science and business, and the development and use of ICTs (Altbach, 2002; 2006; Gürüz, 2008). The English language itself represents certain political and cultural assumptions related to the culture of powerful Western nations, and the use of which serves to perpetuate their power and influence. The hegemony of English creates a consumer market for products from English-speaking nations including higher education (de Wit, 2002; Coulby and Zambeta, 2005). In other words, English acts as both an instrument and a manifestation of globalisation (Coulby and Zambeta, 2005).

\section{Political Trends}

Political globalisation is a powerful dimension of globalisation that influences, and is a consequence of, the other three dimensions (Olssen et al., 2004). Although nation-states remain the main medium of political control, key to the notion of neo-liberalism is the belief that national boundaries create a significant obstacle to the development of the free trade and flow of capital (Rizvi, 2004). Among the challenges to nation-states wrought by globalisation is the loss of some of their power to the systems of multilayered global governance developed in the second half of the $20^{\text {th }}$ century, such as the United Nations, World Trade Organisation, and the World Bank (Olssen et al., 2004; Lauder et al., 2006; Robertson et al., 2007). Green (2006) and Rizvi (2004) argue that despite this new world order, national governments still play a significant role in relation to work, welfare, education, immigration, national security and defence. 


\section{The Knowledge Economy}

The rapid gathering, generation, reuse, evaluation, and exchange of knowledge is increasingly vital to global economic activities (Olssen et al., 2004). The use of the term 'knowledge' now applies to a broad range of information and data sharing four characteristics: 1 and 2) Accessibility and Superabundance - an extraordinary amount of information and data can now be found and is easily available at home or work via ICTs; 3) Marketisation - knowledge is increasingly a commodity sold in the global economic marketplace; and 4) Internationalisation - knowledge, as it flows around the world, is increasingly subject to various international influences (Coulby, 2005a). As economies around the world move progressively toward the production of knowledge, or a 'knowledge economy', the trade in knowledge and knowledge-based processes becomes more important and lucrative than the manufacture of material products (Coulby, 2005a; Varghese, 2008).

According to Green (2006), higher education is critical to national economic development in the knowledge economy for its role in both knowledge production and the training of knowledge workers. Although knowledge is now being produced in a variety of organisations around the world, universities remain very important in the hierarchy of knowledge production (Gibbons, 1998; Yang, 2002; Coulby, 2005b). Many breakthroughs and advances in knowledge production and technological development still occur in universities, and via teaching and publications they play a crucial role in disseminating knowledge (Coulby, 2005a). The level of specialised knowledge and scale of research required to be competitive in the knowledge economy also requires a great deal of international cooperation in the form of international networks and collaborations in which universities have long been active (Zha, 2003).

The requirements of the knowledge economy dictate not only the type of knowledge considered valuable in the global market but also the type of human capital needed. The development of a pool of human capital in the shape of a well-educated and technicallyskilled workforce which has the ability to be intellectually independent and innovative is needed for nations to be globally competitive (Coulby, 2005b; Keeley, 2007). Individuals must be able to conduct research, generate and utilise knowledge from a variety of 
sources in meaningful and lucrative ways all of which requires high levels of education (Gibbons, 1998; CEC-UKCOSA, 2000; Coulby, 2005b). In other words, the global knowledge economy is one in which higher education assumes a major role in the competition between nations (Green, 2006).

\title{
Globalisation and Higher Education
}

\author{
National Level
}

Green (2006) argues that in the current phase of globalisation, national governments continue to have some control over their higher education systems. Turner and Robson (2008) similarly contend that while globalisation has an overall tendency to reduce the traditional national character of higher education institutions and differences between national systems, it still has to contend somewhat with the influence of national policy structures which shape education. Lauder et al. (2006), on the other hand, assert that some of the power once held by nations in regard to educational policy and governance is being taken over by market forces and multilateral agreements, with regulation and financial support remaining the only elements over which the state still has some authority. Loy (2005) contends that "globalisation tends to commodify everything including education' and "education becomes another resource because it trains people in the work skills they need to contribute to the economy" (p.37).

Marginson (2002) claims, however, that national identity continues to be important to higher education systems and institutions as they are still national structures and are important in terms of their impact on national strategy and positioning. He explains that higher education institutions are still part of nation-states and are in some sense contextually-bound. He continues that while establishing a global identity is vital to the competitiveness of the modern university, their identity will always be "...a product of history... [retaining] national, local and disciplinary roots" (p.413). Marginson contends there is now a complicated relationship between the global and national dimensions of higher education, and while "place-bound identities still matter, and in higher education are partly framed by national agents and systems" (p.413), it is also true that "...the positioning of universities within the global system is crucial, and local factors such as 
national identity and disciplinary specialty are among the factors that determine success" $($ p.413-414)

As a consequence of the current phase of globalisation, there has been increasing demand for access to higher education along with decreased public funding at the national level in many countries.

\section{Increasing Demand for Access to Higher Education}

Partly due to the growth of the global knowledge economy and its requirement for highly skilled employees, there has been an increased demand for higher education in many nations (Sadlak, 1998). The rapid growth of the economies, populations, incomes, and secondary education sectors of newly industrialising nations, like China and India, have resulted in increased demand for higher education from their citizens (Mazzarol and Soutar, 2001; Altbach and Knight, 2007; Teichler and Yaĝci, 2009). Although there is continuing improvement in the development of domestic higher education infrastructure in these countries, demand has risen faster than capacity (Sadlak, 1998; Mazzarol and Soutar, 2001). There are currently about 150 million students participating in higher education globally. This is more than a $50 \%$ increase in student numbers since 2000 and as the demand for higher education around the world continues to grow so too will these numbers (Altbach et al., 2009).

In addition to demand for access, the requirement of the knowledge economy for human capital with specialised skills means students are increasingly searching for postgraduate programmes, specialist courses, lifelong learning opportunities, and other new educational opportunities. This has created a considerable challenge for higher education in these countries, and leaves students with the choice to compete for limited places in public institutions, opt for high cost but often less prestigious private higher education, participate in some form of transnational education, or consider studying abroad (Mazzarol and Soutar, 2001; Knight, 2002; de Wit, 2008b; Altbach et al., 2009). The lack of university places has a considerable influence on demand for international study (Böhm et al., 2004). 


\section{Decreasing Public Funding of Higher Education}

In many countries the rapid expansion and massification of higher education, along with the rise in costs of providing it have created a funding dilemma which governments have not been willing to resolve through additional public funding (Adnett, 2010). The public revenue streams of most countries cannot keep pace with demand; a situation further exacerbated by the current global economic crisis (Altbach et al., 2009). In addition, the shift of the public sector in many countries towards neo-liberal philosophies like NPM has had some influence on the public funding of higher education. With its focus on deregulation and privatisation, NPM promotes decreased public funding and marketisation of public sector services. Thus many governments have encouraged their higher education institutions to embrace a market perspective in the belief that additional competition in this sector will make them more accountable for their existence (Gürüz, 2008; Teichler and Yaĝci, 2009).

The changing view of higher education from a public to a private good has also influenced the level of financial support from governments. Universities were traditionally viewed as a public good and a significant part of their return for government and community support was to educate citizens, produce human capital for the labour market, promote civic involvement and advance economic development (Baker et al., 1996; Altbach et al., 2009). However, from the latter part of the $20^{\text {th }}$ to the early $21^{\text {st }}$ century, the view of higher education has changed to one of a private good which primarily benefits individuals rather than nations as a whole. This implies these institutions should be responsible for generating a large portion of their own revenue, and students should be responsible for paying most of the costs related to their education (Altbach and Knight, 2007; Altbach et al., 2009). In many countries, particularly those which have traditionally offered free public higher education, this view remains quite controversial and even the introduction of nominal tuition fees has sometimes been vigorously protested (Altbach, 2002; Bollag, 2007). 


\section{Institutional Level}

Global trends impacting higher education at the institutional level include an increasing focus on research and development, the rising use of ICTs, and the use of English as the primary means of communication in science and technology (Altbach and Knight, 2007).

The purposes of higher education have traditionally been teaching, research, and community service but, more recently, the importance of teaching and community service seems to have declined in favour of research (Naidoo and Jamieson, 2005; Varghese, 2008; Altbach et al., 2009). Research and development have now become a major source of recognition and revenue for universities. In addition, they not only produce but also modularise and sell knowledge as education services and programmes (Robertson et al., 2006). In other words, higher education institutions can be viewed not only as producers but also as brokers of knowledge (Seidel, 1991; Coulby, 2005a).

ICTs are now a key feature of university life impacting, and, in some cases, dramatically transforming teaching and learning (Coulby, 2005a; Altbach et al., 2009). The Internet, for example, provides access to e-mail and online networking platforms for academic collaboration and joint research, and the distribution of electronic journals (Altbach et al., 2009). ICTs have transformed the ways in which research is conducted, stored, retrieved and disseminated, and the continual creation of new technologies has resulted in the need for ICT courses at all levels (Bray, 2003; Altbach, 2006). Additionally, innovations in ICTs have meant that learning and the sharing of knowledge need not be limited by time and space, allowing institutions to offer education globally via non-traditional delivery methods such as distance learning (Green, 2006; Knight, 2002).

The demand for education in English is growing because fluency in English is viewed as highly advantageous in the global knowledge economy, as well as for accessing global networks and culture, and using ICTs (Coulby, 2005c). Universities around the world are increasingly using English as the language of instruction for international classes and degree courses in a range of subjects (Coulby, 2005c). English is also the primary language of research as well as academic and scientific communication worldwide. All of 
this creates, and perpetuates, a global demand for higher education in English (de Wit, 2002; Altbach, 2004b; 2006).

\section{Globalisation, Internationalisation, and Higher Education}

These and other global trends present continual challenges and opportunities to higher education. Internationalisation is one way in which higher education responds (de Wit, 2008a). De Wit (2002) describes the relationship between globalisation and internationalisation as, "Globalization can be thought of as the catalyst while internationalization is the response..." (p. 143). It is typically at the institutional level that the actual practice of internationalisation occurs in the form of internationally-focused policies, programmes, and/or activities (van der Wende, 2001; Knight, 2004; de Wit, 2008a). As knowledge becomes more internationalised, for example, universities find it necessary to be internationalised in terms of not only their curriculum but also their faculty, students, and researchers (Coulby, 2005b). National governments are also increasingly realising and promoting the value of internationalising higher education as a highly advantageous response to globalisation (van der Wende, 2001).

According to Knight, internationalisation is "the process of integrating an international, intercultural or global dimension into the purpose, functions or delivery of higher education" (Knight, 2009, para. 8). De Wit (2002) and Knight (2004) describe four common rationales for internationalising higher education:

1) The political rationale which relates to a nation's position and role in the world, including national security, nation building, and foreign policy;

2) The academic rationale which relates to providing an international dimension in higher education, including scholarly exchanges, internationalising curriculum, and attainment of standards of international excellence in research;

3) The cultural and social rationale which relates to the exporting of national culture through promoting the teaching of cross-cultural understanding between nations or communities through such activities as study abroad programmes; 
4) The economic rationale which relates to the economic or trade issues/aims of a nation or of higher education institutions as a result of internationalisation, such as the recruitment of international students to increase institutional revenue.

There is not always a sole rationale for internationalisation, rather there are often multiple rationales at any one time which are not necessarily mutually exclusive but may differ in importance during different periods of national history and development (de Wit, 2002; Yang, 2002; Knight, 2004). In other words, rationales for internationalising higher education have changed (and continue to change) over time together with the needs of societies and their economies, and of education itself (Yang, 2002; Zha, 2003; Varghese, 2008).

In the $21^{\text {st }}$ century, it is economic rationales that play the predominant role in the internationalisation of higher education (van der Wende, 2001; Yang, 2002). Cultural, academic, and political rationales remain important but now seem to be derived from or are at least closely related to economic rationales (Wagner and Schnitzer, 1991; Zha, 2003).

\section{The Global Market for Higher Education}

The decreasing public funding of higher education has put increased pressure on universities to find alternative sources of revenue pushing many into embracing a market perspective (van der Wende, 2001; Knight, 2002; 2004; Naidoo and Jamieson, 2005). Competition with an increasing range of providers for funding and students has also contributed to a shift toward a market orientation in higher education (Mazzarol and Soutar, 2001; Knight, 2004). Many higher education institutions now operate similarly to businesses, using business terminology and placing an emphasis on students as customers and conducting marketing activities (Hemsley-Brown and Oplatka, 2006; McGettigan, 2009; Teichler and Yaĝci, 2009). Moreover, many attempt to create some form of differentiation between themselves and their competitors through, for example, the creation of a strong brand image (Mazzarol and Soutar, 2001). Marginson (2004b) asserts it is "meaningful to refer to a global market [as] [t]here is a defined field of production 
(higher education) with identifiable products (degrees and diplomas) that increasingly conform to a Bachelor/Masters/Doctoral structure..." (p.16).

\section{Education as a Tradable Service}

Education differs in many aspects from other typically traded goods because it is a highly intangible, complex professional service (Mazzarol et al., 2000). The intangibility of education services makes it especially difficult to communicate the nature of the service to a potential consumer, and it is a service in which the purchaser themselves is subject to a process of selection (Baker et al., 1996; Ross et al., 2007). Furthermore, the purchase of education services is often accompanied by high costs that are fixed and difficult to separate, and includes costs other than money such as time and loss of potential income (Conway et al., 1994; Baker et al., 1996). The qualities of various education services can be difficult for students to evaluate and the differences between programmes offered by different institutions are not always apparent. This is particularly the case when straightforward and reliable information is not available to students (Mortimer, 1997; Baldwin and James, 2000; Mazzarol and Soutar, 2001). Bourke (2000) states information is crucial for trade in educational services, and is a critical variable for students when making educational choices. Trade in education services is now a major export industry as evident in the focus on education in regional, bilateral, and global trade agreements like the General Agreement on Trade in Services (GATS) (Bashir, 2007).

\section{International Higher Education as a Service Export}

International higher education is now decidedly seen as a competitive enterprise, and its services as global commodities (Altbach and Knight, 2007; Altbach et al., 2009). The purchase of education services by international students is a form of export for the countries who 'sell' it; an especially important one for the developed English-speaking 'selling' countries of the UK, U.S., and Australia who dominate the global market (Vickers and Bekhradnia, 2007; Douglass and Edelstein, 2009). These countries have an advantage in that they have long embraced a market perspective and liberal trade approach. They are also able to maintain their competitiveness by offering English language instruction, 
less rigid degree structures, student-centered approaches to learning, and strong experience in the off-shore delivery of education (van der Wende, 2001).

\section{Branding and Reputation}

Since measuring the quality of education services is difficult, branding and reputation are key aspects of marketing to students (Ivy, 2001; Mazzarol and Soutar, 2001). Bourke (2000) states 'reputation' can have two strands. The first is the reputation of the individual institution. Students are more likely to think an institution delivers quality education, and are more likely to select it, when they are familiar with its reputation (Bourke, 2000; Suter and Jandl, 2008). Mazzarol and Soutar (2001) similarly assert the value of a university degree is often measured more by the university's reputation than by the content of its courses. Lee (2008) states the academic reputation of an institution may be even more important when the student is committing to study in a foreign country. In addition, image is often seen as an important component of quality and institutions can charge high fees based on their reputations as high fees are often a proxy for quality (Böhm et al., 2004; Mazzarol and Soutar, 2001; Bolsmann and Miller, 2008a). The second strand of 'reputation', according to Bourke (2000), is the reputation of the host country. As the quality and nature of an institution's resources and capabilities are in part affected by host country circumstances, it becomes very difficult to separate perceptions of individual universities from the host country image (Bourke, 2000; Gray et al., 2003). Recognising national identity is integral to global reputation many host countries have developed general country campaigns designed to differentiate and brand themselves, and complement the marketing activities of individual universities (Marginson, 2002; Gray et al., 2003; GAO, 2009).

\section{Providers in the Marketplace}

Among the major providers of higher education services in the global marketplace are public and private universities. Due to their relatively long history and support from the state, public universities are often perceived as more prestigious institutions (as compared to private institutions) and admission is frequently limited and very competitive (Altbach et al., 2009). There has been tremendous growth in private higher education in many 
countries in recent decades, including for-profit higher education institutions, corporate universities, and professional associations offering education services (Altbach and Knight, 2007; Altbach et al., 2009). The private sector often operates as demand-absorbing providing access to students who cannot gain admittance to public institutions because they do not qualify or because of limited capacity (Altbach et al., 2009).

Most public universities are not yet completely marketised entities, as are most private institutions, but rather still operate under combined public-private funding, although they now often have to compete for some types of funding, such as research grants (Turner and Robson, 2008). Both public and private universities generate income from tuition fees, research, selling university-related products, and offering consulting services (Altbach et al., 2009). Moreover, they generate revenue from transnational and other international education activities like recruiting international students (Knight, 2004; Marginson, 2004b; Chadee and Naidoo, 2009). International student recruitment is an important part of the internationalisation and revenue-generating strategies of many public and private higher education institutions (Bolsmann and Miller, 2008a; 2008b).

\section{The Competition for International Students}

International student recruitment is one of the most significant and tangible facets of internationalisation and of the global higher education market (de Wit, 2008b; Douglass and Edelstein, 2009). The number of international students has risen substantially from less than 200,000 in the 1950 s to over three million in the first decade of the $21^{\text {st }}$ century (Altbach et al., 2009; Teichler and Yaĝci, 2009; UNESCO, 2010).

\section{Student Flow Patterns and Demand}

Besides changing numbers, the flow patterns of international students have also changed over this period. Prior to World War II the mobility of international students was incidental and individual, only becoming quantitatively significant after the war as the scale of flows became much greater (Cummings, 1984; Altbach et al., 1985; 2009; Gürüz, 2008).

Distinct national patterns of mobility began to emerge with the main flows of students tending to be uni-directional from 'South' to 'North', with 'South' referring to primarily 
developing countries and 'North' to developed, mainly Western, countries (Altbach et al., 1985; Cammelli, 1991; de Wit, 2002). The direction of international student flows during this time was also a result of historical or colonial links and language ties between countries (Mazzarol et al., 1996; Mazzarol and Soutar, 2002).

From the 1960s through the 1990s, South-North flows continued to be the most dominant flow pattern, and the developed OECD countries, particularly the UK and the U.S., dominated the list of receiving countries (Cummings, 1984; de Wit, 2002; 2008b). In the 1980s and 1990s, there was significant growth in international student mobility within the EU (i.e., North-North flows), and from sending countries in Asia (especially China and India). Asian students were studying in large numbers in the main English speaking countries because of the increasing demand for English-language education (McMahon, 1992; de Wit, 2008b; Chadee and Naidoo, 2009).

In the $21^{\text {st }}$ century, international higher education is a multibillion dollar industry which is demand-driven and characterised by intense competition (Gürüz, 2008). The number of international students has generally continued to increase keeping pace with the overall expansion of higher education. There have however been slight decreases in growth rates over the last decade due to the visa problems in the U.S. after $9 / 11$, the economic and immigration changes that have taken place in Europe and Australia, and the global economic crisis (Agarwal et al., 2008; de Wit, 2008b; Douglass and Edelstein, 2009).

The current types of student demand for international education fall into two major categories: excess and differentiated. Excess demand is a result of the lack of higher education capacity in general in a country or lack of capacity in elite public institutions ( $\mathrm{Li}$ and Bray, 2007). Although most of the literature on international students described international education as a first choice for students, Brooks and Waters (2009a; 2009b) assert this is not always the case and refer to 'second chance' students who go abroad to study when opportunities, like access to elite public universities, have been closed off at home. These students do not see international education as a better option necessarily but as an acceptable alternative to compensate for their perceived failure within the domestic 
system. For these students "overseas study can provide a second chance [italics theirs] at 'success'"' (p.199).

Differentiated demand refers to students who could have secured a place at home but preferred to study abroad "to secure qualities not available domestically" (Li and Bray, 2007: p.814). Some students opt to go abroad to study specialist subjects or pursue programmes or courses not available at home (Li and Bray, 2007). Other students view international education as more prestigious than domestic education, and see it as a way to reinforce or boost their 'positional advantage' in terms of social status and life opportunities like desirable jobs and high incomes (Marginson, 2004b; 2006; Waters, 2006a; 2006b; Brooks and Waters, 2009a, 2009b; Waters and Brooks, 2010). Positional demand includes the demand for English language education. Marginson (2004a) asserts "...the acquisition of linguistic and cultural skills in English is one of the primary motivations for positional investment by international students" (p.28).

\section{Flow Trends}

International students flows are now much more complicated and multidirectional than in the past (Li and Bray, 2007; de Wit, 2008b). This is due to the increasingly broad range of study destination choices and student motives (Li and Bray, 2007; de Wit, 2008b; Altbach et al., 2009). Though the figure below from Marginson (2004b) shows only the major flows, it is a good visual of the multidirectionality and asymmetry of student flows during the first decade of the $21^{\text {st }}$ century. 
Figure 1. Student flows in the worldwide environment of higher education.

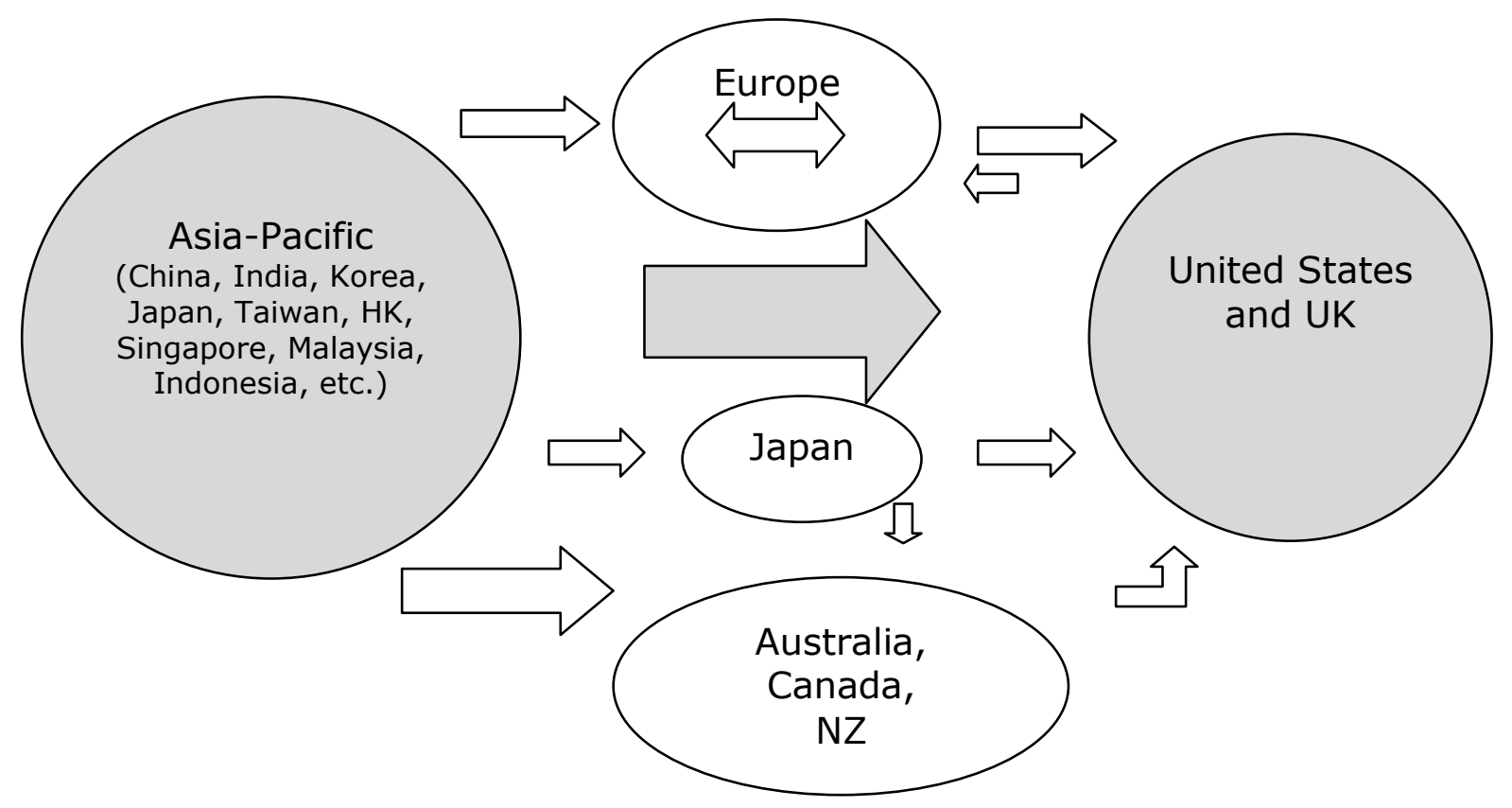

Source: Marginson (2004b).

South-North (or perhaps more appropriately East-West) flows, still the largest, are indicated by the large shaded arrow and consist mainly of students from Asia entering the academic systems of the U.S. and the UK, with smaller flows to Australia, Canada, New Zealand, Europe and Japan (Altbach et al., 2009). North-North flows tend to be fewer in number, as well as more balanced and two-way, an example of which is the considerable student mobility within the EU in recent years (de Wit, 2008b; Altbach et al., 2009).

Data collection for the thesis took place from autumn 2008 through spring 2009. To help create a more detailed picture of the state of the international student market at that time, I use the classification presented by Lasanowski (2009). She identified twelve countries as significant education suppliers operating in the international student market in $2008 / 2009$, who together attracted approximately $85 \%$ of the world's international students.

The Major Players

The U.S., the UK, and Australia were the 'Major Players' in the international student market. They are part of a group of highly competitive Anglo-Saxon, English-speaking 
countries which currently dominate the international student market hosting around $44 \%$ of the world's international students (de Wit, 2002; Lasanowski, 2009). The U.S. and the UK were the two most popular host countries in terms of numbers, with three in every ten international students choosing to study in one of these destinations, although they experienced some overall decline in market share due in part to new competitors (Lasanowski, 2009).

Australia was a major player in terms of competitive strategy if not a strong reputation for high quality education, with numbers of international students not lagging far behind the UK. It benefitted from geographic proximity to Asia attracting the majority of its international students from that region. However, there was some slowing in growth from Asia as countries, like Singapore and Japan, endeavoured to transform themselves into regional centres of higher education and to attract students from other Asian countries (Lasanowski, 2009). Attracting international students to their institutions was a major source of revenue for the major players and competition between them was fierce, especially for postgraduate students (Altbach 2004a).

\section{The Middle Powers (and Regionalism)}

Germany, France, and China were the 'Middle Powers', a group representative of the growing regionalism in international student mobility. Lasanowski described them as more regionally than globally competitive, attracting a large majority of their students from their neighbouring countries or former colonies with which they share linguistic or sociohistorical ties. In 2008/2009, these three countries had a combined market share of approximately $25 \%$. China, with a $7 \%$ share of the market, was a newcomer to the level of middle power. It recruited most of its international students from other Asian countries, but was also becoming a popular destination for students from the West due to the growing importance of its economy (Lasanowski, 2009).

\section{The Shape Shifters}

Lasanowski labelled Canada, Japan and New Zealand as the 'Shape Shifters'. Together these countries accounted for around $10 \%$ of the market. Although existing in "the 
regional 'shadow' of their larger, more popular neighbours (respectively, the US, China and Australia)" (p.3), they have benefitted from being affordable, quality education alternatives to the Major Players. In addition, they have reputations for safety, unique cultures, beautiful scenic environments, and offer programmes in English (including Japan) (Lasanowski, 2009).

\section{The Emerging Contenders}

Finally, in the 'Emerging Contenders' category were Singapore, Malaysia and South Korea. Lasanowski (2009) labelled them as such because they were becoming increasingly important in the market, together hosting over $5 \%$ of the world's international students in $2008 / 2009$. The majority of their international students were from within their regions and they were working hard to transform themselves into regional education hubs. In addition, they were also upgrading their educational infrastructure, increasing their Englishlanguage provision and collaborating with foreign providers in order to become more attractive to students outside of Asia (Chadee and Naidoo, 2009; Lasanowski, 2009). Singapore and Malaysia were particularly attractive because they are multicultural, and benefit from strong linguistic and cultural ties with countries inside and outside of Asia (Lasanowski, 2009).

\section{Factors Affecting International Student Mobility in the $21^{\text {st }}$ Century}

According to Lasanowski (2009), key factors affecting international student mobility in 2008/2009 included educational affordability or cost, demand for education in English, training for the global labour market, and opportunities for employment and migration. In other words, as competition intensified in the international student market, countries which provided the best educational value for money, primarily in English, as well as employment experience and a chance for more permanent migration to the host country were well-placed for becoming successful host countries.

\section{Cost}

The rising cost of higher education was (and is) becoming an increasing concern for the growing number of self-funded international students who besides tuition fees, must 
consider expenditure on visas, application fees, travel, and daily living costs (which are often higher than at home). While the more expensive countries like the U.S. and the UK continued to attract the more affluent students, major destinations like Australia and Canada, as well as emerging hosts like Singapore and Malaysia, all of whom offered cheaper tuition and living costs attracted cost-sensitive students looking for education that offered quality as well as affordability. Cost was also driving the increasing regionalism in mobility, especially in Asia (Lasanowski, 2009). In addition, international students had access to better information on international study options than in the past enabling them to compare prices and make more informed choices (Vickers and Bekhradnia, 2007).

\section{English-Language Provision}

Demand for education in English continued to remain great for reasons given earlier in the chapter (Altbach, 2002; 2006; Gürüz, 2008). Lasanowski (2009) stated that as long as English remained the global lingua franca, studying in one of the main English-speaking countries would continue to be popular because these countries offered good to high quality education with high 'brand' visibility in the international marketplace. In addition, the qualifications they awarded were internationally recognised, highly portable, and perceived to be particularly valuable for entering the global labour market.

\section{Migration}

Many international students were not only pursuing international education for the value of the study experience but another predominant reason was the opportunity to stay in the host country either temporarily or permanently and undertake employment (Yang, 2007; Lasanowski, 2009). Suter and Jandl (2008) claim the higher the degree level, the more likely graduates will stay in the host country to live and work. Doctoral study in particular is fast becoming a precursor to migration as research careers are exceptionally global (Bernardo, 2002; Abella, 2006).

Hugo (2003) states there is some evidence students do consciously consider the immigration policies of various host countries when they are making decisions about where to study. Such policies appear to play an increasingly important role in international 
student decision-making, giving institutions a marketing advantage in recruiting these students, and influencing destination choice and patterns of mobility (Hugo, 2003; Ziguras and Law, 2006; Lasanowski, 2009). Via international student recruitment, universities play a role in the selection of migrants and are increasingly seen as key providers of highly skilled migrant labour for their countries (Suter and Jandl, 2008; Naidoo, 2010).

\section{The Global Recession}

In 2008 , shortly before data collection began for the research, a meltdown of U.S. financial institutions caused the crash of stock markets around the world resulting in a global recession (Hawthorne, 2008; Rong, 2009). This recession has (and will have for some time to come) a negative impact on not only national economies but also universities and students worldwide. Altbach et al. (2009) foresee a period of crisis for higher education with universities across the globe experiencing considerable budget constraints, as well as pressure to establish or increase tuition fees (Altbach et al., 2009; Egron-Polak, 2011).

Hawthorne (2008) and Douglass and Edelstein (2009) predict the recession will have at least a short-term impact on overall flows of international students as they become more price conscious. The recession is certain to affect study destination choice, especially for undergraduates, with students likely to opt for studying regionally or at home if capacity allows, or pursuing transnational education options accessible from home (Hawthorne, 2008; Rong, 2009). However, Douglass and Edelstein (2009) assert that, in the longer term, as the world's population increases in number and mobility, and the needs of the global labour market change, the pool of international students will continue to grow. According to Lasanowski (2009), "[even] in the most volatile of world economies, students recognise that education is a valuable asset towards future employment, with those looking to expand opportunity for employment likely to consider overseas education" (p.38).

I now turn to a discussion of the host country perspective for recruiting international students. 


\section{The Host Country Perspective}

There are a number of costs and concerns for host countries and institutions in hosting international students. There are costs incurred, for example, to host countries and institutions in regard to immigration-related processes for admitting and tracking students (Baker et al., 1996; Mazzarol and Soutar, 2001; NRC, 2005; Suter and Jandl, 2008). For countries allowing international graduates to stay and work there are worries about the potential for depression of wages in certain occupations and increased unemployment for domestic graduates (Chishti, 1984; Vickers and Bekhradnia, 2007).

Academically there are worries about whether international students will displace home students, and whether the quality of education is affected by the presence of international students as poor language skills may slow down the pace of instruction or force change to the curriculum (Baker et al., 1996; CEC-UKCOSA, 2000; Suter and Jandl, 2008). Hosting large numbers of international students can be costly when universities have to cater to their special needs in terms of, for instance, the provision of English language training (Altbach et al., 1985; Mazzarol and Soutar, 2001; Suter and Jandl, 2008). As a new group of international students must be recruited each year to replace those completing their courses, host institutions must continually market themselves abroad, a costly undertaking (Böhm et al., 2004; Hemsley-Brown and Oplatka, 2006; Stachowski, 2011).

Despite such costs, it seems to generally be the case that host countries and institutions benefit considerably from hosting international students. Full-fee paying international students, for instance, have become a major source of additional revenue for higher education institutions, accounting for a significant portion of their budgets and providing revenue needed to subsidise other facets of the institution such as research output and improvements to services for domestic students (Ziguras and Law, 2006; Bolsmann and Miller, 2008a; 2008b; Lee, 2008; Douglass and Edelstein, 2009). International students also contribute financially to local economies in their host countries through their spending on daily living costs (Davey, 2005; Vickers and Bekhradnia, 2007; Suter and Jandl, 2008).

International students contribute to the internationalisation of the curriculum, as well as the cultural diversity on courses and campuses which benefits home students and staff 
(Gray et al., 2003; Böhm et al., 2004; Bolsmann and Miller, 2008a; Lee, 2008). They can also be critical to the viability of some courses, programmes and academic departments, constituting a majority of students in some doctoral programmes (CEC-UKCOSA, 2000; Altbach, 2004a; Böhm et al., 2004; Vickers and Bekhradnia, 2007). The presence of these students is often taken as an indicator of the international status and excellence of an institution, and can provide a marketing advantage in the recruitment of new international students (Bolsmann and Miller, 2008a).

During their period of study, international students not only gain academic knowledge but also develop strong ties to the host country (Chishti, 1984; Vickers and Bekhradnia, 2007). Students' experiences of living and studying in the host country can develop into long-term trade and cultural relationships, promoting mutual understanding and cooperation (Altbach, 1991; Baker et al., 1996). All of the major host countries consider the hosting of international students to be part of their broader foreign policy goals as these students advance knowledge and understanding of the host country's culture, lifestyle, and political beliefs in their home countries (CEC-UKCOSA, 2000; NRC, 2005; Douglass and Edelstein, 2009).

For host countries and institutions to be competitive with respect to global knowledge production, it is essential they attract international students studying at the postgraduate level (Altbach et al., 1985; NRC, 2005; Douglass and Edelstein, 2009). International postgraduates especially have a significant and positive impact on teaching and research, and their recruitment is particularly important as they tend to be concentrated in the STEM fields $^{3}$ (Altbach et al., 1985; Finn, 2007; Casey, 2009; Adnett, 2010). Many host countries also consider international students as a talent pool for recruiting highly skilled human capital needed in the labour market purposely crafting their migration policies to attract the best and the brightest students to apply for study (ACE, 2006; Suter and Jandl, 2008; Teichler and Yaĝci, 2009). This involves offering student-friendly visa schemes and immigration procedures, such as online visa applications, that facilitate the arrival and integration of these students (Lasanowski, 2009). Many also offer students, especially postgraduates, the possibility to remain in the country after graduation and undertake

\footnotetext{
${ }^{3}$ The STEM fields include Science, Technology, Engineering and Mathematics (Lederman, 2009).
} 
employment, and possibly obtain permanent residency (Davey, 2005; ACE, 2006; Suter and Jandl, 2008).

International graduates are the ideal migrants because not only are they highly skilled but they have considerable experience in the host country, a good command of the host country language, and can be easily integrated into the labour market and social sphere (Alberts and Hazen, 2005; Suter and Jandl, 2008; Lange, 2009). These graduates are generally young, of working age, unlikely to have dependents, often work highly skilled jobs in well-paid professions and pay far more in taxes than they receive from the government, especially if they eventually return home (Vickers and Bekhradnia, 2007; Douglass and Edelstein, 2009; Lasanowski, 2009).

I next present information on the three host countries selected for the research: the U.S., the UK, and Ireland. More is said in Chapter 5 about why these countries were selected for the research so I present here only information on the background and nature of these countries as host countries.

\section{Sample Host Countries}

As noted earlier by Lasanowski (2009), the U.S. and the UK were major players in the international student market and ranked as the number one (U.S.) and number two (UK) most popular study destinations in $2008 / 2009$. There are many reasons for this. The U.S. with its long time commitment to mass higher education has one of the largest higher education systems in terms of capacity, and one of the most well-financed, diverse and high quality systems in the world. It has a devolved system which is not administered at the state and local levels resulting in not only much variation within the system, but also a large degree of institutional autonomy and academic freedom (de Wit and Rumbley, 2008; Gürüz, 2008). The UK has also long been a global leader, second only to the U.S., in the provision of international higher education worldwide. The UK's higher education system, with approximately 165 higher education institutions, boasts some of the most prestigious, internationally renowned universities in the world (Universities UK, 2010; Postgrad.com, 2011a; 2011b). 
Though both countries have long histories of hosting international students, there are some important differences in their approaches to international education and international students. The U.S. has no federal body or national policy that controls the international dimension of higher education meaning any administration or financing for international activities must be generated by the institutions themselves or by students (de Wit, 2002). The UK government has had a national policy on international education since 1999 with the introduction of the 'Prime Minister's Initiatives', PMI1 (1999-2004) and PMI2 (2006-2011) (Böhm et al., 2004; Gürüz, 2008). The aim of both PMIs was to attract more international students to the UK through intensive recruitment, easier application and visa processes, opportunities to work during and after study, and an overall improvement in the quality of the international student experience (Findlay and Stam, 2006; Suter and Jandl, 2006; UKCISA, 2008; Douglass and Edelstein, 2009).

International students are attracted to the U.S. and the UK because they offer high quality education in English, top ranking 'brand-name' universities, and numerous educational and funding options (Mazzarol et al., 2001b; Bernardo, 2002; Böhm et al., 2004; Lasanowski, 2009). In 2008, for example, the U.S. and the UK accounted for all top ten universities on the Shanghai Jiao Tong University Academic Ranking of World Universities and the Times Higher Education World University Rankings (ARWU, 2008; THES, 2008). Both countries are major global providers of postgraduate education, particularly for doctoral and other research-related degrees. They are especially interested in attracting international students studying in the STEM fields (Douglass and Edelstein, 2009). Consequently, international postgraduates in the U.S. account for sizable percentages, over $55 \%$ in 2008/2009, of overall enrollment in the STEM fields (de Wit and Rumbley, 2008; Phelps, 2010).

In addition, both countries have strong global positions economically, politically, and technologically, as well as globally disseminated cultures and language (Altbach, 2004a; Marginson, 2006; Bolsmann and Miller, 2008a; Gürüz, 2008). Students are also attracted to these countries because of the many opportunities for employment during and after study, and the possibility of more permanent migration (Bernardo, 2002; Findlay and 
Stam, 2006). The U.S., in particular, has experienced significant stay rates for international postgraduates, particularly doctoral recipients (Suter and Jandl, 2008).

According to IIE (IIE, 2009a), the top five source countries for the U.S. in 2008/2009 were India $(103,260)$, China $(98,235)$, South Korea $(75,065)$, Canada $(29,697)$, and Japan $(29,264)$. Students from Asia (East, South, and West Asia) have remained the leading source of international students in the U.S. for the past twenty-five years (de Wit and Rumbley, 2008). Within these regions, the most prominent sources countries have been China, India, Japan, Korea, and Taiwan (Altbach, 2004a). Regionally, Canada is generally among the top five or six source countries for the U.S. swapping rankings periodically with Taiwan (de Wit and Rumbley, 2008; Phelps, 2010). Taiwan was the sixth most important source country for the U.S. in 2008/2009 with 28,065 students (IIE, 2009a).

In $2008 / 2009$, the UK hosted a record 341,791 international students (UNESCO, 2010). The UK hosts two main categories of international students: 1) EU students and 2) non-EU (including Commonwealth) students. The top five EU source countries for the UK in $2008 / 2009$ were Ireland $(15,360)$, Germany $(14,130)$, France $(13,090)$, Greece $(12,035)$, and Cyprus $(10,370)$ (UKCISA, 2010). In 2008/2009, the top five non-EU source countries for the UK were China $(47,035)$, India $(34,065)$, Nigeria $(14,380)$, the U.S. $(14,345)$, and Malaysia $(12,695)$ (UKCISA, 2010). India was the fastest growing source country accounting for $14 \%$ of all non-EU international students (Universities UK, 2010).

Ireland, the third host country targeted in the research, attracts international students because it offers quality higher education, has a reputation for being a relatively safe and friendly country, and has an enviable geographic location with relatively easy access to Europe and North America and membership in the EU (IEBI, 2008; Gürüz, 2008). However, Ireland has a small higher education system relative to the UK and the U.S., with only seven universities and its institutions do not have strong international reputations comparatively (MES, 2004; Fearn, 2008). Ireland has also been hosting international students for many years, but although sharing some of the main drivers of market attractiveness as the U.S. and the UK, in particular an Anglo-Saxon type higher 
education taught in English, it experiences much smaller scale international students flows (Cox, 1997; Boucher, 1998; Gürüz, 2008; IEBI, 2008).

Like the U.S., Ireland has no formal national policy on international education. Despite the announcement in 2004 of a forthcoming government policy there was no such policy in place as of 2008 (IEBI, 2008; Enterprise Ireland, 2010). Ireland has been a prominent destination, however, for English language studies for many years with this industry bringing in large numbers of international students and a great deal of revenue to Ireland (IEBI, 2008; International Student Guru, 2010). Finally, although Ireland has allowed international students to work during the study period since 2001, they have only more recently (since 2007) recognised the importance of retaining highly skilled graduates for the labour market after graduation (Tremblay, 2002; MES, 2004; Abella, 2006; Fearn, 2008).

Like the UK, international students in Ireland fall into two main categories: EU and nonEU. International student totals were not available for 2008/2009 for Ireland, but information from other sources indicated that in 2008, Ireland experienced a considerable decline in applications from two of its top source countries, India (44\%) and China (29\%), as well as a decline in numbers of EU exchange students. The main reasons given for these declines included the strength of the Euro making the cost of studying higher, more favourable exchange rates in the UK, and the lack of part-time jobs available in Ireland for students due to the recession. Other reasons were a lack of awareness of Ireland, especially in Asia, as well as the lengthy visa process to study in Ireland which included more paperwork and higher refusal rates as compared to other host countries (MES, 2004; Enterprise Ireland, 2010; International Student Guru, 2010). At the same time, Ireland also experienced a significant decline in the number of English language students from approximately 140,000 in $2006 / 2007$ to 94,000 in 2009 .

In 2009/2010, Ireland hosted 28,893 international students from 159 countries, generating almost $€ 430$ million for the economy annually. In $2009 / 2010$, the top five EU source countries for Ireland were France (2068), the UK and Northern Ireland (1512), Germany (1450), Spain (1187), and Italy (674). The five most important non-EU countries 
of origin in 2009/2010 were the U.S. (4467), China (3355), Malaysia (1094), India (1125), and Canada (710) (Enterprise Ireland, 2010). Non-EU students accounted for $64 \%$ of the total international student population, with $63 \%$ of these students studying at the Bachelor's level, $25 \%$ at the postgraduate level, and the remainder on other programmes, such as English language programmes. There was a significant increase in the number of international students taking postgraduate programmes in 2009/2010, especially at PhD level where numbers rose by $8 \%$. International postgraduate students were mainly studying Science, although significant numbers were also studying Humanities, Engineering, Computer Science, and Medicine and related disciplines (Enterprise Ireland, 2010).

All three host countries have without a doubt benefitted from internationalisation and the hosting of international students in terms of revenue generation, contributions to teaching and research, and as a pool of highly skilled migrants for their labour markets (de Wit, 2002; Gürüz, 2008; Douglass and Edelstein, 2009).

Next, I turn to the impact of international student mobility on source countries.

\section{The Source Country Perspective}

While the education and migration policies of host countries are influential in determining the movement of students, source countries also have the potential to impact international student flows (Altbach, 1991; Gribble 2008). The approaches and rationales of source countries to managing international student migration have generally reflected and varied with each country's stage of economic development, and demographic and political circumstances (Mazzarol et al., 1996; CEC-UKCOSA, 2000).

Some source countries, for example, have very lenient policies regarding students who want to study abroad allowing them to go as long as they can acquire the necessary support, while other source countries only allow students to study in certain host countries and/or in certain higher education institutions (Altbach, 1991; Gribble 2008). Those source countries which permit their students to go abroad for study recognise there are important potential benefits of doing so. Some view it as a way to meet excess demand for higher 
education without the necessity of funding further facilities at home (Altbach et al., 1985; CEC-UKCOSA, 2000). In addition, for many sending countries who lack specialised training available at home in key disciplines, especially scientific and technological fields, encouraging their students to study abroad is a way to strengthen their development in these areas without having to invest more money into expanding facilities. Students are able to get this training overseas and (presumably) return home upon completion of their studies bringing their newly acquired skills and knowledge (Morgan et al., 2005; Gribble, 2008; Lee, 2008).

International student mobility benefits source countries because it opens their education systems to new knowledge and ideas (Altbach, 1991; Wagner and Schnitzer, 1991; CECUKCOSA, 2000). Additionally, highly educated migrants often form social and professional bridges and other networks between their home and host countries sharing their expertise, assisting in the economic and social development of their home country, and developing relations between nations (Morgan, 2005; Lee, 2008). Another potential benefit of international graduates who do not return home may come in the form of remittances or transfers of money from international migrants to family members at home (Morgan et al., 2005; Adnett, 2010).

There can also be significant costs or problems for source countries of allowing students to study abroad. While the tendency to rely on the importing of higher education may reduce pressure to expand domestic higher education capacity, it can also reduce incentives for quality improvements leading to inadequate funding, overcrowding, low quality academic programmes, and poor working conditions for academic staff and administrators (de Wit, 2008b; Adnett, 2010). As most international students are self-funded, they generate significant income for their host countries while causing a drain on the funding of higher education at home because of lost tuition fees (Altbach, 2006). In addition, the disbursement of private funds for study abroad involves foreign exchange which is a rare commodity in many developing nations and could be used for other purposes (Altbach et al., 1985; CEC-UKCOSA, 2000). 
An immediate cost to the home country of graduates migrating is the cost of their initial education which represents a financial and social loss to their home country (Morgan, 2005; Appleton et al., 2006; Khan, 2010). This migration can also have a negative impact on the domestic higher education system because of the danger that the best students might not return home to help with the educational training of future generations (CECUKCOSA, 2000; Adnett, 2010). In addition, the subjects studied abroad by students are not always relevant to local needs so do not necessarily assist in the building of higher education or the solving of local problems (Altbach et al., 1985). A 'leadership deficit' can occur when the most enterprising students migrate to other countries as these students are often believed to be potential agents of change in their home countries (Neice and Braun, 1977; Baker et al., 1996; Khan, 2010). Another cost occurs when the highly educated of working age settle in their host (or another) country creating a drain on the much needed tax revenue of developing countries (Morgan, 2005; Appleton et al., 2006; Khan, 2010).

A major potential cost to source countries in allowing students to study abroad is brain drain. Morgan (2005) defines brain drain as "...the emigration of highly educated and skilled professional and technical workers from developing countries to the developed ones" (p. 1). Relevant to the discussion here on international student mobility and migration, he specifies that the term "...generally refers to the long-term migration of skilled people who have been the recipients of considerable educational investment by their own society" (p. 1). Brain drain can have a damaging effect on the social and economic development of these countries through eroding their stock of human capital, an already rare resource, as well as having adverse impacts on the human capital development of future generations (Morgan, 2005; Appleton et al., 2006; Gribble, 2008). More recent research on migration has led to a shift from that of a one-way brain drain paradigm to one of 'brain circulation' (Hugo, 2003; Morgan, 2005).

\section{Sample Source Countries}

According to UNESCO (2010), the top ten source countries and number of students abroad for $2008 / 2009$ were as follows: 
1. China - 441,186

2. India $-170,256$

3. South Korea $-112,588$

4. Germany - 83,524

5. U.S. $-50,728$

6. Japan $-50,380$

7. Malaysia $-47,395$

8. France $-45,191$

9. Canada $-44,883$

10. Russian Federation $-43,982$

Asia continued to be the leading and most rapidly growing region of origin of international students particularly to the OECD countries, and within the Asian region, East Asia and the Pacific had the largest group of students abroad at 846,618 (Huang, 2008; Lange, 2009, UNESCO, 2010). The newly industrialising countries of Asia, China and India in particular, were the largest importing countries (Chadee and Naidoo, 2009; Motivans, 2009; Adnett, 2010).

Given its high demand for international education, the focus of the thesis was on the Asian region. Five Asian source countries were selected for the research: China, India, Japan, Korea, and Taiwan. While more is said in Chapter 5 about why these countries were selected for the research, this section presents information on the background and status of each as a source country in $2008 / 2009$.

China and India have both undergone rapid economic growth in recent times with average growth rates of over $9 \%$ and $4 \%$ respectively (Li et al., 2008; Sahasrabudhe, 2008). Their rapid economic development has resulted in populations with high levels of secondary education, rising personal incomes, and raised aspirations (Li and Bray, 2007; Gürüz, 
2008; Sahasrabudhe, 2008; Dimmock and Ong Soon Leong, 2010). This economic boom has also led to an increased demand for educated and skilled labour in both countries, but with their vast populations they struggle to meet the growing demand for access to higher education (Yang, 2007; Li et al., 2008; Sahasrabudhe, 2008; Phelps, 2010; British Council, 2011b).

Both countries have a relatively small number of highly reputed, publicly funded institutions, such as the various IITs (Indian Institutes of Technology) and IIMs (Indian Institutes of Management) in India (Mazzarol et al., 2001a; Altbach, 2007; Gürüz, 2008; Phelps, 2010). To increase capacity, they have allowed rapid growth in private higher education as a way of absorbing excess demand without much additional public expenditure, but quality in these private institutions has been questionable with very few having aspired to the top of the academic hierarchy, and almost none are research universities (Altbach, 2007; Li and Morgan, 2008; Li et al., 2008; Sahasrabudhe, 2008).

China and India have had changeable policies on international student mobility, alternately tightening and loosening restrictions on the movement of international students over the years (Altbach, 1991; Li and Bray, 2007; Biao and Shen, 2009; Sahasrabudhe, 2008). However, recognising their problems with higher education capacity and limited resources to train future faculty, researchers, and knowledge workers in significant numbers, particularly in the STEM fields, they have in recent years adopted a more encouraging and supportive attitude to international study (Yang, 2007; Sahasrabudhe, 2008; Douglass and Edelstein, 2009).

China's history of student mobility can be seen in figures from Gürüz (2008) who states that in 1960 there were only 119 Chinese students studying abroad and after opening to the West for a period in the 1970 s the number jumped to 13,997 by 1974 . Numbers increased tenfold to 181,200 in 2002 , and again to 441,186 in 2008 . China is now the number one source country worldwide with nearly half a million Chinese students undergraduates and postgraduates - studying outside of China in 2008/2009 (UNESCO, 2010; British Council, 2011a). 
The top five host countries for Chinese students in 2008/2009 were the U.S. $(110,246)$, Japan $(77,916)$, Australia $(57,596)$, the UK $(45,356)$, and South Korea $(30,552)$ (UNESCO, 2010). The U.S. has long been a popular host country for Chinese students hosting over one hundred thousand in 2008/2009 (Mazzarol et al., 2001b; Gürüz, 2008). While the UK was the third most popular host country for Chinese students in $2004 / 2005$, by $2008 / 2009$ it had been relegated to fourth place behind Australia (Mazzarol et al., 2001b; UNESCO, $2006 ; 2010)$. While Ireland was not a top host country for China, China was an important source country for Ireland ranking number two for 2006/2007 and 2009/2010 (Enterprise Ireland, 2010). Having completed their undergraduate education at home, Chinese students are strongly oriented toward a postgraduate market (Mazzarol et al., 2001b). Of the Chinese students studying in the U.S. in $2008 / 2009$, for example, $58.5 \%$ were postgraduates (IIE, 2009C).

India is now the second most important source country of international students worldwide after China. In 1955, India sent 3190 students abroad with numbers wavering between 10,000 and 13,000 during the 1960 s and 1970s. In the 1990 s, after the opening of the Indian economy, the number of Indian students studying abroad began to rise rapidly and, by 2008 , over 170,000 Indian students were studying abroad (UNESCO, 2006; 2010; Gürüz, 2008). The top five host countries for Indian students in $2008 / 2009$ were the U.S. $(94,664)$, Australia $(26,520)$, the UK $(25,901)$, New Zealand $(4094)$, and Germany $(3257)$ (UNESCO, 2010). Despite India's historic colonial and family ties to the UK, the U.S. has been the foremost provider of international higher education for Indian students for almost fifty years (Gürüz, 2008). The UK does, however, still host large numbers of Indian students, though now ranking behind not only the U.S. but also Australia as the third most important host country for India in 2008/2009 (Gürüz, 2008; UNESCO, 2006; 2010). Gürüz (2008) asserts the reason for the declining popularity of the UK with Indian students is that colonial ties no longer play as strong a role in their choice of host country as does finding the best educational option for future employability. In $2009 / 2010$, India was in the list of top ten source countries for Ireland with 1125 Indian students studying there (Enterprise Ireland, 2010). 
South Korea, Japan and Taiwan are all developed Asian countries with highly educated populations which have experienced rapid economic development and expansion of their education systems (Mok, 2003; Leadbeater and Wilson, 2007; Yonezawa and Kim, 2006; British Council, 2011c). All have small, elite and selective public higher education sectors with limited capacity alongside large demand-absorbing private sectors (Arimoto, 1997; Finkelstein, 2003; Mok, 2003; Yonezawa and Kim, 2006; Gürüz, 2008; Altbach et al., 2009; British Council, 2011c). Access to higher education, particularly public institutions, has been highly competitive because education is regarded as an important means of social mobility in these countries (Marginson, 2004a; Yonezawa and Kim, 2006). Much of the cost of participation has shifted to parents and students and parents spend a significant amount on private tutoring designed to secure entry to the most prestigious schools and universities for their children (Marginson, 2004a; Yonezawa and Kim, 2006; Altbach et al., 2009). However, as a result of rapidly declining fertility rates and decreasing university age cohorts in Japan and Korea, the supply of higher education is now beginning to exceed demand at the undergraduate level in these two countries (Yonezawa and Kim, 2006; British Council, 2011c).

Korea and Japan have long allowed their students to study overseas, while Taiwan has only done so since the lifting of martial law in 1987 (Mazzarol et al., 1996; Mok, 2003; Chen and Zimitat, 2006; Gürüz, 2008; British Council, 2011d). All three countries have some excess and positional demand for international and English-language education (Marginson, 2004a; Altbach, 2007; Yang, 2007; Bodycott, 2009)

Despite increasing capacity at home, in $2008 / 2009$, Korea still ranked third in the list of top source countries importing international education as it continues to have high positional demand for such education, and also relies on universities abroad for provision of postgraduate education, particularly at the doctoral level (Bernardo, 2002; Marginson, 2004a; UNESCO, 2010). The top five host countries for Korean students in 2008/2009 were the U.S. $(69,198)$, Japan $(23,290)$, Australia $(6270)$, the UK $(4031)$, and Germany (3929) (UNESCO, 2010). The U.S. has long hosted significant numbers of students from Korea and was the number one host country in $2008 / 2009$. However, while the UK was one of the top five host countries for Korean students in 2008/2009, Korea was not in the 
top ten source countries for the UK (UNESCO, 2006; 2010; Gürüz, 2008; UKCISA, 2010). Ireland also has some history of hosting Korean students, particularly in English language programmes, though in much smaller numbers than the UK and the U.S. In 2005/2006, Ireland hosted 169 Korean students, and in 2006/2007, 212 students. In 2009/2010, the numbers of Korean students in Ireland decreased to 157 mainly a result of declining enrollments in the English language sector (Enterprise Ireland, 2010).

Japan has also long been a top source country for many developed countries, and in 2008/2009, ranked sixth in the list of top source countries worldwide (Gürüz, 2008). The majority of Japanese students study abroad at the undergraduate versus postgraduate level, which may be due to the fact that in Japanese society it is difficult to find a job once you are over a certain age (Alberts and Hazen, 2005; CCEM, 2006; Gürüz, 2008). The top five host countries for Japanese students in $2008 / 2009$ were the U.S. $(34,010)$, UK (4465), Australia (2974), France (1908), and Germany (1858) (UNESCO, 2010). The U.S. has long been the top host country for Japan (Gürüz, 2008). While the UK was the second most popular host country for Japanese students in 2008/2009, Japan was not on the UK's list of top ten source countries in 2008/2009 (UNESCO, 2006; 2010; UKCISA, 2010). Ireland was not among the top host countries for Japanese students in 2009/2010, but Japan was the sixteenth ranked source country for Ireland with 186 students. This number declined from 359 in 2005/2006 and 354 in 2006/2007. As with Korea, the fall in numbers from Japan is due to declining English-language programme enrollments (IEBI, 2008; Enterprise Ireland, 2010).

UNESCO does not currently publish any information for Taiwan due to the United Nations' recognition of China as the sovereign state for Taiwan. Hence, there are no directly comparable statistics from UNESCO on the top five host countries or total number of international students in $2008 / 2009$ as given for the other source countries above so other sources are used here. The U.S. was by far the most popular host country hosting 28,065 Taiwanese students in 2008/2009 (IIE, 2009a; Lasanowski, 2009). In 2008/2009, Taiwan was a mainly postgraduate market with $54.6 \%$ of students studying at the postgraduate level (IIE, 2009c). The UK was also an important destination for students from Taiwan ranking seventeenth on the UK's top ten list of source countries for 2008/2009 with 5235 
students (Gürüz, 2008; UKCISA, 2010). Ireland was not a top host country for Taiwan, and Taiwan does not seem to have been an important source country for Ireland as it did not rank among the top twenty-five source countries in either $2006 / 2007$ or $2009 / 2010$ (IEBI, 2008; Enterprise Ireland, 2010).

The source countries in the research (with the exception of Japan) were also important for the high number of students who study abroad at the postgraduate level in the STEM fields. Douglass and Edelstein (2009) state in 2007, international students received 34\% of the 44,515 doctorates granted by U.S. institutions. Students from China, India, Korea, and Taiwan accounted for about $20 \%$ of those doctorates, with China becoming the increasingly dominant source of doctoral talent. Also during that year, international students received $46 \%$ of all doctorates in the Sciences and Engineering. In the UK, the number of international students in the STEM subjects increased from $29 \%$ to $43 \%$ of all postgraduate students in the Sciences and Engineering between 1994 and 2005. As in the U.S., most students were from Asia, mainly China, India, Pakistan, Taiwan, and South Korea (Douglass and Edelstein, 2009).

In addition, these source countries are significant sources of skilled migrants and many students from these countries go abroad intending to remain in their host countries for some time following completion of their studies (Mazzarol et al., 2001b; Gürüz, 2008; Sahasrabudhe, 2008). Between $70 \%$ and $80 \%$ of Indian students in the U.S., for example, do not return home after graduation, taking up employment there instead and becoming a major source of highly skilled human capital for that country (Altbach, 2007;

Sahasrabudhe, 2008). Of the Taiwanese students who received an American doctorate in Science and Engineering in 2001, 47\% were still living in the U.S. in 2003 (Suter and Jandl, 2006). Japan has also experienced a significant number of doctoral graduates who have remained in their host countries following the completion of their degrees (Tremblay, 2002; Abella, 2006; Kamibayashi, 2006).

\section{The International Student Perspective}

The characteristics and needs of international students, as well as their aspirations and expectations, have undergone considerable change over the last several decades. In the 
1960s and 1970s, most international students were from poor countries studying abroad on government-sponsored scholarships and grants (Bashir, 2007; Naidoo, 2010). In the 1980s and 1990s, there was a shift in international student policy within higher education from an aid to trade rationale in many countries, and consequently the characteristics of the international student population changed (Altbach, 1991; Bashir, 2007; Naidoo, 2010). First and foremost, this meant reduced opportunities to study abroad for students from poorer countries (CEC-UKCOSA, 2000; de Wit, 2008b). International students became increasingly self-funded and the decisions regarding study abroad were more often made by individuals and their families than governments (Altbach, 1991). International students were also more likely to be studying for a full-degree at the postgraduate level in certain disciplines like Engineering, Business Management, and Computer Science (Wagner and Schnitzer, 1991; Varghese, 2008).

What began as academic mobility in the $20^{\text {th }}$ century has well and truly changed into a highly competitive student recruitment business in the $21^{\text {st }}$ (Knight, 2009). The characteristics of the students themselves have again changed considerably. The markets are not as homogeneous as they once were and the increase in international student numbers has resulted in an increase in new types of participation in international education. On the demand side, rising personal incomes and aspirations in the newly industrialising countries along with rapid developments in communication technologies and transportation have meant that, like higher education in general, international education has become a possibility for more students than ever before. International student mobility continues to be driven by the belief that an international education offers the ability to raise the economic and social status of the graduate (Suter and Jandl, 2008; Naidoo, 2010).

Due to rapid population growth and limited capacity in some source countries, as well as the rise in numbers of students completing secondary education worldwide, more students are opting to study abroad at the undergraduate level than in the past (Tremblay, 2002; Phelps, 2010). The largest growth continues to be at the postgraduate level, with taught and STEM research programmes especially in demand (Bourke, 2000; Böhm et al., 2004; Varghese, 2008). Motivans (2009) states that in 2007 almost one in four mobile students 
(23\%) worldwide was enrolled in Business and Administration programmes, with Science as the second most popular field attracting $15 \%$ of student enrolment, followed by Engineering, Manufacturing and Construction (14\%) and Humanities and Arts (14\%).

The majority of international students now pay full-cost fees and undertake and finance their study on a private and individual basis (Altbach, 2004a; Altbach et al., 2009; Varghese, 2008). However, in contrast with the past, today's students are not necessarily the most affluent or elite in their societies (Böhm et al., 2004; Li and Bray, 2007; Varghese, 2008). The increase in free-moving, self-funded students means there is a growing diversity in the decisions these students make regarding international education (Binsardi and Ekwulugo, 2003; Motivans, 2009). For example, the direction of flows has become more an individual decision than in the past when students were sponsored by their home governments or other organisations. In addition, students have many more international education options than in the past and are increasingly basing their decisions about where to study on their own preferences as well as the desire to get ahead in life (UKCISA, 2008; Varghese, 2008). Biao and Shen (2009) describe $21^{\text {st }}$ century student mobility as "...driven by students' own initiatives, more open-ended, less predictable..." (p. 4).

Undertaking international education is still accompanied by many costs for students. There are not only the direct financial costs of tuition fees but also costs associated with the move itself (Throsby, 1991). There are opportunity costs such as whether studying at home would have been a better (and less expensive) option for students, or the loss of wages or career advancement because of the choice to remove themselves from the labour market (Mazzarol and Soutar, 2002). Finally, there are the psychic costs. The decision to study abroad usually requires that students remove themselves from family and other support networks and attempt to make a life in a foreign country and study in a foreign education system, all based on limited information. In other words, the decision and level of commitment an international student must make to study outside their home country is considerable (Lee, 2008; Khan, 2010). 
International students leave home to study for a variety of reasons, but clearly most leave to seek opportunities or to access what is not available at home. By doing so, they hope to obtain a complex mix of economic, social and cultural benefits (Egron-Polak, 2004; Mazzarol and Soutar, 2001). There is no doubt the characteristics of international students have changed, and as their numbers are only predicted to grow and they become increasingly free movers, an attempt to understand the decision-making processes of these students using new and different paradigms is necessary.

In this chapter, I have set the context for the research by offering a detailed discussion of how globalisation and internationalisation have impacted higher education, and how the trade in international higher education has evolved into a dynamic and lucrative global market. In the next chapter, I present the predominant paradigm for explaining international student mobility, the Push-Pull Theory of Migration. 


\section{Chapter 3: Review of Previous Research}

Chapter 3 describes Push-Pull Theory, reviews studies on international students which have utilised this theory, and highlights the limitations of the theory which prompted my research.

\section{The Push-Pull Theory of Migration}

The development of Push-Pull Theory is credited to English geographer Ernst Ravenstein whose "Laws of Migration" hypothesised migration is governed by a 'push-pull' process. 'Push' factors are defined as adverse conditions in one place which cause an individual to be dissatisfied with that place, and which push him or her to relocate to a new place. Additionally, the new place has 'pull' factors, or favorable conditions or other attributes which are appealing and pull the individual toward relocating there (Dorigo and Tobler, 1983). In other words, push-pull factors are causal variables that determine the size and direction of migratory flows (Portes and Borocz, 1989).

In more recent years, Push-Pull Theory has also been used as an explanatory model of international student mobility because of its migratory nature, and push-pull factors as variables that influence students to pursue study abroad and select certain study destinations. These factors function, often in combination, to create the demand for international education and to explain the degree and directions of the worldwide flows of international students (Altbach, 1991; Mazzarol and Soutar, 2002). Altbach (1991) asserts since the majority of international students are self-funded, understanding the interplay of push-pull factors on individual student choices is vital to understanding student flows. Mazzarol et al. (1996) view the interplay of both the demand for and the supply of opportunities for education in a student's home country as a major force in determining whether students are likely to be pushed and pulled into the international education market.

The focus of much of the early research viewed push-pull factors as macro-level variables like economic globalisation and internationalisation, or meso-level variables associated 
with specific attributes of home or host countries. Generally, these studies defined push factors as economic, socio-cultural and political forces at work within students' home countries that prompt them to pursue overseas study. They defined pull factors as forces at work within a host country or institution that make it appealing to international students (Mazzarol and Soutar, 2001; 2002; Mazzarol et al., 1996; 2001a; 2001b). Figure 2 offers a diagrammatic representation of basic Push-Pull Theory in relation to international student mobility.

Figure 2. Basic push-pull model.

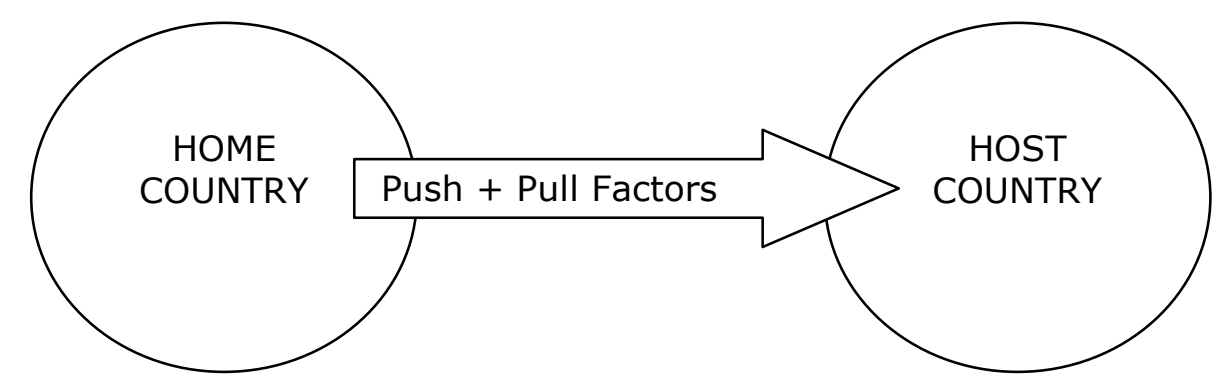

More recent studies have attempted to provide a broader and more multifaceted push-pull model by highlighting the importance of micro-level factors as well, and the interplay between macro, meso, and micro-level factors. Micro-level factors include, for example, how the characteristics, perceptions and motivations of students influence their desire to study overseas and their choice of study destination (Mazzarol and Soutar, 2001; Li and Bray, 2007).

Mazzarol and Soutar (2002) and Maringe and Carter (2007) both attempted to expand the push-pull model by suggesting each host institution also has its own set of "pull" factors which make it attractive to students, and make it more or less attractive than its competitors. They list institutional pull factors as including the institution's reputation for quality, its market profile and international standing, the variety of courses offered, faculty expertise, and adequate resources and research facilities. While institutional pull factors are of great importance to students' decisions, they will not be discussed individually in the thesis. Rather, in seeking to explain a student's choice of an international education, I have decided to focus on the two main questions traditional Push-Pull Theory seeks to answer (and which are also the fundamental research questions in the thesis): why do 
students decide to study abroad, and why do they choose certain host countries? Naturally both of these questions subsume, to some extent, the topic of institutional choice.

Next, I review a number of past studies on international student decision-making, mainly in chronological order, which used Push-Pull Theory. I have attempted to highlight what each study has added to the development of the push-pull model and understanding of international student mobility.

\section{Menon and Carspecken (1990)}

Menon and Carspecken used Push-Pull Theory to understand the drivers of international student mobility because they felt it to be a very practical theory of migration which emphasises the importance of the process of rational choice, action, and the social structure of opportunities available to individuals. They contend in the case of international students, these students decide to pursue study abroad because making a rational choice in favour of international education will lead to more opportunities in a variety of areas such as career and personal life.

Menon and Carspecken used data from semi-structured interviews with twenty male Indian postgraduates who had recently-graduated from three different U.S. universities to develop partial life histories of each student. They felt knowing the life histories of students from their early years through to university, including the socio-cultural setting of their life histories, was important to understanding their choices and behaviour. Based on the data collected via these life histories, they developed a three-stage model of the migration process: Stage One - Home experiences and the external catalytic process; Stage Two - Migration: and Stage Three - Resettlement and Psychic Readjustment. This model stresses the importance of the cultural factors which influenced the life history of students and motivated them to pursue study abroad, as well as the relationship between these factors and various global, economic and political conditions - or push and pull factors - within which their home and host countries were situated.

Stage One, the stage of most interest to the research here, consisted of four elements. They describe the first two elements as the preparatory forces and agents, such as early 
schooling experiences and cultural and familial influence and expectations, and perceived opportunities or lack of opportunities within the home country. The third element was the perceived push factors in the home country, including the socio-economic status of the students, India's position economically as a developing country in the global order and its attempts to modernise. The final element was the perceived pull factors in the host country, including the desire for a high income and professional career status, the prestige of a Western degree, the desire to experience Western culture, and the migration policies of the host countries which permit students to stay after graduation.

Menon and Carspecken's research is important for being one of the earliest studies to apply the push-pull model to the understanding of international student mobility. It also offers a broad approach to our understanding of this issue because it highlights not only the influence of macro and meso-level factors on students' choices but also micro-level factors such as students' life histories. Their study of three stages of mobility is broader (perhaps too broad to delve sufficiently deeply into each stage) than the thesis research.

Altbach et al. (1985) and Altbach (1991; 1998)

Altbach et al. (1985) and Altbach $(1991 ; 1998)$ posit that the decision to study abroad is made from at least three perspectives - the individual student, the home country, and the host country - each with their own priorities and motivations. Based on a review of the literature, they identified two main categories of push-pull variables affecting international student flows from the developing world. The first category pertains to macro and mesolevel variables affecting the magnitude and direction of major flow patterns and which reflect the context of the host and home countries within which students make their choices. The home country context might include variables such as economic difficulties leading to a decrease in state funding for international exchange, economic growth resulting in an increased demand for higher level skills and training, and political changes. Important variables associated with host countries might include changes in foreign policy to restrict or encourage student mobility, and changes in education policy that emphasise international studies. 
The second category consists of key push-pull variables affecting the personal decisions of students to study abroad. Some of the key variables include poor quality education, lack of research facilities, enhanced value of foreign qualifications, and discrimination against minorities. The importance of having this as a separate category from the variables described above is to highlight that individual students (and their families) are part of the decision-making process and that as students are increasingly self-funded, their decision to study abroad is primarily an individual one.

Altbach (1998) highlights how push factors are important for generating the initial interest in studying abroad, however it is the host country variables, or pull factors, that provide direction to students' choices. Altbach contends students are 'pulled' or attracted to certain host countries because of the availability of financial aid specifically, high quality education, cutting edge educational and research facilities, agreeable political and socioeconomic conditions, and the opportunity to gain international experience.

The strength of these three papers is their emphasis on the multidimensional aspect of the variables influencing student flows from developing to developed countries. Although they briefly refer to other types of flows, they concentrate on these students because at the time of their work the major flows were South-North. A major weakness of these papers is the lack of data presented to substantiate their list of push-pull factors.

\section{McMahon (1992)}

Using an outbound push model and an inbound pull model, McMahon analysed aggregate national data in an attempt to explore the patterns and reasons for student flows from developing to developed countries during the 1960s and 1970s. The eighteen countries making up the sample were selected to represent all major developing areas in the world and, within this subset, were divided into higher, middle, and lower income countries.

Her push model focused on the conditions in the sending country, while her pull model signifies the international context within which academic mobility takes place. Her push model theorised that the number of international students undertaking education abroad from a particular sending country was dependent on such variables as the economic 
strength of that country, its degree of involvement in the world economy, the level of importance and amount of resources apportioned to education, and the availability (or lack) of educational opportunities offered. Her pull model theorised students were drawn to a particular host country, in this case the U.S., because of the strength of its economy relative to the economy of their home countries, economic and trade ties between the two countries, and the level of political interest in the sending country exhibited by the host country in terms of foreign development and student financial aid.

McMahon's findings showed the economic strength of the sending country and the strength of trade links between the sending and host countries, as well a significant level of involvement of the sending country in the global economy were all positively linked to student mobility. In addition, students interested in studying abroad were more likely to come from countries with educational systems that although weak, were still able to provide students with some level of academic preparedness for studying in developed countries.

She states the explanations for international student flows vary by country and by different points in time. Her findings suggest both models were strongest in explaining the flows of students from the higher income developing nations to the developed world. These countries generally had a strong national interest in education combined with a high level of involvement in the global economy, and their economic capacity relative to and trade links with the host country meant there was also some type of academic linkage between the countries as well.

The value of McMahon (1992) lies in the fact it is a large-scale study, and offers a snapshot of the international student flows of a particular period. In addition, it has been cited in important later studies of international student mobility using the push-pull typology (Mazzarol et al., 1996; Li and Bray, 2007; Sahasrabudhe, 2008). However, it was a strictly quantitative study, and while McMahon highlights the dynamic nature of the push-pull model, she only explores this process from the perspectives of home and host countries. She did not survey individual students and does not take into account the importance of individual-level variables on student mobility. 
Mazzarol-led studies: Mazzarol et al. (1996); Mazzarol et al. (2001a); Mazzarol et al. (2001b); Mazzarol and Soutar (2001; 2002)

The five studies led by Mazzarol provide extensive research into the application of PushPull Theory to the study of international student mobility. Through utilising similar methodology, these studies offer valuable comparisons of prospective international students from different home countries and different educational levels, as well as students from the same home countries but different educational levels. In addition, all of the studies had sizable samples, and used data collection methods that surveyed students directly for their views and motivations.

The first three studies (Mazzarol et al., 1996; Mazzarol et al., 2001a; Mazzarol et al., 2001b) used survey questionnaires to identify the push-pull factors important to prospective international students. In all three studies survey respondents were presented with a list of the same twenty-two pull factor items which were identified via a literature review of previous research. These pull factor items included easy to obtain information about education programs; knowledge and awareness of the host country; comfortable climate; and high quality/good reputation of education.

Students in each of the Mazzarol-led studies were asked to indicate the importance of these pull factors as related to their decision to choose a particular host country, and then to rank them accordingly. Additionally in each of the three studies, a factor analysis was conducted on these twenty-two items to reduce the number of variables in the data set to a more manageable one, to examine the relationships among the items, and to determine the underlying dimensions being measured by these variables. Since the sample of students surveyed in each study was different, the results of each factor analysis also differed.

In the final two studies (Mazzarol and Soutar, 2001; 2002), Mazzarol and Soutar offer a comparative discussion of the push and pull factors as identified in the first three Mazzarol-led studies conducted between 1996 and 2000. 
The Mazzarol-led studies are also valuable to the study of Push-Pull Theory and international student mobility because they influenced most of the other studies discussed below. Maringe and Carter (2007) and Sahasrabudhe (2008) referenced Mazzarol and Soutar (2002) as part of their general literature review while Li and Bray (2007) cited Mazzarol and Soutar (2001) as a study of 'particular relevance' to their work. For Yang (2007), Mazzarol and Soutar (2002) was an influential study discussed at length in her literature review and used as a point of comparative analysis when presenting her data. Pimpa $(2003 ; 2005)$ implied that his study added to the understanding of Push-Pull Theory and international student mobility as described in Mazzarol and Soutar (2002). Finally, Bodycott (2009) mentioned that their list of push-pull factors highly influenced his own, and Chen's (2007) synthesis model was partly based on their push-pull model. Each of the five Mazzarol-led studies is looked at in more detail below.

Mazzarol et al. (1996)

Mazzarol et al. (1996) surveyed 254 Taiwanese and 276 Indonesian students representing four different education sectors in the international education market: higher education (undergraduates and postgraduates), English-language training, vocational education and training, and school level education. Sixty-four percent of these students indicated they were intending to study overseas. The discussion of Mazzarol et al.'s study will include the data only from the higher education sector because it is most relevant to the thesis.

Mazzarol et al. used the survey data to model two separate choices of international education. First, they examined a student's decision about whether to study at home or overseas. They found there were strong push factors operating which propel students into the international education market mainly reflecting problems with the quality and capacity of higher education in their home countries. These factors included the perception an overseas qualification is superior to a domestic one, the perceived need to better understand Western culture, difficulty gaining entry to domestic institutions, and the unavailability of certain courses in the home country. A factor analysis of the list of twenty-two pull factors generated six factors that attract students to study in a specific host country: Cost Issues, Knowledge and Awareness, Environment, Recommendations, Social Links, and Geographic Proximity. 
Most students indicated the U.S., not Australia, was their first choice of host country and, therefore, comparisons of the importance of the pull factors were made primarily between these two countries. The findings suggested there are some similarities and differences in the importance of certain pull factors for students from different source countries. Mazzarol et al. also found similarities and differences among students from the same home country regarding the importance of certain pull factors, and hence host country preference. Finally, Mazzarol et al. highlight differences in the importance of the pull factors based on educational level.

The importance of Mazzarol et al. (1996) lies in its suggestion that while the list of pushpull factors are generally the same for students seeking an international education, the degree of influence of these factors on students' final decisions is affected by the interaction of these factors with students' educational levels, home countries, and host country preference.

Mazzarol et al. (2001a)

In this 2001 study, Mazzarol et al. sampled 152 prospective international postgraduates from India who were intending to study primarily in the STEM fields. They selected this particular sample, because for many years India has been a major source country worldwide for international students, particularly postgraduates, in the fields of science and technology. The purpose of the study was to explore the reasons why these students choose to study in countries other than Australia. Although they had not selected Australia as a study destination, almost eighteen percent had seriously considered it prior to making their final choice of host country. The majority of students were seeking to undertake either an engineering or a computer science degree, with sixty-three percent selecting the U.S. as their final study destination.

The survey data showed there were six push factors important in motivating these students to study abroad. The most common was the perception that a foreign education was better than domestic education, followed by the intention to migrate to the host country in future. Another push factor was difficulty gaining entry to a domestic institution in India due to lack of capacity. A push factor which applied to all academic fields in the 
study was the situation where a particular course was not available at home. In addition, the lack of infrastructure needed for research in India's higher education institutions resulted in many students seeking to develop their knowledge and access better research opportunities overseas. Students were also pushed to study abroad by a desire to better understand Western culture. Finally, the level of economic reform and modernisation in India was a factor that pushed students overseas.

For this sample, the factor analysis on the list of twenty-two pull factor items driving their choice of host country resulted in the identification of six factors and one independent variable. The six factors, in order of importance to students were: Reputation/Work, Awareness/Control, Acceptance, Friends and Relations, Environment, and Cost. Finally, the independent variable was identified as the perceived level of discrimination in the host country. Mazzarol et al. examined the relationship between these factors and the various academic disciplines targeted in the study to identify any significant differences between students studying in different fields. They found the largest difference was in relation to the factor Reputation/Work. Students who intended to study computer science and engineering were more likely to rate this factor as a highly influencing pull factor. Differences were found for the other factors and although significant were small.

Mazzarol et al. also used the survey data to examine the relationship between the pull factors (and one independent variable) and all host countries considered by students before making a final choice, as well as the relationship between the final choice of host country and these factors. In regards to the former, for example, for those students who considered Australia, the factor Environment was important while it was viewed as less important by students who considered other host countries. In terms of the latter, students who selected the U.S. as their final host country were less likely to consider Environment and Cost, but Reputation was a major pull factor as the U.S. was believed to be superior in fields of study such as engineering and computer science.

Mazzarol et al. (2001a) adds to the knowledge on international student mobility by looking at the impact of push-pull factors on a very specific sample of students - specific in terms of home country, degree level, academic disciplines, and host country preferences. Their 
results strengthen the argument that push-pull variables do not apply equally to all students, and that home country, degree level, academic disciplines, and host country preferences also play a part in students' decisions. Additionally, the importance of this study is that it is one of the first studies to highlight how host countries can have negative push factors (although they do not label them as such) which deter students from selecting these countries and drive them towards other host country options.

\section{Mazzarol et al. (2001b)}

Mazzarol et al. (2001b) utilise the same methodology as the two previous studies but this time use it to collect data on the importance of push-pull factors from students in one particular source country but who were studying at several different educational levels. In this study, they sought to investigate the reasons why Chinese students did not choose to study in Australia. They surveyed 698 prospective international students from several major sectors of education, including undergraduate and postgraduate institutions, vocational training, and English language courses with the majority stating they were going to be self-funded.

A survey of these students found the six most highly rated push factors that influenced their decision two study abroad were: to gain a better understanding of Western culture, the belief an overseas course is better than a domestic one, difficulty gaining entry to domestic institutions, intention to migrate to host country, a specific course was not available in home country, and a broad category of 'other reasons'. Approximately $85 \%$ of the sample across educational sectors indicated the desire to acquire greater knowledge of Western culture was their number one reason for wanting to study abroad, followed by the perception that overseas courses were better than local ones.

Mazzarol et al. noted there were significant differences between undergraduates and postgraduates in terms of the importance of various push factors. Although both groups of students had similar opinions as to the difficulty of gaining entry to local courses and the desire to learn about Western culture, postgraduates were more likely to consider an overseas course as better than a local one, view English-language education as a way to increase career prospects, and to indicate they hoped to migrate to the host country. 
Many undergraduates did believe an international education would enhance their career options, but were not as certain about using education to migrate to the host country. Mazzarol et al. hypothesised this was possibly due to traditional age differences between undergraduates and postgraduates.

As in the two previous studies, Mazzarol et al. conducted a factor analysis on the twentytwo pull factor items which yielded five factors and one independent variable. The independent variable was Information Availability, and although it did not fit within the overall factor structure, it was most important for students across all education sectors. It refers to the level of ease students experienced in getting information about the academic programmes in the potential host country. Next in level of importance was Environment, followed by Reputation and Recognition, and Knowledge and Awareness. Of lesser importance but still significant to about half the sample was Cost followed by Social Links.

In addition to identifying the pull factors important to their selection of host country, Mazzarol et al. did a comparative analysis of the ratings of these pull factors and the selection of different host countries. They found the relative importance of the different pull factors for students was generally the same in their choice of the various host countries although some of the host countries are viewed as somewhat more appealing on some factors. Finally, Mazzarol et al.'s results indicated a relationship between host country preference and degree level. For example, Australia was seen by students as an undergraduate destination while students intending to pursue postgraduate degree programmes were more likely to choose the U.S., Canada, or the UK.

The importance of Mazzarol et al. (2001b) is that it not only expands on the knowledge concerning the relationship between push-pull factors and educational level, but it also offers an insight into how prospective international students perceive various host country alternatives.

Mazzarol and Soutar (2001; 2002)

Mazzarol and Soutar $(2001 ; 2002)$ offer an examination of the push-pull factors important to the international students in all three studies discussed previously (Mazzarol et al., 
1996; Mazzarol et al., 2001a; and Mazzarol et al., 2001b). The sample characteristics of students from these three studies will not be reiterated here.

Mazzarol and Soutar found that all students, notwithstanding their country of origin, mentioned eight important factors that prompted them to pursue study abroad. Only a few are mentioned here. For the majority of students the key push factor in deciding to pursue overseas study was their belief an international education was better than one obtained locally. A second important push factor was the notion they could acquire a greater understanding of the West through studying abroad, although the importance of this factor was significantly lower for the Indian students. They attributed this to the fact that the Indian students were postgraduates, and, in general, likely to be older and have more life experience than students from Taiwan, China, and Indonesia.

Another factor analysis was done on the twenty-two pull factor items for all four source countries together. This resulted in the identification of six factors considered by students in all four countries surveyed to be important influences on their final choice of host country. These factors in general order of importance were: Knowledge and Awareness, Personal Recommendations, Cost Issues, Environmental Issues, Social Links, and Geographic Proximity.

Mazzarol and Soutar found a definite distinction between undergraduates and postgraduates regarding the degree of influence of various push-pull factors upon. For example, the level of knowledge and awareness about a potential host country was not as important to postgraduates as it was to prospective undergraduates. Further, Indonesian undergraduates were more likely than postgraduates to consider migration as a push factor influencing their decision to study abroad. Their work again strengthens arguments about the importance of home country, host country preference, and educational levels on the significance of various push-pull factors. In addition, through their research, they were able to identify one set of pull factors for determining choice of host country and other for determining choice of host institution. 
Mazzarol and Soutar (2002) is of additional value because they highlight potential changes to the importance of traditional push-pull factors as a result of the development transnational education options such as branch campuses. They note how these new modes of delivery are changing the educational opportunities in many traditional source countries. Mazzarol and Soutar predict such innovations will change the influence of traditional push-pull factors creating a challenge for host countries and institutions in recruiting international students. However, they envisage the awareness and reputation of the host country and its institutions are apt to remain of great importance in the list of key pull factors. In addition, personal recommendations from family, friends, alumni, and other reference groups are apt to remain as important influences on the decisions students make regarding international study.

Pimpa (2003; 2005)

Pimpa $(2003 ; 2005)$ adds to the theoretical knowledge of Push-Pull Theory and international student mobility by looking in-depth at one of the major push factors influencing a student's choice to study abroad: familial influence. He believed familial influence was more complex than just family members making simple recommendations to students or providing financial support, and felt in order to understand the 'full mechanism' of familial influence, its impact on all five key decisions should be studied. The five key decisions of international education identified by Pimpa are: the decision to study abroad, the selection of host country, city, academic course/programme, and then university.

Pimpa first conducted three focus group interviews each with nine students in order to develop a list of specific variables that described how family influences students' decisionmaking. The data showed family influence on the five key decisions can be put into one of following five categories: finance, information, expectation, competition, and persuasion. To further examine and compare the relationships between the five key choices of international education and the five factors of family influence, Pimpa surveyed 803 international students from Thailand at the undergraduate and postgraduate levels. He found familial influence to be multidimensional having the potential to impact all five key decisions to differing degrees. For example, he found for the students surveyed, family 
financial support had the greatest influence on the five key choices as it limited the possible host country choices while also influencing the university and academic programmes selected.

Information from family members could also influence students' as family members provided important information about places of potential study. Family expectations had a strong impact on Thai students as many felt it was expected of them to acquire an overseas degree, to become fluent in a foreign language, and to get useful international experience. Although students mentioned the issue of competition among family members, particularly with extended family, it did not have a strong impact on the decisions of Thai students in comparison to the other types of familial influence. Persuasion by family members was found to be a very significant factor and could be so strong that students were not only persuaded to pursue overseas study but sometimes family members convinced students which host country and institution to select. Overall, family expectations had a greater impact on the international education choices of Thai students than did competition or persuasion.

The data indicated all five categories of familial influence impacted students' decisions to pursue overseas study, choice of host country and host city but had less impact on the student's choice of institution and academic programme. Pimpa contended the reasons for this was that the choice of academic programme was a more personal choice for students in comparison to other international education choices.

In his 2005 study, Pimpa conducted subsequent analysis on the 2003 data focusing on the impact of family types on Thai students' international education choices. He examined the influence of familial expectation on students from families with and without experience in international education, and the influence of social competition on students from Bangkok and those from outside of Bangkok. Finally, he explored the impact of all five familial influencing factors on students from nuclear, extended and alternative families.

Pimpa found the expectations of families with and without international education experience to be significantly different for the five key decisions with more expectation to 
study overseas placed on students who were from families with such experience than those from families without. The influence of social competition was greater for students from Bangkok than from outside Bangkok, particularly in relation to the decision to study abroad, choice of country, and academic course. Finally, family expectations had a stronger influence on students from nuclear and extended families while familial competition was found to be strongest for students from extended families.

Pimpa's study is valuable because of its emphasis on the multidimensionality of push-pull factors, and his assertion that in order to fully understand the choices of international students, it is important to consider each choice and the different aspects of these factors, and how they influence those choices. He makes a strong case for this by conducting an in-depth study of familial influence - a particular, and very important, push factor. In addition, he also presents an interesting comparative study of how the influence of a particular push factor on the key choices of international education varies based on individual student characteristics such as education level and family background. Finally, Pimpa, in contrast to some of the earlier studies cited here and like the thesis, surveys current instead of prospective students.

Li and Bray (2007)

Li and Bray's study adds much to the body of knowledge on international student mobility by providing a fuller picture of how push-pull factors operate and significantly broadening the push-pull model. Most of the studies cited here talked about push factors as positive or negative factors related to home countries and pull factors as related to host countries. $\mathrm{Li}$ and Bray contend that home countries can also have their own pull factors and host countries their own push factors. Home country pull factors make study at home appealing, and include the desire to remain with family and the increasing internationalisation of domestic institutions. Push factors associated with a certain host country can increase the appeal or the strength of the pull factors of other potential host countries. Students may be pushed away from studying in one country and towards study in another, for example, because of increasingly restrictive immigration policies for international students in the first country. 
Li and Bray thus broaden the push-pull model from one-way into a more multidimensional model with reverse push-pull factors that "...push students to go (or not to go) abroad for a degree, and...pull students to come (or not to come) to study in a specific country" (de Wit et al., 2008, p. xii). Li and Bray contend that students' choices related to international study are determined by the dynamic interaction of these reverse push-pull factors.

They theorised that because the higher education market is a globally integrated one a change in the push-pull forces of one country can lead to a change in the push-pull forces of another country, and a change in even one of these factors can result in changes in student flow patterns. In addition, their model offers one way to explain why some students opt for overseas study while others elect to study at home. Figure 3 offers a diagrammatic representation of a more multidimensional model of Push-Pull Theory based on Li and Bray's work.

Figure 3. Multidimensional reverse push-pull model.

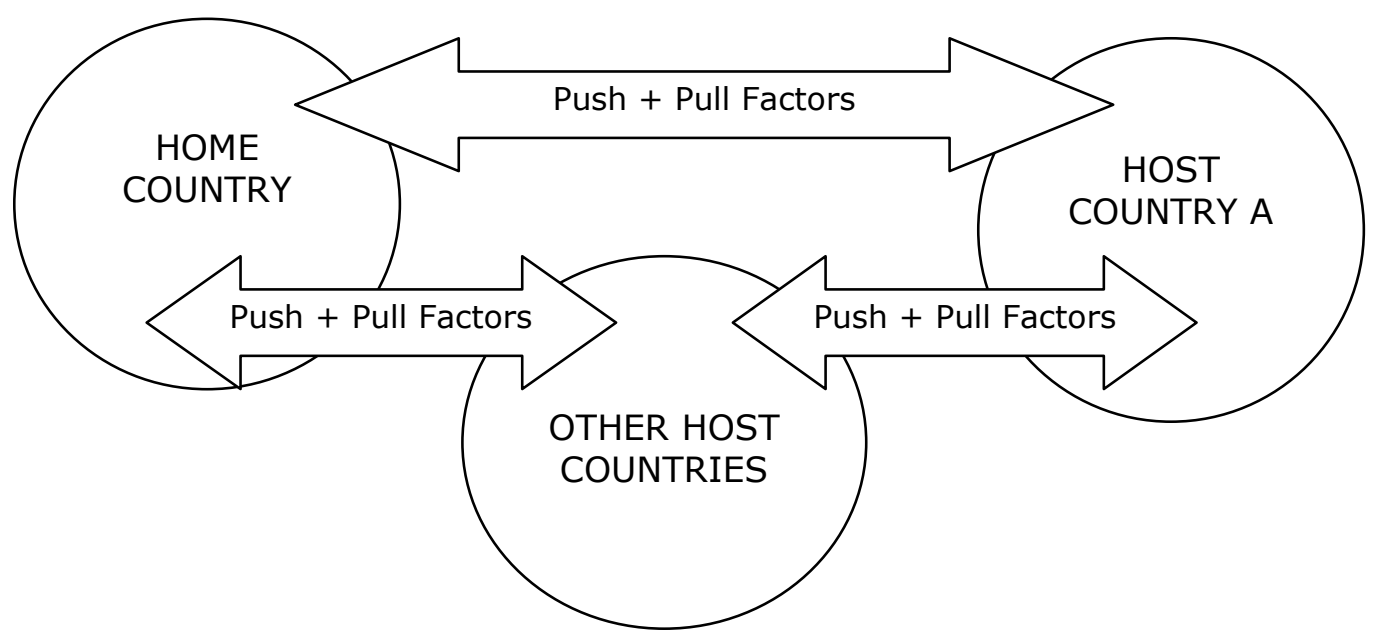

Li and Bray make a second significant addition to the literature on student mobility by examining the patterns of mainland Chinese student flows to two of China's overseas territories, Hong Kong and Macau - locations they describe as "...a sort of bridge between the fully domestic and the fully international..." (p. 791). In other words, Hong Kong and Macau are simultaneously domestic and international because although they are autonomous administrative districts having independent higher education systems and institutions, they are still part of China. Thus they offer students the chance to live and study 'halfway' between the domestic and fully international. Using their multidimensional 
push-pull model, they examined how push-pull factors can be used to explain why some students stay at home, some go halfway to Hong Kong or Macau, or some go to a foreign country to study.

Data was collected via questionnaires from 323 current students and interviews conducted with eighteen current students studying in Hong Kong and ten in Macau. Interestingly, the results showed the top three push factors for students choosing Hong Kong or Macau were negative push factors associated with studying in mainland China such as the low quality of higher education and the lack of internationalisation on the mainland.

Students were also asked why they did not go outside of China and its territories for study with both those studying in Hong Kong and Macau again mentioning negative push factors as the reasons but this time associated with foreign host countries such as the application and visa processes were too complicated or it was difficult to get admitted. The absence or partial absence - of such factors in Macau and Hong Kong acted as pull factors for these two territories. Many of the students decided to go to Hong Kong and Macau because of their belief that these territories could be used as a stepping stone to a fully international experience. Students also mentioned negative push factors associated with studying in Hong Kong and Macau that made study in foreign countries more appealing, including the lack of foreign language climate, and the lower international standing of the institutions in these territories.

Li and Bray also add to the understanding of international student mobility by emphasising that it is not only external forces (such as push-pull factors) but there are also micro-level factors which are important. Micro-level factors generally refer to the personal characteristics of students, and include socio-economic status, academic ability, gender, age, motivation, and aspiration. Their research showed that these characteristics can have a major impact on students' behaviour and international education choices, and are key to facilitating a more complete understanding of how students respond differently or not at all to similar push-pull forces. Li and Bray's research with mainland Chinese students in Hong Kong and Macau highlights the distinctive characteristics of students as compared to their peers who remained at home for study or opted to study abroad. In their research, 
the students who went 'half-way' were more internationally-minded than their peers who stayed in China, while the geographic proximity of Hong Kong and Macau and the strong links with home were more important to them than to their peers who went abroad for study.

\section{Chen (2007)}

Chen's study attempted to increase understanding of the decision-making process of international postgraduates and to develop a more complete model of choice for understanding factors important to students in their selection of Canada as a host country and a Canadian postgraduate school. Chen developed a 'synthesis model' to describe the decision-making process of international postgraduates, which borrows from sociological models including Social Capital theory.

Chen's survey sample consisted of 140 current international students from China, Hong Kong, Japan, Korea, and Taiwan who were enrolled in postgraduate programmes at two large Canadian universities. In-person, semi-structured interviews were also conducted with twenty-three survey respondents. The aim of the interviews was to gain further understanding regarding how postgraduates make choices about international education.

Chen asserts there are three main groups of factors which impact students' decisions. The first group of factors consists of Student Characteristics such as socio-economic status, personal characteristics and preferences of students, their academic ability, and their social capital. The second group pertains to the influence of Significant Others such as family, friends and teachers. The third group encompasses the positive and negative pushpull factors of home and host countries, personal drivers resulting from external influences, and characteristics of the host institution.

Student Characteristics had the most influence on the decision to study abroad, next were positive Push Factors from the Home Country, followed by Pull Factors from Canada, and finally Significant Others. Significant Others was one of the least important factors influencing students' decision to study overseas. The influence from Significant Others was 
found to be irrelevant or of negligible importance for more than half of the sample because they did not have any family or friends living/studying in Canada.

Positive push factors seemed to wield more influence than did negative push factors in the decision to study abroad, with some of the top push factors including the desire for an advanced degree for personal satisfaction and opportunity to gain valuable foreign language skills. Chen also noted a considerable difference in the perceived advantages of studying overseas based on country of origin. Studying overseas was seen positively by Chinese, Korean, and Taiwanese students but not Japanese students. Japanese students more often rated a foreign education as not having a lot of value or future economic benefit in Japanese society.

Chen's results showed the choice of Canada as a host country was influenced most by the Pull Factors from Canada, then Push Factors Related to Home Country, and finally Significant Others. Of the Pull Factors from Canada, those associated with the Canadian Environment had the strongest pull in attracting students to Canada, with economy/costs and visa/immigration factors next. Those students who selected Canada as their first choice were attracted to it because of the perception it offered a safe and multicultural environment, while for those students for whom Canada was not a first choice, important pull factors included the ease of immigration and proximity to the U.S. In addition, negative push factors associated with other potential host countries, such as higher tuition and longer programme duration, pushed students away from these other countries and towards study in Canada.

Chen's study is important because of her in-depth look at the selection choice of one particular host country by international postgraduates from a variety of Asian sources countries. In addition, she found the factors associated with host institutions, such as academic quality and administration, have the strongest effect on postgraduates' decisions, with factors associated with the host country next, and then followed by the factors associated with the decision to study abroad. She also highlighted how an overseas education was not necessarily viewed positively or as a source of future advantage by all students. Finally, Chen's choice to make Student Characteristics and Significant Others 
separate categories in her model further emphasises the importance of these factors to international student decision-making allowing for more agency by students than in the traditional push-pull model (Cantwell et al., 2009).

\section{Maringe and Carter (2007)}

Maringe and Carter's (2007) study explores the factors impacting the decision-making process and selection of host country for international students from Africa. They conducted focus groups with twenty-eight current students, mostly postgraduates, from various regions of Africa who were studying at two universities in the UK. These students were studying in the Social Sciences, including Law and Engineering, as well as Nursing, Mathematics, Pharmacy, and Medicine.

The primary aim of the focus groups was to ascertain the push-pull factors influential in the decision to select the UK for study as well as a particular host institution within the UK, and with this information to develop a provisional model of destination choice for African students. To assess the suitability of a provisional model of choice generated by the focus groups, they also conducted in-depth interviews with two students (one each from each institution), and two staff members who had experience recruiting African students. Based on the data collected, they developed a decision-making model for African students consisting of six influencing factors: Push Factors, Key Influencers, Pull Factors Country Level, Pull Factors Institution and Course Programme Level, Risks and Anxieties, and Experiential Dissatisfiers.

The most important push factors for these students were those related to the economic and political circumstances at home. Economic factors included the lack of economic growth in their home country or the positive attitude among local employers toward those having UK qualifications. Political factors included the level of political volatility in their home countries. Students also talked about having to undertake study abroad because of the lack of local higher education capacity. Key influencers on students' decisions included friends, family, and co-workers who had previous experience living and/or studying in the UK or at the same institution. 
Pull factors at the country level influenced students to choose the UK over other potential host countries because they felt it offered the best opportunity to obtain a valuable international experience. Maringe and Carter asked students in the focus groups why they chose to study in England and to list the other host countries they had seriously considered during their decision-making process. The answers to these questions revealed the key pull factors attracting African students to the UK included the quality and international recognition of higher education qualifications from the UK, the belief that a British qualification would be an investment in terms of future career opportunities, and the UK offered a safe and secure place to study. Although 'Pull Factors at the Institutional and Course Programme Level' was listed as one of the elements in Maringe and Carter's model, they found for many of the African students, choosing the UK as a host country was more important than choosing a host institution due to the positive brand association of UK universities.

Risks and Anxieties refer to students' perceptions of the risks and anxieties connected with undertaking overseas study such as the financial risk, and course-related and academic risks such as anxiety about academic failure. Experiential Dissatisfiers encompassed three main elements: information inadequacies, financial uncertainties, and post-registration marketing deficiencies. Information inadequacies, for example, refer to students' assertions that they do not have sufficient access to information needed at various times during the decision-making process.

The importance of Maringe and Carter's study is its focus on the decision-making of African students - a group of international students for whom there is a lack of research as compared to the larger body of research on Asian students. The results of this study suggest there are some similarities in the influence of push-pull factors on these two groups of students and their reasons for undertaking overseas education. Finally, it should be mentioned that as with Pimpa's study, the students in Maringe and Carter's sample were current not prospective international students which may make some difference in the importance of various push-pull factors as memory and experience may have altered the importance of these factors for students. 
Yang (2007)

Yang (2007) analyzed the push factors influencing the decisions of Chinese students to study abroad, as well as the pull factors influencing their selection of Australia. The list of pull factors she presented to students for rating was based on the same list in the Mazzarol-led studies described earlier. In the first phase of her study, Yang surveyed a sample of sixty-five prospective international students, and during the second phase, she conducted in-depth one-on-one interviews with thirty current students, both undergraduates and postgraduates, already studying in Australia.

Prospective students stated the most important push factor prompting them to pursue international study was their perception an overseas course was better than a local one, and similarly the current international students indicated the most important factor pushing them to study overseas was the desire to obtain an internationally recognised qualification because they perceived an overseas course was better than a local one. The next two most important push factors were also similar for both groups of students: the difficulty of gaining admission to higher education in China, and intention of future migration to the host country. Less important push factors for both groups of students included the desire to obtain a better understanding of Western culture.

There were some differences however in terms of pull factors or reasons students selected Australia as a host country. For prospective students, the most important pull factor was their belief that Australian higher education was of high quality while for current students this pull factor ranked third. Current students were most influenced by the future migration opportunities available via Australia's skilled migration policy, a pull factor which was ranked as second most important for prospective students. Additionally, lower tuition fees and cost of living in Australia as compared to other host countries was second in importance for current students and third for prospective students.

Although not given as a purpose for the study, Yang (2007) is valuable for its comparison of the importance of push-pull factors between prospective and current international students in their decision to study abroad and choose a host country. The finding of differences in the importance of various pull factors between the two groups implies that 
some change may occur in the importance of these factors during the selection process. However, it should also be noted that data was collected from these groups using different methods, and the sample included students from only one source country and focus on the selection of only one host country, all of which may have had some affect on the findings.

\section{Sahasrabudhe (2008)}

Sahasrabudhe (2008) conducted an investigation of the push and pull factors influencing Indian master's students studying Engineering in terms of their decisions regarding overseas study as well as their choice of the U.S. as a host country. The study took place at a private research university with a large international student population.

Sahasrabudhe's final sample of ten respondents participated in semi-structured one-onone interviews. She found the key push factor steering students toward international study was the students' dissatisfaction with the quality of their undergraduate education in India stemming from the view that Engineering faculty in India did not have enough experience and did not possess sufficient capability or subject knowledge. In addition, students complained their coursework concentrated on rote memorisation of knowledge and examinations that did not offer sufficient opportunities for the practice of analytical and independent thinking.

Students felt the infrastructure and resources of the Indian institutions they attended were being stretched too far in an attempt to satisfy excess demand which lowered the overall quality of both students and programmes and added to the dissatisfaction of the respondents. Students felt they did not gain the requisite knowledge and skills from their undergraduate programmes needed to perform effectively on the job prompting them to seek more education in their field. In addition, students noted the limited number of quality postgraduate engineering programmes in India to which admission is highly competitive. All of these conditions in combination acted to push these students to study abroad.

Although her sample was very small, a finding of particular significance from Sahasrabudhe was that all push factors listed as important by students were negative showing deep dissatisfaction among students about the higher education options available 
in India. This is a significant finding for India and other source countries as these are factors that have the potential to be changed unlike positive push factors such as the desire to learn about Western culture. The lack of positive push factors listed as important may indicate that these students would have preferred to study in their home country.

de Wit et al. (2008b) and de Wit and Rumbley (2008)

In their book 'The Dynamics of International Student Circulation in a Global Context', de Wit and his co-authors attempt to analyse the dynamics of international student circulation in the context of four countries viewed mainly as sending or source countries - Egypt, India, Indonesia and South Africa - and two countries viewed primarily as receiving or host countries/regions - Europe and the U.S. The focus of their case studies was degree seeking international students and their movements both into and out of certain countries. In Chapter 2, de Wit provides a list of forty-nine push and pull factors each divided into three subcategories: educational factors, political/social/cultural factors, and economic factors. An example of an educational push factor is the availability of higher education, and an educational pull factor is cost of study. The list is too long to recreate here but in order to facilitate comparative analysis between the different countries and regions in the sample, they condensed the main push and pull factors into four broad categories: mutual understanding (political, social, and cultural factors), revenue earning (economic factors), skill migration (economic factors), and capacity building (educational factors).

They provide tables showing the importance of these push-pull factors for the EU and the U.S. Each of the push-pull factors is rated on a scale from very significant/very positive to insignificant/very negative, and whether it was increasing, unchanging or decreasing in importance. The push factor of unmet demand for higher education in the EU, for example, was rated as minimally significant/negative and as decreasing (de Wit, 2008c: p. 194). For the U.S. with its large higher education system, the same push factor was rated as insignificant/very negative and unchanging (de Wit and Rumbley, 2008: p. 227). Again, due to the space limitations of the thesis, the cases and tables are not discussed or recreated in detail here. 
The work of de Wit and his colleagues augments the literature on Push-Pull and international student mobility by supporting past findings, giving attention to the current flow trends, and further broadening the definition of what constitutes a push factor. First, they support the multidimensional reverse push-pull model emphasising that the dominance of certain factors changes over time, some disappear, and new ones are created. Next, they posit that push-pull factors vary between and across countries and regions giving as evidence the recent increase in South-South flows of international students as opposed to the traditional South-North flows. Lastly, they provide a broader description of push factors to encompass how the understanding of student mobility has changed. They describe push factors as "...those factors that stimulate students to study abroad for their degree" (p. xii) but which are not necessarily defined in terms of home country characteristics. A major weakness of the book is that it is never stated clearly what data is used as the source of the ratings of the various push and pull factors.

De Wit et al.'s work is valuable because it takes into consideration the impact on the pushpull paradigm of the new innovations in international education delivery over the past decade. Their discussion highlights how students can choose from an increased range of international education options, not only the traditional form of delivery wherein students move to the country of the provider, but the newer forms, such as branch campuses and distance education, which allow students to stay in their home country while providers come to them.

\section{Bodycott (2009)}

Bodycott (2009) explored the perspective of students and parents toward the importance of the various push-pull factors influential on the decision to study abroad and choice of host country. Bodycott focused his research on prospective international students from the Chinese mainland, a society, he explains, which is based on strong Confucian ideals about the role and status of parents. Parent-child relationships in a Confucian society are characterised by the concept of filial piety or xiao qin. The concept implies that parents will do all they can (financially and otherwise) to ensure their child gets the best education and a better future and, in turn, will repay their parents by respecting their wishes and listening to their advice about international education. In addition, overseas study also 
raises the social status of the child and family in Chinese society. Hence, the student's decisions regarding international education are not necessarily based on individual choices but are impacted by xiao qin. In other words, in the Chinese context parents are also important stakeholders in the decision-making process.

Bodycott employed a two-stage research strategy. First, he surveyed 251 mainland Chinese parents and 100 students and second, he conducted five focus group interviews with five parents and five students who had previously completed the questionnaires. Data from the surveys and interviews was used to explore the similarities and differences between the opinions of parents and students regarding the importance of various pushpull factors.

Parents rated the importance of certain push factors differently from students. For example, parents rated the lack of higher education capacity in mainland China, and opportunities beyond the educational experience like improving employment and immigration prospects as the most important push factors. The two latter factors can be described as economic push factors, and their importance to parents in Chinese society is due to the desire to ensure the future economic security of not only the child but other family members as well. Students, on the other hand, rated the higher quality of education abroad and the opportunity to have an international experience as the most important push factors.

There were also differences between parents and students concerning the importance of various pull factors. Students appeared to put more emphasis on the tangible aspects of the study environment including lifestyle, onsite accommodation and facilities, the variety of programmes available, and the English-speaking environment. Parents, on the other hand, seemed more concerned about the practical aspects of studying abroad including the future benefits related to employment and migration prospects, the proximity of the host country, and tuition and other associated costs. Facilities, lifestyle, and chance for international experiences were not viewed as very important by parents. 
Bodycott's study adds to the knowledge on international student mobility in two ways. First, he stresses that in order to have a deeper understanding of international student decision-making it is important to take into account the cultural basis of the societies from which these students come and the impact culture has on their decisions. In addition, he draws attention to the importance of parents and family in many source countries as significant stakeholders and co-decision-makers. Although Bodycott never directly states the education level of his students, from other remarks in his study, they appear to have been potential undergraduates which may also partially explain the level of parental influence on their decisions.

\section{Wilkins and Huisman (2010)}

Wilkins and Huisman (2010) surveyed 160 current international students in order to identify the factors influencing the decision of these students to study abroad and their choice of host country. The sample consisted of twenty-eight undergraduates and 132 postgraduates from a range of source countries (primarily Asia) who were studying at the same research-intensive university in western England. A self-completed questionnaire was administered to students and they were asked to indicate the importance of a list of sixty push-pull factor items to their own international education choices.

The push factors indicated by students as most important to their decision to study abroad were to improve employment prospects, to experience a different culture, and to improve their English-language skills. The pull factors mentioned most often as important in their selection of the UK were quality of education, the high rankings of UK institutions, better employment prospects, and best for improving English-language skills. In addition, for postgraduates, the shorter duration of programmes in the UK was a significant attraction.

Like de Wit (2008b) who pointed out how the dominance of certain factors changes over time, Wilkins and Huisman's study is important to the literature because their findings suggested that pull factors have become more influential on students' decisions to study abroad than push factors. They attribute this to the recent improvements in the social, political, and economic conditions in many source countries which have resulted in fewer push factors driving students abroad for higher education. These improvements include 
the expansion of higher education capacity in these countries meaning lack of capacity is becoming less important as a push factor with fewer students mentioning this as a reason for seeking to study abroad. However, doctoral students were still more likely to mention that either the course they wanted was not available at home or if it was available, it was of lower quality than courses abroad.

\section{Collective Contribution of the Push-Pull Studies and Influence on the Thesis}

Although I have individually pointed out above what each study has added to the understanding of international decision-making and mobility, it is also important to highlight their collective contribution and their influence on the thesis research. These push-pull studies represent two decades of research on international students and have added much to the knowledge and understanding of this subject. These studies have built upon each other to some extent with McMahon (1992) and the Mazzarol-led studies in particular being used as building blocks for later studies. These studies have gone beyond the initial model which associates the push factors exclusively with home (source) countries and the pull factors exclusively with host countries, and which depicted the push-pull relationship as between one source and one host country only. They have added further dimension to the understanding of the push-pull factors and broadened the definition of what constitutes each type of factor.

They have also expanded the push-pull model to provide a fuller and more dynamic picture of how push-pull factors operate together and how a change in one can affect others. They have provided evidence that the dominance of certain factors changes over time, some disappear, and new ones are created, attributing these changes to developments in the social, political, and economic circumstances in many source and host countries. The expanded model also depicts the push-pull relationships between a single source country and multiple host countries, as well as between two or more host countries. Together these studies provide multidimensional views of the variables influencing international student flows on the micro, meso, and macro levels. Most of the studies looked at a range of push and pull factors. Pimpa $(2003,2005)$, on the other hand, added to knowledge by contributing an in-depth examination of one of the major push 
factors influencing a student's choice to study abroad (family). More such in-depth research needs to be undertaken on individual push-pull factors.

Together the studies focus on a wide range of source countries from developing to developed countries, although in terms of host countries/regions they concentrate primarily on South-North flows. While the majority utilised relatively contemporary data on student flows, one (McMahon, 1990) also looked at historical flows. Collectively they surveyed students in a range of academic disciplines, and at a variety of degree levels (pre-university, undergraduates and postgraduates) and within these levels prospective, current and recently-graduated international students. Yang (2007), for example, offered a valuable comparison of the importance of push-pull factors between prospective and current international students in their decisions to study abroad and choose a host country, while Li and Bray (2007) explain why some students opt for the full international study experience whereas others elect to either study at home or to study 'half-way' between home and the international (for example, mainland Chinese students studying in Macau). Finally, Bodycott (2009) added the voice of parents to knowledge on this subject highlighting the importance of parents and family in many source countries as significant stakeholders and co-decision-makers.

Over time recognition of the importance of the characteristics of individual students (including culture, personal circumstances, and perspectives) on student mobility, not just host and home country circumstances, became stronger in the studies. Evidence is provided of how these characteristics can have a major impact on students' behaviour and international education choices, and are key to facilitating a more complete understanding of how students respond differently or not at all to similar push-pull forces. In other words, over time these studies increasingly show that push-pull variables do not apply equally to all students, and that it is a combination of push-pull factors and individual student characteristics which play a part in students' decisions. They also highlight the potential changes to the importance of traditional push-pull factors as a result of the new developments in international education, such as branch campuses and distance education, as these new modes of delivery are changing the educational opportunities available in many traditional source countries. 
Prior to discussing the limitations of Push-Pull Theory, identifying the gaps in the research and how I aim to fill some of the gaps, I would like to point out some areas in which the push-pull studies above influenced the thesis research. The following studies had particular influence on the thesis: the Mazzarol-led studies (1996-2002), Pimpa (2003; 2005), Li and Bray (2007), Maringe and Carter (2007), and Chen (2007). These studies were influential in furthering my understanding of the multifaceted nature of international student mobility. Chen's (2007) study was especially relevant to the research as Social Capital Theory was utilised as part of her 'synthesis model.' However, our definitions of what constituted social capital differed. Chen states the decisions related to international education are influenced to some extent by 'Student Characteristics' which she defines as including social capital, and a factor she calls 'Significant Others', a term she used to refer to family and relatives (among others). She does not explain why she makes a differentiation between social capital as a 'Student Characteristic' and 'Significant Others'. In the thesis, social capital is defined as a resource possessed or acquired by students made up of their social networks in which 'Significant Others' are included. One of the findings from Chen's (2007) research which I found especially intriguing was that an overseas education was not necessarily viewed positively or as a source of future advantage by all students.

The push-pull studies also informed the design of the thesis research, selection of methodology, and choice and development of the methods of data collection. Based on the considerable number of studies in the literature using the push-pull paradigm and the limitations of this theory, I decided that one way for me to add to knowledge was by using a new and different theoretical framework to explore why students decide to study abroad and why they select certain host countries. In addition, after a review of the push-pull literature and reflection on the limitations of the model, as well as the consideration of my own ontological and epistemological positions, I decided I could add best to knowledge by employing a qualitative methodology and methods.

In regard to methods, a number of the push-pull studies, like the thesis research, used questionnaire surveys (i.e., Mazzarol et al., 2001a; 2001b; Pimpa, 2003; 2005; Li and 
Bray, 2007; Chen, 2007; Yang, 2007; Bodycott, 2009; and Wilkins and Huisman, 2010), and/or interviews of students to collect data (Menon and Carspecken, 1990; Li and Bray, 2007; Chen, 2007; Maringe and Carter, 2007; Yang, 2007; Sahasrabudhe, 2008). While these studies did provide some guidance in the development of the questionnaire survey and interview questions used in the thesis research, there were some important differences. I offer a comparison between the thesis and the Mazzarol-led studies as an example.

In the Mazzarol-led studies, the researchers opted for a more quantitative approach to data collection using survey questionnaires. Their surveys limited students' answers to a list of twenty-two predetermined pull factor items from which students were expected to tick which items were important to their choice of host country. In the thesis, questions in the questionnaire survey about why students chose to study abroad and why they selected their particular host country were left deliberately open-ended so as not limit students in giving their reasons for selecting a certain host country. In addition, while the Mazzarolled studies had sizable samples, they did not conduct any in-depth interviews with the students surveyed. In the thesis, I wanted to explore in detail the decisions made by students in my sample so opted for individual face-to-face semi-structured interviews in which, as with the questionnaire, key questions were open-ended. Reasons for the decisions I made on data collection methods were in an effort to generate rich data and to allow the student voice to come through in the data. Further comparisons between the push-pull studies and the thesis research are made in Chapter 7 after the presentation of the analyses and data in Chapter 6.

\section{Limitations and Gaps in the Existing Research}

There is no doubt that valuable insights into international student decision-making have been gleaned using Push-Pull Theory. The theory does, however, have a number of limitations when applied to this issue which are not insignificant. A strict interpretation of Push-Pull Theory, for instance, assumes migration should go from the poorest to the richest regions of the world meaning that students should migrate from certain parts of Africa, for example, to the rich Western countries (Menon and Carspecken, 1990; Davis, 1995). Menon and Carspecken (1990) argue that such an interpretation is too utilitarian 
and based on a narrow view of human behaviour, and does not always account for the impact of changing economic, social and cultural conditions around the world. For example, an examination of the history of international student flow patterns shows that although there have been flows of international students from Africa to the West, the largest flows have been - and continue to be - from fast growing newly industrialising economies like China and India to the West (Portes and Borocz, 1989; Davis, 1995; de Wit et al., 2008). Furthermore, traditional Push-Pull Theory does not always adequately address more recent trends in international student mobility such as the growth of intraregional flows, or the movement of students between developing countries or from developed to developing countries (de Wit et al., 2008).

Another major limitation of Push-Pull Theory is that it is primarily quantitative in nature. Push-pull models have been helpful in identifying some of the social, political, and economic structures impacting international education, but many of the studies which have applied these models to the case of international students have seemed to characterise push-pull factors as purely mechanical determinants of student mobility (Sahasrabudhe, 2008; Cantwell et al., 2009). In other words, much of the existing research represents push-pull factors as external forces which impact on the choices and behaviour of students without enough consideration given to student agency or the fact that much depends on the personal characteristics of students (Li and Bray, 2007). Although economic, cultural, and structural circumstances do influence international education choices, these choices are also impacted by the values, attitudes, preconceptions, family circumstances, culture, life history, and the personality of each student (Wilkins and Huisman, 2010).

In addition, studies using push-pull models do not often take into account that each of the push-pull factors can be multidimensional, and that each of these dimensions impacts each of the choices involved in undertaking international education (Pimpa, 2003). Moreover, although push-pull models provide information about students who are considering or have chosen to study overseas, they do not often explain why some students have not been affected by push-pull forces or why some students who were considering overseas study did not ultimately do so (Li and Bray, 2007; Cantwell et al., 
2009; Wilkins and Huisman, 2010). In other words, the primarily quantitative approach of Push-Pull Theory may limit our understanding of the diversity of meanings of international education to and the ultimate decisions of students (Cantwell et al., 2009).

Additionally, while Push-Pull Theory can help to explain the size and direction of some student flows, as international students are increasingly free movers and the consumption patterns of source countries change, the theory does not pay enough heed to self-initiated or spontaneous student flows. Although occurring in the broader national, regional and global context, the decision to study abroad is now essentially a private choice for students greatly dependent on their personal characteristics and circumstances (Portes and Borocz, 1989; Altbach, 1998; Li and Bray, 2007). Whereas economic motives were once the key determinant of student flows, now social and cultural motives, like the desire to increase cultural awareness or social status, are gaining in importance (MurphyLejeune, 2003; Hung, 2010). In summary, understanding the decisions made by students at the individual level provides the key to understanding their choice to study abroad and their choice of host country (Mazzarol et al., 1996).

The weaknesses of Push-Pull Theory highlight the need for more research utilising alternative theoretical frameworks and methodology that lets international students speak for themselves so that their decision-making can be understood on a more personal level. There has been relatively little work done on international students using other theoretical frameworks, and there has been little done using multidisciplinary frameworks which look at the research questions from different angles. The research here employs a combined multidisciplinary theoretical framework consisting of three theories: Human, Cultural, and Social Capital.

In order to let the student voice guide the research, the present study also uses a qualitative framework to capture the complexities of the decision-making process of students and to highlight the multiplicity of student voices. I do this in two ways. In the first stage of the research, I disseminated a survey questionnaire to students. Unlike the push-pull studies reviewed above, I did not present students with pre-prepared lists of factors with tick boxes, but rather I presented them with a series of open-ended questions 
allowing them to respond and explain, in their own way, their reasons for going abroad and for their choice of host country. In the second stage of the research, I conducted indepth interviews with students allowing for further exploration of their survey responses as well as their individual life stories, and how these experiences influenced their decisions regarding international education. This is explained further in Chapter 5.

In this chapter I have provided an overview of the research that has been done to explain why students pursue overseas study, looking in detail at how Push-Pull Theory was used in a number of studies to understand international student decision-making. Next, I discussed the collective contribution of these studies and how they influenced the thesis research. I concluded with a critique of this theory and identified some of the remaining gaps in knowledge. Finally, I explained how the thesis research aims to make a contribution to knowledge utilising a new theoretical framework along with a qualitative methodology and methods. An in-depth discussion of each of the capital theories is presented next in Chapter 4. 


\section{Chapter 4: The Theoretical Framework}

This chapter introduces the combined theoretical framework of Human, Cultural and Social Capital used in the research and the relevance of each theory to international students.

Three theories - Human, Cultural, and Social Capital - were combined to create a theoretical framework to guide the research, analyse and interpret research data, and answer research questions. The three capital theories originate from two different disciplines within social science: Economics and Sociology. Both of these disciplines are relevant to the policies, practices and problems of education, and thus the integration of capital theories from both fields provides a comprehensive theoretical framework for explaining and understanding, but not necessarily predicting, the decision-making behaviour of international students. As Bourdieu (1986) observed, "It is in fact impossible to account for the structure and function of the social world unless one reintroduces capital in all its forms and not solely in the one form recognized by economic theory..." (p.46).

Although the three forms of capital are different, they are related to one another in complex ways with one often employed in the development of the other two (Bourdieu, 1986; Coleman, 1999; Keeley, 2007). They overlap and build upon one another to give a more complete picture of students' reasons for deciding to study abroad and choosing a particular host country. The reasons why students decide to leave their homes and travel large geographic and cultural distances to study are far too numerous and complex to be explained by a single one of these theories. These theories also go beyond Push-Pull Theory in drawing attention to the wider concepts surrounding international student decision-making, such as social production and reproduction. Finally, they are important sociological and economic theories that have had significant influence on both national and international public policy discourse, and have been used frequently in education research and practice.

These three theories also provide a relatively new approach to research on international students as, unlike Push-Pull theory, they have not been used extensively to study why 
international students decide to study abroad nor why they select particular host countries. I was not able to locate any studies where these theories were used in combination, although I did find two studies which used one of the three theories. The first was Agarwal and Winkler (1985) who proposed a theory of international student demand for U.S. higher education which was highly influenced by Human Capital Theory. The second was Chen (2007) who utilised Social Capital Theory in conjunction with Push-Pull Theory as part of a synthesis model to study why East Asian students chose particular host institutions in Canada.

Prior to introducing each of the capital theories, I offer a brief explanation of the term 'capital' as used in the thesis.

\section{What is Capital?}

Although Moore (2004) states the term capital is generally associated with a narrow economic definition of monetary exchanges intended to yield some profit, it is much more than that. In the research presented here the definition of capital in relation to the three capital theories can be characterised as any resource that is not consumed but is invested in an effort to create more (Lamont and Lareau, 1988; Fukuyama, 2003).

Bourdieu (1986) also attempts to expand the notion of capital to something broader than just economic capital. He actually differentiates three forms of capital: economic, cultural and social. He emphasises that each requires, and is the product of, an investment of an appropriate kind and each can yield a return on that investment (Reay, 2004). He explains further that each of the three capitals can be exchanged or converted into one another or into economic capital. It is this convertibility that determines the value of the capital as capital with limited convertibility usually has low value (Bourdieu, 1986; Lamont and Lareau, 1988; Biao and Shen, 2009). Biao and Shen (2009) similarly state, "Social and cultural capital [for example] will mean little if they cannot be converted to other types of capital, especially economic capital. Similarly, economic capital acquires its sociological significance only when it is converted to social and cultural capital..." (p.513-514). Biao and Shen contend however, that different forms of capital must maintain some degree of autonomy from one another for conversion to be sustainable, "Otherwise, for example, if 
educational degrees were for sale, they would lose their intrinsic value and would subsequently have no market value. They would also be deprived of their symbolic power for legitimating the privileges of the degree holders" (p.514).

They also make the important point that "[the] conversion between forms of capital, however, never occurs automatically...It is always conditioned and mediated by social institutions..." (p. 514) because it is "'...deeply embedded in a social system of capital conversion" (p.521). The social institution which is the main focus of the thesis is education, particularly higher education. Education allows individuals to accumulate and develop various types of capital "...but more importantly it "lifts" people to a higher scale of capital conversion" (Biao and Shen, 2009: p.514), or at least it is believed to have the power to do so.

\section{Human Capital Theory}

Economists Theodore Schultz (1961) and Gary Becker (1993[1964]) contended investment in labour, or human capital, is one of the most important forms of capital investments made by nations and individuals. Schultz (1961) stated, "...it is obvious that people acquire useful skills and knowledge... these skills and knowledge are a form of capital...this capital is in substantial part a product of deliberate investment...it has grown in Western societies at a much faster rate than conventional capital, and...its growth may well be the most distinctive feature of the economic system" (p.1). He further asserts, "This knowledge and skill are in great part the product of investment and combined with other human investment, predominantly account for the productive superiority of the technically advanced countries" (p.3). Becker (1993[1964]) places the concept in a more global context, "...the analysis of investments in human capital helps in understanding a large and varied class of behaviour not only in the Western world, but also in developing countries and countries with very different cultures" (p.17). This is an important point with respect to international students who are from a wide variety of countries and cultures. 


\section{Defining Human Capital}

Human capital refers to the knowledge, skills, abilities, and traits possessed by individuals that contribute to their personal, social and economic well-being, and "that affect particularly human capabilities to do productive work" (Schultz, 1961: p. 8). It is a form of capital because investment in it "... [yields] income and other useful outputs over long periods of time" (Becker (1993[1964]): p.15). In other words, investing in human capital can both entail a significant time period during which investments are made with longterm benefits (potentially) accrued, and shorter term benefits foregone (Healy and Côté, 2001). Becker identifies it as a unique type of capital "...because you cannot separate a person from his or her knowledge, skills, health or values the way it is possible to move financial and physical assets while the owner stays put" (p.16). Like other forms of capital, it can be traded in the market for financial gain but the possession of it cannot usually be sold to or bestowed on another individual. Human capital is not necessarily fixed but can increase through application, experience, training, and formal or informal education. Human capital can be expensive to acquire and is similar to other types of capital because it can depreciate through non-use or lack of maintenance, become obsolete, and decline with age (Schultz, 1961; Healy and Côté, 2001).

Human capital can include general skills and competencies anywhere from basic literacy to more highly specialised skills and competencies, such as technical ability and foreign language skills. The type of economic activity associated with the knowledge economy has enlarged the demand for people possessing human capital in the form of increased educational levels and highly specialised skills, including non-cognitive and interpersonal skills like leadership, motivation, self-discipline, flexibility, and cross-cultural communication skills (Becker, 1993[1964]; 2006; Sweetland, 1996; Healy and Côté, 2001; Keeley, 2007). Human capital can also include the innate capacities of individuals or abilities resulting from the informal learning opportunities that may take place within the family, although the knowledge, skills and competencies that are valuable human capital in the knowledge economy are mainly, though not exclusively, acquired via formal learning and experience. In addition, the ability of individuals to be adaptable and trainable is a critical part of an individual's human capital (Woodhall, 1987; Castells, 1998; Healy and Côté, 2001). 


\section{Human Capital Investments}

While human capital investment is important to nations for developing a quality labour force, Schultz (1961) reminds us that investment in human capital is also important on an individual level and that, "...people invest in themselves and that these investments are very large...By investing in themselves, people can enlarge the range of choice available to them. It is one way free men can enhance their welfare" (p. 2). He identified five activities in which individuals invest time and money to increase their human capital: "(1) health facilities and services..., (2) on-the-job training..., (3) formally organized education at the elementary, secondary and higher levels, (4) study programmes for adults that are not organized by firms...[and] (5) migration of individuals and families to adjust to changing job opportunities" (p.9).

Becker (1993[1964]) supports Shultz's assertion of the importance of investment in these activities to the development of human capital stating, "[These various forms of investment] differ in their effects on earnings and consumption, in the amounts typically invested, in the size of returns, and in the extent to which the connection between investment and return is perceived. But all these investments improve skills, knowledge, or health, and thereby raise money or psychic [consumption] incomes" (p.11). He focuses particularly on the benefits to investment in education saying "...schooling raises earnings and productivity mainly by providing knowledge, skills, and a way of analyzing problems" (p.19). In addition, he suggests one further example of investment in human capital relevant to the research on international student decision-making, "...searching for information about prices and incomes" (p.11).

Although their work on Human Capital Theory highlights how an individual's investment in their own human capital can, for example, increase their lifetime earnings, Schultz (1961) contends, "Not all investment in human capital is for future earnings alone. Some of it is for future well-being in forms that are not captured in the earnings stream of the individual in whom the investment is made" (p.7). Becker (1993[1964]) adds "...nothing in the concept of human capital implies that monetary incentives need be more important than cultural and nonmonetary ones" (p.21), but people also invest in and strive to develop their own human capital in order to reap future non-monetary benefits (Mazzarol 
and Soutar, 2001). Non-monetary benefits might include higher job satisfaction, and improved health and mental well-being (Healy and Côté, 2001).

Education level has been most often used as a proxy measure for human capital as years of participation and qualifications obtained enable a calculation of the rates of return to investment of different levels and kinds of education (Sweetland, 1996; Baláz and Williams, 2004). Educational credentials and qualifications are also regularly used as indicators of human capital in the labour market (Healy and Côté, 2001; Baláz and Williams, 2004). The evaluation of educational credentials as a proxy however, does not include human capital acquired through informal education or life experience, or human capital that is culturally bound or tacit (Healy and Côté, 2001).

The two investment activities, as identified by Schultz, which are of primary interest to the thesis are education and migration. Although the research will be looking primarily at individual benefits to investment in education and migration, this should not be taken to intimate that the societal benefits resulting from such investments are less significant. However, it is important to say that human capital is now generally viewed as an individual property requiring individual investment with the benefits produced by such investment occurring mostly on an individual level (Becker, 1993[1964]; 2006; Healy and Côté, 2001; Green, 2006; Keeley, 2007).

\section{Individual Investment in Education}

Becker (1993[1964]) contends, "Education and training are the most important investments in human capital" (p.17). Participating in formal education is one way through which individuals invest in and develop their human capital, anticipating there will be significant costs and, hopefully, significant benefits accompanying this investment (Sweetland, 1996; Healy and Côté, 2001; Keeley, 2007).

\section{Costs and benefits}

Estimating the total costs to individuals of investing in formal education is challenging. One reason for this is the difficulty of separating out which costs can be attributed to 
public and which to private investment. In regard to higher education, although there is still some public financing in most countries, investment in higher education is now considered a private investment. Individuals are responsible for most of the associated costs, and returns to this investment tend to be greater to the individual than to society in general (Schultz, 1961; Sweetland, 1996).

The costs to individuals of investing in higher education can be both indirect and direct. Indirect costs refer to the time and effort spent on higher education as well as opportunity costs such as income forgone or the loss of promotion potential while attending university (Schultz, 1961; Agarwal and Winkler, 1985; Varga, 2009). Direct costs include tuition fees, expenditure on books or equipment, and living expenses (Woodhall, 1987; Mazzarol and Soutar, 2001). When estimating the RoR to investment in higher education, it is also important to take into account its distributed nature (i.e., investment and benefits generally occurs over a long period of time) (Becker, 1962).

Although realising the costs incurred of investing in higher education can be significant, individuals hope any costs will be outweighed by future economic benefits, such as increased future earnings over their lifetime (Agarwal and Winkler, 1985; Woodhall, 1987; Maier, 2009). Becker (1993[1964]) claims there is evidence to support the statement that "The earnings of more educated people are almost always well above average, although the gains are generally larger in less-developed countries" (p.17) making such an investment attractive. This is an important point for international students, the majority of whom are from developing or newly industrialising countries.

\section{Rates of return}

According to Human Capital Theory, the costs and benefits to individuals of investment in higher education can be measured by looking at the profitability, or RoR, on this investment. To calculate the RoR of educational investment, future financial benefits must be weighed against the costs of acquiring that capital, including tuition fees and money not earned in employment during the time in education (Schultz, 1961; Woodhall, 1987; Keeley, 2007). However, it is not simple or easy to determine an exact calculation of the 
private RoR, or full costs and benefits of investment in education because, for instance, these benefits are not always certain or may only become evident through consumption (Healy and Côté, 2001; Maier, 2009).

Human Capital Theory contends that students invest in higher education because they perceive the private RoR to be high in terms of future monetary and non-monetary benefits (Becker, 1993[1964]; Woodhall, 1987; Sakellaris and Spilimbergo, 2000; Becker, 2006). However, the costs and benefits of investing in higher education can be tricky for students to calculate because some are intangible, or accurate data can be difficult to locate and evaluate (Green in Lauder et al., 2006). For example, Maier (2009) asserts the benefits of educational investment are difficult to measure because they do not accrue all at once but are usually generated throughout the course of the career and lifecycle. As it is difficult for students to determine exact RoRs, they often make educational choices based on inexact or subjective calculations or comparisons, and are frequently influenced by the opinions and beliefs of significant others in their lives (Green in Lauder et al., 2006; Maringe and Carter, 2007).

\section{Sorting: signalling and screening}

Related to Human Capital Theory is the idea of the sorting of workers. Sorting refers to the signalling and screening of workers based on their educational qualifications (Weiss, 1995). Weiss (1995) explains that students select a certain length of schooling to "signal" their ability to potential employers while employers require a minimum level of schooling in order to "screen" their workers. Signalling theories hypothesise that individuals choose to pursue higher education because such credentials signify to others they possess certain knowledge, skills and abilities as well as high levels of motivation and aptitude. They hope this investment in education will distinguish them from others in the labour market (Throsby and Heaton, 1995; Healy and Côté, 2001).

Screening theories hypothesise that during the job search, employers screen applicants to determine if they possess the 'appropriate' characteristics in terms of presentation, ease, style, language and high levels of education. The possession of such characteristics 
enhances the productivity of the educational capital gained from qualifications (Harker, 1990). This screening also overlaps with the notion of cultural capital which is presented later in the chapter. Walker and Zhu (2003) contend both signalling and screening imply a positive correlation between education levels and wages with individuals selecting particular signals that will maximise the RoR to their educational investment (Spence, 1973).

\section{Individual Investment in Migration}

Just as with investment in education, migration can foster human capital development (Schultz, 1961; Stark and Wang, 2002). Individuals migrate for a number of reasons hoping to reap returns in the form of access to better job opportunities (Sjaastad, 1962; Baláz and Williams, 2004; Faggian et al., 2009), greater job security or to avoid rising or high levels of unemployment (Mazzarol and Soutar, 2001), higher salaries (Sjaastad, 1962; Baláz and Williams, 2004; Appleton et al., 2006; Faggian et al., 2009), or the opportunity to upgrade or acquire new skills by migrating to a technologically-superior country (Sjaastad, 1962; Faggian et al., 2009). Dustmann (1999) hypothesises that the amount of investment made by migrants in developing their human capital, and particularly in developing country-specific human capital, depends on the duration of time they expect to remain in the host country labour market.

Biao and Shen (2009) state, "...the spatial scale at which one converts one type of capital to another determines the efficiency of the conversion and subsequently the total value of the capital" (p.514). In other words, while investment in migration can yield some returns it also incurs certain costs - both direct and indirect monetary and non-monetary costs. The direct monetary costs associated with - and necessitated by - migration might include immigration/visa costs, food, lodging, and transport (Findlay and Stam, 2006). Indirect monetary costs might include opportunity costs in the form of earnings foregone during the travel period as well as the time required to search and be trained for a new job. Nonmonetary costs might include the psychic and personal costs of changing living environments and leaving familiar surroundings and people, and acclimating to a new climate (Sjaastad, 1962). 


\section{International Education and Human Capital}

The pursuit of international education comprises two of the five important human capital investment activities identified by Schultz (1961): formal education at the higher education level and the migration of individuals to take advantage of educational and job opportunities.

Rate of return

According to the theory of human capital, once a student has made the decision to invest in higher education, he/she will choose the option that yields the highest RoR whether that is attending a university at home or abroad. International students considering study abroad have already decided the rate of return on pursuing international education is worth the investment (Agarwal and Winkler, 1985). These students are also presumably aware that the cost associated with this type of education will be much higher than if they were to study at home, and in the absence of funding opportunities will put great pressure on their own, and often their family's, financial resources. They hope, however, that any additional costs will yield a high RoR in terms of future benefits (Agarwal and Winkler, 1985; Mazzarol and Soutar, 2001).

Agarwal and Winkler (1985) explained that after students have made the decision to study abroad, they presumably compare the costs and benefits of the various options, and choose those which yield the highest RoR. In an attempt to guarantee a high RoR, students might consider the quality of education offered, the international reputation of the host country's education system, and whether qualifications from the host country will be recognised at home (Mahroum, 2000; Mazzarol and Soutar, 2001; Biao and Shen, 2009). Benefits to investment in international education include increased foreign language competence, cross-cultural skills, and formal knowledge acquired abroad (Baláz and Williams, 2004). There are also important opportunity benefits such as the chance for students to change their visa status and immigrate to the host country (Agarwal and Winkler, 1985; Mazzarol and Soutar, 2001; 2002). 
In addition to educational and migration-related costs, RoR can be impacted by costs associated with searching for information about international education options. Costs might include the time it takes and the ease with which students can find information on various host countries and institutions (Becker, 1993[1964]; Mazzarol and Soutar, 2001). Agarwal and Winkler (1985) explain that although students incur opportunity costs whether they study at home or abroad, in the case of international students such costs can be greater when host countries limit the employment options for students. International students are limited, in many host countries by the terms of their visas, to only part-time work during the study period (Mazzarol and Soutar, 2001; 2002).

\section{Value-added human capital}

Besides the benefits of increasing their human capital through studying at the higher education level, students expect international education will provide benefits in the form of the acquisition of rare and valuable human capital (Biao and Shen, 2009). Wiers-Jenssen (2008) explains that although the standard version of Human Capital Theory does not differentiate between international and domestic education, research on human capital and the labour market differentiates between country-specific and general human capital. Wiers-Jenssen theorises that the identification of country-specific human capital demonstrates that international and domestic education are not equivalent and that international education provides added value in terms of the potential for acquiring host country-specific human capital that cannot be accrued via domestic education.

Language, cultural and professional skills that have been adapted to a particular host nation context are examples of country-specific human capital. Although this type of human capital is generally more applicable in the labour market of the host country, it can also be valuable for accessing particular sectors of the labour market in the student's home country (Dustmann, 1999; Wiers-Jenssen, 2008). Wiers-Jenssen (2008) also states that some types of country-specific human capital can also be considered as transnational human capital. He gives proficiency in English as an example because it can be utilised in many countries. 
Like Wiers-Jenssen, Murphy-Lejeune $(2002 ; 2003)$ also refers to the notion of 'value added' capital as a reason for students to undertake international education, with value being added to overall capital development in several key areas: knowledge, strategic skills, social competences, and personal and interpersonal attitudes. Although MurphyLejeune does not use the terms human, social and cultural capital, the areas of development which she highlights are examples of these capitals. In addition, experience in the social and cultural context of the host country provides added value because it is important to the acquisition of tacit cultural knowledge (Baláz and Williams, 2004).

Mobility capital

Mahroum (2000) calls higher education "...the major backdoor for international mobility..." (p.36). Two facets of this mobility will be discussed here: 1) migration for the purpose of study and 2) labour and permanent migration after graduation.

Migration for study

International students are an important part of international migration systems, and postgraduates, in particular, are an integral part of the transnational mobility of the highly-skilled (Szelényi, 2006). Baláz and Williams (2004) describe student migration as important to human capital development because it is "...the only form of skilled labour migration where the principal manifest function is [bold mine] human capital acquisition" (p.217). They contend international students are the only group of migrants who move for fixed time periods primarily to increase their human capital. They can be considered as more than regular sojourners as their stays are far from temporary with those pursuing full degrees spending one or more years in the host country (Szelényi, 2006).

Murphy-Lejeune (2002) refers to 'mobility capital' wherein the experience of living abroad is itself a form of transnational human capital. She defines mobility capital as "...a subcomponent of human capital, enabling individuals to enhance their skills because of the richness of the international experience gained by living abroad" (p.51). Similarly, Findlay et al. (2006) contend mobility capital is linked to other forms of capital because 
international study not only helps students to develop their overall human capital through improving language skills and acquiring international work experience but also increases their chances for better employment prospects and upward mobility by enhancing their social capital and cultural capital as well. In addition, some students migrate for education because they are interested in having international careers, in working and living abroad and international education can be seen as the first step towards this goal (Mahroum, 2000).

Labour and permanent migration

An aim of many international students is to use their education as a pathway to immigrate or at least take advantage of some period of labour migration in the host country (Li et al., 1996; Mazzarol and Soutar, 2001; Baláz and Williams, 2004). For these students adjusting their visa status while in the host country as a student may be easier than applying for an immigrant visa from home (Agarwal and Winkler, 1985). Like other highly skilled migrants, international students' reasons for migrating can include access to high value employment experience, job opportunities in a country with a certain knowledge base, and higher salaries (Faggian et al., 2009).

\section{Critiques of Human Capital Theory}

There have been many criticisms levelled at Human Capital Theory. Kivinen and Ahola (1999) and Coffield (1999), for example, argue that education is not the sole factor important in the economic equation and the reality of matching supply to demand in the labour market is much more complicated and variable than Human Capital Theory suggests. Other critics have disputed the empirical evidence which suggests education increases worker productivity and yields returns to society in the form of economic growth (Woodhall, 1987; Throsby and Heaton, 1995; Maglen, 1990; Schuller, 2001). A third set of criticisms assert Human Capital Theory focuses too much on the market or economic function of education while giving little heed to its socio-cultural functions (Coffield, 1999; Mazzarol and Soutar, 2001; Ninnes and Hellstén, 2005). 
Public Policy and Human Capital Theory

The growth of neo-liberalism in the 1990s advanced a market-driven approach to economic and social policies that embraced Human Capital Theory. Neo-liberal nations supported the notion that education and training were crucial for the production of highly skilled workers for the global knowledge economy (Lauder et al., 2006; Bonal and Rambla, 2009). Thus Human Capital Theory was offered as a rationale for education planning in many developed countries, reflected in such policies as "Skill New Zealand", "Surpassing Ourselves (USA), "Investors in People (UK) (Lauder et al., 2006; Wallis, 2002), and the Council of Australian Governments (COAG) Human Capital Reform (Bexley et al., 2007). The OECD even published its own report defining human capital and identifying attributes of individuals relevant to economic activity (OECD, 1998; Schuller, 2001).

Despite such criticisms, the $21^{\text {st }}$ century has witnessed the continuing influence of Human Capital Theory nationally, regionally and internationally on education planning and policies in an effort to drive economic growth and competitiveness (Lauder et al, 2006; Bonal and Rambla, 2009). The EU, for example, announced in autumn 2010 a new programme for international cooperation entitled the 'EU International Higher Education and Human Capital Development Cooperation Programme' (EU Delegation, 2010). Bonal and Rambla (2009) have gone so far as to call Human Capital Theory a "fundamental frame of reference for the establishment of priorities and education policy strategies" (p. 147).

As stated above, individuals invest in international education to increase their human capital. Below I present Cultural Capital Theory and discuss how individuals also expect to increase their cultural capital through investment in international education.

\section{Cultural Capital Theory}

The concept of cultural capital developed primarily from the research of French sociologist Pierre Bourdieu. 


\section{Defining Cultural Capital}

Cultural capital refers to the cultural advantages an individual enjoys which are acquired through education, family, and other sources that confer social power and status upon that person (Bourdieu, 1986; Schuller, 2001). The concept is based on the notion of the existence of a cultured habitus. Habitus is comprised of distinctive cultural dispositions and habits, including attitudes, manners, preferences, orientations, behaviours, and goods common to all members of the same class (Bourdieu, 1971a; Lamont and Lareau, 1988; Bourdieu and Passeron, 1990[1977]; Reay, 2004). Habitus can also include linguistic competence and aptitude in terms of fluency, grammar, accent, and tone (Lamont and Lareau, 1988; Sullivan, 2001). The cultural competencies related to habitus derive value from and confer distinction on their owner based on their degree of scarcity in the overall distribution of cultural capital (Bourdieu, 1986).

Habitus interacts with various social 'fields' - a 'field' is defined by Bourdieu as a set of social relations and structures within which social activities occur. Via implicit rules, norms and traditions, the dominant cultural habitus maintains and reproduces itself within the structure and relations of these various fields (Bourdieu, 1971b; 1977b; Bowl, 2003). Bourdieu deems education one type of social 'field' with its own set of practices and policies that are implicit, unquestioned, and customary (Bourdieu, 1971b; Bowl, 2003).

Bourdieu theorises high value cultural capital is associated with the culture of the dominant group in society and is unevenly dispersed across social classes thus rendering the value of an individual's cultural capital dependent on his or her possession of or familiarity with the dominant culture (Bourdieu and Passeron, 1990[1977]; Sullivan, 2001). The operation of habitus, the effects of which are generally not obvious or direct, can be so powerful that members of non-dominant groups may not be cognisant of its influence and may internalise the belief they are not entitled to or adequate enough to take advantage of opportunities available to members of the dominant group (Bowl, 2003).

Bourdieu asserts cultural capital has the properties of traditional capital in that investment can be made into cultural capital in the expectation of some return (Sullivan, 2001). He argues cultural capital, along with social and economic capital, is one of a number of 
resources in which individuals invest, and which can be converted into one another to further an individual's upward mobility. Bourdieu points out that because cultural capital, under certain conditions, can be converted into other forms of capital, it is a 'transubstantiated' form of economic capital. Examples of this might include a financial investment in cultural objects or higher education (Bourdieu, 1986; Moore, 2004).

Cultural capital is most useful when it can be converted into economic capital (McDonough et al., 1996). The benefits produced from investment in cultural capital, however, do not necessarily appear in the form of economic capital although Bourdieu reminds us that, "...economic capital is at the root of all other types of capital..." (Bourdieu, 1986: p. 54). Reay (2004) points out that there is not always necessarily a close relationship between economic and cultural capital, and cultural capital can exist without the support of economic capital and operate independently from it. Cultural capital can also overlap with human capital but differentiates itself when it is converted into symbolic capital (Schultz, 1961; Lamont and Lareau, 1988).

The returns to cultural capital investment can include the acquisition of personal qualities such as speech, appearance, manners, and dress associated with the dominant habitus. Returns also include the acquisition of educational credentials that position the individual for social and occupational success (Sullivan, 2001; Moore, 2004). The returns to cultural capital investment generally differ by social class, thus explaining the variations in investment in cultural capital by these classes (Lamont and Lareau, 1988). Bourdieu (1986) states the costs of acquiring cultural capital can be large, requiring high levels of economic capital, particularly in terms of the money and time needed for acquisition.

Bourdieu and Passeron operationalised cultural capital as knowledge of high culture and participation in high status activities like attending the symphony or visiting an art gallery (Bourdieu and Passeron, 1990[1977]). Other researchers have attempted to use proxies such as cultural activities which take place in the home like reading and family discussions, languages understood and spoken by parents, or levels of educational attainment and qualifications held by family members (Bourdieu and Passeron, 1990[1977]; Lamont and Lareau, 1988; Reay, 2004). 


\section{Forms of Cultural Capital}

Bourdieu (1986) identified three types of cultural capital: 1) embodied, 2) institutionalised, and 3) objectified.

\section{Embodied cultural capital}

Embodied cultural capital refers to cultural capital that is inherited or internalised, and is generally accumulated unconsciously during the period of socialisation (Bourdieu, 1986). Embodied cultural capital is limited to the characteristics appropriated by an individual and thus cannot be transmitted or bestowed instantly on another. It is intrinsic to the owner and is symbolised by valorised qualities such as dress, accent, the use of educated language, or skill in using ICTs (Bourdieu, 1986; Sullivan, 2001; Maringe and Carter, 2007). Bourdieu states the ability to use educated language or the language of the dominant group, for example, is a type of 'linguistic capital' (Bourdieu and Passeron, 1990 [1977]). He sees it as a symbolic form of capital which individuals can use in their struggle for power and status such as accessing high level positions in the labour market. When there is one language that dominates the market, like English, this language becomes the norm against which the worth of other modes of expression and languages are compared (Snook, 1990).

Institutionalised cultural capital

Bourdieu defines institutionalised cultural capital as the institutional acknowledgment of an individual's cultural capital through, for example, the recognition of academic qualifications and credentials (Bourdieu, 1986). Investment in institutionalised cultural capital requires time, money and effort. Time is particularly important because the more time an individual can spend in education without having to work or worry about money the more the individual can pursue valuable levels of cultural capital which will help them to succeed in future (Bowl, 2003).

Institutionalised cultural capital also ceases to exist along with its possessor, but unlike embodied cultural capital, it cannot in and of itself be transmitted to the next generation. When it takes the form of educational qualifications it has some sense of being separate 
from the individual because it is officially and independently sanctioned bestowing on the possessor a legally recognised form of cultural capital (Bourdieu, 1986). This allows institutionalised cultural capital to be assigned a certain level of economic worth enabling the individual to convert it directly into human and economic capital in the labour market (Bourdieu, 1986; Reay, 2004). Institutionalised cultural capital can also symbolise a range of embodied cultural capital traits, and the attainment of certain credentials can facilitate access to high status and powerful positions (Bourdieu, 1984; 1986; Waters, 2007).

\section{Objectified cultural capital}

Cultural capital in the objectified state, as described by Bourdieu, is represented by cultural goods such as paintings, instruments, books, computers, dictionaries, and other cultural objects associated with the dominant cultural habitus (Bourdieu, 1986; Reay, 2004). There is a link between objectified and embodied cultural capital in that although the material object itself is transmittable to those possessing the requisite economic capital, the purchaser cannot necessarily appropriate the embodied cultural capital associated with that object or with the seller if they do not already have it. Thus individuals can reap profit from their own embodied cultural capital by selling goods with objectified cultural capital or services related to their expertise associated with the objectified goods (Bourdieu, 1986).

The thesis focuses primarily on the embodied and institutionalised states of cultural capital which depend on socialisation in the family and educational field for their development.

\section{Cultural Capital Investments}

Bourdieu explained that the two major conduits of cultural capital transmission crucial to the process of social reproduction are family socialisation and education (Bourdieu, 1971a; 1986; Bourdieu and Passeron, 1990[1977]). Both family socialisation and education help children to develop the 'proper' habitus for further capital accumulation and conversion. Bourdieu states a large amount of the transmission of cultural capital is hidden making it appear to be a natural, hereditary attribute of an individual when it is, in fact, socially transmitted within the family or through education from one generation to the next in an 
effort to enhance, maintain, and reproduce cultural advantage and other benefits (Bourdieu, 1971a; 1986; Moore, 2004).

Bourdieu also regards cultural capital as being a cumulative resource meaning the more cultural capital an individual accrues at an early age, the easier it will be to accumulate more throughout life (Bourdieu, 1977a; DiMaggio and Mohr, 1985). Inequality is generated when some individuals, because of membership in the dominant group, enter a social field already possessing valuable cultural capital or exclusive knowledge on how to obtain it, and thus have a greater likelihood of accruing more than those who do not (Bourdieu, 1986; Bowl, 2003).

\section{Family Socialisation and Resources}

Bourdieu argues it is through the process of family socialisation that children inherit cultural capital. The value of this cultural capital is dependent on the level of parents' social capital, socio-economic status, educational experiences and qualification levels, and familiarity with the dominant culture and the education system (Bourdieu and Passeron, 1990[1977]; Sullivan, 2001; Reay, 2004). Via socialisation within the family, parents attempt to endow their children with the cultural capital necessary to maintain their social position, as well as to acquire the cultural knowledge valued by the educational system and which is important to academic success (Bourdieu, 1971a; 1986; Sullivan, 2001; Zimdars et al., 2009).

High levels of human and financial capital within the family are also important to the cultural capital development of children because they provide children with the educative resources, support, and time free from having to work in order to participate in education (Bourdieu and Passeron, 1979[1964]; Becker, 1993[1964]; Schuller and Bamford, 2000). Cultural capital development is strongly linked to participation in cultural activities inside and outside the home, such as reading or going to the theatre, which serve to promote intellectual and academic development, and to communicate a particular status (Bourdieu, 1977a; Sullivan, 2001). Also important to the development of cultural capital is the time put in by parents in helping children acquire cultural capital (Sullivan, 2001; Reay, 2004). 


\section{Education}

Bourdieu (1977b) states, "...the habitus acquired in the family underlies the structuring of the school experience... and the habitus transformed by schooling, itself diversified, in turn underlies the structuring of our subsequent experiences' (p. 87). Schooling represents the institutionalised transmission of culture and is a powerful social mechanism through which the habitus of the dominant group is affirmed and transmitted to all social classes, strengthening the advantage of the dominant classes and reproducing the power relations between all classes (Bourdieu, 1971a; Bourdieu and Passeron, 1979[1964]; 1990[1977]). Bourdieu states the characteristics of the dominant cultural habitus are embedded in all facets of schooling, including policies, curriculum, and teaching practices (Bourdieu, 1971a; Sullivan, 2001; Moore, 2004). The norms, values, and attitudes reinforced in the classroom and school setting are also associated with the attributes of the dominant class (Bourdieu and Passeron, 1979[1964]; Lamont and Lareau, 1988).

Additionally, Bourdieu explains, the educational system presupposes all who enter it possess this cultural capital but, in reality, the possession of cultural capital differs based on social class. Thus students do not come to education on equal terms but rather with differing amounts of knowledge on how to navigate the 'field' of education creating an uneven playing field (Sullivan, 2006). In other words, education implicitly requires students to have a particular linguistic and cultural competence and familiarity with the dominant cultural habitus to achieve success (Bourdieu, 1977a; 1986; Moore, 2004; Zimdars et al., 2009).

The amount of economic and cultural capital within the family also influences the educational choices of children in terms of their attitude to education, access to differing qualities of education, and sense of entitlement to such access (Bourdieu and Passeron, 1990[1977]; Van der Werfhorst et al., 2003; Waters, 2006a). Bourdieu and Passeron (1990[1977]) contend that in families with high levels of cultural capital, parents generally have a high regard for educational attainment, an attitude which is passed on to their children influencing them to also value and take advantage of educational opportunities (Sullivan, 2006). 
High levels of cultural capital also enable children to access additional social environments where education is deemed valuable and where they can gather information about different educational opportunities and which, in turn, influences the probability they will pursue further education (Zimdars et al., 2009). In other words, support and encouragement from family and community can influence an individual's inclination and desire to undertake higher education. Parental influence conveyed to children via inherited cultural capital can impact not only whether the child undertakes higher education, for example, but also which higher education institutions students choose (Nora, 2004; Van de Werfhorst et al., 2001).

In sum, inherited cultural capital helps children to develop their own embodied cultural capital which, in turn, facilitates educational success. This further enables them to convert their embodied and prior institutionalised cultural capital into admission to higher education, and ultimately obtain valuable university credentials (DiMaggio and Mohr, 1985; Nora, 2004; Sullivan, 2006).

\section{Higher Education and Cultural Capital}

Bourdieu identified higher education as one 'subfield' within the broader 'field' of education and explained that, although having its own unique set of social relations, it is also interlinked with the structural relations of other fields such as the labour market (Bourdieu, 1971b; Bowl, 2003). He asserts that universities act as repositories of cultural capital making higher education a powerful force for social and cultural reproduction (Bourdieu, 1977b; DiMaggio and Mohr, 1985; Bowl, 2003). Baldwin and James (2000) similarly describe higher education as having a social sorting role that determines access to privileged occupations and positions.

Traditionally, the reproduction of the dominant group's status was associated with specific career paths and certain higher education qualifications (Bourdieu, 1984; 1986; Reay, 2004; Waters, 2006a). However, the expansion of mass higher education in the last fifty years has facilitated the upward mobility of people from diverse social classes enabling them to obtain these credentials and access these career paths (Van der Werfhorst et al., 
2003; Reay, 2004; Zimdars et al., 2009). In addition, as the number of university graduates has increased, the value of certain qualifications has decreased no longer ensuring access to high-level occupations for only those who hold these degrees (Reay et al., 2001; Van der Werfhorst et al., 2003; Zimdars et al., 2009). The change in the value of such credentials has been a source of anxiety for those who have relied on their acquisition to acquire and maintain social status (Bourdieu and Passeron, 1990[1977]; Waters, 2006b; Heath, 2007). Bourdieu (1984) explains:

When class fractions who previously made little use of the school system enter the race for academic qualifications, the effect is to force the groups whose reproduction was mainly or exclusively achieved through education [i.e. middleclass] to step up their investments so as to maintain the relative scarcity of their qualifications and, consequently, their position in the class structure (p. 133).

The proliferation of university graduates with undergraduate degrees, along with a saturated graduate job market, has led to growing competition for increasingly higher level (and scarcer) university qualifications, as well as access to top rated universities and academic programmes (Van der Werfhorst et al., 2003; Zimdars et al., 2009). Many individuals have elected to continue their studies at the masters or doctoral levels in order to further reinforce or boost what Waters and Brooks (2010) term their 'positional advantage'. In other words, the completion of a postgraduate qualification is a strategic move by students to secure economic and social advantage, particularly when competing for the most desirable jobs (Brooks and Waters, 2009a, 2009b; Waters and Brooks, 2010).

The acquisition of postgraduate level qualifications has become a new way social barriers are maintained, and in which individuals who have access to high levels of cultural capital, and likely economic capital, can maintain their positional advantage. Although the massification of higher education has meant social and economic gains have been made by other social classes, due to the economic capital needed to undertake postgraduate study, students from these classes generally continue to be excluded from acquiring such high level qualifications and consequently reaping greater economic rewards (Bowl, 2003). 
Thus, postgraduate education plays a prevailing role in educational advantage and social reproduction, and the conversion of economic capital into cultural capital has become an even longer and more institutionalised process (Reay et al., 2001; Biao and Shen, 2009; Zimdars et al., 2009).

\section{International Education and Cultural Capital}

\section{Education}

An increasingly popular option for maintaining or securing positional advantage is the pursuit of international education. This option allows students to bypass localised systems of social reproduction and pursue alternative education strategies (Bourdieu, 1984; Waters, 2006b; Biao and Shen, 2009). Waters (2006b) contends the dominant group is now using international education as a spatial strategy to secure advantage, maintain the scarcity of their academic qualifications, and acquire more valuable cultural capital. They are investing in the acquisition of internationally-recognised cultural capital which can potentially be converted into other forms of capital (Waters, 2006a; 2006b; Waters, 2007; Brooks and Waters, 2010). Biao and Shen (2009) refer to the investment in international education as a kind of 'venture investment' to highlight the fact that the returns to such investment are not guaranteed. Using the push-pull analogy, they claim individuals make this investment nonetheless because they are "...not only "pulled" by potential benefits, but [are] more importantly "pushed" by anxiety about the future..." (p.516).

It is also the amount of economic capital required that determines whether a student is able to undertake an international education which favours the more economically and socially privileged students, although non-affluent students are increasingly willing to make this investment (Reay, 2004; Waters, 2006a; 2006b; Waters and Brooks, 2010). Waters (2006a; 2006b) argues the pursuit of international education by members of the dominant social group reinforces local forms of social reproduction by, for example, shifting the means of accessing prestigious or high paying occupations in the domestic labour market towards those who hold overseas qualifications. These occupations gradually become associated with an international education, and in particular, a Western university qualification. Overseas credentials often become highly valorised at the local 
level (in the student's home country) meaning they are frequently perceived to be more valuable than domestically-obtained academic credentials. This leads to the devaluation of local credentials largely held by members of non-dominant social classes and which, in turn, reinforces social reproduction at the local level (Waters, 2006a; 2006b; Brooks and Waters, 2009a).

Waters (2006b) and Biao and Shen (2009) point out how Western countries, as a result of their status as much sought-after host countries, are also implicated in transnational forms of social reproduction because of the way in which domestic social reproduction in the home country and the perceived superiority of Western culture and education reinforce each other. In her 1999 book on the mobility of Asian students, Ong asserts for many of these students an international, particularly a Western education, is the first step in their strategy for accumulating various kinds of capital. Ong calls a Western university degree "the ultimate symbolic capital necessary for global mobility...which guarantees the holder has acquired the cultural knowledge, skills, and credentials that enable the transposition of social status from one country to another" (p. 90).

Ong also proposes another kind of cultural capital, location capital, which she defines as type of capital that is part economic and part cultural capital. She explains that selecting a certain location, such as a host country with a strong international reputation and profile in which to undertake international study, is also part of the capital accumulation strategy. As the number of returned students with international qualifications increases in certain source countries, prospective international students increasingly rely on the reputation and rankings of institutions and programmes as an initial part of their screening process (Bowl, 2003; Chen, 2007; Biao and Shen, 2009). In other words, the choices related to international study have also become highly strategic and a means by which students distinguish themselves from other graduates and secure positional advantage (Brooks and Waters, 2009b; Waters and Brooks, 2010).

Academic qualifications not only guarantee the possession of specific knowledge and skills in a certain field by the holder of the qualification but actually signify the possession of a certain cultural capital (Bourdieu, 1984; Waters, 2007). Based on Bourdieu's work, Waters 
concludes the pursuit of an international degree, particularly from the West, represents more than simply a desire for increased human capital, but is also about accumulation of a particular and exclusive type of cultural capital - an internationally-acquired cultural capital - one that sets these students apart from those who studied domestically and is essential for global mobility and occupational success (Bourdieu 1986; Ong, 1999; Waters, 2006a; 2007).

For many students, one of the most common and widely acknowledged cultural capital benefits of overseas study is the accompanying foreign language skills, particularly in English (Waters and Brooks, 2010). Sullivan and Enever (2009) state that English language skills are a modern form of high status cultural capital, and international students are part of a new mobile elite that have fluency in the dominant global language as well as their local/national language. Other important cultural capital attributes these students are assumed to have acquired include the potential for working cross-culturally and the possession of an international outlook (Brooks and Waters, 2009a; Waters, 2006a). The acquisition of these attributes is not entirely incidental as the chance for exposure to other cultures and the opportunity to broaden cultural and intellectual horizons is an important reason for studying abroad for some students (Baláz and Williams, 2004; Motivans, 2009). Hung (2010) argues that these broader experiential motives are becoming an increasingly common determinant of the demand for international education.

\section{Migration}

Szelényi (2006) asserts international study is "an intermediate period between temporary and long-term migration" (p.185) in which students have the chance to live and study (and sometimes work) in the country in which they may later choose to settle more permanently. This provides them with cultural capital in the form of day-to-day contact with the cultural, economic, and educational environment of their host country. MurphyLejeune (2002) claims international students can be considered as a kind of "migratory elite" because they are "Ready 'to move'...open to changes in their environment: language, personal entourage, lifestyle, working style" (p. 51), distinguishing them from most of their peers. Waters (2006a) goes so far as to suggest that students who have 
been educated in the West ought to be thought of as 'a distinctive cultural group' (p. 185). She explains, "Drawing on the work of Bourdieu (1996), I argue that through their peculiar (and situated) experiences of education 'an extraordinary concentration of symbolic capital is effected' (Bourdieu 1996: 79)..." (Waters, 2007: 478).

\section{Public Policy and Cultural Capital Theory}

As with human capital, the concept of cultural capital has long been a theme of public policy in many developed countries often directed at decreasing social exclusion and increasing inclusion. In the UK, for example, Reay (2004) mentions there has been a growth of education policy initiatives since at least the mid-1980s which attempt to promote equality of opportunity in education by accentuating the role of parents in schooling. These initiatives have attempted to draw on or increase the cultural capital resources of parents in order to raise pupil achievement and educational standards. Another example is the Labour government's attempt to address the problem of social exclusion with the implementation of the New Deal for Young People. The New Deal aims to help people without cultural capital by offering them a way to develop their human capital and re-enter the labour market (Nicholls and Morgan, 2009).

\section{Critiques of Cultural Capital Theory}

One criticism which has been levied at Cultural Capital Theory concerns Bourdieu's explanation of school success which some criticise as focusing too much on the amount and type of cultural capital inherited from parents and not taking enough account of intragroup variations of individual talent or achievement (Moore, 2004; Reay, 2004). Some critics assert the concept of cultural capital is undertheorised and Bourdieu is deliberately vague about how the concept can be operationalised (Lamont and Lareau, 1988; Sullivan, 2001). Finally, some argue his explanation of cultural capital can only be applied to the French context (Ong, 1999; Reay, 2004). A point made by Ong particularly relevant to the thesis is that the strategies of cultural accumulation proposed by Bourdieu do not always apply to the situation of international migrants. 
The third, and final, theory forming the theoretical framework of the research is Social Capital Theory. Kivinen and Ahola (1999) assert the human and cultural capital invested in obtaining educational credentials is not enough for success, particularly in the labour market; a network of social links and relationships, or social capital, is also needed. Social capital is necessary for enhancing the rate of capital accumulation because of the personal support, trust, and sharing of knowledge and information it provides (Coleman 1988; Neri and Ville, 2006).

\section{Social Capital Theory}

The three names linked most often to the development of Social Capital Theory are Bourdieu, Coleman, and Putnam, each of whom has contributed different elements to the understanding of the concept (Bexley et al., 2007). Bourdieu links social capital to his notion of cultural capital by explaining that cultural capital is part of individual social capital (Morgan, 2008). He describes social capital as an individual asset that derives its worth from the power of the social networks and resources an individual can access given their status as a member of these networks. The power of these social networks is used by the dominant group to maintain and reproduce their position in society (Bourdieu, 1986; Bexley et al., 2007).

It was due, however, to the work of American sociologist James Coleman in the 1980 s and early 1990s and American political scientist Robert Putnam in the mid-1990s that the concept gained real prominence (Portes, 1998; Putnam, 2000). In contrast to Bourdieu, they highlight the prevalence and value of social networks to individuals across all social classes, and how the merits of network membership can benefit all individuals (Bexley et al., 2007). Like Bourdieu, Coleman does acknowledge the value of social capital to individuals, but he also recognises it as an important resource for the broader community. Coleman's work brought more attention to the benefits of social capital for members of non-dominant groups, and focused on how access to social capital can affect the accumulation of human capital (primarily education) (Bexley et al., 2007). Like Coleman, Putnam emphasised the collective versus individual aspect of social capital concentrating more on the community level of social capital and the benefits to community of 
investment or non-investment in this type of capital (Portes, 1998; Putnam 2000). The work of all three theorists informs the view of social capital in the research.

\section{Defining Social Capital}

Social capital, as defined by Coleman (1988), refers to the social connections and networks upon which an individual can draw to advance their economic success and wellbeing. The establishment of these social networks and connections is a purposeful investment and, like human and cultural capital, can serve as a valuable resource available to individuals (Portes, 1998; Schuller and Bamford, 2000; Putnam, 2001). These networks can be formal or informal, useful over the short or long term, and once created are maintained as long as they continue to provide benefits (Coleman, 1988; 1999; Keeley, 2007). Coleman described these networks as including not only family relationships or relationships an individual has in the immediate community, but also links with friends in other communities and geographic locations, colleague, and acquaintances (Keeley, 2007).

An individual's social capital consists of both inherited networks as well as networks purposely created by the individual for some specific objective (Dasgupta, 2000). Networks can be inherited from family members, such as parents, for example, who invest in networks which they then pass on to their children. Inherited networks can constitute an important source of social capital, which most individuals maintain at some level because creating new networks involves some investment costs like time, effort and money (Coleman, 1988; Healy and Côté, 2001).

The strength of an individual's social capital depends on the size of their networks and the resources available to them through access to the other members of the network (Burt, 2003; Coleman, 1999). In other words, it is not the individual but rather the others in the individual's social networks that are the real source of the individual's advantage (Portes, 1998). Individuals can then draw on these resources to help facilitate certain actions and generate future benefits (Coleman, 1988; Portes, 1998; Schuller and Bamford, 2000). 
Social capital is generally a positive thing and can have considerable influence in shaping the opportunities available throughout an individual's life. Like cultural capital, social capital has a cumulative property meaning the more social capital individuals possess from an early age, the more likely their social capital will continue to increase over their lifetime (Healy and Côté, 2001). Coleman (1988; 1999) and Putnam (2000) state the benefits, or private returns to investment in social networks can be both economic and noneconomic. Putnam (2000) and Neri and Ville (2007), assert social capital investment can be positively linked to economic growth and stability, as well as increased political and civic involvement, crime prevention, companionship, and health and happiness.

\section{Dimensions of Social Capital}

Coleman (1988) identified three dimensions of social capital that comprise valuable capital resources for individuals: 1) obligations, expectations, trustworthiness, 2) information channels, and 3) norms and effective sanctions. The first dimension focuses on the importance of trust among members of social networks (Coleman, 1988; Schuller and Field, 1998; Putnam, 2000). Social capital is usually high when the strength of these networks and the associated level of trust and reciprocity between people belonging to these networks produces a system of mutual 'obligations and expectations' necessary for helping each side to achieve their objectives (Coleman, 1999; Schuller and Bamford, 2000).

The second dimension of social capital is the access to information channels via which individuals can acquire valuable information crucial as a basis for action (Coleman, 1988). Coleman (1988) highlights the importance of not only the size of networks but also the density, asserting 'dense networks' with strong ties are necessary for the creation of social capital. Granovetter (1973) and Burt (2003), on the other hand, argue that having networks which are large and diverse with 'weak ties' is better for social mobility because they increase an individual's chances of having a contact with useful information, and can make the individual himself a more valuable network contact to others, leading to a further expansion of the individual's networks. Granovetter (1973) contends dense networks generally transmit redundant information since individuals in these networks are likely to know the same people and learn of the same opportunities (Portes, 1998; 
Putnam, 2000). Dasgupta (2000) contend weak ties can be very valuable in certain situations, such as the search for employment for example, because these ties generally involve a greater number of connections with a wide range of people and, in turn, are a broader source of information.

The third dimension of social capital, norms and effective sanctions, highlights the importance of effective norms for facilitating or constraining certain actions by individuals in an effort to promote the common good (Schuller and Bamford, 2000). Social networks allow for the creation of communal values, norms, and understandings within society making it possible for individuals and groups to resolve collective problems within or between groups (Coleman, 1999; Healy and Côté, 2001; Keeley, 2007). It is primarily the first two dimensions discussed above - trustworthiness and information channels - that are relevant to the research presented here.

\section{Types of Social Capital}

There are three types of social capital discussed in the literature: bonds, bridges and links. Bonds, which generally consists of strong dense ties, are the relationships among people who are alike or share a close identification, for example family members or kinship-based groups, friends, communities, and people belonging to the same ethnic or religious group, who collectively bond for a common purpose or benefit (Putnam, 2000; Healy and Cote, 2001; Morgan, 2008). Bonding provides communities or groups with a feeling of identity and shared objectives while sustaining norms and societal rules which reinforce trust and provide benefits for members of the group (Healy and Côté, 2001; Morgan, 2008). Children can benefit from the social capital of their parents, family members and friends who are all important reference groups in providing individuals with a foundation for building social capital (Healy and Côté, 2001).

Bridges refers to ties that cross diverse social groups or classes, such as the relationships between distant friends, acquaintances, and colleagues (Healy and Côté, 2001) Granovetter (1973) states bridges are examples of weak ties, although all weak ties are not necessarily bridges. Bridging is critical in societies where there is substantial ethnic, political, religious and other kinds of diversity because bridges are needed to promote the 
opportunities for members of all groups to be included in important social networks that provide access to information and influence (Putnam, 2000; Healy and Cote, 2001; Morgan, 2008). The third type of social capital, links, is defined as the relationships among people of different social levels within a social structure (Morgan, 2008). In a social structure where resources, power, and information are not accessed equally by all groups, individuals create links to people at different levels within the wider social structure who do have access to these assets (Woolcock, 1999; 2001; Healy and Cote, 2001).

Investment in strengthening or creating new social bonds and bridges can provide significant benefits to both individuals and to societies such as better physical and mental health, higher life expectancy, higher chances of participation in education, and lower crime rates, while increased investment in developing social links can help an individual in finding employment and gaining access to important career-related information (Healy and Côté, 2001; Putnam, 2001). All three types of social capital are important to the research presented here.

\section{Virtual Social Networks}

Both Putnam (2000) and Healy and Côté (2001) assert there is some indication that levels of social engagement are shifting towards more informal, individualistic, and transitory types of social relations. The ability to access these non-traditional social networks, such as those available through ICTs, is important to promoting the rapid flow and sharing of knowledge and information. The increased availability and affordability of personal computers has resulted in an explosion of such networks on the Internet taking the form of e-mail communication, on-line discussion groups, blogs, chat rooms, and social networking sites (Fukuyama, 2003).

Putnam (2000) explains communication is a basic requirement for establishing and maintaining social networks and connections, and that use of ICTs as an instrument of communication gives people a new way of connecting with others as well as a space where new types of social networks and connections can be created and maintained virtually. This kind of communication is not subject to barriers of time and distance, or geography. Putnam (2000) refers to this as 'virtual social capital' with networks situated within the 
context of 'virtual' communities. Virtual networks are valuable as channels for information and opinion sharing, platforms for debate and discussion, as well as a space in which various kinds of social support can be found. Knowledge of English is valuable for building virtual social capital as much of what is on the Internet is in English; in other words, English is needed for not only using technology but for also being included in virtual networks (Enever, 2009).

As a result of the seeming casualness and fluidity of most virtual networks, Putnam (2000) regards them as a type of 'weak tie' which individuals can use to obtain valuable information and take certain actions. He states they have a disadvantage in comparison to face-to-face networks because they often lack the social embeddedness necessary for building real trust and reciprocity that enables the creation of strong social capital. Information also needs a social context to be meaningful. DiMaggio et al. (2001) conclude the Internet can be seen as a tool which augments or complements social ties rather than replaces them.

\section{Social and Other Forms of Capital}

Describing the relationship between social capital and other forms of capital, Putnam (2000) states, "...most researchers agree that social capital does help individuals to prosper. The only real debate is over how big a role social capital plays relative to human or financial capital" (p.322). Individuals who invest in creating and maintaining large, wellstructured, and diverse networks that provide access to information and control often obtain a higher RoR from their investment in these networks. Through utilising the resources of such networks, they can learn about and take advantage of opportunities to convert and develop their capital (Burt, 2003).

As with other forms of capital, individuals who already have some level of social capital are more likely to accumulate more, and levels of social capital can decrease through non-use (Putnam et al., 2003). As with other forms of capital, measuring levels of social capital can be problematic because much of what constitutes social capital - networks and social connections - is relational and implicit making it difficult to quantify. Proxy measures used include the measurement of levels of civic engagement and participation in community 
associations, the assessment of levels of trust and commitment, and the use of comparative attitudinal surveys (Putnam, 2000; Healy and Côté, 2001; Schuller, 2001).

However, social capital has its own unique characteristics which differentiate it from other forms of capital. By its nature social capital is intrinsic to the relationships between individuals, and thus cannot be considered to be embodied by or be seen as the sole property of a particular individual as can human and cultural capital (Coleman, 1988; Healy and Côté, 2001). Investment in social capital does not necessarily or primarily benefit the individual making the investment, but can, as well or instead, benefit others who belong to the network (Coleman, 1988; Burt, 2003; Putnam et al., 2003; Putnam, 2001).

Coleman (1988) and Schuller (2001) emphasised that social capital is complementary to human capital as individuals and their human capital cannot be viewed as being entirely separate from and unaffected by the surrounding social structures. In other words, the acquisition and effective utilisation of an individual's human capital is dependent on the social context in which individuals and their human capital are expected to function. Coleman (1988) maintains both capitals are significant to individual growth and success arguing (non)investment in the one can result in the (under)development of the other.

Like Bourdieu, Bowl (2003) asserts there is a relationship between social and cultural capital in which social capital is used to gain and maintain advantage, and strengthen cultural capital. Individuals whose families have traditionally participated in higher education will likely possess greater social capital in the field of education than will those individuals without this background. Both forms of capital are also important to networking for employment through providing individuals with access to valuable information, advice, connections and, ultimately well-paid employment (Portes, 1998; Neri and Ville, 2007).

\section{Public Policy and Social Capital Theory}

Like the other two capitals, the concept of social capital has increasingly entered into public policy discourse. International bodies such as the OECD are increasingly concerned with issues like social exclusion and marginalisation, and link social capital with issues of 
good governance, social equity, inclusion, and community engagement (Bjornskov, 2006; Green: Lauder et al, 2006; Morgan, 2008). Bexley et al. (2007) argue it is social capital as defined by Putnam that has been most influential at the public policy level. Schuller (2001) and Bexley et al. (2007) also cite the growth of the importance of social capital as a result of "...the active patronage of the World Bank" (Schuller, 2001: p. 91).

\section{Social Capital Investment}

\section{Education}

Participation in education is one possible way of sustaining and increasing an individual's social capital. There are important links between levels of educational attainment and social capital with social networks often advancing the importance of education, and education, in turn, enhancing an individual's social capital (Healy and Côté, 2001).

Coleman claims social capital resources inherent in the family and community can provide an important advantage for children (Coleman, 1988; Schuller and Field, 1998). Social capital, particularly the relationship between students and their parents and the level of effort parents invest in the student's learning, and their willingness to discuss school matters with their children, can also have a positive impact on educational achievement and pursuit of educational opportunities (Coleman, 1988; Portes, 1998; Schuller and Field, 1998; Schuller and Bamford, 2000). Children who are surrounded by home, school and community environments high in social capital, and in which parents have certain expectations and aspirations for their children, are also endowed with considerable support networks, trust, and access to valuable information and knowledge (Coleman, 1988; Portes, 1998; Neri and Ville, 2008). Thus social capital of the family can help determine the success of the next generation in the field of education, as well as their life chances and opportunities (Lamont and Lareau, 1988; Reay, 2004). Glaeser (2001) contends there is a strong association between social capital and years of schooling. He states, "The education-social connection relationship should probably be seen as the most robust and most important fact about the formation of social capital" (p.16) because "...a significant part of education is learning social skills...training...in appropriate behavior in a variety of social settings" (p.17). 
Coleman $(1988 ; 1999)$ claims organisations, including educational institutions, can be actors who have and who can facilitate social capital (Coleman, 1988; 1999). Universities, for example, are institutions of shared learning and cooperation which provide a space where different social networks can meet and interact, and where academic colleagues provide one another with ideas and information (Schuller and Bamford, 2000; Healy and Côté, 2001). Participation in higher education can increase a student's social capital through giving them the opportunity to join various organisations and build professional and other types of social networks. These networks can be used later to obtain employment and achieve social and occupational mobility as they provide students with advice, job leads, strategic information, and letters of recommendation (Coleman, 1999; Putnam, 2000; Keeley, 2007). Just as social capital can be a resource for accessing educational opportunities, the continuing pursuit of education in the form of postgraduate study "...is a resource for social capital development" (Morgan, 2008: p. 39).

\section{Migration}

Massey and García España (1987) state that "International migration is a social, as well as an economic, process" (p.737). They mean that individuals generally migrate to increase their human capital but it is their social capital that "...gives a powerful momentum to the migration process" (p.733). The choice of international migration is usually a result of strategies formulated by individuals and their families in order to improve economic circumstances, gain political freedom, or reunite family members. Migration is more likely when the net returns to migrating are perceived as higher than for non-migration (Massey and García España, 1987; Massey, 1990). Some migrants have no social ties in the receiving country and thus arrive in the host country denuded of social capital. In this case, the costs of migration include the time, effort, and perhaps money, needed to replenish their social capital (Massey, 1990; Neri and Ville, 2006) Migrant networks serve as important sources of social capital. Massey (1990) defines migrant networks as "sets of interpersonal ties that link together migrants, former migrants, and nonmigrants in origin and destination areas through the bonds of kinship, friendship and shared community origin" (p.69). These networks involve dense and reciprocal social relationships that carry mutual obligations of assistance and support. In addition, connections to experienced migrants can help lower the direct, opportunity, and 
psychic costs of migration through providing information about the practicalities of life, references to possible employers, and assistance upon arrival in the receiving country (Massey and García España, 1987). As the number of migrants expands, some ultimately settle permanently in the receiving country and form populations or diasporas. These communities offer a secure and stable environment that helps new migrants to adapt (Massey and García España, 1987; Healy and Côté, 2001).

\section{International Education and Social Capital}

Brooks and Waters (2010) highlight the importance of social capital to decisions surrounding international education. They state much of the discourse on international mobility assumes it to have an individualised nature characterised by independent and autonomous movement uninfluenced by previous social networks. Brooks and Waters argue, however, that the decision of students to pursue higher education abroad does not fit this characterisation but rather students are influenced and guided in a variety of ways by a range of social networks in which they are embedded (Sahasrabudhe, 2008; Brooks and Waters, 2010). They suggest students who decide to undertake international education are often located within social networks in which the valorisation of mobility is a norm, and thus these networks can provide practical information and support, as well as a high level of encouragement. In addition, the influence of these networks can have an overlapping and multidimensional nature with family influencing many of the decisions surrounding international education.

Brooks and Waters (2010) highlight three types of social networks or relationships which have a major influence on the decisions of prospective international students: kinship networks, friendship networks, and partners.

\section{Kinship Networks}

The first type is kinship networks or familial influence, a type of bonding capital. Family can play a significant role in influencing the educational plans of students including the choice of attending higher education in general, and the decision to pursue international education (Van de Werfhorst et al., 2001; Nora, 2004; Pimpa, 2005). The decision to 
undertake study abroad can be a very strategic one, not only for the individual but also as a way to secure advantage for the whole family (Brooks and Waters, 2010). The decision to study overseas is usually made in consultation with family members, and parents particularly, can be among the most significant influences on the decision to study abroad, providing the financial means, as well as information and encouragement (Steadman and Dagwell, 1990; Mazzarol et al., 1996; 2002; Pimpa, 2003; 2005). As a result of these kinship networks, students are able to access the 'start-up' capital and other resources needed to undertake international education (Putnam, 2000).

Kinship networks have varying influence not only on the initial decision to study abroad, but also on the other choices associated with international education such as the selection of host country and institution (Steadman and Dagwell, 1990; Lawley and Perry, 1997; Mazzarol et al., 1996; 2002; Pimpa 2003; 2005; Chen, 2007); city (Pimpa 2003; 2005), and academic programme and/or area of study (Steadman and Dagwell, 1990; Pimpa $2003 ; 2005)$. The influence of family is important in the selection of a host country, particularly when parents or other relatives lived or studied in, visited, or had some other connection with the country (Lawley and Perry, 1997; Mazzarol et al., 1996; 2002; Pimpa, 2003; 2005; Szelényi, 2006). The influence of kinship networks, particularly parents, varies with a student's age and degree level (Lawley and Perry, 1997; Mazzarol and Soutar, 2002; Pimpa, 2003, 2005); gender (Steadman and Dagwell, 1990; Mazzarol and Soutar, 2002); and level of market sophistication (Mazzarol and Soutar, 2002).

\section{Friendship Networks}

The second type of social network which influences students is friendship networks. Brooks and Waters (2010) found in their research with potential and former international students that friendship networks were important influences on decisions to study abroad. These networks are influential in facilitating educational mobility when there is a peer culture in which travel is valorised. The positive experience of friends can also be a source of valuable information and create links to specific host countries or institutions which help to make them "...seem less 'unknown' than they would perhaps have been otherwise" (Brooks and Waters, 2010: p. 150; Szelényi, 2006). Friendship networks can have influence not only on the initial decision to study abroad but also the other choices related 
to international education such as choice of host country (Lawley and Perry, 1997; Mazzarol et al., 1996; 2002); host institution (Steadman and Dagwell, 1990; Mazzarol et al., 1996; 2002); and area of study (Steadman and Dagwell, 1990). Friendship networks are usually less influential on students than kinship networks (Lawley and Perry, 1997).

\section{Partners}

The third type of social network consists of relationships with partners (i.e., spouses, boyfriends and girlfriends). These relationships can be influential in facilitating educational mobility. In some cases they may have been central to the decisions made by the student, while in other cases they may not have prompted the initial decision to study abroad but had influence on some of the other choices such as selection of host country and/or institution (Brooks and Waters, 2010). As with friends and family, Brooks and Waters (2010) state that relationships with those who valorise travel or have themselves been internationally mobile can have some influence on an individual's decision to pursue international education.

\section{Other Social Capital Resources}

Students can also be influenced by other social networks, besides family and friends, in which they are embedded. For example, Steadman and Dagwell (1990) and Mazzarol et al. (1996) indicate that teachers and other "gatekeepers", through recommendations and personal experience, can have some influence on the choices of international education such as the selection of host country, institution, or discipline. Faculty members from students' previous degree programmes can be influential in highlighting the opportunities available in certain host countries (Szelényi, 2006).

Mazzarol and Soutar (2002) emphasise the importance of alumni networks in promoting international education, and as a source of influence on choice of host country and institution. Brooks and Waters (2010) state the students in their sample indicated their domestic educational institutions were an important influence in facilitating their mobility because of the experience of former students who had studied abroad (i.e., migrant networks). The students said that having such examples provided reassurance and information regarding international education. 
The studies of Lawley and Perry (1997) and Mazzarol and Soutar (2002) suggested education agents were also a valuable source of influence and information for students. Mazzarol and Soutar (2002) stated because of the overwhelming variety of international education options, students are likely to be influenced by the opinions of agents, especially when an agent has personal experience abroad. Education agents also have more influence when students, as well as their families and friends, have less direct experience with international education.

\section{Information Resources}

Easily accessible information about international education options is critical for prospective students in making comparisons between the options available (Szelényi, 2006). Students use their social networks as an important source of information to inform their decision-making. Word of mouth recommendations from alumni, friends, and family act as a risk reducing strategy for prospective students in their 'purchase' of international education services (Moogan et al., 1999). Pimpa's (2005) sample gathered information about host country, academic programmes, part-time employment, and accommodation from a variety of social capital resources, such as family members who had experience overseas. Chen (2007) found students used a wide variety of resources to gather information, including "...family/spouse, relatives, professors, sponsors, or employers" (p.760) as well as friends and authors of journals or books. Chen also highlighted the use of embassies and libraries, school brochures, educational tours and fairs, and direct contact with academics via e-mail or at conferences as information resources.

The Internet is an important resource from which students gather information about international education options. Sources of information on the Internet include university websites, education portals, social networking sites, and study abroad discussion groups (Gomes and Murphy, 2003; Szelényi, 2006; Sahasrabudhe, 2008). Chen (2007) found the majority of her sample indicated the Internet was the most useful resource for getting information about studying abroad, host institutions and their rankings and reputations, and specific information regarding academic programmes. 


\section{Renewing Social Capital}

While international students make extensive use of existing social networks in their goal to study abroad, they arrive in their host country denuded of the social capital on which they have generally depended for information, moral and emotional support, and who contributed to their academic success at home (Putnam, 2000; Neri and Ville, 2008). In order to meet the many challenges of living and studying in a different society, they must set about renewing their social capital to some extent (Neri and Ville, 2008; Brooks and Waters, 2010).

Students attempt to renew their social capital through classroom and club activities, employment, and friendships with students from the same home country (Bexley et al., 2007; Neri and Ville, 2008). The degree to which international students renew their social capital by developing new social networks can influence the length and difficulty of the transition period. In addition, these new networks can yield important information about the workings and expectations of an unfamiliar educational system and social environment (Neri and Ville, 2008). In addition, a large immigrant community of similar background outside of the university can be a resource for conserving and maintaining social capital (Putnam, 2000; Waters, 2007). Interactions with such communities provide the benefits of mutual aid, emotional support, opportunities for socialisation, and some sense of premigration habitus (cultural capital) at a time of great social dislocation for students (Putnam, 2000; Waters, 2007).

Students also hope to create social links with academics and other professionals in their field in hopes these links will give them access to new knowledge and resources about research and career opportunities (Portes, 1998; Putnam, 2000; Davey, 2005). Finally, students can also use the opportunity of studying in a foreign country as a way to set up links and networks that might facilitate future migration, or establish future business or political contacts (Agarwal and Winkler, 1985). 


\section{Critiques of Social Capital Theory}

Criticisms of Social Capital Theory include those by Schuller (2001) and Bjornskov (2006) who claim because of the multifaceted nature of social capital one of the major weaknesses of it as a concept is that there has been no consensus on a single definition of what constitutes social capital. Morgan (2008) states it "...is still relatively vague and under developed as a concept of policy value..." (p.1). Bjornskov (2006) asserts there are already an array of definitions so what is not needed is another definition, but rather more work on "...an empirically based distinction between the potentially different dimensions of social capital" (p. 24)

Fukuyama (2003) and Dasgupta (2000) say one of the greatest limitations to the theory is the lack of agreement on knowing what to measure and how to measure it. Fukuyama also disputes Putnam's view of social capital as a public good but rather asserts individuals invest in social capital to reap private individual benefits not to purposefully create public benefits. Finally, Portes (1998) warns of the tendency of social capital discourse to portray it as "a cure-all for the maladies affecting society at home and abroad" (p.2).

In this chapter I provided a detailed description of each of the three capital theories utilised in the theoretical framework, and emphasised how they are relevant to international education and the decisions made by international students. This chapter, in combination with the previous three, has laid the foundation for the second half of the thesis which focuses specifically on the research. I begin in Chapter 5 with a discussion of the methodology and research design. 


\section{Chapter 5: Methodology and Research Design}

Chapter 5 explains the choice of methodology, and discusses the epistemological and ontological issues; the research design; ethical issues; sampling procedures and access; and the methods utilised for collecting data.

\section{Methodology}

Most research draws from two methodologies: quantitative and qualitative. Although a distinction will be made in this discussion between quantitative and qualitative methodologies for ease of understanding, it is important to note that they are not necessarily separate and can be used to complement one another (Wellington and Szczerbinski, 2007). Wellington (2000) goes so far as to call some of the distinctions made between them, a "false polarization of the two approaches" (p.17).

In quantitative research, the researcher aims for complete objectivity in the attempt to explain, predict, and control phenomena. Quantitative research also aims to produce generalisable knowledge using statistical methods such as random sampling and experimental control groups (Wellington and Szczerbinski, 2007). In regard to education research for example, a quantitative approach often attempts to develop universal 'laws' which contribute to the explanation and prediction of educational phenomena (Fairbrother, 2007). Qualitative research, on the other hand, considers reality as a subjective notion which is socially or individually-constructed, and while concerned with explanation, does not attempt prediction. A qualitative methodology also emphasises the importance of the researcher as part of the research process, and promotes researcher reflectivity. It does not aim to produce generalisable knowledge, but rather highlights relevance and transferability, and tends to use opportunistic or purposive sampling (Bryman, 2004; Fairbrother, 2007; Wellington and Szczerbinski, 2007).

Social science research, in its attempts to provide understanding of a wide range of social phenomena, can use a variety of approaches and methods to collect, interpret, and analyse data, but has traditionally utilised a qualitative methodology (Wellington and 
Szczerbinski, 2007). The reason is that quantitative research frequently does not differentiate the study of the natural world from that of humans and society. A qualitative methodology is generally more appropriate to the investigation of social phenomena, as it takes into account the importance of context, whereas a strictly quantitative methodology can be too restrictive to provide true understanding and interpretation of phenomena that is often subjective and socially or individually-constructed (Bryman, 2004; Fairbrother, 2007; Wellington and Szczerbinski, 2007). Qualitative research methods include ethnography, historical research and case study research (Fairbrother, 2007).

While taking into account the criticisms of qualitative research, such as its subjectivity, replication difficulties, and lack of generalisability, I decided that a qualitative methodology was the most appropriate for my enquiry given my research questions and desire to let students speak for themselves in the research (Bryman, 2004; Fairbrother, 2007). My interest was in not only the observable behavior that has resulted from the decisions of these students, but also the unobservable individual, cultural and social variables that influenced those decisions and the context in which they took place. My aim was not to generalise the findings of this research to the situation of all international students but to form a deeper understanding of why the international students within my sample decided to study abroad and why they selected certain host countries. A further advantage of using a qualitative methodology was that it allowed for the collection of not only significant amounts of data from a first-hand perspective, but also data that was rich in detail (Wellington and Szczerbinski, 2007).

\section{Epistemological and Ontological Considerations}

A researcher's ontological and epistemological assumptions strongly influence his/her research design, including choice of methodology and methods. In my case, as a result of my background and research training in the field of Psychology (Bachelor and Master's degrees), my ontological leanings as a researcher about the nature of being and of reality tend more toward social constructionism. The reason is its emphasis on reality as a subjective, internally, and individually-constructed concept with the social world as something which individuals can affect (Bryman, 2004). This means that a study of the 
social world can be done through exploring and interpreting the reports individuals give about their experience and their interpretation of reality (Grbich, 2007).

Ontological questions about the nature of being and reality lead to questions about epistemology or, in other words, questions about what constitutes truth and knowledge, and how these are constructed. My ontological assumptions, as described above, have given rise to an interpretivist epistemological orientation because of its focus on the individual's viewpoint in creating meaning (Bryman, 2004). In other words, what an individual knows about the world is seen as subjective and constructed but is also based on shared signs and symbols common within the world in which they live. This can lead to multiple realities as individuals experience events and situations differently and, from these experiences, construct individual understandings and truths. As a researcher, my job is to analyse these multiple realities and find common themes that enable a more indepth understanding of certain issues (Grbich, 2007). In the thesis research, I attempted to explore the perceptions of individual students regarding how and why they made certain decisions regarding their international education, and to identify common themes in their answers across the sample population (Bryman, 2004).

The use of an interpretivist epistemology and constructionist ontology are common to qualitative research (Bryman, 2004). In regard to the thesis research, these assumptions led to my choice of a qualitative methodology which, in turn, influenced my choice of particular methods to use for data collection. The two methods selected were questionnaire surveys and semi-structured interviews because they can be used for collecting qualitative data. In addition, and importantly, their flexibility allowed me to formulate and ask open-ended questions that encouraged students to respond in as free a manner as possible and not to be limited by the options I provided for them. More information about the reasons I chose these methods, and the advantages and disadvantages of each is given later in this chapter.

Using questionnaire surveys and interviews as described above enabled me to explore the multiple realities of students by surveying and interviewing as broad a range of students as possible within the parameters I had set for the overall study population. This allowed 
me to generate an in-depth understanding of the issues involved and to seek patterns of meaning and understanding of the issues from these students. My research focus was on exploring the way these students interpreted and made sense of their experiences and decisions in the worlds in which they live, and how their understanding of these was constructed based on their interpretations of certain events and circumstances within the context of wider social environments (Grbich, 2007).

In addition, I also sought common patterns of meaning across the sample population (Grbich, 2007). These patterns were the focus of the analysis in which data was coded and categorised to elicit various common themes. In line with my ontological and epistemological assumptions, it should be mentioned that the interactions between the students and myself, as well my interpretation and analysis of what students said in the data, has been impacted by my own subjective and constructed understanding of the world. In order to counter the impact of such interviewer effects upon the findings, a substantial display of the student voice is given in Chapter 6: Presentation and Analyses of Data using numerous quotes from students as evidence to support my interpretations of the data (Grbich, 2007). Further reflection on my role as researcher and my possible impact on the findings of the research can be found in Chapter 7: What does the data show?

\section{Research Design}

There are two aspects of the research design which require mentioning: the use of a comparative design strategy and the cross-cultural nature of the research.

\section{Comparative Design Strategy}

A comparative research design entails the exploration of the research questions using the same research methods in two or more different contexts. The rationale behind the use of a comparative design is that a comparison of the similarities and differences in the findings from different contexts can provide a greater understanding of various social phenomena in order to elucidate or generate reflections on existing theory. 
The research presented here was originally intended as comparative research. The main rationale behind choosing a comparative design was fairly straightforward - the nature of two of the research questions was comparative - see Questions 5 and 6 on p.20. The choice of three different host countries was meant to enable the examination of the research questions in several national contexts, identify similarities and differences, and increase the possibility of the research having some transferability. However, as noted in Chapter 1, after conducting my analysis I realised that for reasons of time, space, and coherence, I would not be able to answer my fundamental research questions in full and include a complete analysis of the comparative data collected. The reasons for using a multidisciplinary perspective were explained in Chapter 3.

The three host countries were selected as appropriate contexts for comparison because of the following similarities: they are all popular host countries that attract sizable numbers of international students; their higher education systems have good reputations; and the majority of their higher education programmes are conducted in English, a large draw for most international students. Even though they share some important characteristics, they also have some important differences that cannot be ignored. Although all are Englishspeaking countries, they have different socio-cultural settings, and the history and development of higher and international education in each has differed to some extent. In addition, their positions in the international higher education market also differ with the UK and the U.S. the two most important host countries for international students worldwide. The background of each of these as host countries was discussed in Chapter 2 .

\section{Cross-cultural Research}

There is one more layer to the research that needs to be highlighted: the cross-cultural aspect. Cross-cultural research involves the investigation of issues from two or more countries or socio-cultural contexts. Key strengths of cross-cultural research are its emphasis on the notion that the study of social phenomena cannot generally be separated from cultural influence, and that the cultural specificity of research findings must be taken into account. Some of the problems that can affect cross-cultural research include whether there is true comparability between any already existing or secondary data used from different countries, whether the comparability of data has been compromised because of 
translation to and from different languages, and whether the samples of participants or contexts are comparable (Bryman, 2004).

In addition, there may be difficulties when researchers are working outside of their own cultural contexts. If researchers are not familiar with or are insensitive to certain national/cultural contexts this could result in a greater potential for bias and unquestioned assumptions on the part of the researcher (Fairbrother, 2007). Generalisability can also be an issue in cross-cultural research because many of the research findings cannot be assumed to pertain to countries other than those which were the subject of the research (Bryman, 2004). It is important to note that the research presented here has at least two different layers of national/cultural contexts - the contexts which the students come from and the ones in which they are studying - that could have potentially affected the research findings.

\section{Research Ethics}

Ethical approval for the research was received from the School of Education in August 2008. There were several potential ethical issues such as access, confidentiality, and cultural sensitivity. In accordance with the ethical guidelines of the university, I requested approval for my research from the relevant host institutions before contacting students. The strategy was to approach the various International Offices at these institutions to get their agreement for the research to be conducted at their university and their help in contacting students. Personally, I also felt that contacting representatives of the university at the outset was more ethical than contacting students without the knowledge of their institutions and, in addition, their assistance also allowed me to reach a larger sample of students then if I had tried to contact students directly. Since the international students in the research were all adults there were no ethical issues in this regard.

Throughout I attempted to take all possible measures to ensure the privacy, anonymity, and non-traceability of participants. For example, when administering the questionnaires, I did not ask the International Offices for student names or contact information but simply asked them to forward an e-mail from me to their students containing a link to the questionnaire. Students could then respond anonymously if they wished. The online 
survey tool I used allows the option of collecting respondents' IP addresses which I did not opt to do. On the other hand, these privacy constraints did not allow me to follow-up with students who did not complete the questionnaire. Students who indicated on the questionnaire that they were interested in participating in the interview phase however, were asked to give their name and contact information. I used this information solely to communicate with them about arranging an interview date and time. The names of all interviewees were coded on the interview transcripts to protect their identity, and every attempt was made in the thesis to anonymise the host institutions that took part in the research.

It was explained to participants that all data generated would be used solely for the purpose of the research, and would be treated as confidential and with anonymity. In each phase of the research participants were told that, while information might be published, every effort would be made to prevent their identification in any published material. In addition, all information would be stored safely and securely by the researcher, with only the researcher and her supervisors having access to it for the sole purpose of the thesis.

I explained the aims and process of the research, including the time involved in participating, to research participants prior to the start of data collection in both phases of the research. I disclosed my full identity to all participants at the outset of the research and provided them with my contact details so they could contact me with questions or concerns about any part of the research prior to participating. Participants were also informed that they could contact my supervisors or the Research Ethics Coordinator of the School of Education if they required further information or wished to make a complaint relating to their involvement in the research, and were given the appropriate contact details. Participants were informed they had the right to withdraw at any stage without prejudice or negative consequences and were assured that withdrawal or non-participation would not affect them at the time of withdrawal or at anytime in future. Finally, they were informed that they had a right to read any data pertaining to them.

All participants were provided with detailed participant information and participant consent forms, and were given ample time to read these documents. The first two pages of the 
online questionnaire contained information about the aims and process of the research and a participant consent form. It was stated that completion of the questionnaire implied consent to participate in the questionnaire phase although participants were never subject to undue pressure in any phase of the research; it was made clear to them that participation was completely voluntary. They were told prior to the completion of the questionnaire that if they decided to participate in a follow-up interview for the research that would also be completely voluntary; and when contacted later to schedule an interview, some respondents declined to do so. In the interview phase, all participants were presented with written participant information and asked to give written consent to participating with consent forms being securely stored by me. These participant information and participant consent forms can be seen in Appendices A and B.

The research was conducted according to students' schedules and every effort was made to avoid any unnecessary burden on participants. In the questionnaire phase, students had the freedom to respond to and return the survey at any time convenient to them as the questionnaire was in an electronic format. All interviews were scheduled at times convenient to the participants and I attempted to limit them to a maximum of forty-five minutes. Finally, in compliance with the ethics guidelines of my university, I made every effort to conduct myself professionally throughout all phases of the research, to treat all participants with respect and dignity, and to shield them from any risks involved with participating in the research. In addition, due to the cross-cultural nature of the research, particular effort was made to ensure sensitivity to any differences relating to culture and other factors such as race, gender, and religion. Finally, after completion of data collection and analysis, I attempted to contact all interviewees to renew the offer to send them a summary of the findings and, if they so wished, a copy of their individual transcript.

\section{Sampling and Access}

The selection of host universities for this research is addressed next, followed by a discussion about the selection of the sample of student participants. 
Host University Sample

Three universities were chosen as data collection sites for the research - one each from the UK, Ireland, and the U.S. The sites were chosen primarily because my supervisor and I had contacts there meaning their selection was both purposive and convenient. The information on each university given below was gathered around the time of data collection, and in an effort to maintain the anonymity of these institutions I have not cited any sources here.

The university located in the UK, referred to in the research as 'University UK', is a large university of about 30,000 students with over thirty academic schools and departments spread over several domestic campuses. In 2008/2009, University UK hosted over 7000 international students from over 100 different countries. The Irish university, referred to as 'University Ireland', has around 20,000 students, and thirty-five schools divided into five colleges (academic divisions) each with a graduate school. In 2008/2009, University Ireland hosted over 4000 international students. Finally, the American university, referred to as 'University U.S.' has over 20,000 students, and eleven schools (academic divisions) offering eighty fields of study. In the academic year 2008/2009, University U.S. hosted approximately 2000 international students.

All three universities have a global focus and perspective, and are highly committed to internationalisation, including the hosting of international students. As a result, they offer numerous services to their international students such as general advice, visa and immigration counseling; special orientation programmes designed to assist international students in acclimatising to the country and university life; buddying programmes; English language and academic support; a number of university scholarship opportunities; counseling, religious, and health services; careers advice; and support with preparing to work in the host country after graduation.

\section{Student Sample}

Due to the qualitative nature of the research and the sizeable population of international students at each institution, I decided to pursue a non-probability purposive sampling strategy. A non-probability purposive sampling strategy uses processes of selecting 
participants that do not aim for statistical random sampling, but is rather based on the judgment of the researcher in selecting participants, and entails identifying a sample for a certain purpose. It is also a sampling strategy that is usually associated with qualitative research. The category of non-probability purposive sampling includes such sampling techniques as criterion, convenience, and snowball sampling (Wellington, 2000; Wellington and Szczerbinski, 2007).

The sampling strategy used had several levels: criterion sampling was used as an overall sampling strategy to identify participants for the research. Criterion sampling refers to samples selected based on some predetermined criteria. Using criterion sampling was important for this research because it allowed for easier comparability of data across countries, although it also narrows opportunities to generalise findings to samples that do not fit the criteria.

Other than the requirement that all participants be classified as international students at their host institutions, there were six predetermined criteria for selecting participants for the research:

1) students should be studying at the postgraduate level;

2) students should be considered full-time students at their host institution;

3) students should preferably be pursuing a full degree at their host institution (not doing a short-term exchange programme);

4) students should preferably be fully self-funded (although partially self-funded and fully funded were acceptable as long as the student was able to make his or her own decision about host country);

The reasons for focusing on international postgraduates in the research were explained in Chapter 2. Participation was limited to full-time students to ensure they were typical international students because international students are normally not permitted to study 
part-time in any of the three host countries. Full degree and self-funded students were more likely to be typical international students who make their own individual decisions about where to study while exchange students are often limited by their home university as to where they can study and fully funded students by their funding organisation.

5) students should be from one of five Asian source countries;

For purposes of comparability across host countries, the source countries targeted in the research were the top five Asian source countries for the U.S. in 2008/2009: India, China, South Korea, Japan and Taiwan (IIE, 2009a).

6) students should be studying in one of seven fields of study.

Again for easier comparability across host countries, the fields of study targeted in the research were chosen primarily because they are the top fields studied by international students in the U.S. The majority of these fields are STEM subjects: Engineering, Business/Management, Physical and Life Sciences, Mathematics, and Computer Science (IT). Law and medicine were also included as they are subjects highly studied by international students in the U.S. (IIE, 2009b).

Within this overall criterion sampling framework, convenience and snowball sampling were used for the questionnaire phase while convenience, opportunistic, and snowball sampling were used to identify interviewees. Convenience sampling refers to the selection of a sample of participants who are familiar to the researcher and are easily reached and available, while opportunistic sampling refers to the selection of a sample of participants that appear during the period of data collection (Wellington and Szczerbinski, 2007). Snowball sampling, although not always necessarily purposive, is a form of sampling in which one participant suggests another who suggests another and so on. It can be useful for identifying potential participants when there are problems with low participant numbers and/or gaining access to more participants (Wellington, 2000). While these sampling techniques provide the researcher with more research participants, they are not as rigourous as statistical sampling so that it is very unlikely the sample will be 
representative of the population which of course limits generalisability of the data (Bryman, 2004). Interviewees, on the other hand, were self-selecting, identifying themselves by indicating on the questionnaire that they were willing to participate in an interview.

It is important at this point to explain how the targeted sample reflected wider patterns among international students during the 2008/2009 period of data collection. As noted above, the criteria that participants had to be full-time students and preferably pursuing a full degree at their host institution was to ensure that they met the standard requirements for being considered an international student in the three host countries. It was also preferable that participants be fully self-funded students not only to increase the probability that they were able to make their own decisions about where to study, but also because recent trends in international student mobility indicate that international students are becoming increasingly self-funded free movers responsible for making individual decisions regarding international education (Binsardi and Ekwulugo, 2003; Lasanowski, 2009; Motivans, 2009).

Given its high demand for international education, the focus of the thesis was on the Asian region and five Asian source countries were selected for the research: China, India, Japan, Korea, and Taiwan. In 2008/2009, Asia was the leading and most rapidly growing region of origin of international students worldwide, and within the Asian region, East Asia and the Pacific had the largest group of students abroad at 846,618 (Huang, 2008; Lange, 2009, UNESCO, 2010). Of the five source countries targeted in the research (number of students studying abroad shown in parenthesis), China $(441,186)$, India $(170,256)$, South Korea $(112,588)$ and Japan $(50,380)$ were the top four source countries of international students worldwide for 2008/2009 according to UNESCO (2010).

According to UNESCO (2010), the U.S. was the number one study destination hosting 624,474 international students with the UK as number two hosting 341,791 students. The third host country targeted in the research, Ireland, hosted 12,794 international students in $2008 / 2009$. While it significantly trailed the U.S. and UK in numbers of international students, of the eighty countries from which UNESCO collected statistics about internationally mobile students, Ireland was thirty-seventh making it a middle-ranking but nonetheless an important host country. For four of the source countries targeted in the 
research, the U.S. was the number one host country: China $(110,246)$; India $(94,664)$; Korea $(69,198)$; and Japan $(34,010)$. The UK was also an important host country for these particular source countries; it was number two for Japan (4465), number three for India $(25,901)$, and number four for China $(45,356)$ and Korea (4031) (UNESCO, 2010). As noted in Chapter 2, in reference to Taiwan, as UNESCO does not publish any information for Taiwan due to the United Nations' recognition of China as the sovereign state for Taiwan other sources were used for statistics on Taiwanese international students. Chen and Zimitat (2006), for example, state that as of the time of their writing, the number of Taiwanese students studying overseas had increased over the previous twenty-five years from 3000 to 50,000. Taiwan's Ministry of Education notes there were 33,021 students who obtained visas from foreign nations in 2007; the U.S. issued the most visas at 14,916 while the UK was second issuing 7132 visas, and only nine visas were issued for Ireland (Taiwanese Ministry of Education, 2008).

In $2008 / 2009$, the U.S. was by far the most popular host country for Taiwanese students hosting 28,065 students (IIE, 2009a; Lasanowski, 2009) while the UK was also an important destination for students from Taiwan ranking seventeenth on the UK's list of top source countries for 2008/2009 with 5235 students (Gürüz, 2008; UKCISA, 2010). As reflected by the number of student visas issued in 2007, Ireland was not a top host country for Taiwan, and Taiwan does not seem to have been an important source country for Ireland as it did not rank among the top twenty-five source countries in either $2006 / 2007$ or $2009 / 2010$ (IEBI, 2008; Enterprise Ireland, 2010). Given the statistics on visas issued and the number of students studying in just the UK and U.S. alone during the data collection period, it is safe to assume that the number of Taiwanese students studying abroad approached or was equivalent to the numbers of Japanese students overseas signifying that Taiwan was an important source of international students worldwide in 2008/2009.

The largest growth in international student numbers in the first decade of the $21^{\text {st }}$ century has been at the postgraduate level for the reasons given in Chapter 2 (Bourke, 2000; Böhm et al., 2004; Varghese, 2008). Also as explained in that chapter, China, India, Korea and Taiwan are all significant postgraduate markets for the U.S. and UK. For example, 
$54.6 \%$ of Taiwanese students studying in the U.S. in 2008/2009 were studying at the postgraduate level (IIE, 2009c). Although known primarily as an undergraduate market (Alberts and Hazen, 2005; CCEM, 2006; Gürüz, 2008), Japan was included in the research for two reasons. First, as noted above, it is a significant source country worldwide, and second, it is a significant source of international students in the U.S. As explained earlier in this chapter, the source countries for the research were the top five sources countries for the U.S. in 2008/2009 based upon the assumption that this would make for easier comparability of data across host countries.

The significant growth in numbers of international postgraduates has meant that taught and STEM research programmes are especially in demand (Bourke, 2000; Böhm et al., 2004; Varghese, 2008). The sixth and final criterion for the sample was that participants should be studying in one of seven specific fields of study. These fields of study, particularly the STEM subjects, were not only important fields studied by international postgraduate students in the U.S. (these students accounted for more than $55 \%$ of overall enrollment in the STEM fields) but were also important fields of study for international postgraduates worldwide (Finn, 2007; de Wit and Rumbley, 2008; Casey, 2009; IIE, 2009b; Adnett, 2010).

The source countries in the research (with the exception of Japan) were also chosen because they have high numbers of postgraduates in the STEM fields. In the UK, for example, the number of international students in the STEM subjects increased from $29 \%$ to $43 \%$ of all postgraduate students in the Sciences and Engineering between 1994 and 2005. As in the U.S., most students were from Asia, mainly China, India, Pakistan, Taiwan, and South Korea (Douglass and Edelstein, 2009). Motivans (2009) states that in 2007 almost one in four mobile students (23\%) worldwide was enrolled in Business and Administration programmes, with Science as the second most popular field attracting $15 \%$ of student enrolment, followed by Engineering, Manufacturing and Construction (14\%).

\section{Characteristics of Final Sample}

Findings from the research were taken from the data generated through both the questionnaire survey responses and the interviews. The size and general characteristics of 
the final sample are discussed here while more details on the final sample for each of these two methods can be seen in Appendices E, F, and G.

Although a large number of questionnaire surveys were returned (698) only seventy-four $(11 \%)$ were usable because the majority of respondents did not meet the six screening criteria. This was disappointing but not totally surprising due to the number of criteria for participation and limited access to students. Steps were taken to increase the sample size and this, as well as the reasons I had only limited access to students, are discussed in more detail in the next section on access.

Of the seventy-four usable questionnaires, over half (53\%) were from students studying in the UK, almost one-third (30\%) from students studying in the U.S., and less than a quarter $(18 \%)$ were from students in Ireland. Well over half of the respondents were male $(57 \%)$, single (95\%), aged $20-25$ years $(68 \%)$, living in the host country without a partner or spouse (92\%), studying for a Master's degree (70\%), and completely selffunded $(57 \%)$. The majority of respondents were studying Business/Management ( $41 \%)$, followed by Engineering (26\%), Physical and Life Sciences (23\%), and then Law (5\%) and Math/Computer Science (5\%).

In terms of countries of origin, almost half of the respondents were from India (47\%) and slightly under half were from China (43\%). There were many fewer respondents from Taiwan (4\%), Korea (3\%), and Japan (1\%). The low numbers for Taiwan and Korea were surprising especially given the large numbers of postgraduates from these countries studying in the U.S. The low numbers from Japan may be due to the mainly undergraduate market from that country. There was one student from Malaysia who completed the questionnaire and was included in the sample. Although Malaysia was not one of the countries chosen for the sample because it was not one of the top five source countries for international students in the U.S., it is from the same region as the other countries (Asia) which, as noted elsewhere in the thesis, is the leading region of origin of international students. After some discussion with my supervisor, I decided to include the Malaysian student because of the interesting responses from this student, an already modest sample size, and the growing importance of Malaysia as both a source and host 
country (Lasanowski, 2009). Although not among the top five source countries, a significant number of Malaysian students go to the U.S. for study. Malaysia was twentyfirst on the list of source countries for the U.S. in 2009 (IIE, 2009). The UK was also one of the top study destinations for Malaysian students at the time of data collection (de Wit et al., 2008).

In regard to the interviews, out of the seventy-four usable questionnaires, there were twenty-three survey respondents who volunteered to be interviewed. In discussions with my supervisor prior to data collection, we agreed upon a goal of at least twenty interviews as we felt this would be a sufficient number of interviews to exhaust the number of different themes which might emerge from the interview data. However, out of the twenty-three who volunteered, only seventeen students ultimately agreed to be interviewed. Over three-quarters of these interviewees were male (76\%), living in the host country without a partner or spouse (88\%), studying for a Master's degree (82\%), and nearly the same amount were aged $20-25$ years (71\%). All interviewees were single with just about half ( $47 \%)$ completely self-funded. Over half were from China (59\%), followed by India (35\%) and Taiwan (6\%). There were no interviewees from Korea or Japan, and the Malaysian student did not opt to be interviewed. Nearly half of the interviewees were studying Engineering (47\%), followed by Business/Management (24\%), Physical/Life Sciences (18\%), and Math/Computer Science (12\%). There were no interviewees studying Law.

A sample of seventy-four questionnaire respondents and only seventeen interviewees cannot be put forth as representative of all international students, or even all international postgraduates, thereby limiting any broad generalisability of the findings (Maringe and Carter, 2007). Although I present information on how many questionnaires were returned completed or not completed in Appendix E, not having a count of the students at each university that fit my sample criteria makes it difficult to discuss not only the representativeness of the sample, but the response rate of the questionnaires and interviews as well. 
The modest sample size meant that the demographics of the questionnaire sample were not as evenly divided across host and source countries as I had hoped, but the questionnaire data did provide some valuable insights into broader patterns of student views and experience as well as informing the development of the interview schedule. Of the seventy-four usable questionnaires, over half were from students studying in the UK, while less than half of the students who responded to the questionnaire were studying in the U.S. and Ireland combined. In other words, the questionnaire data more strongly reflected the views and experience of international students studying in the UK. As the greatest numbers of questionnaire respondents were from India (47\%) and China (43\%), and only very small numbers from the other three source countries targeted, it can also be argued that the findings generated by the questionnaire reflected the views and experience of international postgraduates from India and China but not necessarily students from Taiwan, Korea and Japan.

In terms of the questionnaires, as over half of the respondents were male (57\%), single (95\%), aged $20-25$ years (68\%) and studying for a Master's degree (70\%), the question arises as to how far the findings also reflect the experience and views of international students who are female, married, mature students, and/or students studying for a PhD. In addition, the numbers of questionnaire respondents studying Law (5\%) and Math/Computer Science (5\%) were quite low so the findings do not reflect the experience and views of these students as strongly as they do for students studying Business/Management (41\%), Engineering (26\%), and Physical and Life Sciences (23\%).

In regard to the interviews, again the sample size was modest but the data generated from these seventeen interviews conducted was considerable, rich in detail, and enlightening. Of the seventeen interviews, almost half (47\%) were students studying in the UK, almost one-third (29\%) were studying in Ireland, and almost one quarter (24\%) were students in the U.S. As with the questionnaires, it can be argued that the interview data more strongly reflects the views and experience of international students studying in the UK. In regard to country of origin, again the majority of interviewees were from China (59\%) and India (35\%) followed distantly by Taiwan (6\%). As there were no interviewees 
from Korea or Japan the findings from the interviews do not reflect the experiences of international students from these countries.

The percentages of interviewees who were male $(76 \%)$, single $(100 \%)$, aged $20-25$ years (71\%), and studying for a Master's degree (82\%) were even greater than those of the survey respondents. This raises, to an even greater extent, questions about how far the findings also reflect the experience and views of international students who are female, married, mature students, and/or students studying for a PhD. In regard to fields of study, Engineering (47\%), Business/Management (24\%) and Physical/Life Sciences (18\%) were the main fields of study of the interviewees followed by Math/Computer Science (12\%). As there were no interviewees who were studying Law, the findings from the interviews do not reflect the experiences of international postgraduates studying Law in the three host countries.

As with any research, the implications of the size and characteristics of the sample for the analysis and outcomes of the research must be considered as I have done above. However, my goal was not to produce knowledge generalisable to the situation of all international students. Instead I wished to highlight its relevance and transferability by providing a deeper understanding of why the international students in my sample decided to study overseas and why they selected certain host countries. Taken together, the questionnaire and interview data offer some interesting insights into the international student experience and the decisions made by these students. An additional, and equally important, objective was to provide a starting point for further and expanded (in terms of more host and source countries, for example) research on international students using the theoretical framework comprised of the three capital concepts to understand and explain international student decision-making.

\section{Access}

Gaining access to participants is often one of the most challenging aspects of research and can require a great deal of time, energy, and persistence. Getting access to student participants in particular entails identifying, contacting, and securing the consent of students as well as their institutions. It is, therefore, important to have or create strong 
working relationships with the relevant institutions to gain access and permission to survey their students (Wellington and Szczerbinski, 2007).

After identifying the three universities for data collection, I approached my contacts at each university and asked for their help in distributing the questionnaire to their international student cohort. They all agreed, but would only do so once, meaning that I was not able to get access to the students a second time. Though this resulted in a number of questionnaires completed, in an effort to increase the sample size further I also contacted the leaders of different Student Societies (e.g., Asian Society, Chinese Society) at each university to ask for their help in getting the questionnaire to their members. I received only a few responses agreeing to forward the information to their members. In addition, a student from University U.S. who heard about my research through the International Office put me in contact with another student who subsequently participated in the survey, and one of the society presidents I spoke with agreed to participate. The characteristics of the final sample are discussed in Chapter 6 .

\section{Research Design and Methods}

The research is based on an extensive review of the literature including data from secondary sources (presented in Chapters 1-4), and primary data collection. Primary data collection consisted of two phases: 1) a questionnaire containing a mixture of open and closed questions; and 2) in-depth, face-to-face, semi-structured interviews. The purpose of utilising two different data collection methods was, first, via the questionnaire to get a broad picture of the sample and the issues involved and, second, via interviews to obtain a more in-depth picture of students motivations and individual experiences (Wellington and Szczerbinski, 2007).

\section{Triangulation}

Triangulation is a research strategy, associated with both quantitative and qualitative research approaches, in which two or more methods or sources are utilised to collect data on the same issue(s) (Wellington, 2000; Bryman, 2004). The purpose of triangulation is to elucidate more completely the depth, complexity, and prevalence of an issue by examining it from more than one angle or point of view. To increase the effectiveness of 
triangulation, the choice and design of methods used in a particular research project should have some relationship to each other. If such a relationship exists then these various methods or sources of inquiry can be used in a complementary or comparative fashion to generate data and check for the consistency of the data, or data from one method or source can be integrated with data resulting from a different method or source (Wellington, 2000).

A mixture of methods or sources, provided they are exploring the same issue, can significantly increase the likelihood of the strength and accuracy of the data, help guard against bias, and offer some suggestion of the universality of a particular phenomenon (Wellington, 2000; Wellington and Szczerbinski, 2007). Drawing on evidence from a mixture of methods or sources also helps to support claims of the 'trustworthiness', or reliability and validity of the research, which can result in more confidence in the findings and the ability to cross-check them (Wellington, 2000; Bryman, 2004; Wellington and Szczerbinski, 2007). In addition, using triangulation is one technique for reducing the effect of the problems or weaknesses inherent in individual research methods, as well as allowing the researcher to take advantage of the strengths of each method (Wellington, 2000).

Wellington and Szczerbinski (2007) take the discussion of triangulation further by noting that the triangulation of data need not be based only on different methods but can also be based on the use of different researchers, points in time, or locations. The research detailed here uses a combination of what they briefly describe as 'space triangulation' in which the researcher(s) undertakes a comparative study of different locations, and 'between method triangulation' in which different methods are used to gather data on the same research questions.

The information received via the questionnaires had considerable influence on the development of the interview schedule and helped to highlight those questions that needed to be followed up in interviews because they seemed unclear to respondents or required more in-depth information. Triangulation was also important to the research for verifying that I was headed in the 'right direction' and for determining whether the data 
collected during the interviews also reflected the views and attitudes of the students who completed the questionnaire but did not participate in the interview stage of the research.

Another essential part of triangulation is to ensure that the researcher's interpretation of answers from respondents is a true and accurate representation of the respondents' views and attitudes (Wellington, 2000). In the research, I attempted to do this in interviews by reviewing with them most of their open-ended answers to the questionnaire to determine whether they might have misunderstood the questions or I might have made a mistake in interpreting their responses, and I also asked follow-up questions about their answers. In other words, the interviews were used to look for new information as well as to check on the mutual understanding of questions and answers used in the questionnaire. Finally, as noted previously, although the use of triangulation can help to lessen the problems associated with the methods used, it is important not to ignore the inherent weaknesses and strengths of these methods. It is also important when attempting reflectivity on the research to note the disadvantages as well as the advantages of the methods used, and thus they are addressed in more detail below (Wellington, 2000).

\section{Methods}

Before discussing individually the methods used to gather data, it is important to distinguish between methodology and methods. As stated earlier, methodology refers to the overall research strategy, including the epistemological and ontological orientations of the researcher, while methods are the specific tools used to generate and collect data. The selection of appropriate research methods should always be determined by the nature of the research questions under consideration keeping in mind that all methods have their strengths and weaknesses, and the use of more than one method can be better for understanding an issue from many angles, particularly social issues which are often inherently complex. In addition, and referring once again to the sometimes false dichotomy between the qualitative and quantitative approaches, most data collection methods used in social science research will generate both qualitative and quantitative data. A questionnaire, for example, a research tool typically associated with quantitative research, can be used to collect qualitative data as well (Bryman, 2004; Wellington and Szczerbinski, 2007). 
The benefits of using questionnaires to collect data are considerable. They can be administered to a large number of people at once, and can provide a simple way to collect a large amount of data. They are also convenient to complete for research participants, if administered as self-completion questionnaires, because the participants can complete them when they have free time and at their own pace (Bryman, 2004). In this research I used self-completion questionnaires. This type of questionnaire is a faster way to collect data with a large sample than conducting interviews, and can reduce the possibility of any bias attributable to interviewer effects or characteristics that may affect how respondents answer the questions (Wellington, 2000; Bryman, 2004). Questionnaires can also be developed to gather qualitative data that explores the views and perceptions of respondents - a factor important to this research. The main disadvantages of selfcompletion questionnaires are their poor rate of return, greater risk of missing data, lack of opportunity for the researcher to clarify misunderstandings and to further explore respondents' answers (Bryman, 2004; Wellington and Szczerbinski, 2007).

The development of the questionnaire and interview schedule began with a review of questions asked in past studies of international student decision-making. Although many of these questionnaires used a multiple choice format to ask students about their reasons for studying abroad or choosing a certain host country, I felt it would be better to keep the majority of questions open-ended to let the students speak for themselves and not be limited by the options I provided for them. Following the advice of Wellington and Szczerbinski (2007) as well on formatting a questionnaire, my questionnaire was divided into different sections and began with simple, closed questions to elicit demographic data and concluded with open-ended questions exploring students' opinions, feelings, experiences, and decisions. The questionnaire can be seen in Appendix C. It is important to point out that the questionnaire shown in the appendix while worded for the international students studying in the UK was exactly the same, with only the host country name changed, for those studying in Ireland and the U.S.

The questionnaire began with participant information, participant consent, and instructions pages where participants were informed of the aim of the research, the ethical considerations, and how to complete the questionnaire as well as the researcher's contact information. The second section consisted of a series of seven preliminary filtering 
questions used to filter out respondents who did not meet the pre-determined criteria set for the sample. The third section focused on the gathering of biographical and other background data and consisted of a series of eighteen both closed and open-ended questions. The open-ended questions in this section generally required short, simple answers such as how long the student had lived in the host country. The main aim of the section was to get a detailed profile of the international students participating in this study and to highlight characteristics such as gender, age, and course level.

The fourth section consisted of a series of predominantly open-ended questions exploring students' reasons for studying abroad, their reasons for wanting to study in the U.S./UK/Ireland, what other countries they considered for study, whether they thought their host country was still a good choice, and whether they intended to return home after graduation or do something else. The space for answering the questions in this section was unlimited. Finally, as one objective of the questionnaire was to identify interviewees, the last question asked if respondents were willing to participate in a follow-up interview to please provide their name and contact information.

I decided to use electronic distribution for the questionnaire because it allows quick and easy access to respondents around the world as well as allowing for a quick and easy way for respondents to return their questionnaires. Electronic questionnaires can also make transcription less of a burden because data will already be in an electronic format making it easier for it to be collated and organised very quickly. In addition, these questionnaires are inexpensive to administer and as my target sample was spread over a large geographic area it would have been too costly and time consuming to travel to each place to administer the questionnaire directly (Bryman, 2004; Wellington and Szczerbinski, 2007).

A weakness of electronic questionnaires is that they sometimes do not have as high a response rate as paper-based questionnaires (Wellington and Szczerbinski, 2007). Additionally, there may be problems with sampling as those who responded to the questionnaire are in fact a self-selected sample that may not be representative of the entire population being studied (Wellington, 2000; Bryman, 2004). Other disadvantages 
include, 'invitation to participate' e-mails may be unintentionally or intentionally mistaken for spam or phishing e-mails and deleted, there is no opportunity for the researcher to build a rapport with respondents, and potential respondents many have concerns about confidentiality of information being exchanged via the Internet (Wellington, 2000). In addition, questionnaires not attractively or neatly presented may be disregarded by potential respondents (Wellington and Szczerbinski, 2007).

\section{Pilot Study}

Piloting a study is a necessary stage in the development of research instruments, and thus the questionnaires and interview schedules in the thesis were piloted with a small number of students prior to being administered to a larger sample (Wellington, 2000). The chief purpose of the pilot study for the questionnaire and interviews was to test whether the wording and meaning of questions in both were clear and unambiguous (Wellington and Szczerbinski, 2007).

The first draft of the questionnaire was reviewed with my two supervisors and after making the suggested revisions, was piloted in August of 2008. The sample for the pilot study was a convenience and snowball sample consisting of fifteen international students thirteen from China, one from Japan, and one from Norway. Access to the group of Chinese students was facilitated by an acquaintance who had been a teacher in China and knew many Chinese international students studying in the UK. She kindly sent the questionnaire to all the Chinese students she knew. The Japanese student was also an acquaintance; and the Norwegian student volunteered after having learned about my questionnaire from another participant.

While the source countries of these students (except Norway) fit the criteria of the sample required for the main research, the students who participated in the pilot study were from different subject areas and were not all postgraduates as specified in the criteria for the main research. As the purpose of the pilot study was simply to 'try out' the questions to identify areas needing revision for purposes of clarity, these findings were not included with data from the main research. 
Upon completion of the questionnaires, I e-mailed each student to ask whether they thought the wording of the questionnaire was simple and easy to understand, and if they had any suggestions for improvements. Only a couple of students responded answering that they had no problems understanding the questions asked and had no suggestions for changes. My Chinese acquaintance recommended that I make a slight revision to the question which asked students what actions they took to pursue study in all the host countries they had considered. She suggested that the actions should not be in the order of 'Applied for a visa' followed by 'Accepted to a university' but rather in the reverse order since students do not apply for a visa until after they are accepted by a university as they are required to send a copy of their offer letter from the university along with their visa application. Finally, in regards to the question asking 'Do you still think study in (host country name) was a good choice for you?', a few students commented that they had only been in the country a short time so could not answer this question. Hence, I added an additional choice of 'Can't say' in response to this question with space to allow students to make further comment if they wished.

\section{Main Data Collection}

\section{The questionnaire}

Survey Monkey (http://www.surveymonkey.com) was used to develop and disseminate the questionnaire for the main data collection. This is an online survey tool that helps researchers to create and develop surveys in an electronic format. Survey Monkey was easy to use, and gave me the tools to develop an attractive and clearly presented questionnaire in which only one question appeared on the screen at a time to ensure respondents answered the questions in the order I intended. This online tool also enabled me to use filtering questions and skip logic. Skip logic refers to the ability of the questionnaire to allow students to skip questions not relevant to them and to stop students from proceeding with the questionnaire if they did not answer critical questions, thereby ensuring they did not inadvertently or purposely skip a key question. It also allowed me to make necessary changes to the questionnaire after dissemination. 
Finally, Survey Monkey allowed me to send out an e-mail containing a link that took students directly to the questionnaire and then when completed the questionnaire was sent directly to my account with Survey Monkey. This was much easier for respondents than dealing with attachments, or having university staff or respondents worry about sending questionnaires back to me. The dissemination of the questionnaire to international students took place from November 2008 to March 2009.

Two revisions were made to the questionnaire after it was first sent to participants in November. The first revision concerned a culturally sensitive issue brought to my attention by my Chinese acquaintance. This concerned the wording of four of the questions which asked for students' country affiliations (i.e., country of birth, country of residence) accompanied by a list of the five source countries targeted in the research. She brought it to my attention that my use of the word 'country' in the questions implied that Taiwan was a separate country from China and that many Chinese did not believe this. She explained this is highly contentious among younger Chinese who tend to feel quite nationalistic about this issue. She worried that if I did not rephrase those questions, word might spread among the Chinese students and result in a boycott of my research. Needless to say, I wanted to be as culturally sensitive as possible so although I kept the same source country options, I took the word 'country' out and rephrased the questions to what is currently shown in Appendix C. I had no further complaints about the use of the word 'country' in relation to Taiwan in the main research so it seemed that the rephrasing of the questions was acceptable to the Chinese participants.

The final revision involved the use of the preliminary screening questions. During the preliminary screening part of the questionnaire, if students did not answer 'yes' to all of these questions, they were immediately taken to a screen thanking them for their time but telling them they were not eligible to participate in the research and providing a link for exiting the questionnaire. Although they had only answered a few 'yes/no' questions at the point they were told they were not eligible, some students took offense to the sudden appearance of a screen saying they were not eligible and contacted me with their comments. Based on this feedback, I took out the sentence saying they were not eligible and changed it to a screen simply thanking them for taking the time to answer the 
questionnaire and providing the link for exiting. Once this change was made, I had no further complaints about this issue.

The interviews

As noted previously, the second phase of primary data collection for the research involved the use of interviews. The purpose of conducting interviews with a sub-set of students who completed a questionnaire was to clarify the data collected via the questionnaires, elicit more details from students regarding their answers, and to yield new data that may not have been captured by the questionnaire.

Interviews are a suitable method for qualitative research because they are useful for producing data that are rich and detailed (Bryman, 2004). Using interviews allows researchers to explore "an interviewee's thoughts, values, prejudices, perceptions, views, feelings and perspectives' and to "elicit their version or account of situations" (Wellington, 2000, p. 71). One of the most important advantages of using interviews in research is the opportunity for decreasing or eliminating ambiguity of research questions or interviewee answers because the researcher can clarify the meaning of questions or prompt the interviewee for more information (Wellington, 2000; Bryman, 2004). Interviews can also be very flexible, not only in allowing the interviewer to vary the order and wording of the questions, but also in allowing him or her to adapt the direction of the interview in response to that desired by the interviewee or further investigate any significant issues that may arise during the interview (Bryman, 2004).

Wellington and Szczerbinski (2007) describe interviewing as a method that allows a researcher to "reach the parts which other methods cannot reach" (p. 81). For example, interviews allow the researcher to prompt and probe participants' answers and understanding of the questions, and allow the interviewer to modify the order and phrasing of the questions when necessary; both of which are not usually possible with a questionnaire. Interviews have an advantage over various observation methods, for instance, because they allow researchers to explore an array of issues that may not be visible or possible to investigate using observation so that questioning subjects in an 
interview format is the only possible way to learn more about these issues (Bryman, 2004).

Interviews also have weaknesses that must be taken into account. For example, interviews can, depending on their length, be very time consuming to conduct, transcribe and analyse, and there is always a chance that after spending much time and money on interviews, there will be nothing significant discovered. Some researchers also question whether the use of interviews does indeed permit real and deep access to the perceptions and views of the interviewees because contact with interviewees is often limited to the length of the interview, which they argue limits a genuine and profound understanding of the issues. In addition, interview questions are often about events that happened in the past meaning that the accuracy of the data is reliant on the interviewee's skill at recalling certain events. Finally, interviewees may under-report or distort the truth about events or behaviors that make them anxious, are too sensitive, or make them appear in a bad light (Bryman, 2004).

The nature of the rapport established between the interviewer and interviewee is crucial as well (Wellington, 2000). A sufficient level of rapport is needed in order to resolve any issues of ambiguity or lack of clarity for example. Interview data can be biased if the social involvement between interviewer and interviewee is too great because then interviewees may be more likely to display a social desirability bias in their responses by answering the way in which they believe the interviewer wants (Bryman, 2004; Wellington and Szczerbinski, 2007). In addition, there are a myriad of interviewer effects and other possible errors that may bias interview data. Interviewer effects include the individual characteristics of the interviewer such as gender or ethnic or social background (Bryman, 2004). The interviewer will also possess some background knowledge and undoubtedly some preconceptions of the issues that he or she brings to the interview that may influence not only the transcription of the interviews but also the analyses and interpretation of the data (Wellington, 2000). Other errors which may result in bias include question order effects when questions are asked in different orders to different interviewees, the excessive use of leading questions or prompting during interviewing, and interviewee fatigue that may occur during lengthy interviews. Finally, as mentioned 
earlier, there is the chance that ambiguity of the questions or the lack of agreement over the definition of the language being used could negatively affect the quality of the data (Bryman, 2004; Wellington and Szczerbinski, 2007).

I conducted face-to-face, individual, in-depth, and semi-structured interviews with students. I felt the best way to conduct interviews on my topic would be in person although there were alternate options available such as telephone or online interviews. These were second choice options however because telephone interviews, for example, make managing the interview more difficult, and it can sometimes be hard to contact people by telephone or to determine if the interviewer is actually speaking with the correct person. In addition, telephone interviews do not allow for the use of visual aids or physical gestures to assist in understanding. In addition, the duration of a telephone interview is often difficult to sustain past twenty or twenty-five minutes while an interviewer is more likely to be able to sustain an in-person interview for a much longer period of time (Bryman, 2004).

Although one of the main reasons for using the Internet for questionnaire dissemination was because my sample was widely distributed geographically, I felt conducting interviews via the Internet was not the best option. The rationales for this decision included the necessity for the interviewees to have access and ability to use the appropriate online facilities, the likelihood of losing or having a bad online connection which can undermine the flow of the interview, and the difficulty in establishing rapport with interviewees online (Bryman, 2004). In-person interviews were also deemed better for this research in order to allow me to observe the effects of the questions on interviewees, enable a rapport to be established with greater ease, and help facilitate the exploration of the interviewee's opinions, perceptions, and experiences. Individual interviews were used because I wanted to delve deeply into each person's individual experience, motivations, and points of view, something which would not have been possible in group interviews (Bryman, 2004; Wellington and Szczerbinski, 2007).

I used a semi-structured format after carefully considering the advantages and disadvantages of all three possible interview formats, semi, unstructured and structured. I 
did not use unstructured interviews because I had many areas to cover and wanted to have some control of the direction of the interviews. I did not use structured interviews because of their inherently inflexible nature (Wellington and Szczerbinski, 2007). Although the questions were primarily pre-determined, I wanted to give interviewees some room for open responses, be able to vary the sequence of questions as fitted the flow of the interview, and wanted the latitude to ask further questions in response to significant issues might arise; it would have been difficult or impossible to do all of these with a structured interview format (Wellington, 2000; Bryman, 2004). Finally, I felt that semistructured interviews were better than the other two formats for achieving my goal of uncovering the genuine opinions and feelings of interviewees, and ensuring that I was able to cover all important and relevant topic areas with students in the limited timeframe of the interview (Bryman, 2004).

The interview schedule was designed on the basis of the review of the literature, the research questions, the questionnaires, consultation with my two supervisors, and the pilot interviews. The process of developing the interview schedule started with drafting of a series of questions that I felt would touch on areas of inquiry important to answering the research questions, and then discussing this list with my supervisors. Based on this discussion, I selected the questions that would be most helpful in targeting the areas of interest and arranged the questions into an interview schedule (Wellington and Szczerbinski, 2007). Two pilot interviews were conducted in winter 2009 with two students who responded to the pilot questionnaire. The feedback from these interviews suggested that only slight wording changes were needed to a couple of questions. The final version of the interview schedule used for the main data collection can be seen in Appendix D. The interview schedule shown in the appendix while worded for the international students studying in the U.S. was exactly the same, with only the host country name changed, for those studying in Ireland and the UK.

I conducted interviews with students using (primarily) pre-determined questions, the majority of which were open-ended. An attempt was made to use the same interview procedure with all interviewees, including the actual administration of the interview, and as much as possible, asking the same questions of all students. The interviews were 
conducted in English so the questions had to be carefully worded to be easily understandable for international students who had varying levels of English ability. All interviews took place in the libraries or graduate centers of the students' universities between March and May 2009. In addition, all interviews were recorded with a digital recorder, and were conducted and transcribed by me. My goal was to conduct approximately twenty interviews because I felt this number of interviews would be sufficient to give significant depth to the data, and would result in a thorough consideration of the main themes of the research.

As noted above, all interviews were recorded using a digital recorder so it is necessary to briefly address the advantages and disadvantages of recording interviews, particularly in contrast to relying on only notetaking. Some of the advantages of digitally recording interviews are that these recordings help the interviewer to retain the actual language used by the interviewee, provide an objective record of what was said while data from notes can be more difficult to verify, and give the interviewer more of an opportunity to focus on what is happening in the interview verbally and non-verbally. Notetaking can be distracting for both interviewer and interviewee (Bryman, 2004). Interviewers can also use recordings as a tool for reflection on their own role in the interviews (Wellington and Szczerbinski, 2007). Finally, disadvantages of digital recordings include the fact that they can be more costly, can produce large amounts of data which is time consuming to transcribe and analyse, the context of the interview can be overlooked, and the use of a recorder may disturb interviewees causing them to become self-conscious or anxious about their answers being permanently preserved (Bryman, 2004; Wellington and Szczerbinski, 2007).

In this chapter, I discussed in detail the reasons for my choice of methodology and methods, and other issues related to the research such as research design and sampling. Next, in Chapter 6, I present the analyses of the data. 


\section{Chapter 6: Presentation and Analyses of Data}

This chapter focuses on the presentation and analyses of the data. It is an attempt to understand a previously researched problem - why international students decide to study abroad and why they select particular host countries - from a fresh perspective, using fresh data. The chapter begins with the presentation of participant demographic data for both the questionnaire and the interviews. The remainder of the chapter focuses on the analysis of the qualitative data using the theoretical framework introduced in Chapter 4. Direct quotes from students are used as evidence to support the findings.

\section{Return Rates}

\section{Questionnaires}

As discussed in the previous chapter, access to questionnaire respondents came through contact with the International Offices and student societies of each university. Table 1: Questionnaires Return Rates, in Appendix E, shows the number of questionnaires returned, and of these, the numbers which were usable and not usable (and why) for the three host countries.

\section{Interviews}

Interviewees, also as discussed, were identified via the questionnaires, and follow-up was made with all students who indicated they were interested in participating in the interview phase. Table 2: Interviewee Response Rates, also in Appendix E, shows the number of students who completed the questionnaire and volunteered to be interviewed, as well as the number who were actually interviewed. As can be seen in the table, I was able to successfully contact and schedule interviews with all volunteers from University U.S. and University Ireland. Although I made several attempts to contact each of the remaining five volunteers at University UK, they either stated they were too busy or did not respond. 


\section{Participant Data}

\section{Questionnaires}

As per the screening criteria, all participants were international students and were pursuing full degrees as full-time students at their respective universities. Demographic data and statistics from (usable) questionnaires by host country can be found in the following tables in Appendix $\mathrm{F}$.

UK: Table 3 provides a breakdown of demographic data for all questionnaire respondents for University UK, and Table 4 provides information on the characteristics of the questionnaire respondents who met the screening criteria.

U.S: Table 5 provides a breakdown of demographic data for questionnaire respondents for University U.S., and Table 6 provides information on the characteristics of the questionnaire respondents based on the screening criteria.

Ireland: Table 7 provides a breakdown of demographic data for questionnaire respondents for University Ireland, and Table 8 provides information on the characteristics of the questionnaire respondents based on the screening criteria.

\section{Interviews}

Tables containing demographic data and statistics for the interviewees by host country can also be found in Appendix F.

UK: Table 9 provides a breakdown of demographic data for interviewees from University UK, and Table 10 provides information on the characteristics of the interviewees based on the screening criteria.

U.S.: Table 11 provides a breakdown of demographic data for interviewees for University U.S., and Table 12 provides information on the characteristics of the interviewees based on the screening criteria. 
Ireland: Table 13 provides a breakdown of demographic data for interviewees for University Ireland, and Table 14 provides information on the characteristics of the interviewees based on the screening criteria.

\section{Qualitative Results}

Qualitative data analysis is challenging because it is not straightforward, nor are there many rules for this kind of analysis that are "well-established [or] widely accepted" (Bryman, 2004, p.399). There are, in fact, many ways to analyse qualitative data making the challenge greater because it is dependent on the researcher's sensitivity to the process and intellectual judgment. On the other hand, this gives the researcher flexibility in analysis and interpretation (Wellington, 2000). In qualitative research it is important to maintain reflexivity throughout, of which more will be said in Chapter 8 .

As qualitative research generates rich and complex data, I had to read, re-read and reflect on the data throughout the analysis phase in order to get "a sense of the whole" (Wellington, 2000, p.149) and what the data revealed about my research questions. I ordered the data by color coding according to my theoretical framework. Coding is a device used in qualitative data analysis to help the researcher conceptualise the data according to the specific research questions. It allows the researcher to systematically label, separate, group and categorise data. Care must be taken however, because coding can influence the quality of the analysis and lead to unnecessary fragmentation, or the loss of the context and flow of the respondents' answers making them more difficult to understand and analyse (Bryman, 2004).

I put all questionnaire data into an Excel spreadsheet separated by question and within each question by type of capital. I attempted to align each answer with one of three capitals. Once I had the items roughly organised into these three categories, I continued examining, recombining, and recoding to determine patterns or relationships. This resulted in both a priori categories and a posteriori sub-categories, themes, and sub-themes. The three a priori categories, human, social and cultural capital, were pre-established based on the chosen theoretical framework but it was necessary to do an a posteriori subcategorisation to further clarify and understand the data. These sub-categories also 
needed to be refined and were broken down even further into themes and sub-themes. The data revealed two sub-categories for each type of capital, existing capital and potential capital, and a varying number of themes and sub-themes for each of these. For example, within the human capital category and potential human capital sub-category, a theme entitled 'Cost effective education' emerged together with related sub-themes of 'Cost of tuition fees' and 'Funding opportunities' as shown below:

Category: Human Capital

Sub-category: Potential Human Capital

Theme: Cost-Effective Education

Sub-themes: 1) Cost of Tuition; 2) Funding Opportunities

There was a great deal of qualitative data to be analysed from the seventeen interviews. I started by first transcribing them and using the categories, sub-categories, themes and sub-themes identified from the questionnaire analysis, to code and categorise the comments of the interviewees. I attempted to keep these categories, sub-categories, themes and sub-themes as flexible as possible to accommodate new ones that emerged from the interviews or to modify existing ones. This involved reading, coding, and categorising the data several times. Because of the more in-depth responses generated by interviews, a number of new a posteriori themes were identified. For example, 'Parents' educational experience' emerged as a form of existing cultural capital used by students. In addition, a few of the established themes from the questionnaire analysis such as 'Family in host country' were re-labelled as 'Family' and divided into sub-themes such as 'Family as source of influence and support' and 'Family as source of information'.

It is important to explain decisions made during the analyses to clarify and support the interpretation of the data. As noted in Chapter 4, the three capitals are interrelated. However, for ease of understanding the data, I attempted to make the categories as exclusive as possible and to assign each data item to only one capital category. Areas of overlap between the capitals that emerged in the data will be discussed in Chapter 7. As with many qualitative studies, there were also challenges in neatly apportioning some of the participants' statements into one of the three main capital categories and as the 
questionnaires were anonymous there was no opportunity to clarify these statements with most participants, except the seventeen interviewees. This meant categorisation in these cases was dependent on the researcher's interpretation.

One such challenge concerned categorising comments which were very short or lacked enough detail for easy interpretation. For example, some consisted of just one word such as "education", or said "Already Answered." For such responses, I examined students' questionnaire responses as a whole, and this enabled me in most cases to interpret, code and categorise them. Another challenge had to do with the wording students used. Some students, for example, discussed the importance of the 'quality/ranking' of higher education in the host country while others commented on the importance of the 'reputation/recognition/renown' of higher education in the host country. I felt that 'quality/ranking' was linked more closely with human capital while the terms 'reputation/recognition/renown' reflected a sense of cultural capital, and so categorised such responses accordingly.

As a reminder, a multi-method research strategy was used in the research with the purpose of the questionnaire being to identify relevant issues; and the purpose of the interviews to yield new data as well as to provide an opportunity to triangulate, confirm, and check information collected in the questionnaires. The analyses of the qualitative data from the questionnaire and interviews are presented below. I attempted to present the data impartially, clearly and coherently. One way in which I do this is by presenting exact quotes from students because it is important to hear the participant voice. This also emphasises the authenticity of the data, as well as illustrating the main themes and perspectives and the participant support for them (Wellington and Szczerbinski, 2007).

\section{Considering Overall Patterns in the Data}

Prior to the presentation of the various sub-categories, themes and sub-themes found in the data, it is important to consider some of the overall patterns in the data. One of the main findings from the data was that human capital was the most mentioned type of capital by students when giving their reasons for deciding to study overseas and for 
choosing a host country. Human capital was followed in importance by cultural and then social capital. This pattern proved to be true across three of the six pre-determined sample criteria - source country, host country, and field of study. I provide evidence of this pattern here by examining students' answers to the three key questions (referred to above) on the questionnaire. Approximate numbers of responses assigned to the respective capital categories are shown in parentheses. Numbers of responses do not always correspond to sample numbers as students often gave more than one answer to the key questions some of which fell into more than one capital category, and sometimes they did not provide answers (or answers which could be categorised) to the questions.

\section{Patterns by host country}

As shown in Table 1, Appendix E, there were thirty-nine usable questionnaires from students studying at University UK, twenty-two at University U.S. and thirteen at University Ireland. The reasons of these students for deciding to study overseas are broken down by host country in Table 15a below.

Table 15a: Reasons by Host Country

1. What reasons were important to you in deciding to study overseas in general?

\begin{tabular}{|c|c|c|c|}
\hline & Human Capital & Cultural Capital & Social Capital \\
\hline UK & 31 & 16 & 2 \\
\hline U.S. & 19 & 8 & 2 \\
\hline Ireland & 6 & 8 & 1 \\
\hline TOTALS & 56 & 32 & 5 \\
\hline
\end{tabular}

As can be seen, students studying in the UK and the U.S. when asked why they decided to study overseas cited human capital reasons twice as frequently as cultural capital reasons for doing so, while social capital reasons were significantly less for both groups. Students studying in Ireland responded slightly differently mentioning cultural capital more frequently than human capital reasons but only by a very small margin, while only one student in Ireland gave a social capital reason for their decision to study overseas. Totals for all three host countries show that human capital reasons were almost twice as 
important to students as were cultural capital reasons and over ten times as important as social capital reasons.

The reasons of these students for choosing a country for study are broken down by host country in Table 15b below.

Table 15b: Reasons by Host Country

2. What reasons were important to you in choosing a particular COUNTRY for study?

\begin{tabular}{|c|c|c|c|}
\hline & Human Capital & Cultural Capital & Social Capital \\
\hline UK & 31 & 15 & 9 \\
\hline U.S. & 19 & 12 & 7 \\
\hline Ireland & 11 & 4 & 4 \\
\hline TOTALS & 61 & 31 & 20 \\
\hline
\end{tabular}

In terms of reasons for choosing a country of study, human capital reasons were again most cited and mentioned approximately twice as often as cultural capital reasons. This was true for students studying in all three host countries. For students studying in the UK and the U.S., cultural capital reasons were most often mentioned after human capital reasons, followed by social capital reasons. The results were again slightly different for students studying in Ireland. Although these students also cited human capital reasons most often as important when choosing a host country, they cited cultural and social capital reasons as equally important. Totals for all three host countries show that human capital reasons were cited almost twice as often as cultural capital reasons and over four times as frequently as social capital reasons.

Table 15c, which can be seen below, shows the three main reasons students chose their current country of study again broken down by host country. 


\section{Please give the THREE main reasons, IN ORDER OF IMPORTANCE, why you} chose to study in the UK/U.S./Ireland?

\begin{tabular}{|c|c|c|c|c|c|c|c|}
\hline & \multicolumn{2}{|c|}{$\begin{array}{l}\text { Human } \\
\text { Capital }\end{array}$} & \multicolumn{2}{|c|}{$\begin{array}{l}\text { Cultural } \\
\text { Capital }\end{array}$} & \multicolumn{2}{|c|}{ Social Capital } & \multirow{2}{*}{$\begin{array}{c}\text { TOTALS } \\
37\end{array}$} \\
\hline \multirow{3}{*}{ UK } & R\#1 & 27 & R\#1 & 10 & R\# 1 & 0 & \\
\hline & R\#2 & 29 & R\# 2 & 5 & R\#2 & 5 & 39 \\
\hline & R\#3 & 24 & R\#3 & 10 & R\#3 & 2 & 36 \\
\hline \multirow{3}{*}{ U.S. } & R\#1 & 20 & R\# 1 & 1 & R\#1 & 1 & 22 \\
\hline & R\#2 & 14 & R\# 2 & 5 & R\#2 & 3 & 22 \\
\hline & R\#3 & 13 & R\#3 & 8 & R\#3 & 3 & 24 \\
\hline \multirow{3}{*}{ Ireland } & R\# 1 & 5 & R\# 1 & 5 & R\#1 & 3 & 13 \\
\hline & R\#2 & 9 & R\# 2 & 1 & R\#2 & 2 & 12 \\
\hline & R\#3 & 7 & R\#3 & 5 & R\#3 & $\mathbf{0}$ & 12 \\
\hline TOTALS & & 148 & & 50 & & 19 & 217 \\
\hline
\end{tabular}

When students were asked for their three main reasons for selecting their current host country, students in the UK and the U.S. overwhelming cited human capital reasons as the primary reason for choosing their respective host countries. For students in the UK, cultural capital reasons came next in importance as a number one reason for students choosing the UK as their current host country, while social capital was not a number one reason for any students for choosing the UK. Cultural capital and social capital were not of high importance to students in selecting the U.S. as a host country as only one student gave a cultural capital reason and only one a social capital reason as their primary reasons for choosing the U.S. The results from the students studying in Ireland showed students cited human and cultural capital reasons equally as primary reasons for choosing Ireland as a host country, with only slightly less saying their choice was due to social capital reasons.

Human capital reasons were again the most cited as the second reason students in the UK chose that country for study, followed at a considerable distance, but in equal numbers, by cultural and social capital reasons. The second main reason students studying in the U.S. chose that country fell primarily in the human capital category. This was more than twice the number of cultural capital reasons and almost five times the number of social capital reasons for them in choosing the U.S. as a host country. The findings for the second main reason for selecting Ireland for students studying there showed again the importance of 
human capital. These reasons were cited almost five times as much as social capital reasons and nine times as often as cultural capital reasons.

Finally, students studying in the UK said their third most important reason for choosing the UK were primarily human capital reasons. This was more than twice the number of cultural capital reasons and twelve times the number of social capital reasons given for choosing the UK as a host country. For students who chose the U.S., their third most important reason for doing so again fell primarily in the human capital category. This was almost twice the number of cultural capital reasons and more than four times the number of social capital reasons given. Again, the results were a bit different for students who selected Ireland. These students said their third most important reason for choosing Ireland as a host country were mainly human capital also but were followed closely by cultural capital reasons. There were no students studying in Ireland whose third main reason for choosing that country for study was related to social capital reasons. In looking at the totals for each capital category, human capital reasons were by far the most important for students in selecting their current host country. Human capital reasons were given almost three times as often as cultural capital reasons and almost eight times as often as social capital reasons.

Students' responses to the three key questions broken down by source country are presented in the next three tables.

\section{Patterns by source country}

The reasons of these students for deciding to study overseas are broken down by source country in Table 16a below.

Table 16a: Reasons by Source Country

1. What reasons were important to you in deciding to study overseas in general?

\begin{tabular}{|c|c|c|c|}
\hline & Human Capital & Cultural Capital & Social Capital \\
\hline India & 32 & 11 & 3 \\
\hline China & 25 & 16 & 1 \\
\hline TOTALS & 57 & 27 & 4 \\
\hline
\end{tabular}


Of the seventy-four usable questionnaires, thirty-five students were from India, thirty-two from China, three from Taiwan, two from Korea, one from Japan, and one from Malaysia. I will present the data by source country for students from India and China only. The reason for this is that the numbers for the remaining three source countries were quite small making it difficult to argue overall trends for these groups. However, I would like to emphasise that quotes from these students taken from the questionnaire and interviews were equally as important as those from students from India and China, and are thus included with the discussion of the sub-categories, themes and sub-themes below.

For students from India across all three host countries, human capital reasons were by far more important to students for studying overseas than were cultural or social capital reasons. Human capital reasons were given almost three times as often as cultural capital reasons and over ten times as much as social capital reasons by Indian students. Of the students in the sample from China, again most decided to study overseas mainly for human capital reasons; however, in this case, the frequency of human capital reasons was less than twice as much as for cultural capital reasons. Finally, only one Chinese student mentioned that social capital was an important reason for deciding to study overseas. For both of these host countries combined, the overall pattern showed that human capital reasons were of most importance to these students in deciding to study overseas. Human capital reasons were given over twice as often as cultural capital reasons and over fourteen times as often as social capital reasons.

Next, the reasons of these students for choosing a country for study are broken down by source country in Table $16 \mathrm{~b}$ below.

Table 16b: Reasons by Source Country

2. What reasons were important to you in choosing a particular COUNTRY for study?

\begin{tabular}{|c|c|c|c|}
\hline & Human Capital & Cultural Capital & Social Capital \\
\hline India & 31 & 9 & 8 \\
\hline China & 32 & 14 & 11 \\
\hline TOTALS & 63 & 23 & 19 \\
\hline
\end{tabular}


Similarly, when asked for reasons important in selecting a country of study, Indian students gave human capital reasons almost four times as often as cultural and social capital reasons which were mentioned about the same number of times. For Chinese students in terms of selecting a country of study, again human capital reasons were most often mentioned. However, there was not as big a difference between the number of human capital reasons given in relation to cultural capital and social capital reasons as for Indian students. Human capital reasons were given by Chinese students only twice as often as cultural capital reasons and about three times as often as social capital reasons. As with Indian students, there was not a big difference between the number of times cultural and social capital reasons were given as important in choosing a country for study. In looking at the totals for each capital category, human capital reasons were given about three times as often as cultural and social capital reasons for Indian and Chinese students combined.

The next table, Table 16c, showing the three main reasons students chose their current host country broken down by source country can be seen below.

\section{Table 16c: Reasons by Source Country}

3. Please give the THREE main reasons, IN ORDER OF IMPORTANCE, why you chose to study in the UK/U.S./Ireland?

\begin{tabular}{|c|c|c|c|c|c|c|c|}
\hline \multirow{3}{*}{ India } & \multicolumn{2}{|c|}{$\begin{array}{l}\text { Human } \\
\text { Capital }\end{array}$} & \multicolumn{2}{|c|}{$\begin{array}{c}\text { Cultural } \\
\text { Capital }\end{array}$} & \multicolumn{2}{|c|}{$\begin{array}{l}\text { Social } \\
\text { Capital }\end{array}$} & \multirow{2}{*}{$\begin{array}{c}\text { TOTALS } \\
34\end{array}$} \\
\hline & R\#1 & 30 & R\#1 & 4 & R\#1 & 0 & \\
\hline & R\# 2 & 24 & R\# 2 & 3 & R\# 2 & 8 & 35 \\
\hline & R\#3 & 23 & R\#3 & 8 & R\#3 & 4 & 35 \\
\hline \multirow{3}{*}{ China } & R\# 1 & 18 & R\#1 & 11 & R\# 1 & 4 & 33 \\
\hline & R\# 2 & 23 & R\# 2 & 7 & R\# 2 & 2 & 32 \\
\hline & R\#3 & 19 & R\#3 & 13 & R\#3 & 0 & 32 \\
\hline TOTALS & & 137 & & 46 & & 18 & 201 \\
\hline
\end{tabular}

In regard to the three main reasons why students chose their host country, no Indian students mentioned any social capital reasons as a number one reason for choosing their current host country. Indian students gave human capital reasons as most important and more than seven times as often as they did cultural capital reasons. In terms of their 
second most important reason for selecting their host country most Indian students again gave human capital reasons most often. Interestingly, for Indian students social capital reasons were given over twice as often as cultural capital reasons as the second most important reason for choosing their current host country. Finally, when asked their third most important reason for choosing their current host country, these students gave human capital reasons almost three times as often as cultural capital reasons and over five times as often as social capital reasons.

Chinese students also gave primarily human capital reasons as their number one most important reason for choosing their current host country although this was followed relatively closely by cultural capital reasons. Human capital reasons were given less than twice as often as cultural capital reasons and over twice as often as social capital reasons. As their second most important reason for choosing their current host country, Chinese students overwhelmingly gave human capital reasons. Human capital reasons were given over three times as often as cultural capital reasons and over eleven times as often as social capital reasons. Finally, in regard to their third most important reason for selecting their host country, Chinese students gave mainly human capital reasons although again these were followed closely by cultural capital reasons. No Chinese students cited any social capital reasons as a third most important reason. When looking at the totals for these source countries combined, the overall pattern of human capital reasons as predominant followed by cultural and then social capital reasons is again evident. Human capital reasons were given almost three times as often as cultural capital reasons and over seven times as often as social capital reasons.

Students' responses to the three key questions broken down by field of study are presented in the next three tables.

\section{Patterns by field of study}

The reasons of students for deciding to study overseas are broken down by field of study in Table 17a below. 
Table 17a: Reasons by Field Of Study

1. What reasons were important to you in deciding to study overseas in general?

\begin{tabular}{|c|c|c|c|}
\hline & Human Capital & Cultural Capital & Social Capital \\
\hline Business/Management & 20 & 17 & 3 \\
\hline Engineering & 17 & 7 & 0 \\
\hline Law & 4 & 1 & 1 \\
\hline Math/Computer Science & 2 & 2 & 1 \\
\hline Physical/Life Sciences & 14 & 6 & 5 \\
\hline TOTALS & 57 & 33 & 0 \\
\hline
\end{tabular}

When looking at students' responses by field of study in regard to their decisions to study overseas, again the overall patterns show that human capital reasons were most cited, followed by cultural and then social capital reasons. There were two exceptions. First, of the nineteen students studying Engineering, none of them gave social capital reasons as important to their decision to study overseas. Second, students studying Math/Computer Sciences mentioned human and cultural capital reasons equally as often and did not mention any social capital reasons as important in deciding to study overseas. It is important to keep in mind that this was a small group of only four students. The totals show that human capital reasons were given almost twice as often as cultural capital reasons and over eleven times as often as social capital reasons.

The reasons of students for choosing a country for study are broken down by field of study in Table 17b below. 
Table 17b: Reasons by Field Of Study

2. What reasons were important to you in choosing a particular COUNTRY for study?

\begin{tabular}{|c|c|c|c|}
\hline & Human Capital & Cultural Capital & Social Capital \\
\hline Business/Management & 20 & 12 & 7 \\
\hline Engineering & 17 & 7 & $\mathbf{2}$ \\
\hline Law & 3 & 2 & 1 \\
\hline Physical/Life Sciences & 4 & 7 & 6 \\
\hline TOTALS & 17 & 30 & 20 \\
\hline
\end{tabular}

Human capital reasons were most cited by students in all fields of study in answer to the question about reasons important to choosing a country of study, followed by cultural and then social capital reasons. However, this difference between the numbers of times each capital was mentioned were not always large as can be seen when looking at the numbers for students studying Law and Math/Computer Science. Again, the sizes of these two groups were small having only four students each. The totals show that when choosing a country for study, human capital reasons were mentioned more than twice as often as cultural capital reasons and more than four times as often as social capital reasons.

The final table, Table 17c, showing the three main reasons students chose their current host country broken down by field of study can be seen below. 
3. Please give the THREE main reasons, IN ORDER OF IMPORTANCE, why you chose to study in the UK/U.S./Ireland?

\begin{tabular}{|c|c|c|c|c|c|c|c|}
\hline \multirow{3}{*}{ Business/Management } & \multicolumn{2}{|c|}{$\begin{array}{l}\text { Human } \\
\text { Capital }\end{array}$} & \multicolumn{2}{|c|}{$\begin{array}{c}\text { Cultural } \\
\text { Capital }\end{array}$} & \multicolumn{2}{|c|}{$\begin{array}{l}\text { Social } \\
\text { Capital }\end{array}$} & \multirow{2}{*}{$\begin{array}{c}\text { TOTALS } \\
30\end{array}$} \\
\hline & R\# 1 & 17 & R\#1 & 11 & R\#1 & 2 & \\
\hline & R\# 2 & 15 & $\mathbf{R} \# \mathbf{2}$ & 7 & R\# 2 & 7 & 29 \\
\hline & R\#3 & 16 & R\#3 & 13 & R\#3 & 1 & 30 \\
\hline \multirow[t]{3}{*}{ Engineering } & R\#1 & 19 & R\# 1 & $\mathbf{0}$ & R\#1 & $\mathbf{0}$ & 19 \\
\hline & R\# 2 & 16 & R\# 2 & 2 & R\# 2 & 2 & 20 \\
\hline & R\#3 & 11 & R\#3 & 6 & R\#3 & 2 & 19 \\
\hline \multirow[t]{3}{*}{ Law } & R\# 1 & 3 & R\# 1 & $\mathbf{0}$ & R\# 1 & 1 & 4 \\
\hline & R\# 2 & 4 & R\# 2 & $\mathbf{0}$ & R\# 2 & $\mathbf{0}$ & 4 \\
\hline & R\#3 & 2 & R\#3 & 1 & R\#3 & 1 & 4 \\
\hline \multirow[t]{3}{*}{ Math/Computer Science } & R\# 1 & 1 & R\# 1 & 3 & R\#1 & $\mathbf{0}$ & 4 \\
\hline & R\# 2 & 3 & R\#2 & 1 & R\#2 & $\mathbf{0}$ & 4 \\
\hline & R\#3 & 3 & R\#3 & 1 & R\#3 & $\mathbf{0}$ & 4 \\
\hline \multirow[t]{3}{*}{ Physical/Life Sciences } & R\# 1 & 13 & R\# 1 & 4 & R\#1 & 1 & 18 \\
\hline & R\#2 & 15 & R\# 2 & 1 & R\#2 & 1 & 17 \\
\hline & R\#3 & 12 & R\#3 & 2 & R\#3 & 1 & 15 \\
\hline TOTALS & & 150 & & 52 & & 19 & 221 \\
\hline
\end{tabular}

When looking at the three main reasons students chose to study in their current host country by all fields of study combined, the totals show the same overall pattern as discussed throughout this section. Human capital reasons were given as one of the three main reasons almost three times as often as cultural capital reasons and almost eight times as often as social capital reasons. However, looking at the fields of study individually provides some interesting information. For example, for Engineering students, cultural and social capital reasons were not important as a number one reason for choosing their current host country. These students overwhelmingly mentioned human capital reasons as their top reason. Another interesting example is the responses given by Math/Computer Science students as their number one reason for choosing their current host country. These students gave cultural capital reasons more often than human capital reasons, and did not cite any social capital reasons as being of importance. As noted earlier, this was a very small group of students. It is important to acknowledge that a larger sample of students in this field of study, or for any of the fields of study targeted in the research, might have resulted in more diversity in the answers given. 


\section{The Questionnaire and Interview Data}

Data analysis was based on the three concepts of human, cultural, and social capital out of which two sub-categories developed: existing capital and potential capital. Existing capital refers to capital students themselves possessed or had access to prior to studying overseas while potential capital refers to capital students hoped to gain as a result of studying abroad. Finally, from these two sub-categories, there were a number of themes that emerged, some of which were further divided into sub-themes for better illustration of the findings.

The final list of sub-categories, themes and sub-themes for each capital can be seen below in the tables included with the discussion of each capital. The three capitals are presented in the order most commented upon in the questionnaire with human capital first, cultural capital second, and social capital last. Within each category, the sub-category of existing capital is discussed first followed by potential capital, and within each of these two subcategories, the relevant themes and sub-themes are presented roughly in the order most mentioned by students.

The data used as evidence in this chapter derived primarily from three key questions on the questionnaire (see Appendix C):

- What reasons were important to you in deciding to study overseas in general?

- What reasons were important to you in choosing a particular COUNTRY for study?

- $\quad$ Please give the THREE main reasons, IN ORDER OF IMPORTANCE, why you chose to study in the UK/U.S./Ireland?

Questionnaire data is supplemented with quotes from the interviews throughout the discussion below. Further interviewee information can be found in Table 18 in Appendix G.

It is important to remember that all data was collected after students had made the decision to study abroad, selected a host country, and started their programme of study at 
their host institution. The quotes refer, unless otherwise stated, to what students thought/believed before making a final decision to study abroad and/or a final selection of host country. Although participants also talked about their experiences in their host country after beginning their programme of study, the presentation of data focuses on the decision-making period.

\section{Human Capital}

Human capital, simply put, is the knowledge, skills, abilities, and traits possessed by individuals that contribute to their personal, social and economic well-being (Healy and Côté, 2001). Individual investment in education is intended to increase human capital (Schultz, 1961).

\section{Existing Human Capital}

The international students in the research were investing in international postgraduate education to increase their human capital. The data showed that students utilised their existing human capital to further the development of their individual human capital. Mention of existing human capital by students was in reference to the themes in Table 19 below. Each theme is discussed in more detail after the table. 


\begin{tabular}{|l|c|}
\hline \multicolumn{2}{|c|}{ Table 19: Existing Human Capital } \\
\hline \multicolumn{1}{|c|}{ Themes } & \\
\hline Previous university degree obtained \\
\hline $\begin{array}{l}\text { Previous degree/study/work done in the same host } \\
\text { country }\end{array}$ \\
\hline Previous work experience \\
\hline Student's previous academic achievement \\
\hline
\end{tabular}


Previous university degree obtained

In a sense, because all participants in the research were at the postgraduate level, Master's or PhD, they all could be said to have existing human capital in terms of a previously obtained university degree whether that was undertaken in their home, current host or a third country. Not all students explicitly mentioned this capital however, but those who did made comments such as: "I have finished a Master in China so this is the second Master actually" (U.S. \#158) or "I came to Ireland three years ago, after [which] I finished my undergraduate study" (IR\#6).

Previous degree/study/work done in the same host country

Some students said they had already studied in the host country which motivated them to pursue additional education in that country to further increase their human capital. This sub-theme was not as straightforward to analyse as I would have hoped because I did not ask on the questionnaire specifically whether students had done any other degrees in their current host country. Of the seventy-four questionnaire respondents, there were approximately eleven who may have completed a previous degree or other study in their current host country. As there was no chance to follow-up with most during an interview to verify, I can only infer this from the degree programme followed at the time of data collection, the start date of that programme, and the length of time in the current host country.

UK: Of the thirty-nine students studying in the UK who provided usable questionnaires, the length of time in the UK varied from six weeks to over seven years. Students began their current programmes of study between late autumn 2005 and autumn 2008. Of the interviewees, all began their current programmes between autumn 2007 and 2008, and the length of time they had been in the UK varied from two months to two and a half years. At least three students studying in the UK at the time of data collection, UK\#2 and UK\#62 (they were interviewees), and UK\#7 had studied for a previous degree in the UK. UK\#2 who was pursuing a PhD said, "I took MSc at [University UK] as well." UK\#62 began her studies with a Master's degree from another UK university and when considering 
where to study for her PhD said, "since I did my MSc in UK as well and doing a phd in this country followed as a result of it." UK\#62 also gained work experience prior to her current programme of study in the UK, "I was working in a call center...because I had to sustain myself..." UK\#7 said he did not consider studying at home explaining, "Because my [under] graduate degree was from UK too."

U.S.: Of the twenty-two students studying in the U.S. who provided usable questionnaires, the length of time they had been in the U.S. varied from three months to seven years. Students began their current programmes of study between August 2003 and September 2008. Of the four interviewees, all began their current programmes in August 2007 or 2008 , and the length of time the students had been in the U.S. varied from three months to two years. None of the twenty-two students mentioned specifically having done previous study or work in the U.S. although U.S.\#5 said he was doing a Master's degree (normally a two-year programme in the U.S.) which he began in August 2008, but indicated he had been in the U.S. for four years.

Ireland: Of the thirteen students studying in Ireland who provided usable questionnaires, the length of time they had been in Ireland varied from four months to six years, and all had begun their current programmes in autumn 2008. Of the five interviewees, the length of time the students had been in Ireland varied from four months to six years. IR\#6 and IR\#20 participated in student exchange programmes in which they completed the final year of their undergraduate degree in Ireland, and then continued to the Master's level. IR\#26 did his Bachelor's degree in another Irish university, and "...one year for like something called Foundation Course. It's for me to adapt how to live here, the way people live here and the way people study something like that. It's something mixed with the language course things."

Follow-up was possible with the interviewees and showed that six had a previous degree or other form of study in their current host country. IR\#6, for example, originally went to Ireland as an exchange student. The exchange programme involved completing two or three years of a Bachelor's degree at home and the final year in Ireland. Upon completion 
of her Bachelor's degree, she had nearly finished one Master's in Ireland and was working on a second.

Previous work experience

Although previous work experience was not asked about in the questionnaire, one student mentioned such experience. U.S.\#165 wrote, "I was in job for two years before coming here. All the experiences contributed in the decision-making." This comment shows that this form of existing human capital did have some influence on students' choices regarding international study.

I was able to explore existing human capital in the form of work experience during the interviews and found nine out of seventeen interviewees had some previous work experience. The work experience of the interviewees included short-term and internship placements as undergraduates during university breaks (UK\#2, UK\#133) or internships that were a part of an academic programme (UK\#62). IR\#25, for example, now studying for a Master's, said he worked a part-time job during his Bachelor's study, "Actually I work in Ireland for nearly two years..."

Some interviewees mentioned obtaining work experience prior to their current study programme in a more formal capacity, from being an operator in a call centre to holding more professional and management level positions, as well as working for significant time periods of between two to six years. U.S.\#162, who worked for an international accounting and consulting firm said, "...after I finished my Bachelor degree in 2001, I joined Deloitte and Touche for six years." He said work experience was required for his current MBA programme, "That's how an MBA works, because the average of my classmates, we have around four or five years working experience. Prior to MBA school."

\section{Student's previous academic achievement}

Five interviewees received full funding from the host universities as scholarships or assistantships based on past academic achievement. For example, in the questionnaire, 
UK\#278 said, "I was a university topper in my undergraduate (four years course) and in post-graduate Masters (two years course) ...I [was] nominated for Chancellor's Gold Medal for best Master's Research Fellow...", adding in the interview because of this outstanding academic record he "...got offer letters and scholarship from many places..."

Other students emphasised the high ranking of the universities they attended previously as evidence of their existing human capital in terms of academic achievement. These students received research assistantships from their host universities to cover tuition fees and living expenses, as well as having received offers of funding from other universities to which they had applied because of their academic records. U.S.\#165, who received a Bachelor's degree from the Indian Institute of Technology (IIT), explained "IIT is the pinnacle where you can reach in terms of Engineering education in India..." In addition to the assistantship received from University U.S., he was also offered funding from other universities to which he applied, "I'd applied to England and the Netherlands, and I got offers from both countries and they were very good offers, I was getting full money and that too for Master's. It's really hard to get scholarship for Master's..."

\section{Potential Human Capital}

The potential human capital students hoped to gain from studying abroad can be seen in Table 20 below, after which the themes and sub-themes are discussed in further detail. 


\begin{tabular}{|c|c|}
\hline \multicolumn{2}{|l|}{ Postgraduate level education } \\
\hline High quality education & $\begin{array}{l}\text { 1. Education Quality } \\
\text { 2. Education ranking and international standing } \\
\text { 3. Quality of faculty and teaching } \\
\text { 4. Quality of research }\end{array}$ \\
\hline Cost-effective education & $\begin{array}{l}\text { 1. Short duration of study } \\
\text { 2. Cost of tuition fees } \\
\text { 3. Funding opportunities }\end{array}$ \\
\hline Better career opportunities & $\begin{array}{l}\text { 1. International degrees and job opportunities } \\
\text { 2. Work experience in the host country after graduation } \\
\text { 3. Working at home after graduation } \\
\text { 4. Working during study } \\
\text { 5. High salary }\end{array}$ \\
\hline Access to better resources for study & $\begin{array}{l}\text { 1. Resources } \\
\text { 2. Facilities/Equipment } \\
\text { 3. Technology } \\
\text { 4. } \text { Funding } \\
\text { 5. Expertise } \\
\text { 6. } \text { Knowledge }\end{array}$ \\
\hline High standard of living & $\begin{array}{l}\text { 1. Standard of living } \\
\text { 2. Climate } \\
\text { 3. Safety } \\
\text { 4. } \text { Equal opportunity }\end{array}$ \\
\hline Access to specific course content or specialised programme & $\begin{array}{l}\text { 1. Course/programme content and quality } \\
\text { 2. Course/programme not offered at home } \\
\text { 3. Freedom/flexibility of programme }\end{array}$ \\
\hline \multicolumn{2}{|l|}{ Exposure to specialisation in the field of study } \\
\hline Quick and easy admittance to university & $\begin{array}{l}\text { 1. Application process } \\
\text { 2. Chance of admission } \\
\text { 3. Availability of information }\end{array}$ \\
\hline \multicolumn{2}{|l|}{ Exposure to an economically developed country } \\
\hline Ease of movement & $\begin{array}{l}\text { 1. Visa process } \\
\text { 2. Opportunities for immigration }\end{array}$ \\
\hline
\end{tabular}


Postgraduate level education

Students said they were pursuing a postgraduate degree because of a desire for access to better job opportunities, a desire to gain knowledge, and/or personal reasons. Students pursuing Master's degrees, such as UK\#502, referred to a higher degree as a way to get a better job and be more competitive in the job market, whether that was at home or in another country. He stated:

"To get a job is not difficult but to get a good job is very difficult...it's almost impossible for me to get a good job with the undergraduate degrees...I decided to promote myself...there are more than millions undergraduates in China every year...you may image how fiercely the competition is..."

Students who were investing in PhD studies felt similarly. UK\#2, for example, stated:

"...a PhD degree can proof a better promotion in future. Like in a company, you and your colleague are challenging for the same position, but the benefits you got is the PhD degrees, then you can have the better chance than him."

As the term capital implies investment takes place, I asked students during the interviews if they viewed postgraduate education as an investment. IR\#19, for example, was studying for a Master's and noted both the investments of time and money required:

"I did some kind of research on how the time that I'm investing on top of it because I was working and I would be losing that amount of money and I'm losing a lot of time. But I would be gaining a lot of knowledge from my Master's and this would really push my career..."

Some students said they were in postgraduate education because they wanted to gain knowledge. U.S.\#85 wanted to undertake postgraduate education simply "Because I like studying and researching, further education is a good choice for me", while UK\#278 said: 
"I've always been fascinated with science...Although I got many lucrative job offers but all I wanted to do is pure science. And I just wanted to dedicate myself to science and the PhD was the best option for me."

High quality education

Within the potential human capital sub-category, the theme most mentioned by students in the questionnaire across all three host countries was 'high quality education'. Four subthemes emerged from the analysis of this theme which, according to students, contributed to a high quality education and would, in turn, increase their overall human capital: education quality, education ranking and international standing, quality of teaching and faculty, and quality of research.

1) Education quality: Students commented on the quality of host country education as important, saying: "The quality of education is very good" (UK\#467) and "good higher education system" (U.S.\#85). UK\#7 mentioned education quality three times in the questionnaire indicating it was of significance to him. Asked the reasons important in deciding to study abroad, he said, "Better quality of education", and his number one reason for choosing the UK was "quality of education." UK\#133, who when asked what was important in choosing a host country, also said, "quality of education" adding in the interview, "I choose UK as my study country because it has a very advanced education..."

Three students studying in the U.S. made between four to five comments each regarding this sub-theme indicating it was of high importance. U.S.\#4, for example, when asked if he had considered studying at home, said, "No, Graduate studies is not great in India" and regarding reasons important in deciding to study abroad, he answered, "graduate studies are good." When asked his three main reasons for choosing the U.S., he stated the "quality of education" as the number one reason. In fact, this sub-theme was the number one reason for all three students for choosing the U.S. with U.S.\#67 saying "quality of education" and U.S.\#163 "Good education." 
Students' comments about this sub-theme included direct comparisons between host and home country education quality, such as "The education system is better than the one on my home country" (UK\#53) and "American PhD programme is better than that in China" (U.S.\#44). IR\#25 did not consider pursuing a Master's at home because:

"I decided to study abroad to get my higher education because in China it's okay for education but I thought maybe Western Europe... or American, maybe have a higher level of the education skills so I choose to go abroad to study..."

U.S.\#149 indicated in the questionnaire that she did consider studying at home explaining, "There is also excellent education in China", adding in the interview why she chose to study abroad instead:

"...maybe studying here is real tougher than in China so you can learn lots of things from your study...the education skills are also very good things much good than China and even now lots of Chinese university students, they still want to study in USA."

Other students commented about the opportunity for learning a lot or learning something useful in the host country, which I interpreted as related to respondents' views about the quality of education in the host country, and therefore included such comments in this sub-theme. When asked in the questionnaire if she considered studying at home, UK\#101 said, "No, I think learning in England is more useful", explaining in the interview:

"...by learning in UK I can get not only just the knowledge of my field, I can learn a lot of things...my background is Engineer but during the coursework maybe I work with some architecture, architects, so I can learn a lot more things about architecture."

2) Education ranking and international standing: Students commented on the importance of the ranking and international standing of the universities in the host countries. Some comments from the questionnaire specifically referring to ranking included, "higher ranked 
university" (UK\#7) and "rated highly in the market" (UK\#367). For some students, such as UK\#404, when deciding where to study the ranking of the university was of some importance as he mentioned it at least twice in the questionnaire. He said "ranking of the university" was a reason important in selecting a host country as well as the most important reason he chose the UK.

During the interviews, the topic of ranking arose when students were asked what kind of information they gathered to help them make a decision about where to study. UK\#133, for example, said: "Something about the university such as the university rank..." U.S.\#165 explained, "I used to just look about the rankings of the PhD institutions that I am applying", while IR\#19 noted "...I had grabbed on different kinds of rankings...what are the top business schools of those different countries..."

Other comments included "world class education" (UK\#150), and "Standard of University in International level" (IR\#12). For UK\#375, two of his top three reasons for choosing the UK were the "global presence" of his host country and the ranking of his university as a "top class university..." When deciding where to study, he checked the rankings of various institutions with a number of sources such as the British Council and the Times Higher Education Supplement:

"...these rankings are the first things which I was looking for when I was trying to select a university...[University UK] was in the top ten in the UK for manufacturing. So I said that I definitely have to go to [University UK] and that's why I selected this university... as soon as I saw these rankings, I was like making up my mind that yes I have to go to UK."

Students spoke about what they believed was a correlation between the rankings of universities and future job opportunities. U.S.\#162, for example, commented on this during the interview:

"...the big three consulting firms...they only hire most from top graduate school in U.S. or UK, predominantly in U.S. So if I don't have this kind of degree, even 
though I have successful career in Deloitte before, it will be very difficult for me to make this transition. I'm only applying for the top fifteen $b$ [usiness] schools in U.S. so if I didn't make it then I'm not going to make this investment."

3) Quality of faculty and teaching: Students mentioned the importance of the quality of the academic faculty with whom they hoped to study. IR\#11 said her number two reason for studying in Ireland was "Good supervisor", while IR\#12 gave "Professor" as his number two reason and "Quality of Professor (Project Investigator)" as a reason important in deciding to study abroad. U.S.\#2 referred to quality of faculty twice indicating it was of some importance to her in deciding to study abroad ("faculty") and was her third most important reason for choosing the U.S. ("excellent faculty"). For UK\#278, this was an important reason for choosing the UK saying in the interview, "I got offer letters and scholarship from many places but I preferred the [University UK] in comparison to other universities because I was having the best professors..."

Students also referred to the importance of high quality teaching in the questionnaire. UK\#367 had a friend already studying in the UK who "assured [him] the teaching quality... is good enough in UK" and this was an important reason in deciding on the UK. In the questionnaire, UK\#101 mentioned the quality of teaching twice, once as important in deciding to study abroad ("quality of teaching"), and also as her second most important reason for choosing the UK ("high quality teaching"). For UK\#2, a reason important in choosing a host country was "lecture qualification", the meaning of which he explained in his interview:

"Lecture qualification means that you can get more information...more knowledge from the lecture...before I came I think that MSc degree took here only one year and most of the courses I took only half year, but in China some course will take you one or two years. So I think maybe here is much more better 'cause...all the stuff lecturers tells you is the essential things."

4) Quality of research: Students made references to the importance of quality of research when deciding whether to study abroad and where. U.S.\#111, for example, said "quality 
of research" was an important reason for him when deciding where to study. For IR\#8, quality of research was an important reason for choosing to study abroad, and when asked if he considered studying at home, he replied "No, no international standards in lab." U.S.\#165 said the U.S. was his first choice because of "the strength of the research."

For UK\#278, the quality of research was of significant importance as he mentioned it three times in the questionnaire. As for reasons important in deciding to study abroad, he said "The quality of research conducted in the university overseas", while a reason important in deciding on a host country and his number one reason for choosing the UK was "Best research." During the interview he said:

"I did a lot of research about RAE - Research Assessment Exercise...I just wanted to follow science and wanted to be in the best lab, so the top most four labs... one is in UK...after you finish your PhD so it matters from which lab..."

He summarised his choice of the UK by referring to all four sub-themes under 'high quality education", "UK has got the best education system, the accreditation and university ranking system, the individual ranking of schools; the best scientists and professors; quality research."

For every open-ended question asked on the questionnaire, such as 'What reasons were important to you in deciding to study overseas in general?' this theme was mentioned at least once by students in all three host countries. In addition, when asked the three main reasons, in order of importance, why they chose to study in their particular host country, this was given as first, second, and third main reasons by students from all three host countries.

Cost-effective education

This theme was the second most popular in terms of comments from students overall and consisted of three sub-themes: short duration of study, cost of tuition fees, and funding opportunities. 
1) Short duration of study: Master's programmes in the UK and Ireland are generally one year in length and a PhD generally takes a minimum of three years to complete, while Master's programmes in the U.S. are generally two years in length and a PhD can take four or more years to complete.

This sub-theme can be assumed to have been a more important form of potential $\mathrm{HC}$ for students studying in the UK and Ireland where the post-graduate programmes are normally shorter than in the U.S. Only students studying in the UK listed this sub-theme amongst the top three reasons why they chose to study in the UK, indicating it was of greatest importance to those students. It was the number one reason for UK\#2 who said "Course duration", UK\#45 who said "Short time for obtaining a PhD degree", and UK\#417 who stated "year to complete the degree."

UK\#501 and UK\#62 both gave their third most important reasons for choosing the UK, respectively, as "shorter programme length" and "duration of study being shorter." Saving time on her studies was of some concern for UK\#306 who mentioned it twice in the questionnaire as one of her main reasons for deciding to study abroad. The second of her top three reasons for choosing the UK was to "save time." UK\#502 believed the short duration of his course would save him both time and money:

"...the one advantage in UK course is they are quite short, one years, and that can save me lots of time and money...More importantly is less time as you can see more and more graduates from overseas every year in China so it's better to get home earlier to get a job..."

The duration of study was important for both Master's and PhD students. Among the comments made by Master's students included "UK master is of shorter length" as one of the three main reasons why UK\#501 chose the UK. This sub-theme was of high importance to UK\#135 who referred to it four times in the questionnaire, although he listed it as only the third of his top three reasons for choosing the UK saying, " 1 year course study only." It was also important to him as a reason for deciding to study abroad and selecting a host country, to both of which he answered, "one year Masters 
programme." PhD students, such as UK\#45, said the reason the UK was a good choice for her was "...it needs much shorter time, only three years" and gave her number one reason for choosing it as "Short time for obtaining a PhD degree." Students also made direct comparisons between the duration of programmes in their home and host countries. UK\#2 did not consider studying at home because "Study here requires less time than in my home country", adding in the interview, "...less time means you can graduate earlier and earn some money earlier."

The two sub-themes discussed next are 'cost of tuition fees' and 'funding opportunities.' The original intention was to accept only self-funded students for participation in the research believing they would have greater freedom to choose any host country. However, this would have yielded a smaller sample, and so the decision was made to include students who were partially self-funded or fully-funded and who said they were able to make their own decision about where to study. The final sample was a mixture of funding statuses: well over half (forty-two out of seventy-four) were self-funded, while twenty were fully-funded, and the remaining twelve were partially funded. Of the interviewees, only slightly over half (eight out of seventeen) were completely self-funded, while four out of seventeen were partially funded, with the remaining five fully funded. Given this funding mix, it made sense that the cost of tuition fees and funding opportunities ranked high in importance to students looking to obtain a higher RoR on their investment in international education. I did not ask for details about each student's funding circumstances on the questionnaire, but I did gather information about this from the interviewees for the purpose of triangulation.

2) Cost of tuition fees: In the questionnaire, students referred to this sub-theme as an important reason for deciding to study abroad and deciding on a host country. The students quoted below were either fully self-funded or partially self-funded. This is not meant to imply that fully funded students were not concerned about the cost of tuition fees, but maybe less so than the others.

General comments about the cost of tuition fees included UK\#152 who, when asked what reasons were important in deciding to study abroad, answered "tuition fee." IR\#15 for 
whom the second of her top three reasons for choosing Ireland was it was "cheaper to study than in other country" was a completely self-funded student. Unfortunately, there was no opportunity to follow-up with these students to clarify because they did not volunteer to be interviewed. IR\#25 wanted to study in Europe but had to keep in mind the cost of tuition fees when making his choice of host country, "In Europe there's only two countries that speak English I think, is UK and Ireland. But for UK it's a little bit expensive at that time...But Ireland is cheaper..."

One student, IR\#20, shared his frustration about the discrepancy between international and domestic student tuition fees. As all three host countries have different fee structures for international and domestic students, with fees for international students generally higher, this makes the RoR to investment in international education potentially lower for international students who pay more for the same education. IR\#20 stated:

"So sometimes [I] feel very angry about this situation and the student fee price. I understand the EU student or the Irish student should pay less than that because they live there, their parents live there, they pay a lot of money for the government but it's too long distance for us and EU students. It's four times... I like this country very much. Except the fee."

3) Funding opportunities: Students commented on the importance of funding opportunities for achieving a cost-effective education. As might be expected, students who referred to the importance of funding opportunities were mainly either fully funded or partially selffunded. As for the fully funded students, and possibly the partially self-funded students, having at least some funding assistance from their universities may have meant the difference in being able to study abroad or not.

IR\#8, referred to this sub-theme as his second most important reason for choosing Ireland, saying "fellowship." For IR\#12 and IR\#11, it was the third most important reason for both for choosing Ireland and important in deciding to study abroad. IR\#11 replied, "sufficient scholarship" to both of these questions. IR\#12 mentioned this sub-theme three times indicating it was of significant importance. He responded "funding" to questions 
about reasons for deciding to study overseas and deciding on a country of study, and as his third most important reason for choosing Ireland. U.S.\#2 said he chose the U.S. because of "availability of funds and scholarships" while U.S.\#111 said "funding."

It was the number two reason for U.S.\#28 ("Scholarships for higher study") and UK\#67 ("funding") for choosing their host countries. U.S.\#28, when asked the reasons important in deciding on a host country also responded, "Ease of getting scholarships." When asked the reasons for deciding on a host country, UK\#45 said "plenty of fundings", and U.S.\#7 "well funded." U.S.\#165 said one of the three main reasons he chose the U.S. was the availability of "funding", adding in the interview "...for the first year we get a fellowship."

U.S.\#149 was originally discouraged by her family from pursuing international study because they did not have the financial resources to support her. It was important for her when deciding where to study that the university "...offered the assistantship." At University U.S., she was given funding but was required to work as a teaching assistant while doing her Master's degree. One of the top three reasons for U.S.\#158 to choose the U.S. was the offer of financial assistance from his host university, "... it's not kind of scholarship but research assistant. So I come to work in a lab and the professor will pay the tuition and some living stipend for me." UK\#278 was able to get full funding from his host university because of his previous academic achievement. He said one of the things that attracted him to the UK was:

"...UK gives you opportunity, if you are talented enough, they will give you scholarship...over here you get funding, you get scholarships...I've got a [University UK] scholarship. I've got basically three parts: the first is ORS award that pays for tuition fees, second is [University UK] scholarship every year that I get, third is from my division that my supervisor managed to get for my subsistence."

Similarly UK\#62 chose the UK because she was offered full funding from University UK. She stated: "I'm funded by the university. I got an international tuition fee scholarship so that takes care of my tuition fees and the studentship from the grant of my supervisor 
takes care of my monthly stipend." Interestingly, most comments made by students in the UK that related to the two sub-themes 'cost of tuition' and 'funding opportunities' were in response to the question about reasons important in deciding on a country of study, rather than as a reason important in deciding to study overseas.

Students studying in Ireland did not mention this theme at all as a number one reason for choosing Ireland, but two of them did refer to it as a second most important reason, saying "fellowship" (IR\#8) and "cheaper to study than in other country" (IR\#15), and for another two, IR\#12 as noted above, and IR\#11, it was the third most important reason for choosing Ireland and second reason important in deciding to study overseas. IR\#11 replied, "sufficient scholarship" to both of these questions. Of these students, IR\#15 was the only one who was completely self-funded while the other three were fully funded.

Five students studying in the U.S., mentioned the availability of funding opportunities as the number one reason for choosing the U.S. U.S.\#2, for example, said he chose the U.S. because of "availability of funds and scholarships" while U.S.\#111 said "funding." More U.S. students in total commented and commented more often about the availability of funding opportunities as did students studying in the UK or Ireland. In addition, the theme was listed under all three reasons in terms of the three top reasons students chose to study in the U.S.

For some students, a combination of the three sub-themes influenced their decisionmaking. UK\#496, for example, a self-funded student, referred twice to duration of the programme, saying "less time to complete a master degree" was an important reason in deciding to study abroad, and his number two reason for choosing the UK was "time." He also referred twice to the cost of undertaking international education saying an important reason for deciding on a host country and his number one reason for choosing the UK was "money." UK\#304 also mentioned two of the sub-themes. Asked why the UK was not his first choice, he said "the high amount of the tuition fee" and "less chance of fundings." This makes sense since he was a partially-funded student looking for as much funding as possible to lower additional costs to himself. 
The third most popular theme under potential human capital was 'Better career opportunities' from which five sub-themes developed: international degrees and job opportunities, work experience in the host country after graduation, working at home after graduation, working during study, and higher salary.

1) International degrees and job opportunities: Students commented in the questionnaire about the advantage of an international degree in finding a job, such as "because I could get better job after I finished my education here" (IR\#15), "job prospectus in future" (IR\#8), and "excellent job prospects upon graduation" (U.S.\#2). U.S.\#164 felt international study was important to his future career because he "wanted to pursue opportunities in the US and it is difficult to do that with masters from India."

Other students, like UK\#2, felt an international degree would help them to find work with international companies, and when asked if he thought his experience in the UK would be useful for finding a job, he said, "Yes, quite a lot useful 'cause the job I'm going to looking for is those companies who got connection or communication with the overseas companies." During the interview, he compared the transferability of international degrees, particularly from the UK, to degrees received at home, "I prefer UK PhD's study better 'cause.... when you got a PhD degree here it means you can work all around the world...but with a Chinese degree that's impossible to work outside."

Students talked about the value of an international degree as 'signalling' to employers they possessed valuable human capital attractive in the labour market, thus helping them to obtain job interviews. For example, when asked if he thought an international degree would guarantee a good job and a good salary, IR\#25 replied:

"No, I don't think so...the degree's just like when you knock the door, that's your degree. You can knock the door and use your degree. But when the door is open you have to really have something for the skills and what you know about the market. Something like that." 
Similarly, IR\#26 believed employers in China were more eager to hire someone with an international degree because of what it signals to employers, "They think you got better technology, know about English, and they feel you are better at something." He did not believe, however, that just the international degree itself would necessarily guarantee a good job and a good salary because, "I think the personal ability is more important...I think degree is only a paper like make you have a chance to get a very good interview but where you really get this job depends on your personal abilities..."

Some students felt an international degree was required in order to be competitive in the job market at home, and was important for increasing their chances for future promotion potential. UK\#502 indicated in the questionnaire that he did not consider pursuing a Master's in Bioengineering at home because, "Employment requires overseas study." IR\#19 said "...I can be more competitive in the IT market" while UK\#278 stated "...It gives you an edge whether he has been into the international community so it matters." When asked whether he could get a good job at home if he did not have an international degree, UK\#133 replied, "I think I can but the job of course is not so good as when I get an overseas degree." He added in the interview:

"In China, some people after they graduate and want to improvement for their career, so the three choices: one is to work, to go out to find a job to work; and the other is to just to take the exam - China's exam to take the postgraduate in China - and the other is go abroad for further study..."

UK\#367 stated for him "...the first priority was the job", believing an international degree would "definitely" guarantee a good job and good salary in future. In the interview he explained:

"When you go for jobs even in India...I will be let in at a much higher level than the ones who have experience in India...if I go back to India abroad degree always helps be it the [University UK] or be it...some smaller rated university but since the whole thing is that he studied in an abroad institution, he's seen the outside world as such." 
U.S.\#162 did not consider studying at home because "...if you are talking about long-term career development for Master's degree in Business, overseas degree is highly regarded in Taiwan as opposed to domestic degree...", and was, he felt, one thing necessary for improving his promotion potential:

"...you'll be easier to move into a higher position, a faster track...I always think about moving to a higher, more strategic consulting career...So if I don't have this kind of degree...it will be very difficult for me to make this transition."

He also believed an international degree would help him to access opportunities with the top companies in his field, "...I'm not going to interview with those firms that I always looking for, the top fortune 100 companies in the world had I didn't come here."

2) Work experience in the host country after graduation: Some students talked about the opportunity to obtain work experience in the host country after graduation saying: "...I think experience here is valuable so I want to spend at least three years but no more than five..." (U.S.\#162), and "Gain some working experience in the UK...to broaden my working horizon before coming back home" (UK\#131). Upon completion of his PhD, IR\#20 said he would "...prefer to working in overseas environment. I have studied for a long time. It's easier for me to get the money back fast working overseas." UK\#446 stated "working for a while in the UK to understand how the theories which we learn in uni are applied in practice and also earn some money as a byproduct." In the questionnaire, UK\#367 commented twice on this sub-theme, saying, "Job Placement Opportunity to get workexperience in the first world country" was a reason for studying abroad, and adding that after graduation he planned to" get two-three years' work-ex in uk....coz that is rated very highly back in india..." UK\#375 referred to his desire to work in his host country before returning home:

"Yes, till the time I am allowed over here I will definitely work so that I get as much experience as I can which will be definitely useful because when you come out of the university or your college you are just a new guy." 
He summed up international education and work experience abroad as human capital investment saying:, "...if you have a degree, if you know about something more then it is really easy for a person to go and relocate himself in a different place because he knows at least what he is doing", adding later in the interview "...you have a lot of options when it comes to working. Especially in today's world you can't survive in one place so you need to have experience in various fields if not then various places."

Each of the three host countries have a graduate work scheme offering international students a chance to work for a specified period of time after graduation. Students indicated they had knowledge of these schemes prior to making a decision about where to study. U.S.\#2, for example, referred specifically to the work scheme in the U.S. called Optional Practical Training (OPT), saying that after graduation, she would "complete OPT and then go back." Two students from University UK referred specifically to the two-year permission to work in the UK upon graduation. UK\#446 stated in the questionnaire "UK allows us to stay and work for two more years...", while UK\#135 stated "two year work permit by the new scheme after completion of course" was a reason important to her in deciding to study overseas and in deciding on a host country, as well as being her number two reason for choosing the UK.

3) Working at home after graduation: Students also commented on the benefits of an international degree and experience for working at home, such as U.S.\#113 who said, "have to experience the US to get a good job in India" and UK\#7 who believed having an international degree would allow him to, "Return home and join a firm at a higher level with increased salary." When asked if an international degree would help him find a job at home, UK\#375 said, "If I go back to my country after I finish this course I will have a lot of options."

U.S.\#149 was working on a Master's degree and doing a teaching assistantship to fund her study. She was intending to continue to the PhD level, and upon completion of her $\mathrm{PhD}$ wants to return to China to work at a university. When asked if the international degree would guarantee a good job at home, she replied, "Yeah, maybe lots of universities in China now when they enroll some faculties they think it is necessary for you to have 
overseas education experience...for some famous university in China if you don't have overseas education they won't hire you."

4) Working during study: Some students mentioned they had to work part-time to subsidise their time abroad. IR\#19, who was completely self-funded, said prior to beginning his course, he had planned to work part-time to help sustain himself with "...some kind of part-time job. Anything like a sales guy, or a shop guy, or a shopkeeper. There are any number of jobs." UK\#367, also completely self-funded, stated he knew he would need to work, "...a part time job here...to make money for my monthly expenditures..."

Students studying in the U.S. who had to do research or teaching assistantships in return for full-funding from their host universities also knew they would have to work during their studies. They were obviously attracted by the offer of full funding and also seemed to understand the benefits of working during their studies, but none stated they would have worked part-time without this offer, and only one, U.S.\#149, chose the U.S. specifically in order to get work experience during her studies. She was funded by her university through a teaching assistantship so had to work during her course as a teaching assistant, "... I need to holding office hour and grading like that...In the courses for undergraduates in my department." She stated that getting international teaching experience was necessary to become a faculty member in a university at home, "Yeah, Peking, Tsinghua...even fresh graduate students they won't consider now. You need to have even teaching experience in USA." Again, although most students who mentioned working during study did not specifically state this opportunity was what attracted them to study abroad or their host country, at least one understood the human capital benefits. U.S.\#158 explained doing a research assistantship would be beneficial because, "...after I finish my degree I can go everywhere or work for anybody."

5) High salary: Students commented on their hopes of increasing future earning potential as a result of international study, with comments including, "high salary" as a number two reason for U.S.\#44 to choose the U.S., and "Variety and number of opportunities with 
high earning potential" as the number one reason U.S.\#164 chose the U.S. IR\#8 ruled out studying at home because he felt a degree from there would result in "less salary."

UK\#367 referred to salary three times in the questionnaire. His comments included, "Well the main reason for me coming here was to get abroad work-experience ....and get a well paid job", and "any country... which would give me a good pay job after my degree would be fine with me", with his number one reason for choosing the UK to get a "good pay job." During the interview, he summed up his motivation for studying abroad as, "There are some students for whom the academic matters and they want to get actual knowledge but there are some other people, like me, for whom the final end product, the money, matters." Based on the experience of his classmates, U.S.\#158, expected the investment in education in the U.S. to pay off in terms of a higher salary in future:

"...I haven't looked for a job at that time when I was a graduate in China but based on the experience of my classmates I think maybe if I got an education in the U.S. I get a higher by them [employers] paid job."

UK\#135 and UK\#367 both mentioned the theme 'Better Career Opportunities' four times in the questionnaire. For UK\#135, this theme was an important reason for her in deciding to study abroad and on a host country. Her number two reason for choosing the UK was the "two year work permit by the new scheme after completion of course." She even mentioned it when asked about her plans after graduation. For UK\#367, besides the quotes given above, he said home, not the UK, was his first choice for study because "the big reputed institutes in India also help in getting good placements with fat paychecks...after the degree." This indicated a belief that opportunities for work experience might be more easily gained by studying at home. Although he only decided to study abroad because he did not clear the exams for the top five Indian institutions, he did feel the UK was a good choice, primarily due to the opportunity to increase his human capital through work experience there. Again, the high level of importance of the theme to these two students was evident in their ranking of this theme as a number one (UK\#367) and a number two main reason (UK\#135) for choosing the UK. 
The theme was also of importance to IR\#19, who mentioned it three times. When asked for the reasons important in deciding to study abroad, he replied "international career." His reasons important in deciding on a host country included "The opportunities after the study in the country" while his number two reason for choosing Ireland was "More opportunities" which I interpreted as referring to employment opportunities. Finally, the theme was of high importance to U.S.\#164, who commented on it four times. For U.S.\#164, to "pursue opportunities in developed world" was among the reasons for not studying at home, and for deciding to study abroad and on a host country. The opportunity for increasing his earning potential was also his number one reason for choosing the U.S.

Access to better resources for study

Access to better resources for study was the fourth most popular theme commented on by students under potential human capital. Studying in a host country with rich educational resources offers access to the latest technology, equipment, and knowledge in the student's field of study. The sub-themes which emerged were: resources, facilities/equipment, technology, funding, expertise, and knowledge.

1) Resources: Students made general comments about the importance of the quality of resources available in their host countries, such as U.S.\#7, who said "Access to great research resources" was a reason important in choosing a host country. U.S.\#28 stated, "Better opportunities in a place with more resources for study" was an important reason for deciding to study abroad. UK\#101 indicated in the questionnaire that "rich resources" were her number one reason for choosing the UK. She explained in the interview that these resources included "Library resources. It's very important I think...I also can borrow a lot of books from other libraries...[and] I also can use the username to download some essays, dissertations from website." UK\#375 commented on the importance of the student support resources, "It's good that the university has all the facilities that if you have any problem, go here, do that, all of this..." 
2) Facilities/Equipment: Students also mentioned the importance of the advanced facilities and equipment available abroad. Some of the more general comments on this sub-theme included U.S.\#111 who replied "research facility" and UK\#275 who said "university facilities" when asked the reasons important to them in deciding to study abroad. Other comments highlighted the importance to students of host countries having strong, "well build education facilities" (UK\#275), and "good equipment" (UK\#246).

In the interviews, students made comparisons between the level of facilities and equipment in their home and host countries. UK\#101, who was working on a Master's degree in Sustainable Building Technology, did not consider studying at home because "...[in the UK] I have a lot of equipment to do my research. But in China because most of the university have not enough money, they don't have their own laboratory." UK\#2 stated similarly, "...as far as I see it the experiments' equipment here are quite better, are quite advanced than back in China."

For U.S.\#165, one of the reasons for deciding on a host country was "education infrastructure." Similarly, one of the reasons for choosing the U.S. was, "The environment and infrastructure required for this kind of research is available in US only." When asked about this statement in the interview, he said, "...it is not possible at this particular stage in India. Because the kind of infrastructure that we need for the study is not available." In an effort to increase her human capital, UK\#62 decided to study abroad because "though the biotechnology market is vast in India the infrastructure to study the subject is limited!" She stated the infrastructure in the UK is "Much more advanced." Finally, for UK\#278, among the reasons important to him in choosing a host country was "Best Lab (All Facility and instrumentation, access)...access to all the facility Lab, glass house, internet, library, research journal." Although beginning his PhD at home, he applied to continue his studies abroad because "...over here research is quite fast. You got latest instruments and everything..."

3) Technology: Students referred to the importance of the advanced and up-to-date technology available abroad. When asked the reasons important in deciding to study abroad, students commented: "Learning the most advanced technology"(U.S.\#44), and 
"Better exposure abroad [to advanced technologies]" (UK\#414). When asked reasons important in deciding on a particular host country, students replied: "advancement of science/technology in my field of study" (U.S.\#72), and "technical exposure" (UK\#414). For U.S.\#104, "technology level" was the number one reason he chose the U.S., while IR\#26 believed employers at home were more eager to hire someone with an international degree because, "They think you got better [knowledge of the latest] technology..." U.S.\#149 stated, "... even the [global] economics not so good but the technologies and the education skills are also are very good things, much good than China..." For UK\#133, undertaking study in the UK where he could experience "a lot of the advanced called technology" would enable him to bring something useful back home, "...my country need development so I think we need to learn the advanced technology..."

4) Funding: Students mentioned the importance of the greater funding levels available abroad for research in their field. U.S.\#113 said the "funding level of science" was an important reason for studying abroad, and for reasons important in deciding on a host country. U.S.\#59 stated a reason important in deciding on the U.S. was "funding for research is quite excellent in the US." U.S.\#7 said "Well-funded research" was his third most important reason for choosing the U.S., and he decided to study abroad because his "specific research area is poorly funded in India."

Although U.S.\#165 did consider studying at home, it was the access to better resources, including higher funding levels, that attracted him to the U.S.:

"The basic hurdle or bottleneck is availability of research grants. Indian mindset is not the one that promotes research. Here the government is actually funding. It's pumping literally billions of dollars in research. It's not the same case in India but it's changing...[In India, funding for research is] very less private. Private is I think zero, and all the funding that comes is from the government. So the projects are very lesser number and if you want to do a project of this scale where you need the money first to build the infrastructure and then to hire some specific experts to work on that particular infrastructure you need to have a lot of money." 
5) Expertise: The expertise available abroad was of importance to students, such as UK\#404, who said "expertise" was important in deciding on a host country, and for UK\#414 "technical expertise" was important in choosing the UK. U.S.\#2 felt the U.S. was "...the best where legal education is concerned...", while U.S.\#158 said he decided to study Biomedical Engineering abroad because, in his opinion, his home country did not have the required expertise, "For medical device industry...Especially for higher parts, the MRI and $\mathrm{CT}$, these kind of things also China don't have a lot of expert...Almost foreign companies occupy this like this part. China don't have its own research or companies."

When asked about reasons important in choosing a host country, UK\#278 stated, "...it's about subject matter specialists..." Of the countries he considered for study, the UK was his first choice for two reasons, "Best scientists" and "For me UK is the best place to do the research, as the world's top scientist [are working there]." He elaborated in the interview:

"...it's about the scientists whom I wanted to work with...one of the professors who is here so that's why I chose this university...I just really wanted to step up as far and as quickly as possible so I wanted to be in cutting edge science and to be with the leaders."

6) Knowledge: Students also commented on the more advanced knowledge available abroad. For U.S.\#5, "Great exposure..." and "More exposure..." to the latest issues in his field were important in deciding to study abroad and on a host country. UK\#414 stated, "Better exposure to subject area" and "Knowledge base" were important in deciding to study abroad and on a host country. UK\#2 said "I think that is the most valuable thing of my PhD degree...the knowledge I got", and when asked whether his experiences in Ireland would be useful in the future, IR\#26 replied, "Yes, obviously the knowledge from university. They are very useful."

When asked the reasons important to him in deciding to study abroad, UK\#375 said, "manufacturing engineering has become more of a global study rather than a local one, so 
if we have to be the best in this industry it is necessary to get as much knowledge as possible." When asked why she selected the U.S., U.S.\#149 replied:

"...because for my major, the U.S. has the definite advantage than other countries...'cause in Engineering area I think there are lots of things we learn in China that are just translated from U.S. So if you can just directly learn this advantage techniques...lots of the big things in my area happen in USA..."

One of the three main reasons for choosing the U.S. for U.S.\#165 was "Global Recognition of Knowledge." In the interview, he said he had to go abroad to get such knowledge as it was not available at home, "IIT is the pinnacle where you can reach in terms of Engineering education in India, and from IIT it's the trend that people come to U.S. It's the environment and the knowledge that you have here." In the interview, he explained:

"...so I thought that I need to have this knowledge if I want to contribute anything new to the engineering or scientific company...I thought that in India I could do but to not a level that could help me in my aim...U.S. has at least that talent that can actually initiate the thinking process which is actually needed for a seminal research, very new research for something that can be called an invention."

Finally, for UK\#502, one of the reasons important to him in choosing a host country was "the background of the scientific field" and his number one reason for choosing the UK was "there was a good background in your subject." He stated in the interview:

"But the first cloned sheep, she is born in UK...[this is] one main reason for me to apply to UK's universities is because the first cloned sheep Dolly...She is born in Scotland so I think that just make the UK advantage in this field...very impressed me."

UK\#278 and UK\#414 mentioned this theme, 'Access to better resources', five times in the questionnaire, indicating it was of very high importance to these two students. For UK\#278, this theme was reason number two ("Best scientists") and number three ("Best 
lab") for choosing the UK, while for UK\#414, it was reason number one ("exposure of advanced knowledge") and number two ("technical expertise"). U.S.\#7 and U.S.\#165 mentioned the theme four times in the questionnaire. Several comments from U.S.\#165 were given above. In response to reasons important in deciding to study abroad, U.S.\#7 said, "there are no specialists [in India] in the field of exercise physiology." Both students listed the theme among the top three reasons they chose the U.S. with U.S.\#165 giving it as reason number two ("Global Recognition of Knowledge"), and U.S.\#7 as reasons number one ("Access to new technology") and three ("Well-funded research").

In the questionnaire, only one student in Ireland commented on this theme; IR\#8 said, "Science made me travel" - a statement which could pertain to all or any of the subthemes above. He was not an interviewee so I could not clarify this statement further with him, but based on an earlier comment in the questionnaire that he did not consider study in his home country because there were no international standards in the lab suggests he was looking for a host country with advanced resources to study science.

\section{High standard of living}

Students from across the three host countries commented on the importance of a high standard of living available in their host country from which emerged four sub-themes: standard of living, climate, safety, and equal opportunity.

1) Standard of living: Students comments included general remarks like, "life-style" (UK\#396), "quality of life" (U.S.\#113), "life environment" (U.S.\#27), and "Ireland is beautiful" (IR\#6). Other students provided more detailed comments, such as "a good country must be let me feel like at home i can study smoothly" (UK\#369), "Good country lot to see and learn - lifestyle" (UK\#446), and "If with the same knowledge, ability and information, I can get high quality lifestyle, then why not Ireland?" (IR\#8). After studying in Ireland as an exchange student, IR\#20 decided to continue there for Master's level study because he liked, "... the culture in local environment...I think the Irish people is kindness...And also the Irish person is welcomed to foreign overseas students. That's might be a reason for me to still living here." 
U.S.\#111 said the "quality of life of a non-citizen" was his third most important reason for choosing the U.S. In the questionnaire, one of the reasons important to UK\#367 in deciding to study abroad was the "attraction to a clean, rich [country]..." In the interview, he said, "...for a certain years...you get a better lifestyle...", adding "...the kind of lifestyle you have that is much better because in Bombay it's become too crowded...it's so populated and there is no work ethics...It's like morning you go at nine and you are there 12 o'clock in the night..." He also explained he relied on advice from a friend about the standard of living in the UK, "...as my friend had studied MA Marketing (same as me) at [University UK] and he assured me the...general life is good enough in UK."

2) Climate: For UK\#140 and IR\#12 climate was an important reason in deciding on a host country, with UK\#140 saying "the weather - not very cold" and IR\#12 simply responding "Climate." For UK\#166 "weather" was her second most important reason for choosing the UK. For IR\#19 the weather was a positive element of studying in Ireland because of its similarity to the climate at home, "...but actually for me it's like Bangalore...it has some kind of allure... most of the times it's raining in Bangalore. So I feel that I'm in Bangalore here." IR\#26 stated: "...the most attractive things for me is the weather there" and UK\#502 said, "Weather is important."

3) Safety: Students commented on the importance of the safety of their host country. UK\#131 and UK\#150 stated, respectively, that among their top three reasons for choosing the UK were "Its safety of the country" and "[University UK's] city: peace city." UK\#278 said the "Safety" and the "Peaceful study and living environment for all the international student" were among the reasons important in deciding on a host country and why the UK was his first choice. IR\#25 chose Ireland because "...it's safe here...more secure."

4) Equal Opportunity: For two students, UK\#278 and UK\#467, equal opportunity was a sub-theme associated with the quality of life in their host country, and both referred to it twice in the questionnaire. When asked reasons important to them in choosing a host country, UK\#278 replied "No racism, NO BIAS, Equal Opportunity", and UK\#467 said "amount of racism." Both had this sub-theme as their third most important reason for 
choosing the UK saying, respectively, "promoting talent without any bias, equal opportunity" and "less racism." UK\#278 elaborated in the interview stating he chose the UK because, " ...UK gives you opportunity if you are talented enough they... helps to build your career...UK is really liberal and respects talent...." IR\#6 was more specific about racism towards students of her nationality. She indicated in the questionnaire one of the reasons important to her in choosing a host country was "country environment", explaining in the interview she was referring to the country's acceptance of foreigners, "Like some country it's hard for Chinese to study in. Maybe they don't like Chinese, I don't know." Finally, U.S.\#111 said the "quality of life of a non-citizen" was his third most important reason for choosing the U.S.

For seven UK students, this theme was of importance as they listed it among their top three reasons for choosing the UK. For four UK students at least one of the above subthemes was listed as a number two, and for three UK students at least one of the above sub-themes was listed as a number three reason. These students are quoted above. Of the students studying in Ireland, only one IR\#6, made a comment, albeit broad, that could be interpreted to fit this theme saying her number three reason for choosing Ireland was "Ireland is beautiful." Of the students studying in the U.S., only U.S.\#111, mentioned it as among the top three reasons for choosing to study there. He said the "quality of life of a non-citizen" was his third most important reason for choosing the U.S. This theme was not a number one reason for students from any of the three host countries.

Access to specific course content or specialised programme

Access to specific course content or specialised programmes was mentioned by students as a driver for contemplating international study. Three sub-themes emerged from this theme: course/programme content and quality, course/programme not offered at home, and freedom/flexibility of course/programme.

1) Course/programme content and quality: Students commented on the importance of the availability of desired courses, course content, and course quality. For example, when asked for reasons important in deciding to study abroad, students replied, "Depends on 
what I want to pursue from the course module" (UK\#131), "course content; modules covered" (UK\#275), and "firstly, a course which is futuristic" (UK\#446). When asked to give the reasons important in deciding on a host country, students said "do they have the course which i want to study at" (IR\#6), and "Choice of course" (IR\#8). Among the top three reasons for choosing their particular host country (it was reason number three for both), UK\#418 said, "got the specific subject available for me" and U.S.\#165 said, "the U.S. has the best graduate programmes in my field." When asked in the questionnaire to give the reasons important to her in deciding on a host country, UK\#62 responded "The course modules and study regime", explaining further in the interview, "The structure of the course. The content...the amount of hours expected for certain topic subjects areas...the curriculum or the course structure from the institutes in India where I would have wanted to study did not appeal to me that much." IR\#11 and IR\#24 mentioned it as their number one ("Interesting project") and number two ("programme") main reasons respectively for choosing Ireland.

2) Course/programme not offered at home: Students said in the questionnaire they went abroad for study because the course they wanted was not offered at home. UK\#446, for example, commented on his interest in "[a course] not taught in my home country", while UK\#45 did not consider studying at home "Because the universities in my home country do not have the major I want to study, or the development of the major is just begin." UK\#140 said she did not consider studying at home because "PG courses here involve more lab work and practical experience as opposed to courses back home which are more theory based in my opinion."

In the interviews, students, such as UK\#502 and IR\#19, gave more detailed comments on whether the course/programme they were currently studying was offered at home. UK\#502 said his course in Bioengineering was not available in China, "...I'm searched some possible hometown's university but I didn't find the similar courses to this one...then I have to go abroad to study." IR\#19 did not consider studying at home because his current course in Strategic Management was not available there, "...in India it is more of MBAs, PGDMs, where you do a specialisation of management consulting." 
3) Freedom/flexibility of programme: Students commented on the importance of the freedom and flexibility of programmes in their host countries. For U.S.\#28, for example, the "freedom and flexibility in pursuing research" was an important reason in deciding to study abroad. U.S.\#4 referred to this sub-theme twice, saying "the rules regarding boundaries between courses/subjects/programmes are very relaxed" and listing as her third most important reason for choosing the U.S. "flexibility of education plan." For UK\#131, "Its adaptability of the course vs. home country" was the third most important reason for choosing the UK.

For students studying in the UK, this theme was the number one reason for UK\#446 and UK\#62, and the number three reason for UK\#131 and UK\#246. Some have been quoted above. Of students studying in the U.S., this theme was not given as a number one or two main reason for choosing the U.S., but U.S.\#4 listed it as her number three reason as well as mentioning it twice in the questionnaire. Her comments can be seen above. Of the students in Ireland, IR\#11 and IR\#24 mentioned it as their number one ("Interesting project") and number two ("programme") main reasons respectively for choosing Ireland.

Exposure to specialisation in the field of study

Students commented on the importance of exposure to specialisation in their field as a reason for studying abroad. For some students it was an important factor in deciding to study abroad as well as on a host country. Comments included "the development situation of the major I am interested in" as important to UK\#45, and "are they 'good at' that domain" for IR\#6. For UK\#257, an important reason in deciding on the UK was "uk laws are the mother of most of indian laws, studying law here gives us an understanding of the jurisprudence of a particular law in India." U.S. \#165 explained that although the same or a similar course was available at home, he "...was focused to come to U.S." because he felt that specialisation in his field had not reached the same level as in his host country and thus studying abroad would be the better option, "...[my field is] not at the level where I can study from [the U.S.]...And I think this field in which I'm working is in infancy so it has not reached India that much, to that level..." 
UK\#62 stated she decided to study in the UK because "Biotechnology has more growth in UK than India" and said her second most important reason for choosing the UK was because it was a "biotech hub." In the interview, she added, "But when I chose a subject like Biotechnology...I did a lot of background study and...came to the conclusion that the education system in UK for my field of study would be an added advantage as compared to any other...." UK\#375 similarly stated in his interview:

"Manufacturing Engineering has become more of a global study rather a local one. So if we have to be the best in this industry its necessary that we get as much knowledge as possible. Since Europe being the Manufacturing Hub of the world and UK being the best for studying I selected it accordingly."

When asked in the questionnaire for reasons for choosing a particular host country, UK\#101 focused on her specialisation, saying in the interview, "...I heard that the renewable energy here in [University UK] is a very good subject so I choose it." Although she considered studying at home, UK\#135 decided to go abroad instead, explaining "I considered it, and found it not to match my goals and aims with regard to specialisation in the field" while UK\#414 similarly chose to study abroad because "Better exposure abroad [to subject area]."

UK\#135 mentioned this theme four times indicating it was of high importance, and included it as his number one reason for choosing the UK saying "Specialisation in the field." UK\#502 also mentioned it as the number one reason for choosing the UK saying "good background of my subject." It was the number two reason for UK\#375 who said "Top class university with regards to Manufacturing", and the number three reason for UK\#140 who stated "course availability - stem cells." U.S.\#5 gave it as his number one reason saying, "Great exposure to chosen field." For IR\#6, she mentioned this theme three times indicating it was of significant importance. It was her number two main reason for choosing Ireland, "Ireland is preponderant in IT domain." She added in the interview that although it was an undergraduate exchange programme that originally brought her to Ireland, she felt it was a good choice for her Master's as well, "I think still stay here 
because I study the Computer Science and I think the Computer Science is really good in Ireland...I think that's the reason why our college chose to send us to Ireland."

Quick and easy admittance to university

Quick and easy admittance to a university was important to students in deciding where to study abroad. Three sub-themes emerged from students comments on this theme: application process, chance of admission, and availability of information.

1) Application process: In the questionnaire, students referred to the importance of the ease of the application process saying, "easy to apply" (UK\#496), and "The educational system in UK is similar to Hong Kong so no need to have any further conversion course to be taken" (UK\#131). When considering where to do her Master's degree, IR\#6 said:

"And after I finish my Bachelor's degree I consider to go to other countries...but we have to take another examination for language if I go, so I just think maybe it will be easier to do my Master position [here]..."

UK\#2 did not apply for Master's level study at home because "...we need to take a test before you can be able to have a degree. And that test you need to prepare for at least a year..." UK\#417 selected the UK because, "The reason to choose UK was that it was more easier to get admission into UK universities...UK only requires IELTS and basics degree qualifications." UK\#278 commented that the UK was an attractive host country because "...the application process is a lot easier because you can apply online or just paper-based application...and they don't charge you a fee....and it just asked for TOEFL so I only had to give one exam..."

2) Chance of admission: Students mentioned the high likelihood of getting accepted into the universities to which they applied as important. Reasons important in deciding to study abroad included, "Also since I have seen many people getting accepted in good schools here, I had a certain degree of confidence that I will accepted" (U.S.\#59), and "Success possiblity of my application" (IR\#10). IR\#26 said his third main reason for 
choosing Ireland was "I got an offer." For U.S.\#59, it was his number three main reason for choosing the U.S. saying "seen a lot of people getting accepted in good schools." U.S.\#67 and UK\#502 did not consider studying at home because "the competition is very high" and "...it's also very difficult to get a Master's degrees in my hometown so I think I'll just choosing the easy way to promote myself [by studying abroad]." UK\#62 thought her chance of admission to a university would be easier abroad than at home because of a lack of higher education capacity in India:

"...it is not very difficult to get an admission as an international student in a UK institution...I don't see why students should leave India when there are such good institutes out there. The only reason is probably that there are so many students and maybe not enough places...capacity issue."

UK\#375 said it was much easier to get admitted to a UK university because "Indian education...The admission test itself is very competitive and it may take a very long time to clear it." He commented further on the difficulty of getting admission at home:

"...we are not allotted the Master's degree just because we have got good marks in our Bachelor's because this is the case in most of the countries... when I was selecting this course they definitely did check my undergrad marks but back in my country they do not care about that. You have to pass an exam. We call it 'The General Aptitude Test for Engineers'...but unfortunately there are very few people who have cleared that exams."

Upon completion of his undergraduate exchange programme, IR\#20 said similarly he did not apply to study at home because of the difficulty of getting admitted, "...because in China all the graduates students have to do a exam with a uni...when the students pass that, we must connect with the lecturer...Then some of the lecturers will give them another exam..." IR\# 6 also commented on the difficulty of being admitted to postgraduate programmes in China: 
"... in China if you finish your Bachelor degree, you have to go to examination to go to the Master degree. If you cannot pass that examination there's no way you can get a position to study in the college. And it's really hard I think just the one person in one hundred can go to the college and study."

She said it was even more difficult for her, "Because I didn't finish my Bachelor in China so it's really hard to pass the examination" and it was easier to stay in Ireland and continue to the Master's level because, "...we just need the last year's grade to apply for a position."

3) Availability of information: Students commented on the importance of easily available information about international study options to their decision-making. UK\#278 felt this was important stating, "Because when I am putting that much investment into here so you have to make sure the future is secure." U.S.\#28 was attracted to the U.S. because "the burden of doing research about American unis is lesser compared to other countries American uni websites are fairly straightforward in navigating and answering questions about funding and such", while U.S.\#59 said "Lot of people come to US for studying from India. So informations were readily available." UK\#502 commented on the importance of the availability of information about potential host institutions, as well as the visible presence of UK universities in China on his final decision: "Maybe there are more information about UK's universities..."

Of the students studying in the UK, none mentioned this theme as a first or second main reason for choosing the UK, but one student, UK\#496 said it was her third main reason for choosing the UK. The quote is presented above. Of the students studying in Ireland, for IR\#26, "I got an offer" was his third main reason for choosing Ireland. Of the students studying in the U.S., U.S.\#59, mentioned the theme three times so it was of significant importance to this student, including as his number three main reason for choosing the U.S. saying "seen a lot of people getting accepted in good schools." This theme was not given as a first or second main reason for choosing the U.S. by any of the students studying there. 
Students mentioned they were attracted to their host countries because of their status as developed countries. In the questionnaire, students referred to this as an important factor in deciding to study abroad and on a host country, making comments such as "Economic Situation" (IR\#10), "Good economy" (UK\#246), "wealthy; advanced country" (U.S.\#44), and "It is most developed" (U.S.\#104). In the interview, IR\#19 stated:

"...there is lot to learn from the developed countries being a person from a developing country. So I think it's not just with the career, it's from the environment, it's from the roads, the pollution, it's from the culture, it's from everything...it's from the people..."

IR\#25 replied that his third main reason for choosing Ireland was, 'well developed', explaining in the interview he was referring to the status of the Irish economy at the time of his application to University Ireland:

"...some of the reasons about the economy...that was 2004 I came to Ireland, and in that time it's a very good economy time for Ireland. And everybody got a job. And I did some research about the economy of Ireland before I came to here and they said the high salaries, high wages, and you got a well-paid [job] and the country's looking for labours...The reason is just you got easy money to earn."

For UK\#246 this theme was the number one reason ("Good economy") and for UK\#7 it was the number three reason ("better economic conditions") for choosing the UK. U.S.\#44 mentioned it as the number one reason for selecting the U.S. saying "advanced country." For IR\#10 and IR\#25, it was their number three main reason for choosing Ireland, saying, respectively, "economic structure" and "well developed." 
1) Visa process: The ease of getting a visa for study and work for the student, and in some cases the student's spouse, was mentioned as important. UK\#446, for example, said a reason important in deciding on a host country was the ease with which his spouse could accompany him, "I would add that spouse visa for UK is comparatively easy. I am married and did not want to go abroad without her..." IR\#18 and IR\#25 both believed the process of getting a visa to study in Ireland to be easy with IR\#18 saying his number one reason for choosing Ireland was "Easy to obtain visa." IR\#25 stated he chose Ireland because, "...it's really easy to get a visa. So that's why the reason", while the U.S. was only his third choice because, "...I try to apply but they also have a visa problem, especially with the developing country such as China...maybe you easier got a fund there but you won't easier get a visa. That's the problem."

2) Opportunities for immigration: Students gathered information on opportunities for immigration when considering where to study showing it was of interest to them. U.S.\#27, for example, said "immigration policy" was his number one reason for choosing the U.S., and U.S.\#111, said an "immigrant friendly" country was an important reason in deciding on a host country. U.S.\#164, mentioned this sub-theme twice meaning it was of some importance to him particularly in deciding to study abroad and in choosing a host country, to both of which he replied, "Opportunity to live." Of the top three reasons U.S.\#158 chose the U.S., his number two reason was 'possible immigration opportunity' although he noted in the questionnaire he was planning to return home after study. When asked about this discrepancy in the interview, he responded:

"...chance is chance so based on my information I know that U.S. immigration is much easier...But every year if you got a job in U.S. probably you can get a green card here...And although I want to return back to China in the long-term but probably I spend some time in U.S...And if I got a green card I can came back to U.S. some time later to just visiting, traveling and I don't need to apply for a visa." 


\section{Cultural Capital}

Cultural capital refers to the cultural advantages an individual enjoys that are acquired through education or family and other connections and which confer power and status in society upon that person (Bourdieu, 1986). This data indicated that embodied and institutionalised states of cultural capital, as described by Bourdieu in Chapter 4, were important to students.

\section{Existing Cultural Capital}

Students talked about various forms of existing cultural capital they utilised to increase their overall capital. These are listed in Table 21 below, followed by a detailed discussion of each. 
Table 21: Existing Cultural Capital

\begin{tabular}{|l|l|}
\hline \multicolumn{2}{|c|}{ Table 21: Existing Cultural Capital } \\
\hline Cultural capital embodied by the student & 1. Previous experience in current host country \\
& 2. Previous experience abroad other than in current \\
& host country \\
& 3. Previous visits to host country \\
& 4. Knowledge of host country prior to study \\
\hline Parents' educational experience & 5. Knowledge of English \\
\hline Family tradition of studying/working/living abroad & \\
\hline Cultural capital embodied by home country & \\
\hline Cultural capital embodied by home country education & \\
\hline
\end{tabular}


Five sub-themes emerged from the data that referred to existing cultural capital as embodied by the students themselves. These sub-themes are previous experience in current host country, previous experience abroad other than in current host country, previous visits to host country, knowledge of host countries considered for study, and knowledge of English.

1) Previous experience in current host country: As all participants were postgraduate students, they had some level of cultural capital as an educated person who has completed at least one university degree prior to undertaking international education. They would also have existing cultural capital from that experience if they had had lived, obtained a previous degree, or worked in the host country prior to their current degree programme.

All students were asked in the questionnaire whether they had studied in any countries other than their current host countries. The existing cultural capital students acquired from their time and completion of a previous degree in their current host country presumably influenced their decision to stay in that host country for an additional degree.

IR\#25 completed a previous degree in Ireland, "...another Bachelor Honour degree in Sligo IT...[and] the General English Business study which is for communication skills and business English which is basic English for two years" and gained work experience, "Actually I work in Ireland for nearly 2 years so I have some money myself." When asked why he chose Ireland to continue his education at the undergraduate and postgraduate levels, he noted the influence of existing cultural capital saying Ireland was his first choice for both, "...because after two and a half years studying English in here, I just kind of fit in the society, I fit in the cultures.."

This sub-theme was also not as straightforward to analyse as I would have hoped because I did not ask on the questionnaire specifically whether students had any previous experience besides their current one in their host country but it was fairly evident there 
were more students who had longer experience in the host country. UK\#57, for example, who was in the first year of her Master's programme in autumn 2008, indicated she had been in the UK for two and half years but did not give any further information on why she had been there so long. Since she was not an interviewee I did not have a chance to follow-up. She did mention she has family in the UK however, which could be one possible explanation for the length of time there. Whatever the reasons students had for being in their host country for significant periods of time over and above the length of their current academic programmes, it can be assumed they acquired some level of existing cultural capital in regards to their host countries as a result.

2) Previous experience abroad other than in current host country: Previous experience abroad of any kind may have influenced students' decisions and provided them with the appropriate cultural capital to be able to successfully pursue study abroad.

All students were asked in the questionnaire, 'Have you studied in any other countries besides the [host country] and your home country?'. Those who replied 'yes' were then asked to note what qualifications they received. Five indicated they had experience studying in other host countries, but only three said which these were: UK\#57 said Bahrain, U.S.\#113 the UK, and IR\#8 Sweden, and only one student, U.S.\#113, indicated the kind of qualification received which was a Bachelor's degree. U.S.\#72, who was not an interviewee, said she studied in another country but did not provide any further details about the host country or the qualifications received. UK\#62 had a combination workstudy experience in the U.S., "I did my six months of Master's research project which is a compulsory part of your degree in America on a research scholar status...in FDA."

3) Previous visits to host country: Students could also have developed a modest amount of existing cultural capital from visiting the host country prior to study. However, as only one student in the questionnaire and one interviewee mentioned visiting their host country prior to the start of their academic programme, this was not a common way to gain cultural capital. It did appear to influence choice of host country for the students who mentioned it though. When asked what was important to her in choosing a host country, UK\#501 said "I visited UK twice in summer holiday before and this country gave me good 
impression", while UK\#62 had also visited the UK once prior to her current programme of study to participate in a workshop at another UK university, "I came down in March 2006 for my debut in Oxford... and did my workshop here..." This helped her to gain insight into and become comfortable with the UK.

4) Knowledge of host country prior to current study: Students also had some prior knowledge of their host country and other potential host countries which acted as existing cultural capital. This knowledge was gained from a variety of sources such as the media and entertainment (TV, movies, music, theatre, sports) industries, education, friends and family.

UK\#278 said he knew quite a bit about the UK prior to studying there because, "...we get lots of their literature, books in English, newspapers, reading newspapers everyday, watching movies or some sort of serial..." When asked how much he knew about the U.S. prior to studying there, U.S.\#165 mentioned the information he gathered about the U.S., not only through movies but also through his interest in science, "I was fascinated by NASA, I was fascinated by MIT..." U.S.\#158 mentioned learning about the U.S. from movies and TV, "...American Hollywood movies are very popular in China. And also some TV shows, some TV like Prison Break. That is very famous. I watch that."

Students from India commented they had a certain level of knowledge, or existing cultural capital, regarding the UK because of the former colonial relationship between India and the UK. UK\#62 stated, for example, "I prefer the culture in the UK. Probably the whole fact that cities are more like cities in India. And...because obviously the British ruled in India for 200 years so that way it might be similar."

Students remarked upon the importance of feeling a sense of familiarity and comfort with their host country due to the prior knowledge obtained about that country and, in some cases, its similarity to their home countries. When asked about important reasons in deciding on a host country, U.S.\#56 said "The country I feel comfortable...The country I feel...familiar" and UK\#278 said "No...cultural difference." For UK\#336 and UK\#375, the importance of "familiarity" and "Feels like home" was high with both listing it as the third 
of their top three reasons for choosing the UK. UK\#375 explained further in the interview, "...south Bombay is completely designed like England because English people used to stay there so they wanted have exactly the same feeling. So it really feels as if you are at your home..."

For UK\# 140, a host country that used the same language provided a sense of comfort, "The language had to be an English speaking country because it would be difficult to live in a place where the local language is not understood by me." She listed "language" as her number one reason for choosing the UK. Of the three countries he considered for study, UK\#2 said his home country was first choice, followed by the UK. When asked how much he knew about the UK prior to selecting it, he said:

"I'm not a good information collector so I don't know too much about UK. I only know people here speaks English... I can only get some information about UK people on the television, so TV programme all say how UK people are and how their culture is nice and some stuff like that. I think, oh it's quite good."

Of course students drew on the existing cultural capital of their family and friends to increase their own knowledge of various host countries. U.S.\#158, for example, said he got information from his family, "What they know is that U.S. is the best in their opinion...I guess it's based on their experience. You know they can got information on TV, or some newspaper... Kind of advertisements." UK\#62 said she felt she knew a lot about British culture because:

"...my mom has a Master's in English Literature so I've been reading a lot on English Literature, and mainly the English literature is in English. And if you read the history of a country you can get how it is going, and I knew I would be comfortable in this country."

UK\#375 also mentioned a family link that made him consider the UK saying "I just well already told them that I am thinking of UK... when my dad heard UK, he is very fond of UK 
so he said, 'You should go to UK'" because "...my father did get an option once in his life to come here and work which he denied because he already had a family."

Some students developed their existing cultural capital in regards to knowledge of their host countries through various forms of education, both formal and informal, undertaken in their home countries. For example, when asked how much they knew know about the U.S. prior to studying there, U.S.\#149 said, "Not so much...maybe just from the English classes ..." and U.S.\#158 said, "...I have known a little bit. Not that much...I took an American culture course in university before I came here so...I know some basic ideas about what Americans will do." UK\#375 developed his existing cultural capital through learning about the UK in school, "...like I studied in a convent school... they used to like give us all the knowledge about UK, places and all those stuff."

It is important to note the frequency with which students current host country was their first choice or not. This may have some relationship to the existing cultural capital of students in regards to their host country, or indeed the existing cultural capital of the host country itself. In the questionnaire, all respondents were asked to list up to five countries they considered for study for comparative purposes. Of the thirty-nine students studying in the UK, twenty-eight indicated the UK was their first choice host country. Of the twentytwo students studying in the U.S., the U.S. was listed as the first choice host country by all of these students. The large numbers of students studying in the UK and the U.S. who also selected them as their number one host country choices could be a result of a high level of existing CC embodied by the students in terms of knowledge of the UK or U.S. prior to their current programme, and/or reflecting the high level of existing $\mathrm{CC}$ of the UK or the U.S. themselves.

Almost half of the thirteen students studying in Ireland did not list Ireland as a country they considered for study at all, and only three of the thirteen students studying in Ireland said Ireland was a first choice host country for them. This could possibly indicate these students did not have a high level of knowledge about Ireland prior to studying there and/or that Ireland itself has a low level of existing CC. When asked how much she knew about Ireland prior to studying there, IR\#6, for example, said, "Not a lot. I know in 
England better than Ireland...until now my grandmother think Ireland is a part of England all the time. And I don't know...we don't know a lot about Ireland before." IR\#26 admitted to a lack of existing $\mathrm{CC}$ in regards to knowledge of Ireland before going there for study, saying he knew only, "Hmm...it's an island... Not much."

The data gathered from this question asking students to list up to five countries they considered for study has questionable reliability because students did not answer it consistently with the list of countries they considered for their current programme. Some students, for example, who were doing their second degree overseas at the time of the questionnaire, listed the countries they considered for study for their first overseas degree, and some students who were planning to continue to another degree upon completion of their current study programme, listed the countries they were considering for this second degree.

5) Knowledge of English: Students talked about their existing cultural capital in terms of their knowledge of English. While previous experience with English will be discussed here, the desire of students to increase their English language skills during overseas study will be presented as potential cultural capital. Students mentioned the development of this form of existing cultural capital as resulting from learning English in school. For example, UK\#278 said, "...all my schooling and graduation was the medium of instruction was English...in case of Indian students...[we] are comfortable with English..." UK\#133 stated a reason important to him in choosing a host country was, "Actually I learned English about six years and I want to choose an English country...." UK\#62 said an important reason for choosing the UK was because it is an English-speaking country, a language she speaks fluently:

"...Language is a very important issue...English. I mean I'm a convent educated girl so English is as good a native language for me as my mother tongue so I knew that I didn't have to exploit any other languages...I was not thinking about mainland Europe because language would become a barrier." 
According to Bourdieu's theory of cultural capital, the cultural capital embodied by a student's family, particularly parents, influences whether or not the student participates in higher education (Bourdieu and Passeron, 1990[1977]; Waters, 2006a). The data in the research presented here showed parents' educational experience, or lack of, influenced students to pursue higher education, and, at least in one case, international study.

In the interviews, I was able to gather information about the level of education and the occupations of the interviewees' parents. This sub-theme only emerged during analysis of the interviews since it was not asked about directly in the questionnaire. The information is presented in the Table 22: Parents' Education/Occupation in Appendix H. I have used the words of the interviewees to describe their parents' occupations and educational levels.

As seen in the table, although not all interviewees' parents had higher education, a large number (sixty-five percent) did. While only a slight difference, more fathers than mothers participated in higher education. In terms of students' fathers, twelve out of seventeen had some form of higher education from a two year college diploma to a medical degree, while ten out of seventeen mothers had done anywhere from a two year vocational qualification to a medical degree. Four interviewees had at least one parent who did not have higher education, while another four said neither parent had. U.S.\#149 said, for example, although his father did not complete higher education, he had wanted to do so, but had to go to work instead. As a result, he wanted his daughter to have the opportunity.

IR\#6 had parents who were highly educated, both having PhDs, and who strongly encouraged her to pursue postgraduate education, "...maybe it's related to my family 'cause my father and mother are both PhD. So they hope me to finish at least a Master degree. This I think the first reason I choose to study." U.S.\#158 and IR\#26 both referred to past government policies in China as the reason their parents could not pursue higher education. Now that the policies had changed, these parents encouraged their children to 
do so. U.S.\#158, who said his parents were peasant farmers stated, "The thing is because when my father went to school, in China there is a political reasons and they are forbidding to get an education...Because the policy changed so I can get educated."

UK\#62 referred to her father and uncle's educational backgrounds, "...he's [her father] actually a person who's totally into science...My father has a Master's in Chemistry and Physics both. He coached his younger brother, my uncle, and he's been a NASA scientist in California." Her family background influenced her own choice to study science at the PhD level, "...I wanted to do research. I promised my dad then that I'd not take medicine but I'd be a doctor." Finally, UK\#375 not only had parents who had completed Bachelor's degrees, but he was also motivated to study abroad in the UK because, "...I guess right from my childhood, I was really keen on coming to England because my father did get an option once in his life to come here and work which he denied because he already had a family..."

Family tradition of studying/working/living overseas

Students who had other family members who had studied, worked or lived overseas had a 'family tradition' of international study or migration. These students had access to some level of existing cultural capital (and social capital) through these family members when making their own decisions about international study and choice of a host country. In the same way as drawing upon parental education experience, such students could potentially increase their own cultural capital through the experiences of family members.

Only one student, UK\#501, actually used the term "family tradition." The student said it was her number one reason for choosing the UK. When asked directly on the questionnaire about whether she had family or friends who had studied abroad in the past, although she responded 'yes', she declined to mention which family members or where they had studied. She was not an interviewee so follow-up was not possible. Although not mentioning family tradition specifically as a reason for deciding to study abroad or in a particular host country, ten UK students, one U.S. student, and two Irish students did say in the questionnaire they had family members who had studied overseas, including 
brothers, sisters, aunts, uncles, and cousins, and IR\#26 whose uncle and cousins were all citizens of Canada.

Cultural capital embodied by home country

Students have a certain amount of existing cultural capital in their home country which is a reason why some students considered study at home as a first choice or in addition to study abroad. When asked if they had considered study at home, some students answered 'yes' giving reasons such as, "I would be in a culture I'm more comfortable with" (U.S.\#113), "Because I did not want to leave the country" (UK\#57), and "Speak Chinese. And it's in Chinese. Lecturers speak Chinese. That might be positive advantage in China. And maybe the food. The life situation in there..." (IR\#20).

U.S.\#158 said he considered studying at home because "Home is home. So studying at home is easier and more comfortable" adding in the interview, "...if I got a chance to study in China it's probably the first choice...Maybe something about living closer with my family. I can celebrate the Chinese New Year with them. These kind of benefits." IR\#20 commented on the existing cultural capital of his home country in terms of the strong relationships between children and parents which influenced him to consider study at home saying, "...in Chinese culture parents is a very important part in a particular person's life..."

Students commented on the existing cultural capital of their home country as including a trend for students to study abroad, and in some cases to study in particular host countries. IR\#20 stated, for example, "...Actually in China it's very popular to study in abroad country, and so my parents also prefer me to study in Ireland so they support me until now." U.S.\#28 was influenced in his selection of the U.S. by, "An established culture in my country to prefer US", while UK\#2 chose the UK because "In China, there's a tide of studying in UK, which is even stronger than 'studying in US' now."

Certain aspects of the home country's culture appeared to make international study attractive for students who were looking for more personal freedom from traditional family 
and cultural expectations, though this did not mean the students were not going to return home after graduation. UK\#367, for instance, commented on the pressure from family expectations and obligations at home saying, "...it's kind of a closed family then you want to go out anywhere...you have to ask permission. Even if you consider relationships...you cannot have your own choices, so its about amount of freedom..." UK\#62 explained that in Indian culture there is a lot of pressure for women to marry young which was one reason she considered studying abroad for a Master's degree:

\begin{abstract}
"At that time, the only two condition letters which was open to me for my Master's was in [University $\mathrm{X}$ ], the university I did, and one was [University $\mathrm{Y}$ ]. I realised I had to act quick or else I'd be losing a year in between and I knew if I lost a year when I was twenty-one my parents would get me married. It's always a fear. Or rather it might be setback for me as well so I thought that just let me go out."
\end{abstract}

Existing cultural capital of the home country seems to have also influenced students' after graduation plans motivating them to eventually return home. U.S.\#162 talked about the pull to return to his home country region because of existing cultural capital saying, "...I just think after two years living here, I still feel more comfortable going back to Asia...your friends, your network, and Asia is the place you feel more comfortable with...." UK\#367 stated, "...that's a cultural difference in India and here because in UK... there's not much of a connection between the parents and the children, but in India children have to take care of their parents", adding about his own family, "They [say] after some years please come to India and settle down...Actually you say when Indians you get married around twentyeight to thirty, so...maybe two or three years here and then you settle down in India."

Cultural capital embodied by home country education

Although choosing to study abroad, students mentioned that the higher education available in their home countries also had a reputation for quality, and this made them consider studying at home. IR\#26 stated although in China people think an international degree is very valuable there are some high level universities there as well, "In China a lot of people think like this but there's still a few universities in China that have really high 
value. They are like Beijing University, they're really good." In the questionnaire, UK\#367 stated one of the reasons his preference was to study at home was because of the high quality education offered there, "well wanted to do my post-graduation (MBA) from either from IIM...Symbiosis (pune)...sydenham (mumbai)...NMIMS (mumbai)...or else J.Bajaj (mumbai)...all top rated institutes which assure quality education." In the interview he explained why he opted to study abroad, "...basically I applied for them but I couldn't clear through the top five Indian institutions so doing it from a smaller university was not that good because I wouldn't have got that good job prospect."

\section{Potential Cultural Capital}

Students hoped to increase their existing cultural capital or gain new forms through studying and living abroad. The types of potential cultural capital they hoped to gain are listed in Table 23 below, followed by a detailed discussion of each. 
Table 23: Potential Cultural Capital

\begin{tabular}{|l|l|}
\hline Cultural capital of host country & $\begin{array}{l}\text { 1. Cultural capital of host country } \\
\text { universities/programmes }\end{array}$ \\
\hline Cultural capital of host country education & 2. Degree value and recognition \\
\hline International and cross-cultural experience & \\
\hline Better English language skills & \\
\hline Knowledge of 'Western' values & \\
\hline Personal growth & \\
\hline Increased status in the mind's of others & \\
\hline Cultural capital gains for student's family
\end{tabular}


This theme highlights the existing cultural capital of the host countries selected by students. The existing cultural capital, or, in other words, the reputation or renown, of a potential host country was one factor in attracting (or not attracting) students to that country. I have listed it as a type of potential cultural capital because it was generally not embodied by students or accessible to them prior to studying abroad as were the types of existing cultural capital discussed above. Students hoped there was potential to benefit from the existing cultural capital of the host country during and after their time abroad, and to use this experience to develop their individual cultural capital.

Students mentioned various aspects of the existing cultural capital of the 'West' and of their selected host countries as important in their decision-making. UK\#367, for example, commented on the cultural capital of the 'West' in general as being of importance, and when asked about the reasons important in deciding to study abroad, replied "The attraction towards a clean...rich...hip and sophisticated culture of the west..." UK\#152 said "the reputation" being a reason important to her in deciding on a host country, and "Good reputation around the world" was her number one reason for choosing the UK. For UK\#150, when asked what reasons were important in choosing a host country, he focused on the reputation of the country saying, "UK is a cosmopolitan country and have great culture", while UK\#53 noted the "country history" was important to her. For U.S.\#162, the reputation for diversity in the U.S. was attractive. He said:

"... I don't know whether this is a prejudice or...a bias...but I just think that U.S. 'cause they are already a lot of different immigrants in U.S., the people here are just more diverse so as an international student came from Asia, I think you will feel more comfortable in U.S...it's just my perception."

UK\#131 and IR\#6 highlighted the international reputation of their host countries as important saying, "Its recognition internationally and locally in my home country" and "are they famous in the world." One student, UK\#135, made more specific comments on the renown of the scientific research conducted in her host country stating, "(UK) research in 
science field is well known" which was an important reason for her in deciding to study abroad and in choosing a host country.

Cultural capital of host country education

As with the previous theme 'Cultural capital of host country', this theme highlights the existing cultural capital, or reputation and renown, of the higher education of the three host countries, which was one factor in attracting students to them. Also, as with the previous theme, I have decided to list it under potential cultural capital because it was generally not embodied by students or accessible to them prior to studying abroad, and was instead a form of cultural capital students hoped to benefit from during and after their international experience and use as part of the development of their individual cultural capital. Two sub-themes emerged from this theme, cultural capital of host country universities/programmes, and degree value and recognition.

1) Cultural capital of host country universities/programmes: Students across the three host countries commented on the importance of the reputation of their host countries' universities and academic programmes which, as noted above, they hoped could be utilised to reap some future benefits. Students, such as UK\#53 and UK\#131, referred to this sub-theme as their number one reason for choosing the UK saying "Good reputation of education" (UK\#53), and "Its reputation for the specialised course module" (UK\#131). For U.S.\#73, to "Get a Master degree in a reputable university" was the third of his top three reasons for choosing the U.S., and the "Reputation of the university and the programme" was an important reason for him in deciding to study abroad. UK\#278 stated simply, "...that's why I chose this university. It's got a good reputation." IR\#8 said, "its reputation as universities in general" was important in deciding on a host country.

Although U.S.\#158 did consider other countries for study, his first choice was the U.S. because, "...the reputation of the university...[University U.S.] is a good university..." For UK\#375 one of the three main reasons he chose the UK was the "global presence" of its universities, explaining in the interview: 
"I'm not sure about if I come and tell somebody if I am learning in so-and-so university in U.S. they will remember or they will know the name, but if I tell them that I am studying in [University UK] they do know...Even if I am standing in front of a company guy and he is asking me where...I say I'm [University UK], yes they do know about that. So that's the worldwide presence which I am talking about."

He also talked about how a degree from University UK would provide him an advantage in the job market:

"If I go back to my country after I finish this course I will have a lot of options. [Employers] will obviously recognise these universities and that was the initial thing which we always think about...whenever I am standing in front of a person like an interview, he will ask me certain questions like see if he sees my degree he will be happy that yes he has done a degree from [University UK]...So obviously the options are increased more."

For UK\#502, the visible presence and branding of University UK at home influenced his choice of the UK, "Just like [University UK], it was set in that campus in China. So everything was there for us to understand it is a very famous university in the world." This familiarity made him feel he could trust in an education received from that university saying, "It's not only trust. I know this university does it. I know I will learn something I don't know." For U.S.\#162, one of the reasons important to him in selecting a host country was, "whether the degree or the university in that country was highly regarded or not in the home country." He added in the interview, "...you have to go to a really premium programme...the brand name, the reputation, and their work, the education that I carry might be helpful for me in the future." IR\#20 summed up his feelings about the value of a university's reputation saying, "If you are studying in a very famous college, it's worth for you to study in abroad country."

2) Degree value and recognition: The majority of comments about the existing cultural capital of host country education concerned the value of the degree earned and the recognition of its value in the job market. Some students made broad comments about the 
value of an international degree. For example, U.S.\#27, who when asked if he considered study at home, replied "No, [The Master of Law] degree [in US is quicker to earn and] is more valuable" and U.S.\#67, who said "recognition of degree" was important in deciding on a host country. U.S.\#165 felt the value of the degree would be useful to him in many aspects of life saying, "...everything counts, whatever I'm experiencing over here it's adding, adding value to all the fields like academic, personal...everything."

Other students indicated that when deciding on a host country it was important to choose a country that would provide them with a degree that had value and recognition at the international level, such as UK\#57, who said "value of certificate considered globally", and UK\#150, who stated "UK university degree is recognised and accepted all around the world." This was a number one reason for choosing the UK for UK\#57 and UK\#275, who said, respectively, "value of certificate" and "worldwide recognised degree." Regarding an international degree, UK\#375 believed having an international aspect to his Master's degree would add more value saying it will, "...give me a degree which is at least worldwide recognised... it gives me an international perspective...if I go back to my country after I finish this course I will have a lot of options."

Other students mentioned specifically the importance of the value or recognition of the international degree at home, such as UK\#501 who said an important reason in deciding to study abroad was "UK degree is competitive in job market in China." It was an important reason in deciding on a host country for UK\#336 who said, "recognised in academia or job market in home country." In the questionnaire, U.S.\#162 said among the reasons important in deciding to study abroad and on a host country was whether the "degree highly regarded in my home country" adding "[an] overseas degree can guarantee investment, the recovery of the investment."

When asked if she thought an international degree would be highly valued in China, IR\#6 said:

"Of course. First in China in people's mind they will think maybe all degrees from abroad will higher evaluation in China...I think the whole world will know the 
degree from England, or Australia, or maybe USA are really valuable in other countries...Also, I think England and Ireland the degree is really hard to graduate from the college so it's valuable in China."

UK\#367 said he strongly believed an international degree is highly valued in India and employers in India are more eager to hire someone with an international degree versus an Indian degree:

"And it was not just an imagination of mine, I asked this to a few people whom I know who are in a good post in India and they hire students so I asked them what is the benefits...I asked persons I know from the finance industry...the hotel industry. So like every field it is the same thing, if you're from abroad degree, it holds value."

U.S.\#165 believed an international degree "...adds spice [i.e., value and prestige]" and:

"Wherever you go you can if you say that I got PhD from U.S...just even if you put together a PhD from India and PhD from U.S., they might have the same knowledge and the same caliber but still U.S. has this tag name...you know the tag, it's like the brand. So it's all about the brand, but still I'm now of the very firm opinion that it has a brand and also the quality."

Students also commented on the value of an international degree at home for getting employment with international and multinational companies. IR\#25, for example, when asked if he thought an international degree would be highly valued in China replied, "...in China there's a lot of firms and companies, they just connect to the international trade so they need more people like you got the overseas experience and also you speak very good Chinese. So I think that's an advantage." IR\#20 acknowledged that companies which only want to work locally are less likely to see any value in an international degree:

"Depends on the company. Some companies they just only want to work in China, they never want to work abroad. So just Chinese students they will in the low 
payment and something else will better than the overseas student, because the overseas student have paid a lot of money in the education they want a high payment, want a better environment. So that be a little bit hard for them to choose an overseas student."

Some students commented on what they perceived to be the declining value of an international degree for accessing employment. For example, although UK\#2 said in the questionnaire his second most important reason for choosing the UK was "The value of [the] degree", he also believed international degrees have decreased in value over the past decade:

"...ten years before [only] a few MSc students have graduated from like UK or America but right now there are loads of MSc students in China, and because of some students get fake MSc degree certificate so when they go to an industry or say a company, the company will find their abilities unacceptable, and that's why all the society in China are thinking that MSc degree is less valuable than before."

U.S.\#165 stated that while an international degree still has high value in India in most cases, some employers are more reluctant than in the past to hire students with these degrees because they often have higher salary requirements in a period when organisations are trying to reduce costs:

"Well they don't prefer [international graduates] because...everywhere it is now a mindset to reduce the cost. And if they actually want to have someone who does not directly say that 'I want this much' but his degree says 'Hey, I need to be paid this much'..."

Finally, IR\#6 believed employers in China might be reluctant to hire international graduates because of concerns that as a result of their international experience, students might not be able to readjust easily to Chinese society, and particularly the Chinese work environment. She stated, "The other things, some company not like person from foreign country. They thought maybe you are too open-mind..." 
One of the themes most commented upon by students was their desire to acquire both international exposure as well as exposure to new and different cultures. By undertaking study abroad, students were hoping to gain valuable international and cross-cultural experience that would assist in the development of their individual cultural capital.

This theme was mentioned several times in answer to whether students considered studying at home, "No, i wanted a global exposure" (UK\#381), "I always wanted to study abroad for higher education" (U.S.\#72); reasons important in deciding to study abroad were, "A good exposure to the outside world and what is going on before I settle back at home" (UK\#446), "experience new culture" (U.S.\#104); and in deciding on a host country were, "It has a multicultural environment" (IR\#150). For five students, representing all three host countries, it was number one among the top three reasons for choosing their particular host country. U.S.\#73, for example, stated, "I want to experience something different before entering workforce." Only two students, one studying in the UK and one in Ireland noted it as the number two reason, but for seven, again representing all three host countries, such as U.S.\#67 who said "exposure", it was the number three reason. UK\#257, hoped to continue developing his cultural capital through international experience after graduation, saying he planned to stay in the UK to "work for a couple of years, gain some valuable international exposure."

This theme was also prominent in the interviews. UK\#133, for instance, explained the value of international experience as "...you can also study something from Master's degree and you can get some knowledge useful for your future career and you will get something very useful for your life I think...international experience." IR\#20 said besides obtaining a degree in computer science through international study, he hoped to, "Learn another culture. And I think culture include a lot of things. That's what I gain in a foreign country."

Some students mentioned the desire to learn specifically about the culture of their host country or region. UK\#101, for example, was hoping to "...I can learn more about UK...I can learn some cultural traditions and rituals..." UK\#133 explained her choice of the UK 
thus, "I choose UK as my study country because...has a very different culture between China and UK. That's very attractive thing for me to choose this place..." As noted in an earlier section, IR\#19 said one of the reasons important to him in deciding to study abroad was to lay the groundwork for an "international career" and to gain the "international exposure" necessary for such a career was one of the three main reasons he chose Ireland. In the interview, he explained, "I wanted...especially to learn and understand the European culture...because in India we study a lot about Europe...I wanted to meet the people and look at the actual."

Other students wanted the opportunity to gain exposure to a variety of different cultures. UK\#278 stated "...[its] all about a new experience as well...it's kind of multicultural and multiethnic environment and you meet all sorts of people and get to know more different people from all different countries, their culture." U.S.\#162 said one of his three reasons for choosing the U.S. was about 'cultural exposure', explaining in the interview:

\footnotetext{
"...I [want to] know more things that I don't know before about people's value, about the way people judge things, about the way that people think about things which is totally different from what I had in my country, and I'm not going to learn from that had I never did any education here...And then in terms of the interaction that you have with people either at school or outside when you party or some other social activities. That is very valuable to me and sort of learn how to interact with people from different cultures."
}

\section{Better English language skills}

An important theme mentioned by students under potential cultural capital referred to the wish to acquire or improve their English language skills. This can be viewed as a way of increasing all three types of capital, but as international students do not necessarily study English formally, I have categorised it as a potential cultural capital acquisition.

Similar to the above, this theme was mentioned in answer to several of the main questions, such as what reasons were important in deciding to study abroad, students 
said, "English could be improved in UK" (UK\#501), "learn English" (IR\#18), "practice English" (U.S.\#149); and in deciding on a host country they said, "English speaking" (UK\#336), "English speaking country" (IR\#18). It was given among the top three reasons by students from all three host countries. It was the number one reason for selecting the UK for UK\#336 who said "English speaking", the number two reason for U.S.\#149 who said "Practising my English", and the number three reason for IR\#18 who said "English speaking country."

The topic was also discussed frequently in the interviews. IR\#26 stated that the main reason he did not consider studying at home was because "...I want to learn English really well, and obviously to go abroad is a very good way to learn English." Although already a native speaker of English, UK\#62 felt a degree from the UK would increase her cultural capital because "I'll not talk with my Indian accent." When asked what was important about learning English, IR\#6 said, "Maybe because the English is the most popular language in the whole world...Lots of countries use the English as the government language. So that's the reason I think."

Students commented on the importance of learning English or developing their already existing English language skills for future career opportunities, in other words, converting their cultural capital to human capital. U.S.\#158 wanted to have the opportunity to go anywhere in the world to work and felt improving his English skills through study in the U.S. would help him to achieve this, "English is a major language in the world. If you study in the U.S. you probably can work in the North America or some even parts of Europe and something like Hong Kong, Singapore." U.S.\#149 said she hoped to gain "good English skill" from studying abroad and she choose the U.S. because of the opportunity to 'practising my English." In the interview, she explained:

"I think English is very, very important in China now, and lots of companies when you apply for a position...sometimes they just take the English interviews with you. And even some companies they are native Chinese companies, and they also have some maybe overseas trips so it is very important at present to have a very good English background...as for the international companies in China, they need to 
contact with the headquarters in USA very frequently so they definitely prefer some students they have overseas experience and who can speak frequently English like that. And also Chinese companies they need to trade with other international companies."

Although some students did consider studying in non-English speaking countries, they did not select any of them as host countries, in part, because of their desire to learn or improve their English.

Knowledge of 'Western' values

Students hoped to develop their cultural capital through learning and experiencing Western culture and values during their period of international study. In the questionnaire, students mentioned the importance to them of the opportunity to directly learn about "Western culture" (UK\#332) or "English culture" (UK\#45), as well as to experience the "diversity" (U.S.\#56) and the "multi-cultural" (UK\#57) environment of the host country. Diversity and multiculturalism were seen as Western values. U.S.\#164 and U.S.\#85 referred to this theme three times each indicating it was of significant importance to them. U.S.\#164, for example, said "Ethnic diversity and openness" were not only important reasons in deciding to study abroad and on a host country, but were also his number two reason for choosing the U.S. For IR\#25, one of the reasons for deciding to study abroad, besides gaining a degree, was to experience Western culture:

"In the Western country...they are just very open, friendly. They like to talk. They like to help as well...but in China everybody is very closed...The way how you deal with the people. That's experience for me. It's just everybody like your friends, but in China it's not...you know how to take care of others. You know how to give respect to everyone, to let everyone to respect back to you. That's how you deal with persons."

For some students, Western values represented greater freedom in various aspects of life. U.S.\#85, for instance, said the opportunity for "more freedom including religious freedom 
and free speech" was important to him in deciding to study abroad and on a host country, and was his number three reason for choosing the U.S. UK\#62 wanted to experience the greater freedom for women in Western society, saying, "I can be myself more...A lot of things I say here can be accepted, maybe they will not be accepted in India. The fact that I'm a girl and they really don't appreciate strong, outspoken women." U.S.\#158 also wanted to experience what he believed to be the greater freedom in the West from social expectations:

"...I like to live by myself, but in China you need to do social work. You have classmates and friends, and you just spend the weekend with them. But here in U.S. it's up to you. If you like you can spend it, if you don't like it you can be by yourself. You have more freedom here."

\section{Personal growth}

Students hoped to gain cultural capital in terms of increased personal growth which included the ability to live independently, the ability to manage their own lives, and the development of a more open and mature outlook on life. Most comments on this theme in the questionnaire stressed students' desire to acquire the ability to live independently. IR\#26, for instance, said a reason important to him in deciding to study abroad was to "live more independently", and his number one reason for choosing Ireland was, "I don't know any one here, so I can live independently." It was the number three reason for U.S.\#149 ("Living independently") in selecting the U.S. It was also mentioned in the interviews, with UK\#62, for example, saying among her reason for studying abroad was:

"...I wanted to grow as a person and I didn't want any outside influence...I wanted to make my own decisions...Because when you stay abroad there's a lot of things that you learn that you would never do if you were staying in India under parental influence..."

U.S.\#165 similarly stated: 
"...I develop over a period of time by living here...develop an self-dependent approach of living...you have this kind of confidence that yes, I can survive anywhere [and you] are in a different country, you are handling a different currency, and you are handling a different kind of economy...so you get the knack of it, how to adjust to different situations."

For IR\#26, the most important reason to pursue international study was a long-time desire to live independently saying, "At the beginning when I finish my high school, I was thinking to go abroad. I think it will make me more independently. This is one of the very strong reasons." In fact, he felt so strongly about this that although he had relatives living in Canada and his parents wanted him to study there, he chose not to, "...I think if I live independently I'm gonna train myself really good, I can think independently and work independently, and yes, something for the ability for myself so I think it's good. I don't depend on other people..."

For some students personal growth meant learning how to manage their own daily lives. UK\#375 talked about not only the academic but also some of the other challenges of managing his life abroad:

"I have to find all my own food and do all my own work so that's a completely new environment. Back in our own country we don't have our own home because [even] if we are grown ups we still stay with our family and everything goes according to the family. If you are away from it you have to manage each and every part of it. So that really is a big responsibility. You have to study, you have to work, eat, make food, everything. And then you have to try to get really good marks."

Other students mentioned that learning to manage their lives included dealing with the challenges that accompanied their academic journeys saying, "more challenges, proven that I can work well" (IR\#15), and "My course is one year and very intense. I am able to cope up with the studies so its fine at least for me" (UK\#446). 
Finally, personal growth was discussed by students in terms of developing an open mind. One of UK\#133's reasons for studying abroad was "We need to go abroad to widen our horizons and to broad our point of view to see this world..." UK\#502 said besides obtaining a Master's degree from international study, he would gain "Life experience and a new myself...Open my mind. And to promote myself because I wanna be much more open and helpful..."

IR\#6 explained why she thought the experience of living and studying abroad is a valuable one:

"I think it's useful for the whole life. First you know something others don't know, and I really open my mind in this country I think. You know some person who's thinking in different way from you and you learn how to study here. And as you got a degree that means maybe kind of successful in your life..."

Increased status in the mind's of others

All interviewees were asked the question, 'Besides an education qualification, what else does having an overseas degree say about you to other people?' from which a distinct theme emerged I titled 'Increased status in the minds' of others'. Students' answers to this question described others thinking of them as rich and/or clever, as well as having more ability, a more international outlook, and a more open mind. For UK\#367, for example, besides proof of having completed an international education, he believed in the mind's of other people at home, an international degree would signify, "First thing would be: he's rich. He's intelligent...it's a general perception of the general public, the middle class public, which is a major part of India...That's the main thing. The social status."

UK\#278 stated how being accepted in a university abroad is viewed as prestigious to others: 
"It's usually the competition for admission is quite fierce...they have to maintain their standards...their reputation so they won't be taking just anybody. You have to be the best around so it shows that..."

U.S.\#158 similarly said getting an international education and experience was a "...kind of proud of thing...not everybody can come to U.S., only the best ones can came here..." UK\#62 explained an international degree can even make you a better marriage prospect in India, "...you get a better husband...many students I know just came into the UK to do a degree and just went back home and got married...because of their prospect of getting a better husband."

UK\#2 stated in the interview that to others an international degree indicated greater ability, "...people in China always have a very good impression of the graduate from U.S...people will think those who got high scores in GRE might have better ability..." For UK\#375, besides proof he has knowledge of manufacturing engineering, he believes:

"Yes, maybe those people will definitely understand that yes now he understands how you have to live in the UK and how you have to work in a group because most of these course works which we used to do are dependent upon this group which you have worked on...they will definitely understand that yes he knows how to work in a team, as well as he knows about the culture of UK. So if we ever have to think about any UK assignment, this guy is there for us."

UK\#278 referred to others believing an international degree indicated he had a more international outlook:

"...it gives you much more experience and it's once you go back after this experience it really matters that this guy has been in the international platform so he knows how to interact and how to talk to people and how to make things work and what are the ways." 
U.S.\#162 stated besides proof he has knowledge of business administration, when he returns home, his degree will signify to other people that:

"I think one is language skill. Two is you have a more open-minded perspective towards a lot of different things. Three is...you are more flexible to different people and to different lifestyle, and to different things that you might think is weird or the people around you might think it's weird but you'll be like, ok I've seen this before. And probably just global network, you can pick up the phone and talk to people around, in other different countries and just talk about what you want..."

In addition, there were comments from students indicating that studying abroad could be viewed negatively as well, resulting in a decreased status in the mind's of others. UK\#62, for example, referred to a negative view in the minds of some people at home towards students who undertake study abroad, "I mean they couldn't do very well in your home country and...I'm being very blunt about it...it is not very difficult to get an admission as an international student in a UK institution", while IR\#26 stated:

"Well, they may think if you only get like Bachelor's or Master's, they might think 'yeah, you go outside to study, it's just because your parents can give you the money to abroad.'...but they didn't realise we still work really hard in this period time, like they thought you just go there, get a degree, go home and get a job or something like that."

IR\#25 also stated time spent abroad could be construed negatively by others:

"They might be assume my mind might be a little bit changed. You know the traditional Chinese culture and ways of Western culture definitely have a big conflict...So some of my friends, they wouldn't like to talk to me... everything's changed for me." 
Though this may or may not have been a conscious potential gain for most students when selecting a host country, a few of the interviewees did refer to ways in which their family members might gain cultural capital from their international study experience. UK\#2, for example, commented on how his parents felt about him wanting to study in the UK saying:

"They felt good 'cause children of some of their friends come to UK before and found the result is quite nice so they quite happy with my study here...in China sometimes the news will broadcast like how well the degree in UK is or how well the degree in U.S. is, and how much they need such students. They are quite happy with that...my hometown is a relatively small place so you can get almost every information of every family so they probably felt quite proud of that."

UK\#62 commented on the potential cultural capital gain for her parents saying:

"If [other people] know that your daughter's a doctor then the first thing 'oh, she's doing well...you have done a good job with your daughter'...[and] the first thing which the parents have on their mind is, 'oh, if my daughter does well then she will get a good husband'..."

Finally, UK\#367 noted the greater cultural capital status given to parents who have children studying abroad:

"...in India the whole perception now is to see UK, U.S., they are first world countries. India's the third world and the literacy levels are not that high so the Western culture is very attractive. If your child is going abroad and studying, you get a socially high status so like you get to show off a little..." 


\section{Social Capital}

Social capital refers to the social connections and networks upon which an individual can draw to advance their economic and social status, and well-being (Coleman, 1988). Social capital, while significant, was the least commented on type of capital but it is important to recognise, as discussed in Chapter 4 , that it pervades the other forms of capital in various ways.

\section{Existing Social Capital}

Students referred, in both the questionnaire and the interviews, to a range of existing social capital resources they possessed that had some influence on their decision to study abroad and which host country to select. The data revealed that students considered their existing social capital to derive from a number of social networks which acted as sources of influence, information, and support at home and in the host countries. The existing social networks mentioned by students consisted of all three types discussed in Chapter 4 : bonds, bridges and links. A list of the various kinds of existing social capital mentioned by students can be found in Table 24 below, after which each is discussed in more detail. 


\begin{tabular}{|c|c|}
\hline \multicolumn{2}{|c|}{ Table 24: Existing Social Capital } \\
\hline Themes & Sub-themes \\
\hline Family & $\begin{array}{l}\text { 1. Family in host country } \\
\text { 2. Family in other potential host countries } \\
\text { 3. Family in home country } \\
\text { 4. Family as source of support and influence } \\
\text { 5. Family as source of information }\end{array}$ \\
\hline Friends & $\begin{array}{l}\text { 1. Friends in host country } \\
\text { 2. Friends in other potential host countries } \\
\text { 3. Friends in home country } \\
\text { 4. Friends as source of influence and support } \\
\text { 5. Friends as source of information }\end{array}$ \\
\hline Partners & \\
\hline Home country alumni & \\
\hline Education agents & \\
\hline Home student population in host country & \\
\hline Community of home country nationals in host country & \\
\hline Electronic resources/Internet & \\
\hline
\end{tabular}


In the questionnaire, students were asked if they had any family members or friends currently studying abroad or who had studied abroad in the past.

UK: Of the thirty-nine questionnaire respondents who were studying in the UK, twenty-one had family or friends who were currently or who had studied abroad in the past. Of these twenty-one, only fourteen students provided further information. They described having siblings, friends, cousins and aunts who had studied or were studying abroad in such countries as the U.S., Canada, UK, Singapore, Australia, and Germany. Of the eight interviewees who were studying in the UK, only three indicated in the questionnaire they had family or friends who were currently or who had studied overseas. Of the three who did, one had a brother studying in Singapore, one a sister in the UK, and the third had both a cousin in the U.S. and a friend who had studied at University UK.

Ireland: Of the thirteen respondents to the questionnaire who were studying in Ireland, nine had no family or friends who were currently or who had studied overseas. Of the four who did, two did not give any further information, while the third student indicated she had a cousin who had studied abroad. The fourth student, IR\#26 had an uncle who had acquired Canadian citizenship. Of the three who said they knew people who were or had studied abroad, they indicated this study took place in a wide range of host countries such as Canada, Australia, Germany, England, Spain, the U.S., and the UK. Of the five interviewees studying in Ireland, three said they had family or friends who were currently or who had studied abroad, and one had a cousin studying in Australia and the other was IR\#26 as noted above. The remaining student did not give any further information. None of the family or friends of the respondents had studied in Ireland, although IR\#19 said a former colleague had worked in Ireland.

U.S.: Of the twenty-two questionnaire respondents studying in the U.S., ten knew people who were currently or who had studied abroad in countries such as the U.S., Canada, and Australia. For three of the ten, the people they knew were friends, while a fourth student indicated family members. Six of the ten although responding 'yes' did not give any 
further information. Of the four interviewees studying in the U.S., three said they did not have any family or friends who were currently or who had studied abroad, while the fourth did not give any further information.

There was obviously some confusion among respondents about this question as the interviews revealed that more than three of the interviewees studying in the UK, for example, did in fact have family or friends who were currently or who had studied abroad. One such student was UK\#278 who had two friends who had begun their studies at University UK the year before him. In addition, as the question only asked about 'studying' not 'living' or 'working' it did not always capture data from students who had family or friends who were or had lived or worked abroad, such as UK\#62 who had an uncle who was living and working in California though she did not indicate this in the questionnaire.

Family

Students referred to the importance of having family who were or had studied abroad in either the same or in another host country, lived or were living abroad, and who provided influence, support, advice and information.

1) Family in host country: Students mentioned that in selecting a host country the presence of family in that country or having had relatives who were living or had lived there was important. This meant there was already an established social capital network in that country or some form of existing social capital which they could use to gather advice and information about that country.

Of the questionnaire respondents studying in the UK, nine indicated they had family members or friends who were studying or had studied in the UK, including two friends and a sibling who were also studying or had studied in University UK. UK\#421 and UK\#57, for example, made comments such as "Have relatives close by" and "feasible as family is in UK" as being important to them in selecting the UK. UK\#421 also said having "relatives here" was her third most important reason for choosing the UK. UK\#213 said "family" and UK\#396 said "brother" were their second most important reasons for choosing the UK, but 
what exactly these two students meant by these answers, such as whether they had family or siblings in the host country or these people had simply provided support and advice, is unclear. Neither were interviewees so follow-up was not possible. Although indicating in the questionnaire she did not have any family or friends who had or were studying abroad, UK\#502 revealed in the interview she had a cousin who had studied in the UK and was still living there at the time of the interview.

As noted above, none of the students studying at University Ireland had family who were or who had studied in Ireland. Of the questionnaire respondents who were studying at University U.S., and who said they knew someone who had or were studying in the U.S., none indicated these persons were family members. It is important to reiterate that six of them although responding 'yes' to this question did not give any further information.

2) Family in other potential host countries: Some students also had existing social capital in the form of family who were living in other host countries they considered for study, such as UK\#101 for whom the U.S. was a second choice host country and who had a cousin studying there. When asked about this in the interview, she said, "I just know she study in Boston but I'm not sure the name of the university" giving an impression she perhaps had not made much use of this source of existing social capital.

Existing social capital was sometimes seen as a draw for studying in a certain country. UK\#367 and IR\#6 had family members studying in other host countries they considered which made these countries more attractive possibilities for study. UK\#367 said if the U.S. had offered one year Master's degrees like the UK, he would not have chosen the UK, "...it would have been U.S...Because more of my family been there. My cousin's been there..." IR\#6 studied in Ireland because of an exchange programme in which she completed her final year in Ireland. She said if she had been able to choose where she wanted to go for this exchange programme, she would have selected Australia "Because my cousin is in Australia...He's four years older than me... [he] went to the Sydney to complete the Master degree." 
For IR\#26 and UK\#62, having family in other host countries proved to be a factor that made these countries unattractive to them. IR\#26 had family living in Canada, "My uncle...he got a citizenship in Canadian. He's a Canadian now, and his son went to the University of Waterloo in Canada." The student wished, however, to experience greater independence during his time abroad so chose not to study in Canada saying, "I prefer to study in a country I know nobody." UK\#62 had an uncle living in the U.S. "...he's been a NASA scientist in California. He's settled in California at the moment" and "...he was influencing me to come over there..." Similar to IR\#26, greater independence was an important reason for her in deciding to study abroad, and although she briefly considered the U.S. she decided against it because, "...California would probably be the only place I would love to stay but my uncle is there so, no...That's one reason I just stayed away from it." She stated the UK was the best choice for her because:

"...there are too many relatives in America for me, and they would have just butted into my life and tried to get me married... they just can't cope with the fact that I am having a nice, happy, single, independent life."

3) Family in home country: The existing social capital students had in their home country drew some students to consider study there first, as well as being a reason for returning home after graduation. Students, like U.S.\#149, considered studying at home because of the strength of their existing social capital there. She said one positive thing about studying in China would have been, "...I can live near my parents and also my boyfriend is in China now." For U.S.\#162, the existing social capital he had at home was an attraction to and an advantage for returning to work there after graduation saying, "...you have to think about some intangible benefit, add that to your package, for example, your friends, your network, and Asia is the place you feel more comfortable with..." As with the two themes above, the established social capital networks in students' home countries could also be a factor in making international study more attractive, particularly for students who were looking to obtain some independence during their time abroad.

4) Family as source of support and influence: Student said family members had sometimes influenced not only their decisions to study abroad but also where, as well as 
providing support and encouragement. In some cases, this support was financial. During the interviews, students were asked to give details of their funding situation with some stating that the financial status (or financial capital) of their family members (especially parents) was critical to them in being able to study abroad. This obviously is most relevant to completely or partially self-funded students.

Twelve interviewees said they received financial assistance from their parents. Only three students said their parents paid all their expenses. UK\#2 said, "...my parents just say they will support me financially...wherever I decide to go." Six said they had some help from parents, but also funded themselves via student loans and/or savings from work. U.S.\#162, for example, took advantage of all three avenues of funding saying his funding came from, "...all my savings from my six years working in Deloitte. So I pay about onethird of all the tuition and living expenses of [University U.S.] by myself. The other twothirds is from personal loan. Either from family or from bank." Finally, three funded their studies using a combination of parents' help and funding from their universities. UK\#101, for example, said, "Get money from my family. The other part is I get the scholarship from [University UK]."

UK\#367, although stating his family members did not have a lot of influence on his decision to study abroad, said their financial support was crucial:

"No, the decision was made by me. And then I take the permission because the funds, how much is it available...I didn't know that so I had to ask this is the funding required, can I go abroad? And the answer was yes and everything was done by my parents...[they were] very supportive."

Family members were also sources of emotional support and encouragement for students. UK\#62 talked about the support from her family in regards to studying abroad:

"They have been very, very influential, and very, very supportive. My mom especially. And my dad as well. When it comes to careers he has been very 
supportive...they were just like, '...you're a confident person and you have it in you. Just keep it going'...they have always supported me in what I wanted."

U.S.\#158 also said when he was trying to decide whether to study abroad, he found his family very supportive, "Actually before I apply for school I talked with them and just show my interested to go overseas and all they want to do is just support my decision no matter where I'm going." UK\#133 similarly stated, "My parents, my father and my mother, insist that if you want a good career in future, you need to go abroad...strongly they agree with me."

IR\#20 described how his parents were both supportive and had a lot of influence on his decision to study abroad as well, saying:

"...in Chinese culture parents is a very important part in a particular person's life. My parents hope me to do further study and even me want to stay for a long time in abroad country...my parents also prefer me to study in Ireland..."

His father especially wielded strong influence over this decision, "My parents, especially my father strongly advised me...to study in another country. He thinks it better for me...My parents never...worry about the price of the fee, and my field of the life. They just support us because they have money..."

UK\#101 also said although her family did not have a lot of influence on her decision to study abroad they were very supportive:

"Yeah, they support me. When I decide I want to go to UK to do the Master's degree they are very happy and supportive...actually they all think the overseas degree is more important than the degree which I can get in China."

UK\#375 talked about how his family was supportive because doing a Master's degree abroad would mean, "... my options are open now, like more, and that's how they 
understood it." In addition, his father, who had missed an opportunity to live and work in the UK was influential in his selection of the UK:

"...I just well already told them that I am thinking of UK or Australia, U.S., all of these countries, and when my dad heard UK, he is very fond of UK so he said, "You should go to UK." Fine then, I listened to that part..."

Interestingly students mentioned, as a result of their international experience, having become a source of existing social capital to others they knew who were contemplating international study. For example, IR\#25 acted as a source of existing social capital for his cousin who went to Ireland to study after him, and when asked if he had given her advice prior to living in Ireland responded, "Definitely."

5) Family as source of information: Students also looked to family members, particularly those who had or were currently studying abroad, for information with which to inform their decisions about undertaking international study. When asked who gave her advice and information about studying abroad, IR\#6, for example, said "[her] parents gave me lots of suggestions." Her cousin who did a Master's degree in Australia was also helpful, "...we just talk about maybe to see whether the college is suitable for me or the life, the society things...About examinations or the assignments..."

IR\#26 mentioned how his uncle and cousin in Canada provided advice and information about studying there, "I usually talk to my uncle about these kind of issues. He say in North America it's a very good place to do the research, and sometimes he suggest me to come to Canada." IR\#25 had an uncle who worked as an education consultant to whom he turned for advice:

"...my uncle who work in the agency, he just give me a very big advice for me. He said, 'You have to challenge yourself. Not only in China. There's big opportunity to go outside and to learn some skills and experience and come back to your country and you can find a job'...Most of the Chinese knows you want studies go abroad 
the three choice Canada, the UK, and U.S...my uncle work in an agency, he know everything about this."

UK\#502 had a cousin who had also studied in the UK, though not at University UK, and was helpful with advice and information about living there, "...she helped me a lot...she just offered me some instrument for life...how to get some...food and drinks at the beginning of my life here..." UK\#101, for example, said her 'brother' also provided her with some information and advice about studying at University UK, "I just learn from my brother, and then sometimes he show me some pictures about the university." Lastly, U.S.\#158 said his family offered advice and information about which specific host country would be best:

"...sure they will support that but they gave me advice and U.S. is the best and then you make your own decision...I guess it's based on their experience...they can got information on TV, or some newspaper...they only [know] U.S. is the best but they don't know which university is good or not."

\section{Friends}

Students referred to the importance of having friends who were or had studied abroad in either the same or in another host country, and who provided influence, support, advice and information. Within this theme the term 'friend' refers to non-family members, including acquaintances, academics, teachers and co-workers.

1) Friends in host country: Students mentioned that important to them in choosing a host country was the presence or previous experience of friends in that country. UK\#375, for example, had friends who had studied in the UK before him:

"...there was one friend of mine who used to study in Coventry...Then I was supposed to come to this university last year but there was some sort of a problem. At that moment there was another friend of mine who came...As of now he has already finished his education." 
U.S.\#162, in addition to his English tutor in Taiwan who was from the U.S., said he knew some "Teachers and also some co-workers...predominantly co-workers" who had lived or studied in the U.S., while U.S.\#165 said "...actually I have my colleagues from IIT [his undergraduate institution] who are studying here." Among the top three reasons for choosing their host country, it was the number one reason for IR\#15 ("My friends are all here"), and the number two reason for both UK\#367 ("friend's good experience ...was convincing enough") and UK\#396 ("friends").

A few students mentioned being influenced in their decisions by friends who had not only studied in the same host country but also at the same university. Comments included " $\mathrm{i}$ made a choice for Uk...as my friend had studied MA Marketing (same as me)...at [University UK]" (UK\#367), "friends in UK" (UK\#501), and "my friend was in Ireland" (IR\#14). UK\#133 had two friends who had studied at University UK, "...before I come to UK. Actually I have two friends, classmates...come to this university..."

2) Friends in other potential host countries: Students also mentioned existing social capital in the form of friends who were living in the other host countries they considered for study, such as UK\#375, who said, "...there was some friends of mine who are in the U.S. and some in Australia though these guys were already there before me. They are a year ahead." IR\# 6 had some friends studying in other host countries too, "I have lots of friends in USA and Canada. Also in England." IR\#25 had friends who were living and had studied in both Canada ("...I got a couple friend in Canada as well"), and the UK ("...also I got some friends there. My high school friends. They been there like eight years, nine years something like that. In Manchester. In London. Different cities so I will decide to choose there for second choice").

Interestingly, the students quoted here did not select any of the countries where they had friends as their first choice of host country.

3) Friends in home country: The existing social network of students' friends at home was noted mainly as a resource for use in their decision-making prior to going abroad. UK\#367 said he talked to his school teacher about living and studying abroad, and UK\#502 had a 
teacher from home who had studied in Australia in the past from whom he got information and advice. U.S.\#149 discussed the benefits of studying at home instead of abroad with students senior to her in her undergraduate university, as well as teachers who had studied or worked abroad as Visiting Scholars, while IR\#25 consulted "a friend of my father" who was in the same career field about the value of studying abroad.

4) Friends as source of influence and support: As in the case of family members, students said friends also provided influence and support in regards to their decision to study abroad and, in some cases, which host country and institution to select. UK\#101 said her brother who had also studied in the UK had some influence on her decision to study abroad, "I have like a brother who studied here but before I come here and he told me that I should come because I can gain a lot of different experience here, different from China..."

In the interview, UK\#375 stated, "So definitely there were some of my really close friends who are in U.S. and Australia who really influenced me to think of taking an overseas education", and when asked if these friends had influenced his consideration of the U.S. and Australia as his third and fourth choice host countries, he replied, "Yes, definitely." U.S.\#162 said his former co-workers and teachers who had studied in the U.S. had influenced his choice of the U.S. as well as the kind of university he selected:

"...I know that I'm going to graduate...in overseas whatsoever but I think they help me decide in the sense of which kind of school to apply and also what country to go...like U.S., UK...I think most of them lean to U.S. so that is part of my decision driver...And also I talked to people who graduated from U.S. schools and from UK schools..."

When IR\#6 was considering doing a second Master's in Ireland, she was influenced by her supervisor from her first Master's programme, "And also, when I studied in the last college I talked to my supervisor for the dissertation lots about the whole things and they suggest me to go to [University Ireland]." 
5) Friends as source of information: Students discussed using friends as sources of advice and information about studying abroad in general, such as U.S.\#149, who consulted her teachers who had studied or worked abroad, ".... when I applying for graduate schools I just talk with them about the universities they studied in before, and what kind of courses they offer, like that." UK\#2 said he knew "Some friends of my high school friends and Bachelor degree friends...some are my classmates...at least two to five percent of people I know studied abroad." When asked if he got advice and information from these people, he stated, "Yes, I did. I discussed with them which university is better, and even which country is better to go...Some of them studied in UK...a few studied in Denmark, in Holland, or some other Europe countries. And some of them studied in America...we discuss with each other and exchange the information about universities."

U.S.\#162 utilised two sources of existing social capital to gather information about international students. The first was former classmates:

"...some classmates or people who are senior...and then when you see that they pursued an MBA degree in U.S., you will take a look at their career development after MBA. You will have a knowing what kind of school you are looking for."

The second source was his English language tutor:

"I talked to my English tutor in Taiwan about my interest in UK degree...he's American, and then he say for business...'You want to learn from capitalist world, and for Europe is just more like a socialism area which is I think the whole value and logic behind business is totally different.' So I have to think about that."

Students also got advice and information from friends about potential host universities prior to going abroad. UK\#278, for example, also had two friends studying at University UK who provided him with advice and information, "...I preferred [University UK] in comparison to other universities because...I got good reviews from my friends that this division of plant science is really good..." 
A series of quotes from UK\#375's interview demonstrates how, prior to his study there, he utilised his existing social capital to gather a wide range of information about his host university. When trying to decide whether to study abroad, UK\#375 said he "...started consulting my friends and some people who had already been here. And that's how I tried to gather as much ideas as possible...Yes, they were definitely the key people who helped me." He said one of these friends provided a lot of advice and information from his own experience, "...started giving me ideas about how UK universities goes, and all those stuff. Initially when I was trying to search for some colleges, he was one of the persons whom I was contacting for some of the details..."

In addition, the friends offered information and advice about specific programmes of study helping him to decide which course was best for him:

"These two guys were there who were helping...They were telling me that these were some of the courses which was going on...when I was in India, these friends of mine...they were sending me some informations. They were saying these are the course works which we are doing, this is the assignments, and really helped me. I said okay, fine. That's it. I want to do this one."

Students' comments also highlighted the variety of friends and acquaintances from whom they gathered information and advice to inform their decisions. IR\#6 said she consulted with students from her undergraduate university who were senior to her and had participated in the same exchange programme to Ireland, "...we have the higher grade people. They came here earlier than us but we came from the same college in China, and they gave us some suggestion." IR\#19 got advice and information from a friend, "...who did his Master's in this school and he's now in very good position in a company", and talked to former colleagues who had worked abroad:

"I spoke lots of times by working we discuss on a coffee or catching a beer...I was always keen on how the economies work, and how is the some specific field of consulting, and how is the cultural life over there...how are the people, and how is 
the living, and what are the attractions of that place...what was the difference between working in India and in America. So that kind of thing."

When considering doing a Bachelor's degree in Ireland, IR\#25 talked to his friend living there, saying "...also before me there's a friend, he's studying [University Ireland] as well. He's studying PhD at the moment...and he just give me lots of advice...." Later when considering pursuing a Master's degree, IR\#25 said he received advice and information from one of his lecturers in Ireland, "...he just give me some advice on which college is better and your further career and five years development and he just made a plan for me." When he was considering studying in the UK, UK\#367 consulted a friend who had studied at University UK and who strongly influenced his decision to study there through providing him with a lot of information regarding the standard of living, the teaching quality and "On course works." He also spoke with a former school teacher, "It was my school teacher who was recommended to me so she had given experiences of her past students who had studied here and how they made their life here...."

\section{Partners}

All students were asked whether they had a partner or spouse who was living with them abroad. Five students said their partner or spouse was living with them, but none said whether this was for the purpose of the student's education or for some other reason. As mentioned under the sub-theme 'Visa process' associated with potential human capital, UK\#446 stated a reason important in deciding on a host country was the ease with which he could get a visa for his spouse to accompany him. Two other students referred to having a partner in the same host country as an important reason for choosing that country, such as U.S.\#56 who mentioned this theme twice, once in response to why she decided to study abroad saying "I am in love with someone here", and as her number one reason for selecting the U.S., saying again "I fell in love with somebody here." It was also the number one reason IR\#14 chose Ireland saying "my boyfriend in here." There were no comments on this theme from students studying in the UK. 
Due to the time constraints of the interviews, I was not able to explore the ways in which partners acted as existing social capital for students. The data I was able to collect showed the two interviewees who were living with partners in the host country, UK\#2 and IR\#25, were the same nationality as their partners which may indicate that through shared nationality and cultural background the partner did provide some type of existing social capital for the student. Although not mentioned by any of the students in the study, existing social capital in the form of partners living with them, and depending on whether the partner is working, studying, or participating in some other activity outside the home may provide a base from which further social capital can be developed, such as making new friends through the partner or becoming part of the local community.

Home country alumni

This theme refers to existing social capital in the form of international graduates, or alumni, from the student's home country who provided information and advice to students interested in studying abroad, especially in the same host country or institution. In the questionnaire, three students mentioned having contact with alumni from their home country. When asked the reasons important in deciding on a host country, for example, UK\#62 said "Recommendations from seniors", and U.S.\#27 replied "alumni in home country." This theme was also the number three reason for choosing the U.S. for U.S.\#27 who said "alumni in Asia." Further evidence from the interviews to support this theme can be found in the discussions above of family and friends as existing social capital.

\section{Education agents}

Students mentioned how education agents were an important source of advice and information when making decisions about international study. IR\#18, for example, said "Agency advice" was his number two reason for choosing Ireland. UK\#2 said "Common Appraise in China (especially appraises from 'study abroad agency' in China)" was important to him in selecting a host country, and when he was looking for information about universities or about living abroad he consulted an education agent, "And sometime we went to some agencies and the agencies provided us quite a lot of information..." 
UK\#367 said when looking for advice and information about studying abroad, he also consulted an education agency, "And then there were foreign education institutions who wished to help us out...consultants...so consequently I went towards Edwise. They were really helpful and they give you information, they give you contacts to talk to past students."

Education consultants were also able to provide students with information on particular host institutions as noted by UK\#375. UK\#375 stated he used an education agency known as Edwise:

"...I went to Edwise and they gave me all the options...They told me that mainly you just have to fill out these forms and we will take care of all...I filled out the forms and gave it to them and got an answer from five universities and I selected [University UK]...Edwise is very good with [University UK] so Edwise was actually telling me all the details..."

Finally, as noted earlier under family as source of information, IR\#25 had an uncle who was working as an education agent and provided him with a lot of advice and information.

Home student population in host country

Students mentioned the presence of other international students from home in the host country as important to them as a source of existing social capital to tap into. For example, when asked reasons important in deciding on a host country, U.S.\#28 replied "Presence of relatively large international student body from my country" and U.S.\#59 said "Lot of people come to US for studying from India. So informations were readily available." Another example was given by UK\#45, who when asked if the UK was his first choice said, "No. In fact, my first choice was the USA, because there are more universities in the USA, and most of my classmates applied for studying there." For IR\#10, this subtheme was of at least significant importance since he commented on it three times in the questionnaire. When asked for the reasons important in deciding to study overseas and on a host country, and his number two main reason for choosing Ireland, replying to all, 
"international ratio." Finally, for U.S.\#158, one attraction of studying at University U.S. was the large community of students and scholars there from home:

"[University U.S.] should have more than 200 or 300 Chinese student or scholars here so I have meet some of them before....And every year maybe fifty, sixty undergraduates came here to [University U.S.], and for graduate student the number should be higher than this, and I think maybe every year around ten or fifteen scholars came here to do like a Visiting Scholar..."

\section{Community of home country nationals in host country}

Similar to home country student population in the host country, students mentioned the importance of having a sizeable community of home country nationals in the host country which could be a source of existing social capital. U.S.\#164, for example, said the "Indian community within the US" was his number three reason for choosing the U.S., while UK\#375 said he was attracted to the UK because:

"...if there is any other place away from India which you can call yourself, that would be only two, UK or U.S. There are so many Indians over here now...So it really feels as if you are at your home so that was the main thing which was there because if you have a lot of Indians and you have a lot of stuff."

\section{Electronic resources/Internet}

Students commented on their use of various electronic resources to find information that informed their decisions regarding international study. Using these resources, primarily those found via the Internet, they were able to access information on studying abroad, as well as potential host countries and universities. UK\#375, for example, said, "...definitely Internet was the main source because if you are sitting at home you can't like expect everything to get...you have to find it through the Internet." Regarding studying abroad, IR\#19 said, "Ninety-nine percent of the information was from the Internet", and described the range of information he gathered, "...different kinds of rankings and... what are the top 
business schools of those different countries, and I have grabbed the whole information...how is the teaching and methodology within the business school...how well this business school can provide career prospects."

UK\#2 described the information he obtained from the Internet as including "...about living overseas and how you take test...like IELTS test, GRE test and stuff." When asked what kind of information he retrieved from the Internet, UK\#502 said he used a combination of websites to gather information:

"...basically I just focused on two things. One is the universities and their...subjects and the second is about career future. These just the reason I decide where I should go...I read some other websites not only universities' websites. You know sometimes universities' websites pages you can't believe all of them...just like the official newspapers or something."

Students used general education websites to search for information, such as university rankings, to help them make decisions about where to study. When gathering information about living abroad or studying in the U.S., U.S.\#165 said, "I relied on Internet searches actually...there are plenty of sites which I saw during my application process and one of them was phds.org. I used to just look about the rankings of the PhD institutions that I am applying." IR\#25 also gathered information about doing postgraduate studies in Ireland from a general education website, "Grad Ireland. There's a website for graduates. So there's some advice for how you choose college, how you fill the application forms, what you want to study, which college is have strengths and weakness."

Other students explained they visited host institution websites to find information to inform their decisions. U.S.\#28, for example, referred to the importance of these websites to him in deciding on a host country, "the burden of doing research about American unis is lesser compared to other countries - American uni websites are fairly straightforward in navigating and answering questions about funding and such." 
In addition, students discussed their use of social networking tools, such as chat rooms and blogs, as a source of existing social capital from which they received not only information but also advice and support. UK\#133, for example, said he used, "...in China we use the Shaoling so...it's some website like the Facebook...so we usually use this website." When looking for information online about universities or living abroad, UK\#2 said, "We got some very good website in China. Some people on that website some are from the abroad countries, and they just share their experiences with us and that's very helpful..."

UK\#502 used online blogs to gather information about studying and living in his host country:

"There's one famous called Blog. I like to read these blogs and diaries...Basically I didn't read only one person...I just scan these websites to see what is said about life abroad...they just mainly talk about life...just like you don't have to buy this, you have buy that...just daily life."

UK\#375 was able to use social networking sites to contact people who were or had attended his host institution:

"Yes, on Facebook there were some groups. There is one more known as Orkut that is very famous in India. There were many people from [University UK] who were a part of it so I used to ask these people where we can stay, what is good about this university. They were really good in that. Yes, definitely there was certain blogs as well which I subscribed and trying to read about [University UK]...what is going on...what's good, what's bad, and all these things."

UK\#375 described some of the information and websites he searched online:

"...one was the British Council...that was key actually because when I was trying to search for universities regarding the specific course...and the Times Education rankings, these rankings are the first things which I was looking for when I was 
trying to select a college, trying to select a university....And that's how I tried to gather as much ideas as possible..."

Some students talked about using social networking tools to contact students from their home country who were already studying in the host country. U.S.\#158 talked about using a Chinese social networking site similar to Facebook, "We have discussed with these guys who already in the USA...Most thing is about the living. How to live. And I think this is the most important thing." U.S.\#149 talked about her use of chat rooms specifically for Chinese students as a source of information, "...there's some kind of chat rooms online just for the Chinese students who want to apply for U.S. graduate schools, and we can gather lots of informations there, especially the offers and admissions from U.S., you know each year." IR\#19 explained how he made use of these tools:

"...I was more into Indian students forums because...if I talk to an Indian student in Ireland because we both come from same country...and especially most of the Indians are IT background right so it's like what is the opportunity because we have similar profile so that's the reason why I was more doing the Indian forums."

It is important to note that many students used more than one, and sometimes a variety, of electronic resources in their search for information with which to inform their decisions about studying abroad. When asked what kind of resources she used, UK\#62 replied, "Internet obviously. Can't live without it...I went through FindaPhD.com, looked through the projects...I went through all the universities' [websites] ...five, six universities that I was interested in." In addition, she said, "Obviously I went through the profiles of many ex-students and went through the scientific papers I was studying...I was going through students who did not sound obviously English...I was trying to see their track records..."

In explaining the resources he used to gather information, UK\#278 he said "It's usually I think the university website and Internet. And I would like to mention the website of British Council. It really helped a lot. And there is EducationUK.org. So they were really helpful." When asked, besides family and friends, what other sources he used to get information about studying abroad, UK\#367 responded: 
"The Net. Social networking sites. So get in touch with students here then just ask them like how it is and site was Orkut...And then there was the British Library I managed to go and find the rankings of universities...the courses..."

When asked what resources he used to gather information, U.S.\#162 stated, "...the blogs or the websites, the online chat rooms, for example, like Business Week, they have a good discussion area about b[usiness] schools..." He explained the information he gathered from these sources was:

"...more about the programme. And also more about the job hunting performance of the current students...if I'm, looking for let's say [University U.S.]...and then I will compare like how many people get offer from my dream firms. That can influence my decision but typically the schools don't tell you that. You have to collect that basic information in those sort of resources."

\section{Potential Social Capital}

As can be seen in Table 25, students hoped to increase their social capital during their international experience through developing networks with new people in general, with other international people and students, and academics and professionals in their field in an effort to create a social network that might yield future benefits. Each of these are discussed in detail below the table. Potential social capital was the least mentioned type of capital overall. 


\begin{tabular}{|l|c|}
\hline \multicolumn{2}{|c|}{ Table 25: Potential Social Capital } \\
\hline \multicolumn{1}{|c|}{ Themes } & \\
\hline Network with new people \\
\hline Network with other international people/students \\
\hline Network with academic/professional community \\
\hline
\end{tabular}


Network with new people

Students commented on hoping to increase their social capital through meeting new people in their host country. When asked what was important in deciding on a host country, UK\#381, for example, said "the kind of crowd I would interact there", and UK\#246 said wanting to meet "Good people." UK\#375 said one reason important to him in deciding to study abroad was "Meeting new people." while for UK\#446, "Good country social, people, etc." was his number two reason for choosing the UK. IR\#6 stated, "...of course I want to maybe make good friends" during her international experience, and U.S.\#162 said "One is the friendships that I build, the networks that I build." For UK\#367 one of the benefits of studying abroad was "Obviously...you get to see new people", and this was important to him because, "It gives you a new experience...It's not essential but if you get to speak to others you get to know other people, it helps you." Besides getting a degree from an international institution, U.S.\#158 hoped to make, "...a lot of American friends. This kind of wealth in life."

Network with other international people/students

Students commented on hoping to meet people of other nationalities, including other international students, in order to create social networks. U.S.\#4 commented on this theme twice saying it was important in deciding on a host country that "people from all over the world come to get educated/experience here", while her number two reason for choosing the U.S. was because it has "students from all over world." For U.S.\#5 this theme was of at least significant importance because he mentioned it three times saying "...exposure to working with international people (from all over the world)" was important to him in deciding to study abroad and on a host country. In addition, his number two reason for choosing the U.S. was because of the "Great exposure to people from all over." This theme was not a number one reason for students studying in any of the three host countries and was actually not mentioned at all by students studying in Ireland.

UK\#278 said through international study he hoped to "...meet all sorts of people and get to know more different people from all different countries..." UK\#101 said what she hopes 
to gain from international study is "... I can maybe make a lot of friends from different countries" because, "...sometimes a logic thing is different between us so we can share something...You know about my field and maybe for different countries there are different development so I can catch some advice or suggestion from my friend..."

IR\#19 said besides an educational qualification, he hoped through international study he would gain, "Network of the people, students from different countries" while UK\#2 hoped to gain the following:

"...when you finish your Bachelor degree in China, most of your classmates will work in the same city...but when you study here you got quite a lot of classmates who will work in different place all over the world so it's quite good to have all these communications, all these networks with people around the world."

U.S.\#162 also believed one of the benefits of studying abroad was meeting people from other countries and making future contacts:

"...by knowing about their culture and their value, it will make easier for me to either build friendship or business relationship between people from that country in the future that I may possibly meet in my career... [and] if I have a chance to go to their country or do business with their country, I know those people that I meet in schools are the number one choice that I got contact from there."

Network with academic/professional community

Students mentioned the opportunity for networking with the academic or professional community was important for future research and career opportunities. For U.S.\#113, for example, access to a "scientific community" was important in deciding on a host country, while for UK\#414 "contact with leading researchers in the particular subject" was important in deciding to study abroad and was his third most important reason for selecting the UK. For both UK\#381 ("networking") and U.S.\#7 ("working with experts in the field") it was the second most important reason for choosing their respective host 
countries. This theme was not a number one most important reason for any students, and was not commented on at all by international students in Ireland.

Besides a degree from an international institution, U.S.\#149 hoped studying abroad would allow her to meet "...lots of other maybe very famous persons in your area...'cause in China you cannot directly connect with them..." UK\#278 said he hoped to become part of a professional network:

"...how many people you meet and how much you progress in science...you make contacts...know what other people are doing so...you get connected and you're amongst the people who are really doing science and when you go to these conferences you are networking so it really helps."

This chapter presented an analysis of participants' responses to the questionnaire and interview questions using the theoretical framework of human, cultural, and social capital. Chapter7 offers a further discussion of the findings. 


\section{Chapter 7: What does the data show?}

The primary purpose of this chapter is to answer the research questions presented in Chapter 1. In addition, the chapter discusses briefly the overlap of the different forms of capital found in the data, and offers a comparison with those studies using the Push-Pull Theory presented in Chapter 3.

As discussed in Chapter 4, the three types of capital theory used in the research imply that some investment must take place in order to accumulate fresh capital. The international students in the sample made the decision to remove themselves from the labour market and to undertake postgraduate study abroad incurring opportunity costs during the study period, such as lost income. In doing so, they chose not just to defer consumption of their existing capital, but to invest it in the acquisition of new capital through an international postgraduate education. From this investment, they hoped to accumulate other kinds of new capital or further develop their existing capital in the form of cultural or social acquisition, such as learning a new language and social networks (Waters, 2006a; Waters and Brooks, 2010). The choices made were strategic and a means by which they hoped to distinguish themselves from other graduates and secure positional advantage in the labour market and in society at large (Brooks and Waters, 2009b; Waters and Brooks, 2010).

The data suggests that the students investigated had an understanding of the investment aspect of undertaking international education, and that this investment would potentially yield benefits. None of the students in the sample actually used the term 'capital', but when asked directly during the interviews if they viewed international postgraduate education as an investment, several confirmed their understanding of it as a kind of investment activity (see comments from IR\#19, p.172; and U.S.\#162, p.175-6 and p.218). In other words, although studying abroad may not have been the preference for all students in the sample, they obviously believed this option was worth the investment and would yield a high RoR (Agarwal and Winkler, 1985). Furthermore, they also chose host countries which they felt would yield a high RoR on their investment (Sakellaris and Spilimbergo, 2000) (see comment from UK\#278, p.200). 
I turn now to the four main research questions presented in Chapter 1.

\section{Research Question\# 1}

How do human, social, and cultural capital rank amongst the various reasons international postgraduates pursue international education?

Human capital: Human capital was the most frequently mentioned type of capital (existing and potential combined), and seemed to be the one the students in the sample spoke about most clearly. I suggest this is the case because it is connected relatively easily with conventional economic definitions of capital and is perhaps the easiest for students to understand and observe. It is, for example, straightforward for students to see a direct connection between undertaking higher education and such human capital benefits as higher salaries. While students may not be able to calculate exact monetary figures for the RoR on this educational investment, they are aware that more education usually leads to better career opportunities and higher salaries (Schultz, 1961; Agarwal and Winkler, 1985; Becker, 1993[1964]). For instance, some students claimed that investment in an international education would distinguish them from others in the labour market (Throsby and Heaton, 1995; Healy and Côté, 2001) (see students' comments under 'International degrees and job opportunities', particularly UK\#2, p. 182 and UK\#278, p.183; and UK\#367, p. 183-4 and U.S.\#162, p.184).

The formal qualification was considered the most important acquisition from their international experience, and they believed that its possession would 'signal' to employers that they had obtained rare and valuable human capital (see comment from IR\#26, $\mathrm{p}$. 183). Students also seemed to understand that the migration aspect of international education could foster the development of value-added and country-specific human capital, such as language, cultural and professional skills that have been adapted to a particular host country context (Schultz, 1961; Murphy-Lejeune, 2002; 2003; WiersJenssen, 2008) (in addition to the above, see comments from UK\#375, p. 184-5; U.S.\#113 and U.S.\#149 on p.185; U.S.\#149 and U.S.\#158 on p.186; and IR\#19, p.187). 
Cultural capital: Cultural capital was the second most mentioned of the three forms of capital. Students referred to several types of existing cultural capital sources from which they drew to study abroad. As with human capital, they seemed to understand that investment in an international education would yield returns in the form of cultural advantages, and social and professional mobility (Bourdieu, 1986; Schuller, 2001; Sullivan, 2001). Students appeared to recognise that cultural capital (e.g., reputation/renown of their host country education system, English language skills) was useful for the future, and especially when it could be converted into other forms of capital (McDonough et al., 1996) (see comments from UK\#375, p. 216-217; IR\#6, p. 218-219; and UK\#62 and U.S.\#158, p. 223).

I suggest that cultural capital was placed second in student estimation simply because it was seen as an extra benefit derived from their overseas education and not the main objective. Students considered a postgraduate qualification primarily as part of their human capital development, although it can also be seen as institutionalised cultural capital according to Bourdieu (1986). However, as noted in Chapter 4, the acquisition of cultural capital attributes is not wholly incidental as the chance to broaden cultural and intellectual horizons is an important, although not necessarily the most important reason, for some students to study overseas (Baláz and Williams, 2004; Motivans, 2009).

As noted in Chapter 4, Ong (1999) and Waters (2007) state that the acquisition of an overseas qualification symbolises a wide array of cultural capital traits and knowledge that have international recognition and value. Some students seemed to understand that an international education would increase their cultural capital at home (see comments under 'Increased status in the mind's of others' from p.227-229), as well as that of their families (see comments under 'Cultural capital gains for student's family' p.230). Finally, students were aware that certain acquisitions, such as English language skills, are associated with the dominant global habitus (the concept of habitus as developed by Bourdieu was discussed in Chapter 4), the accumulation of which would provide them with an inherent advantage (Sullivan, 2001; Moore, 2004) (see comments from IR\#6 and U.S.\#158, p. 223). 
Social Capital: There are important links between levels of educational attainment and social capital with social networks often advancing the importance of education, and education, in turn, enhancing an individual's social capital (Healy and Côté, 2001). Students mentioned social capital in two ways: networks at home as comprising their existing social capital and potential social capital resulting from the international education experience (Portes, 1998; Schuller and Bamford, 2000; Putnam, 2001). However students spoke much more about their existing social networks than they did of the social networks they hoped to establish during their study period (Dasgupta, 2000). In fact, social capital, and especially potential social capital, was the form of capital least mentioned by students in the sample overall. I suggest that there are a number of reasons for this.

First, as explained in Chapter 4, investment in social capital does not necessarily or primarily benefit the individual making the investment, but can, as well or instead, benefit others who belong to the network (Coleman, 1988; Burt, 2003; Putnam et al., 2003; Putnam, 2001). Therefore, students may not believe it to be in their interest to invest in the building of such networks, and consequently there is an underinvestment in this type of capital. Another reason social capital might have been the least commented on type of capital is touched upon by Bexley et al. (2007) when they stated that the educators they surveyed said "...students often failed to see the opportunities, such as career opportunities, available to them through their network memberships" (p.74). Thus it may have been that the students in the present research did not understand the importance of establishing social networks in their host country in order to generate future benefits, such as keeping in touch with supervisors for references and notices of opportunities.

Thirdly, Glaeser (2001) suggests that because time horizons are vital to social capital development, individuals who have a high likelihood of mobility are less likely to invest in social capital. For many international students, as they plan or are compelled to return home upon completion of their degrees, building new social capital networks during the study period may not seem worth the investment. Also according to Glaeser, cooperation and coordination are necessary for developing social capital and when people are different (e.g. ethnically, culturally) cooperating and coordinating becomes more difficult. In other words, students may expect that the ethnic and linguistic diversity they will experience 
abroad will make building new social capital networks more difficult and, again, not worth the effort or investment. Lastly, as noted in Chapter 3, Putnam et al. (1993) assert that social capital is often created as a by-product of other social activities. In this way, social capital overlaps and is complementary to other forms of capital, and was categorised as one of these other forms in the data analyses. In the present research, students' comments did demonstrate significant areas of overlap among the three forms of capital; examples of these are given in more detail later in this chapter.

\section{Research Question\# 2}

What human, cultural, and social capital did students possess prior to their postgraduate programme that:

a. enabled them to study overseas?

Underlying the research was the assumption that students would utilise their existing capital or that of significant others to further develop their own capital. Waters and Brooks (2010) maintain that international students are able to remove themselves from the labour market for an extended period because they are a privileged group who have access to considerable amounts of not only economic, but also the human, cultural and social capital necessary for undertaking international education. They state that these students demonstrate this "...privilege in a number of different ways, including the degree of parental support and involvement in education, familial expectations with regard to educational achievement and the amount of/quality of capital invested by the family" (p.221). While all students in the sample may not have necessarily been classified as 'privileged' in their own or host societies, in line with the argument of Waters and Brooks, they did have significant amounts of existing capital upon which they could draw in order to be able to study abroad. Examples of existing forms of capital can be found in the following tables in Chapter 6: Table 19 (Existing Human Capital), p.165; Table 21 (Existing Cultural Capital), p.203; and Table 24 (Existing Social Capital), p.232. Each of these tables is accompanied by relevant evidence from the research sample.

Human capital: Existing human capital which was utilised by students to pursue international education referred to the human capital that students themselves possessed. 
In terms of existing human capital that enabled them to pursue postgraduate level education, students mentioned previous university degrees or work experience obtained at home or in the same host country, other study they had done in the host country, and previous academic achievement.

Cultural capital: Besides institutionalised cultural capital, the data showed that students also mentioned embodied cultural capital, another type identified by Bourdieu (1986). The research findings suggested that embodied cultural capital was primarily equated with existing cultural capital. Students mentioned three types of embodied cultural capital as valuable in the pursuit of an international education. First was their own individual embodied cultural capital, such as previous experience in their current host country or their knowledge of English prior to undertaking study abroad. Second was the embodied cultural capital of their parents and significant others such as parents' education levels and whether there was a family tradition of studying or living abroad. Last was the cultural capital embodied by the students' home countries and home country education systems. In some home countries, international education was valued highly, and particularly so if undertaken in certain host countries.

Social capital: Students mentioned using the three types of social capital - bonds, bridges and links as discussed in Chapter 4 - to obtain the support, advice and information necessary for undertaking international education. As suggested by Brooks and Waters (2010), students existing social capital networks play an important role in facilitating student mobility through giving financial support, encouragement, advice and information that helps students to make decisions regarding international education. Similar to the findings of Brooks and Waters (2010), the decisions made by students in my sample were embedded in the students' existing social capital networks at home and abroad of family (bonds), friends and partners (bridges), and home country alumni, education agents and others (links). Students recognised they could draw on these existing networks to help facilitate their wish to study abroad (Coleman, 1988; Portes, 1998; Schuller and Bamford, 2000). 
According to Neri and Ville (2007) as explained in Chapter 4, international students arrive in their host country denuded of social capital to some extent; a situation some students recognised would happen. UK\#367, for example, said his preference had been to study at home because studying abroad meant, "no comfort zone (no family...no friends...)." Interestingly, some students looked on the partial loss of their existing social capital as a positive and viewed the distance from their home country and existing social networks as one of the benefits of studying abroad. They felt that living away from their existing social networks (particularly family) would allow them to experience personal growth in terms of increased independence (see comments from IR\#26, p.225-226; and UK\#62, p.225). This is one example of social and cultural capital overlap.

What human, cultural, and social capital did students possess prior to their postgraduate programme that:

b. influenced their choice of a particular host country?

There are many examples in the data of how students' existing capital (all three forms of capital) influenced their choice of host country.

Human capital: In regards to existing human capital, for instance, there are several examples of how students' previous experience studying in their host country influenced them to continue building their human capital by going on for another degree in the same host country (see comments under 'Previous degree/study/work done in same host country' from p. 166-168).

Cultural capital: As with existing human capital, for some students, their existing cultural capital influenced their choice of a certain host country. This existing cultural capital was capital developed from experience with that particular country through studying there for an earlier degree, visiting as a tourist, having some knowledge of the country prior to studying there or a family tradition of studying/living there and, as mentioned earlier, the cultural capital of their home country which valorised international education taken in particular host countries (see comments from IR\#25, p.204; UK\#501, p. 205; UK\#62, p. 206; UK\#375, p.206-7; UK\#501, p.210; and U.S.\#28 and UK\#2, p.211). 
Social capital: Similar to the findings of Brooks and Waters (2010), the existing social capital networks of students in my sample, including those comprised of family members, friends, partners and extra-familial networks (e.g., teachers, co-workers), provided specific links and recommendation to specific host countries for study. The experiences of contacts in these networks informed and reinforced students' decisions about where to study. Like Brooks and Waters (2010), these contacts were important in making study destinations less 'unknown' than they might have been otherwise. Evidence to support this is given throughout the section entitled 'Existing Social Capital' in Chapter 6 (see comments from p. 233-252). As noted above, some students wanted distance from existing social capital networks and selected or ruled out a host country accordingly (see comments from IR\#26 and UK\#62, p. 235).

\section{Research Question\#3}

What human, cultural, and social capital do they hope to gain from:

a. $\quad$ studying overseas?

Also underlying the research was the assumption that students choose to study abroad because they hope to further develop their existing capital or to accumulate new capital as a consequence of obtaining foreign academic qualifications - this was described as 'potential capital' in the thesis. Examples of potential capital students hoped to gain can be found in the following tables in Chapter 6: Table 20 (Potential Human Capital), p.170;

Table 21 (Potential Cultural Capital), p.214; and Table 25 (Potential Social Capital), p.253. Each of these tables is accompanied by relevant evidence from the research sample.

Human capital: Potential human capital was the most mentioned capital sub-category. Students obviously hoped to add to their existing human capital with an advanced degree. Students also hoped to gain new human capital from studying abroad mainly in the form of a high quality, cost-effective education with access to better resources for study that would lead to better career opportunities. Some potential human capital themes, such as access to specific course content or specialised programmes, exposure to specialisation in the field of study, and quick and easy admittance to university, mentioned by students are a result of an excess and differentiated demand as discussed in Chapter 2 (Li and Bray, 
2007). Finally, students mentioned that they hoped to gain experience of an economically developed country and ease of movement in terms of an easy visa process and opportunities for future migration.

Cultural capital: In regard to potential cultural capital, students hoped, by opting to study abroad, to acquire valuable educational credentials that would be recognised in the labour market due to the reputation and renown of their host country and its education system, and which would thus help them position themselves for social and occupational success (Sullivan, 2001; Moore, 2004). They also hoped to gain high status cultural capital such as international and cross-cultural experience, improved English language skills, and knowledge and experience of 'Western' values - all of which are required for the global knowledge economy (Brooks and Waters, 2009a; Waters, 2006a; Sullivan and Enever, 2009). Another important cultural capital attribute students hoped to gain was personal growth in terms of becoming more independent, and cultivating a more open mind and a greater international outlook. Interestingly, students also mentioned there were cultural capital gains for their families as a result of this experience.

Social capital: Participation in education is one way of sustaining and increasing an individual's social capital, particularly building social bridges between different groups in society (Healy and Côté, 2001). The students in my sample expressed hopes of developing social bridges and links during their study period. In terms of bridges, students hoped to meet new people in general (not only other international students) from a range of cultural backgrounds, including host country nationals and other internationals. Students hoped to develop social links within the academic and professional communities in their host countries for possible future research and career opportunities.

What human, cultural, and social capital do they hope to gain from:

b. $\quad$ studying in a particular host country?

Human capital: There were many human capital benefits students hoped to gain from studying in particular host countries. For example, they hoped to benefit from the high quality education offered in their host country, especially as opposed to studying at home 
(see comments under 'Education quality' from p.173-174), and a cost-effective education as offered in certain host countries through shorter programmes of study, lower tuition fees, and opportunities for funding (see comments under 'Short duration of study' from p.177-179; 'Cost of tuition fees' from p.179-180; and 'Funding opportunities from p.180182). Students hoped to develop their human capital, in this case health and well-being (Schultz, 1961), by choosing host countries where they could enjoy a high standard of living which included a nice climate, a certain degree of physical safety and security, less chance of racism and greater equal opportunity (see comments under 'High standard of living' from p.193-194). As discussed in Chapter 2, many international students select a host country that offered possible migration opportunities. Students in my sample also mentioned this as important (see comments under 'Opportunities for immigration' on p.201-202.

Cultural capital: As per Ong's explanation in Chapter 4 of 'location capital', another kind of cultural capital, selecting a certain location, such as a host country with a strong international reputation and profile is also part of the capital accumulation strategy. Students in the sample mentioned cultural capital benefits they hoped to gain from studying in particular host countries that were related to the reputation and renown of the host country in general (see comments from students under 'Cultural capital of host country' on p.215-216). In terms of the host country's education system, the reputation and renown of universities and academic programmes in that country, as well as the value and recognition of a degree from that country, were factors that students hoped would develop their own cultural capital (see comments from students under 'Cultural capital of host country education' from p.216-220).

Social capital: There were also social capital benefits students hoped to gain from studying in particular host countries. Students selected certain host countries because they had the impression that the local people would be nice and friendly (see comments from UK\#446, p.254), or the host country had a reputation for diversity so students believed they could meet others from all over the world there (see comments from U.S.\#4 and U.S.\#5, p.254). Finally, students chose certain host countries where they believed they would have the opportunity to create social networks with leading researchers and professionals (see 
comments from UK\#414 and U.S.\#7, p.255). UK\#278 explained that the inability to form links with academics in one of the host countries he considered during the decisionmaking period influenced his final choice of host country:

...even if you applied so some of the professors [in the U.S.] they won't ever reply to your e-mails and that matters a lot...but in UK it's really to be honest, the scientists are really good and if they are busy they will say "I'll get back to you next week.', and the next week they would...

\section{Research Question\#4}

What sources did students use to help them evaluate the benefits of:

a. $\quad$ studying overseas?

Coleman (1988) notes that an important dimension of social capital is the access to information channels via which individuals can acquire valuable information crucial as a basis for action. For students in the sample, these information channels consisted of their existing social capital networks, particularly family and friends. Family and friends provided students with valuable advice and information, for example, on what it was like to live abroad, tips for daily life, specifics on programmes of study and the educational environment, and details on potential host universities (see comments under 'Family as source of information', p.239-240; and 'Friends as source of information', p.243-245). Other social contacts who provided information to students in the sample were home country alumni and education agents (see comments under 'Home Country Alumni' from p.246; and 'Education agents', p.246-247). Although not always in direct contact with the home student population or the community of home country nationals in the host country prior to studying abroad, students saw these two groups as a form of existing social capital which they could tap into upon arrival in the host country (see comments under 'Home student population in host country' from p.247-248; and 'Community of home country nationals in host country', p.248).

Students also gathered information from a variety of electronic resources to which they had access to inform their decision-making. These resources were available primarily via 
the Internet and included general education websites, host country education websites, and university websites. They also used social networking tools such as chat rooms, blogs and sites like Facebook, which Putnam (2000) describes as a form of bridging social capital. Through these resources students gathered information on living abroad, filling out applications, admissions procedures, programmes of study, funding, and alumni career paths to name a few (see comments under 'Electronic resources/Internet' from p.248252).

The 'Availability of information' was categorised as a form of potential human capital although it also encompassed students' existing human capital as well. For example, students commented on the importance of having easy access to information about studying abroad because they did not want to spend too much of their existing human capital in terms of time and money on gathering information. The easy availability of information was also important to their potential human capital because it allowed them to make a more informed decision about the educational investment they were going to make (see comments under 'Availability of information' on p.200).

Another example of the importance of information to the development of human capital came under the sub-theme 'Education ranking and international standing.' As noted in Chapter 6, on the questionnaire students commented on the importance of the ranking and international standing of the universities in their (and sometimes other) host countries. When this was explored further in the interviews, students identified university rankings as one type of information they gathered to help them make a decision about where to study. Sources used for finding information on university rankings included the British Council, the Times Higher Education Supplement, http://www.phds.org, and the British Library (see comments under 'Education ranking and international standing' from $\mathrm{p}$. 174-176; and under 'Electronic resources/Internet' - U.S.\#165, p.249; UK\#375, p.248250; UK\#367, p.251).

What sources did students use to help them evaluate the benefits of:

b. $\quad$ studying in a particular host country? 
An important element of the decision-making process is the collection of information about potential host countries and institutions especially when international students are unfamiliar with the societies and educational systems of prospective host countries (Neice and Braun, 1977). Prior to undertaking study abroad, some students did have existing cultural capital in terms of information on their host country from their own previous experience with the country, visits to the host country, and general knowledge from sources like TV, films, news, and literature. Some also had a family tradition of studying/working/living abroad that provided them with information on specific host countries. In addition, students obviously gathered information on specific host countries and institutions from their various social capital networks which informed their decisions about where to study (see comments from IR\#26, p.239; UK\#2, p.243; U.S.\#28, p.249). Students also mentioned that when many students from their home country went to a specific host country, this meant there was more easily accessible information to guide their decisions as it built a social capital information network (see comment from U.S.\#59, p.247).

\section{How the Forms of Capital Overlap}

As discussed in Chapter 4, one reason for using the three capital theories together as a theoretical framework is because although they are different, they also overlap and build upon one another to potentially give a more complete picture of students' reasons for deciding to study abroad and for choosing a particular host country. In this section, I provide some examples of how the data showed the overlap among the different forms of capital.

First, there is the formal postgraduate degree itself, which Schultz (1961) describes as human capital and Bourdieu (1986) as institutionalised cultural capital. Waters and Brooks tie the two capital theories together, adding the international aspect, with the statement "International credentials are the embodiment of both 'human capital' and 'cultural capital', which can subsequently be exchanged for economic capital in the labour market" (p.219). In the categorisation of the data I attempted to show that the acquisition of an international postgraduate degree is related to both human and cultural capital by listing it with both potential human capital ('International degrees and job opportunities') and 
potential cultural capital ('Degree value and recognition'). The complexity of this overlap is illustrated by IR\#25. He explained that while having an international postgraduate degree would not necessarily guarantee a good job, it would help 'open doors' in terms of interviews. In other words, an international postgraduate degree signals to employers that students possess specific skills and knowledge (human capital) and employers 'screen' job applicants for certain qualities such as an international outlook (cultural capital); both of which help students to get job interviews. I categorised 'Degree value and recognition' as cultural capital because it implies something about the reputation of an internationallyacquired qualification, but I also recognise that it overlaps with the concept of 'signalling' which is discussed as part of Human Capital Theory in Chapter 4. According to Waters (2006a) the pursuit of an international degree represents more than simply a desire for increased human capital. It is also about acquisition of a particular and exclusive type of cultural capital - cultural capital that is internationally recognised.

Bourdieu asserts cultural capital is actually part of individual social capital (Bourdieu, 1986; Morgan, 2008), and the research findings showed that there was indeed some connection between these two capitals. An example of the overlap was apparent in the discussions of the cultural capital theme 'Knowledge of host country prior to current study' (see comments from p.206-208) and the social capital themes 'Family' and 'Friends' (see comments from p.233-244). Students drew on the existing cultural capital of their social capital networks (in this case, family and friends) to gather knowledge of particular host countries to inform their decision-making. Another such connection can be found between the cultural capital theme 'Family tradition of studying/working/living abroad' (see comments from p.210-211) and the social capital theme 'Family' (see comments from p.234-240). In this case, students had access to the existing cultural capital of their social capital networks (family members) in terms of family members' actual experience in the host country with which to inform their decision-making.

As noted in Chapter 4, Coleman (1988) states that there is also a connection between human and social capital; the one actually helps with the development of the other. Schuller (2001), in agreement with Coleman, maintains that individuals and their human capital cannot be viewed as being entirely separate from and unaffected by the 
surrounding social structures. In other words, the acquisition and effective utilisation of an individual's existing social capital was critical to some students for increasing their human capital (see comments under 'Family as source of support and influence', p.236-239).

Students in the sample received help with financing an international education from their existing social capital network, usually their families. For some students this assistance made the difference as to whether they were able to study abroad or not and, in turn, develop their human capital through the acquisition of an international education.

A final example of overlap - this time of all three forms of capital - has to do with students' previous experience in the current host country (i.e., the host country at the time of data collection). As explained under the existing human capital theme 'Previous university degree obtained', since all participants were postgraduate students, they had existing human capital in terms of previously completed higher education. In addition, for those who had obtained a previous degree in the current host country, they would have developed some additional human capital (including country-specific capital) as reflected in the theme 'Previous degree/study/work done in same host country.' Such students would also presumably have acquired some cultural and social capital from that experience; some sense of these cultural and social capital aspects were captured in the themes 'Previous experience in current host country' and 'Friends' (For 'Friends', for example, see comments specifically from IR\#6, p.242 and IR\#25, p.245). The existing human, cultural and social capital acquired from this previous experience almost certainly influenced their decision to stay in that host country for an additional degree. Continuing study in the same host country is not only a way to build on their existing capital, but is also a way to conserve it. For example, existing human capital is conserved because it is not spent on time and resources pursuing study options in another country.

\section{Comparison with Studies using Push-Pull Theory}

In this section, I provide further comparisons between the methods and findings of some of the studies which used Push-Pull Theory (as presented in Chapter 3) and the findings of the thesis research. 
As mentioned earlier, similar to the thesis, a number of the push-pull studies used questionnaire surveys, and/or interviews of students to collect data. Bodycott (2009) interestingly interviewed parents as well, using a focus group format. Many focused on international postgraduates, although not always exclusively (Menon and Carspecken, 1990; Mazzarol et al., 1996; 2001a; 2001b; Pimpa, 2003; 2005; Li and Bray, 2007; Chen, 2007; Maringe and Carter, 2007; Sahasrabudhe, 2008; Wilkins and Huisman, 2010). Also like the thesis, the sample of several of the studies consisted of current international students (Pimpa, 2003; 2005; Li and Bray, 2007; Chen, 2007; Maringe and Carter, 2007; Wilkins and Huisman, 2010), while others used samples consisting of prospective international students (Mazzarol et al., 1996; 2001a; 2001b; Yang, 2007; Bodycott, 2009). Yang (2007) collected data from both prospective and current students, and at least one study (Menon and Carspecken, 1990) surveyed recently graduated international students. In addition, all studies, except Maringe and Carter (2007), focused on students from Asia.

Menon and Carspecken's (1990) findings, for example, were similar to the findings of the thesis, particularly in terms of what they labelled as Stage One (Home experiences and the external catalytic process). As in the thesis, Stage One noted the importance of two factors on student mobility: cultural and family influences, and perceived opportunities or lack of opportunities within the home country. They described these factors as the first two elements of Stage One. However, they do not categorise them as either push or pull factors which were elements three and four of Stage One. This suggests that they felt Push-Pull Theory was not broad enough to encompass all elements important for explaining international student mobility - a main argument of the thesis. The Altbach studies $(1986 ; 1991 ; 1998)$ are also similar to the thesis research in that they highlight the importance of the individual student perspective in student mobility, not just the host and home country perspectives.

As noted in Chapter 3, the following studies had particular influence on the thesis: the Mazzarol-led studies (1996-2002), Pimpa (2003; 2005), Li and Bray (2007), Maringe and Carter (2007), and Chen (2007). These studies were influential in furthering my understanding of the multifaceted nature of international student mobility, as well as 
providing guidance in the development of the questionnaire survey and interview questions used in the research. There were, however, some notable differences between these studies and the thesis. A discussion of differences between the thesis and the Mazzarol-led studies is given in Chapter 3.

Another interesting difference is in some of the factors identified as important. For example, the pull factor identified in the Mazzarol-led studies (1996-2002) 'Most institutions are government administered' did not appear at all in the thesis data, and while they highlight the importance of 'Geographic Proximity', this item was not of great importance to the students in my sample. The latter dissimilarity was likely due to the difference in host countries targeted and the degree levels of students between these studies. In addition, because they focused mainly on why students were attracted to certain host countries, they did not put as much emphasis on the push factors (why students chose to study abroad) while I believe the thesis to be more well-rounded in answering both questions.

As in the thesis, the studies of Bodycott (2009) and Pimpa (2003; 2005) showed the importance of students' families in terms of financing, and providing information, support and encouragement. Pimpa's two studies were not, however, as well-rounded as the thesis in that Pimpa looked at only this one push factor (albeit in-depth) and no others. Like Pimpa's, the thesis found that some factors were multidimensional, for example (and similarly to Pimpa) the social capital factors of 'Family' and 'Friends.' The most recent study cited in the literature review in Chapter 3 was from Wilkins and Huisman (2010). Like the Mazzarol-led studies, they also had a pre-determined check list of sixty factors impacting international student decision-making but this time the list contained both push and pull factor items. However, I argue in the thesis that this type of data collection method is too limiting to generate a true and in-depth understanding of the range of reasons why students decide to study overseas and why they select certain host countries.

\section{Summary}

In conclusion, I argue that the data does indeed answer the research questions presented in Chapter 1. The data showed that in answer to research question \#1, human capital was 
the most frequently mentioned form of capital, followed by cultural and then social capital. In answer to research question $\# 2$, the data showed that students did possess several kinds of human, cultural and social capital, referred to as existing capital, prior to their postgraduate studies that enabled them to pursue study abroad. The data also showed that this existing capital influenced a student's choice of host country. In answer to research question $\# 3$, the data showed that students hoped to gain a range of human, cultural and social capital from studying overseas and from studying in a particular host country. Finally, in answer to research question \#4, students used a variety of social capital and electronic resources to gather valuable information about studying abroad and particular host countries which informed their decisions and provided a basis for action. The research has shown that the theoretical framework consisting of the three capital theories can be applied to the understanding and explanation of international student decision-making. In addition, as discussed throughout the thesis, this framework provides a well-rounded look at the research topic, and showed some differences from the results of studies using Push-Pull Theory although there was no one study found that used the exact same sample for purposes of comparison.

This chapter presented the findings of the research in relation to the four main research questions. These questions centred on the theoretical framework chosen and referred to the literature presented in previous chapters where relevant. The chapter also discussed areas of overlap among the forms of capital.

Throughout my thesis I have argued that there is a gap in knowledge in reference to international student decision-making particularly in terms of the number of theories applied to understanding and explaining it. In Chapter 8, the final chapter of the thesis, I review the original contributions to knowledge of the thesis, look at the limitations of the research, present implications for practice, make suggestions for future research, and reflect on the research process. 


\section{Chapter 8: Conclusion}

This concluding chapter reviews the contributions to knowledge of the thesis, considers the limitations of the research, presents implications for practice, makes suggestions for further research, and ends by reflecting on the research process.

\section{Contributions to Knowledge}

Throughout the thesis I have argued that there is a gap in knowledge about international student decision-making because of the limited number of theoretical approaches used hitherto; most research has used the Push-Pull Theory of Migration. As discussed in Chapter 3, there are some significant limitations to this as a theory of international student decision-making. After a comprehensive review of the literature, I felt there was a need to understand international decision-making using a different theoretical perspective. The research adds to the body of knowledge about international students because a framework using the three major capital theories - human, cultural, and social capital has not been used previously to examine this issue. It also provides richer qualitative information on international student decision-making than do many studies using PushPull Theory and highlights the importance of the student voice in examining this topic.

In addition, the thesis also makes a contribution to knowledge regarding the decisionmaking processes of international postgraduates as there is a need for further research focusing on this much sought-after type of student. Like Chen (2007), I subscribe to the view that international postgraduates are a unique group of students. They are different from domestic postgraduates because they have to deal with the challenges of living and studying in a foreign country. They are often different from domestic and international undergraduates because the majority of postgraduates are at a different life stage than undergraduates. This means they are often older and possess greater maturity and freedom to make their own decisions about international education making it important to separate them from other groups of students when researching and discussing international student decision-making. Finally, the thesis also contributes to existing knowledge by surveying international postgraduates from a variety of source countries 
(both developed and newly industrialising countries), and focusing on fields of study most popular with international postgraduates.

\section{Limitations}

Although the findings of the research did provide satisfactory answers to the research questions posed in Chapter 1, there are some limitations to the research which require mentioning. As with all doctoral research, there were limitations in terms of access, time and financial resources. Access to participants was limited as the International Offices involved stated they would send my survey out only once and would not provide me with students' e-mails to follow up those who did not respond. Both time and financial constraints limited the research to the study of students in only three host countries and only one university in each country. In addition, I was an individual researcher carrying out all phases of the research, including data collection and analyses which were time consuming. Finally, due to time and space constraints, the data for the comparative aspect of the research, which I believe would have further informed and complemented the data presented in the thesis, could not be included. This is, however, an opportunity for further research as noted below. The limitations of each method of data collection were discussed in Chapter 5 and will not be reiterated here.

The limited access to potential student participants meant the sample size was smaller than hoped for, although steps were taken to increase the sample size as noted in Chapter 5. A sample of seventy-four questionnaire respondents and only seventeen interviewees cannot be put forth as representative of all international students, or even all international postgraduates, thereby limiting any broad generalisability of the findings (Maringe and Carter, 2007). Although I could present information on how many questionnaires were returned completed or not completed, not having a count of the students at each university that fit my sample criteria made it difficult to discuss not only the representativeness of the sample, but the response rate of the questionnaires and interviews as well. However, my goal was not to produce knowledge generalisable to the situation of all international students. Instead I wished to highlight its relevance and transferability by providing a deeper understanding of why the international students in my sample decided to study overseas and why they selected certain host countries. The 
data presented provides a place to start in using a theoretical framework comprising the three capital concepts to understand and explain international student decision-making.

Another limitation of the research concerned student funding. The original intention was to screen (via filtering questions) for only entirely self-funded students in the belief they would have greater freedom to choose any host country, while students who were partially self-funded or fully-funded may have been dependent on any offers of funding in order to be able to study overseas at all and so may have had very limited choices (or perhaps even just one choice) of host country. However, limiting the sample to entirely self-funded students would have yielded an even smaller sample size, and so the decision was made to include students who were partially self-funded or fully-funded and who indicated they were able to make their own decisions about where to study. Thus the final sample consisted of students with a mixture of funding statuses. I did not ask for further details about each student's funding circumstances on the questionnaire, but I did gather information about this from the interviewees for the purpose of triangulation.

One problem, which may have impacted the amount and quality of the data collected, was the English language proficiency of the participants. As not all participants were fluent in English raising the question as to whether they were able to truly express how they felt or what they thought in English. This may have been the reason behind some of the one word answers to the questionnaires. There also seemed to be some confusion, which I believe was related to poor English language ability, about one or two questions on the questionnaire such as those asking about what other countries students considered for study and the length of time they had been in the host country (see Appendix C for the exact wording of these questions). UK\#7, for example, felt the latter question referred only to the length of time he had been in the host country for his current programme. Although saying he had completed an undergraduate degree in the UK and at the time of data collection was doing a Master's there as well, when asked the length of time he had been in the UK he said he had only been there for two months. The purpose behind this question was to ascertain the total amount of time students had been in the host country in order to determine whether they had some existing capital in relation to that country. 
In addition, as this study was retrospective (e.g., students were surveyed after arrival in their host country) there may have been memory problems for those respondents who had made their decisions regarding why and where to study abroad more than one year before being surveyed and interviewed. There may also have been some 'post-purchase' bias effect on students' answers since those who participated in this study were already in their host countries at the time of data collection and may have felt inclined to justify their choices. Despite these limitations however, the findings are both significant in themselves and useful for stimulating further research on this topic.

\section{Further Research}

The review of the literature and the findings put forward in this thesis highlighted some interesting areas for further research. First, as noted in Chapter 1 and above, the second of the original aims of the research was to provide a comparative perspective between the motivations of international students in different host countries, and to explore the reasons they selected one host country over another. I hope to conduct further analyses and utilise this data in future research on international students. Further research also needs to be conducted using the new theoretical framework introduced in the thesis with students from a wider variety of source and host countries in order to see if the categorisation applies, needs to be revised, or if new themes and sub-themes emerge. Like Pimpa (2003; 2005), I would also like to see further research done on the multidimensionality of each of the capital themes and sub-themes.

It would also be interesting to conduct comparative research on international student decision-making in which the decisions of prospective versus current students are compared as understanding such differences may provide a way to predict which prospective students are more likely to actually embark on overseas study. In addition, surveying students who consider study abroad but finally opt to remain in their home country and the forms of capital important to them would be an interesting area for further research. Finally, future research on decision-making and the capital concepts, perhaps via a longitudinal study, that also encompasses the returnee period would add significantly to knowledge on international students. 


\section{Implications for Policy and Practice}

In Chapter 2, I explained that as knowledge becomes more internationalised, universities find it necessary to be internationalised in terms of not only their curriculum but also their students (Coulby, 2005b). I also talked extensively in Chapter 2 about the importance of attracting international students for host countries and institutions. I sum up the points made in that chapter by saying that international students are an important part of the internationalisation of any country and its higher education institutions making it vital to understand the reasons these students decide to study abroad, and why they select certain host countries and institutions. As we are now in a period of economic crisis and change, not only for nations, but also for higher education, continued focus on the recruitment of these students can provide significant benefits to both. The findings of research, like that of the thesis, can be used to inform policy and practice on international students.

According to UKCISA (2008), "International students have become much more discerning and are now, more than ever, sought after by universities world wide" (p. 35). If universities want to be successful at recruiting international students in the face of increasing competition and student choice, they must attempt to understand how international students and the context of international education have changed and might change in future. It is necessary for them to regularly survey international students about their decision-making including what they hope to gain from the experience of studying abroad, and why they do and do not chose certain host countries. In the thesis, the U.S. as a host country was influential to some of the methodological choices made such as the setting of the parameters of the sample. As the U.S. continues to be the leading destination for international students understanding why students do/do not choose to study there will help to shed light on the decisions made by international students for other host countries as well; this is important information to have in a competitive global education market. I support Lee's (2008) claim that '[t]he process by which an international student decides to study outside his or her home country is complex and underinvestigated...Certainly, more research is needed on international student flows and especially differentiating their diverse pathways.' (p.323). It is also necessary to examine 
this multifaceted topic using different frameworks and different research questions as I have done in the thesis.

My research adds important information to the area of international student decisionmaking that I believe can inform policy and be utilised in practical ways by those concerned with improving university internationalisation. The findings can be used to not only help recruit international students but also to offer more support to these students and identify new opportunities which help universities to attract these students and continue to promote internationalisation.

I mention here two concrete examples of the ways that the findings can be put to practical use. First, a very important human capital sub-theme for students identified in the research was 'Work experience in the host country after graduation'. While the U.S. and Ireland continue to encourage and provide opportunities for international students to gain work experience after graduation, the current UK government is now working to decrease not only numbers of international students studying in the UK but also their rights to work in the country after the completion of their degree programmes. Changes to work rights are due to take effect from April 2012 with the new measures expected to eliminate what is known as the "post-study work route," which gives students two years to remain in Britain and seek jobs after their programs end (Labi, 2011a; UKBA, 2012). The opportunity for international students to work in the UK after graduation is a very important reason international students come to the UK to study, and thus without this option the UK will be at a real disadvantage in recruiting these students. Labi (2011b) cites a survey of 8,000 international students studying in the UK which found that nearly $70 \%$ of them would not choose to study in Britain without the post-study work option.

This is obviously a very worrying development for those concerned with university internationalisation in the UK as it has the potential to dramatically decrease the numbers of international students coming to study in the UK even without the new immigration quotas for foreign students (Labi, 2011a). UK university officials in particular can use the findings of the current research as further evidence of the importance of such work experience to international students, particularly those from important source countries 
like China and India. When faced with having to deal with the fallout from these severe government regulations on international students' work rights, the evidence from the thesis might help university officials to argue for more resources to develop alternative opportunities for these students to increase or strengthen their employability skills other than through traditional work scenarios. One example of a scheme focused on improving student employability that might be adopted by other universities is the University of Nottingham's Advantage Award (NAA). This scheme offers a broad range of extracurricular modules through which students can increase or develop important employability skills such as leadership, time management, and cross-cultural communication skills (more information on NAA can be found at http://www.nottingham.ac.uk/careers/students/advantageaward/index.aspx). While current modules are open to all students (home and international), more emphasis could be put on developing modules specifically for international students to gain employability skills before returning home that they might have obtained in the past through a traditional employment experience.

A second example of the practical application of the thesis findings refers to three important cultural and social capital themes identified in the research: 'Better English skills', 'International and cross-cultural experience', and 'Network with other international people/students'. Again, this evidence from the thesis can be used by university officials to demonstrate the importance of these issues to international students. These are themes for which practical activities can be implemented to promote internationalisation rather easily and with limited resources. Activities such as peer mentoring programmes do not require a lot in terms of financial resources to set up although they may require a significant amount of time to organise initially. These programmes not only provide extra personal support to international students regarding all of the above themes but are also a means for increasing opportunities to participate in internationalisation for home students as well. Programmes such as these that offer a true integration experience that will potentially attract a wide range of international students. In addition, as noted in Chapter 2 , the social and cultural benefits to home students and staff of hosting international students is a key rationale underlying internationalisation at most universities (Lee, 2008). This kind of peer mentoring experience is also linked to internationalisation-related 
employability skills for home students in terms of gaining or strengthening cross-cultural awareness, competency and communication skills - skills necessary for finding work in the global economy and which may be more difficult for students studying in their home country to acquire.

\section{Reflecting on the Research}

No research can be completely value-free so it is important for me to reflect on this research journey, looking at the methods I chose and the effects I may have had on the research, in other words to be reflective and reflexive.

I feel the methods of data collection and analyses were appropriate for answering the research questions. Given what I know now however, and if I had the chance to do it all again, I would make some changes to the questionnaires and interviews. I would have gathered more data via the questionnaires on students' backgrounds including sources of funding, and parents' occupations and education levels. As students get a number of questionnaires throughout the year, in an effort to motivate them to complete mine and thus obtain a high response rate, I tried to limit the time required to complete the questionnaire. This meant that I had to restrict the number of questions and leave out certain questions, such as those on students' backgrounds. I now regret this as such questions would have generated further valuable data in relation to the theoretical framework. I also wish I had allowed more time to explore particular interview questions, such as 'Besides proof that you have knowledge of a certain subject, what else does having a U.S. degree say about you to other people?', as well as topics initiated by the students themselves such as the capital benefits they thought their families would gain from their international experience. More information in both these areas would have informed the discussion of the forms of capital in interesting ways. In addition, I would like to have had the time, access, and resources to conduct more than seventeen interviews as they yielded rich data.

This study has grown from my own experience and interest in the research topic as explained in the preface to the thesis. I do not wish to reiterate that here but will use this final section of my thesis to be reflexive. Although I did my best to stay neutral and 
culturally aware I must admit to the possibility of cross-cultural misunderstanding between myself and the participants. This definitely occurred with the questionnaires, as the example of identifying Taiwan as a country separate from China showed. I was not aware of any large cross-cultural misunderstandings occurring during the interviews and the data analyses; however, the possibility remains that there might have been some.

Other issues related to me as a researcher which may have affected the research include an attraction to this particular research topic because of my personal work experience and interests, and a possible predisposition towards study in my home country or to students who selected my home country for study. It is also possible that the fact that I am American and an international student had some impact on the interviews. I did tell some students beforehand that I was American and an international student in an effort to create a connection between myself and them in hopes of getting them to agree to an interview. Even though I did not tell all interviewees I was American prior to meeting, I was easily identified by my accent making it difficult to limit this type of researcher effect. In addition, although it was not evident or pointed out to me by interviewees, my being American may have had some effect on students' responses to the question of why they did not choose to study in the U.S. There was a concern that they would feel they could not be truthful to me about their reasons although at least one student was very honest and said the reason she did not choose the U.S. was because 'I hate America.' I was not offended by her remark but may have looked a bit shocked at her outburst.

In addition, there is some possibility that there may also have been at least partial identification with subjects as I am also an international student which may have affected my objectivity and their subsequent responses, resulting in a social desirability bias for instance. Being an international student gave me group affiliation, and some insider knowledge which might have impacted data collection and analyses. However, my situation as an international student was different from my sample because I am from a developed Western country with a highly regarded education system. I did not need to leave home because of lack of university capacity or to pursue a specialism, for example, but did so for more personal reasons. I am similar to students in my sample however, in that I chose to study in a rich Western country with a high quality education system. I do 
feel though that being an international student did provide me with some credibility in understanding students' views and allowed me to create an easy rapport with participants as I appeared more as a peer than a 'researcher'.

Finally, as the thesis involved cross-cultural research, it is also important to consider how my cultural-specific understandings of the capitals impacted the research process and findings. Firstly, I must point out that the three theories used as part of the theoretical framework for the thesis are theories developed by Western social scientists. This brings up the question of the validity and applicability of Western concepts to non-western populations - a major research question in itself. It can be argued, for example, that as they are Western theories, the capital constructs are culture-bound and can be applied only to Western cultures. Criticisms of Cultural Capital Theory, for example, have gone even further and claimed that this theory is bound by national (French) culture and is not necessarily applicable to other Western cultures (Ong, 1999; Reay, 2004). Does this mean that there are specifically Asian perceptions and points of view that evade Western categories? As a researcher I must concede there could be some truth to this but further research is necessary. As this is the first time this particular theoretical framework has been applied to the study of international student decision-making, there is little evidence at this time to support its relevance and generalisability to students from all non-Western cultural settings, although I feel that I have demonstrated its relevance to the five sources countries targeted in the research.

As noted in Chapter 4, I located two studies which applied at least one of the three theories to the understanding of international student decision-making: Agarwal and Winkler (1985) (Human Capital Theory) and Chen (2007) (Social Capital Theory). Their research samples included several of the same source countries as did the thesis, but neither addressed any of the cultural implications of applying these theories to the study of non-western countries nor how their own cultural understandings of the capitals might have affected their findings. In other words, there is obviously further research that needs to be done in terms of cross-culturally validating the theoretical framework I used (and the use of the theories individually) in regard to international student decision-making. While I cannot claim implicitly or explicitly that the theories used are universally applicable 
without more testing, I do believe that these 'Western' constructs of capital provide a useful basis for starting investigations of non-western cultures. My research represents the first attempt to test the appropriateness of the combined theoretical framework of the three capitals with students from Asian societies.

In terms of the data collection process itself, I did not attempt to explain the three capital theories to the participants nor did I use the terminology (i.e., human capital, cultural capital) on the questionnaire or in the interviews. Instead, I asked them broad openended questions such as 'Why did you choose to study abroad?' and 'Why did you select the UK/U.S./Ireland as a host country?' allowing them to answer freely and limiting any researcher bias which might have affected their responses. The cultures of the societies from which students came most assuredly played some part in their reasons for deciding to study abroad and selection of host country since it is very difficult to separate perceptions, attitudes and behavior (including behavioural intentions) from cultural influences (Chol and Green, 1991).

In the interests of being a reflexive researcher, I must admit that my own cultural paradigm and experiences may have affected my interactions with students as well as my understanding of the three capital concepts. My experience includes a three year period of living (Japan) and travel in East Asia (Japan, China). In other words, besides my own cultural paradigm, I do bring some understanding of East Asian cultures (albeit processed through my cultural paradigm) to the research process. My cultural background did influence the research from the beginning in the choice of Western theories taught to me as part of my doctoral education in a Western university, as well as in the choice of host countries for the research (I had a particular interest in the U.S., my home country, and the UK, my adopted country). It also had some impact on the analysis in which I imposed my own understanding of the capitals onto the coding and categorisation of the data. Is my understanding of human, cultural, and social capital the same as that of an individual from an Asian cultural background? Again, I must concede that it is likely there would be some differences in understanding and interpretation based on culture. I provide two examples below of how my cultural understanding of the capitals impacted the research. 
Four of the five source countries (Japan, Korea, China and Taiwan) in the research are Confucian heritage societies. A number of differences exist between these cultures and the Judeo-Christian cultures that dominate in the U.S. and Western Europe (areas where the host countries in the research are located and from where I originate). One major difference between these cultures is that of individualism (mainly applicable to Western cultures) versus collectivism (mainly applicable to Asian cultures) (Chol and Green, 1991). These four societies are considered primarily collectivist cultures in which education and filial piety are highly valued. India, while not a Confucian heritage society, has a traditional culture that also values these elements (Bodycott, 2009). This means that in order to ensure a child receives the best education to guarantee a better future, families will do whatever is possible and often high levels of family income are spent on students' education in these societies. Consequently, decisions about international education are often family decisions not individual ones (Yang, 2007; Bodycott, 2009).

From my own experience in Asia as well as the literature review, I knew that education was of high importance in these cultures and that study in a foreign, particularly Western, country has some social status for students in these source countries. This is reflected in the interview question, 'Besides an education qualification, what else does having an overseas degree say about you to other people?' from which a distinct cultural capital theme emerged I titled 'Increased status in the minds' of others'. However, I did not understand the full extent of filial piety in Asian culture and that students' international education choices were also expected to benefit the family as a whole. This point became clear to me during analysis when I saw a theme developing from the interview data that I subsequently labelled 'Cultural capital gains for student's family'. Based on my own cultural paradigm, I assumed that an international education was primarily for the benefit of the child individually and apart from the family, and any decisions would be primarily a result of the students' personal goals and attitudes about the behavior. In other words, I did not give enough credence to the greater role of familial and other social influences in these cultures. I regret this lack of understanding as I would have liked to follow-up on this theme with all interviewees and think it would have informed the discussions of cultural and social capital in interesting ways. This is not to say however that the strong social bonds with family and friends prevalent in Asian cultures did not emerge in the 
analysis at all. They did so and are reflected in the list of themes and sub-themes categorised as Existing Social Capital.

Next, I describe an example dealing with social capital. Pye (1999) states that social networking practices exist in all cultures although not always in the same ways and can differ significantly across cultures depending on the purpose at which they are aimed. They can also vary considerably within the same region. The emphasis in many Asian societies, on familial relationships and the high regard given to the opinions and advice of family members was discussed above. Pye (1999) explains that in China, for example, 'Family members owe each other support without question; nepotism is a positive practice in China.' (p. 771). The importance of social connections with people outside of the family in Chinese society is captured in the concept of guanxi. Guanxi is essentially a form of social capital very important in all Chinese societies which acts as a '...firmly structured, institutionalized arrangement for ensuring mutual obligation' (Pye, 1999: p. 771). Bodycott (2009) states succinctly that, '...guanxi networks...serve to tie directly and indirectly social networks of friends and connections' (p. 362).

Pye (1999) describes the social connections associated with guanxi as different from family bonds because they '...extend outward to those who share a certain identity, for example, those from the same village, town, or even the same province, those from the same class in school or even the same school in different years, and select acquaintances. [Guanxi] is not a form of emotional bonding but a formal one, defined largely by objective determinants...Shared background alone is enough to force one to recognize an obligation' (p. 771-772). Guidance and advice from guanxi networks, as with family and friends, is highly regarded and some sense of obligation incurred (Pye, 1999). The Japanese concepts of on and giri mirror that of guanxi to some extent in terms of creating a sense of obligation and indebtedness between social connections, although perceptions of what constitutes effective reciprocation differ (Pye, 1999). Although the word guanxi was not used by Chinese students in the research, the concept was referred to generally in some of the interviews, such as in answer to the question, 'Do you think you can get a good job and a good salary at home if you didn't study overseas?' When asked this question 
students emphasised the importance of their parents' networks, or guanxi, for finding employment. IR\#6, for example, responded:

It's really hard to find a good job in China, and also to be honest in China lots of person maybe has good parents. They work for the maybe government or in a big company, then they can just to give you reference to go to the company or government. Still need to take the interview or, you know, the exam. Something like this. But it's really easier to go to those company or government department.

IR\#26 answered similarly:

I think usually like if people in China their parents they don't have a, like, big business or big relationship to somebody, it's very hard to find a good job...now in China the policy is like every family can just have one kid...the kids always take like cared by the parents from their very young until maybe to university maybe to their work. Their parents help them to find a job, and, yeah, take care of their jobs like that.

Interestingly, despite the importance of social networks and connections in Asian societies, social capital was the form of capital least mentioned by students in the sample overall. I provided some possible reasons for this in Chapter 7. Within the category of social capital, students spoke more about their existing social networks than they did of the social networks they hoped to establish during their study period. A finding which particularly surprised me in relation to Potential Social Capital was that only a very small number of students talked about wanting to network with academics and other professionals in their field as part of their career development. Was the reason for this finding that they did not see any point in building these kinds of professional social ties and networks because they had strong connections at home (i.e., guanxi) through which they thought they would find employment? Or was there some other cultural reason for this that I did not recognise? Were there other ways in which students referred to human, cultural, social capital that were influenced by their cultural paradigms that I did not 'see' because it was not part of my own paradigm and understanding of the capital concepts? Perhaps. This experience and my reflexion on it has taught me that both my understanding of the cultures of my 
participants and my own cultural understanding of the theories used have the ability to impact the research findings.

The search for answers to my research questions led me on an academic journey which was extremely valuable. I learned more than I ever thought possible during this experience and am looking forward to using my newly acquired human, cultural, and social capital in future. 


\section{Bibliography}

Abella, M. (2006). 'Global competition for skilled workers and consequences.' In C. Kuptsch and E. Pang (Eds.), Competing for Global Talent. Geneva: International Institute for Labour Studies, International Labour Office.

Adnett, N. (2010). The growth of international students and economic development: friends or foes? Journal of Education Policy, 25(5): 625- 637.

Agarwal, P., Elhmady Said, M., Sehoole, M., Sirozi, M. \& de Wit, H. (2008). 'The Dynamics of International Student Circulation in a Global Context: Summary, Conclusions, and Recommendations.' In H. de Wit, P. Agarwal, M. Elhmady Said, M. Sehoole, M. Sirozi (Eds.), Global Perspectives on Higher Education: The Dynamics of International Student Circulation in a Global Context. Rotterdam: Sense Publishers.

Agarwal, V. \& Winkler, D. (1985). Foreign Demand for United States Higher Education: A Study of Developing Countries in the Eastern Hemisphere. Economic Development and Cultural Change, 33(3): 623-644.

Alberts, H. \& Hazen, H. (2005). "There are always two voices...": International students' intentions to stay in the United States or return to their home countries. International Migration, 43(3), 131-152.

Altbach, P., Kelly, H., \& Lulat, Y. (1985). Research on foreign students and international study: An Overview and Bibliography. New York: Praeger Publishers.

Altbach, P. (1991). Impact and Adjustment: Foreign Students in Comparative Perspective. The International Journal of Higher Education and Educational Planning: Special Issue on Higher Education and the Flow of Foreign Students, 21 (3): 305-323.

Altbach, P. (1998). Comparative Higher Education: Knowledge, The University and Development. Hong Kong: Comparative Education Research Centre, University of Hong Kong.

Altbach, P. (2002). Knowledge and Education as International Commodities: The Collapse of the Common Good. International Higher Education, 28: 2-5.

Altbach, P. (2004a). Higher Education Crosses Borders. Change, March-April: 1-12.

Altbach, P. (2004b). Globalisation and the University: Myths and Realities in an Unequal World. Tertiary Education and Management, 10(1): 3-25.

Altbach, P. (2006). 'Globalization and the University: Realities in an Unequal World.' In J. Forest and P. Altbach (Eds.), International Handbook of Higher Education. Netherlands: Springer.

Altbach, P. (2007). Intelligent Asia: Fostering Asia's Brightest. Far Eastern Economic Review, Jan/Feb: 53-57.

Altbach, P. \& Knight, J. (2007). The Internationalization of Higher Education: Motivations and Realities. Journal of Studies in International Education, 11(3/4): 290-305.

Altbach, P., Reisberg, L. \& Rumbley, L. (2009). Trends in Global Higher Education: Tracking an Academic Revolution (A Report Prepared for the UNESCO 2009 World Conference on Higher Education). Paris: UNESCO.

American Council on Education (ACE) (2006). Students on the Move: The Future of International Students in the United States. ACE Issue Brief. Washington, D.C.: ACE Center for International Initiatives.

Anonymous. (July 2007). Doctors held in bomb probe. BBC News. Retrieved July 9, 2009 from http://news.bbc.co.uk/1/hi/uk/6261076.stm.

Anonymous. (March 2011). Sweden suicide bombing suspect faces terror charges. BBC News. Retrieved July 9, 2009 from http://www.bbc.co.uk/news/uk-scotland-glasgow-west- 
12734188.

Anonymous. (October 2007). Bomb plot: Arrests and releases. BBC News. Retrieved July 9, 2009 from http://news.bbc.co.uk/1/hi/uk/6264230.stm.

Anonymous. (October 2010). Plane bomb suspect 'not radicalised at London's UCL. BBC News. Retrieved July 9, 2009 from http://www.bbc.co.uk/news/education-11495399.

Anonymous. (October 2010). Profile: Umar Farouk Abdulmutallab. BBC News. Retrieved July 9, 2009 from http://www.bbc.co.uk/news/world-us-canada-11545509.

Appleton, S., Morgan, W. J., \& Sives, A. (2006). Should Teachers Stay at Home? The Impact of International Teacher Mobility. Journal of International Development, 18(6), 771-786.

Arimoto, A. (1997). Market and higher education in Japan. Higher Education Policy, 10(3-4): 199210.

Baker, M., Creedy, J. \& Johnson, D. (1996). Financing and Effects of Internationalisation in Higher Education: An Australian Country study. Canberra: Australian Government Publishing Service.

Baláz, V. \& Williams, A.M. (2004). Been There, Done That': International Student Migration and Human Capital Transfers from the UK to Slovakia. Population, Space and Place, 10, 217237.

Baldwin, G. \& James, R. (2000). The Market in Australian Higher Education and the Concept of Student as Informed Consumer. Journal of Higher Education Policy and Management, 22(2): 139-148.

Bashir, S. (2007). Trends in international trade in higher education: Implications and options for developing countries (World Bank Education Working Paper Series no. 6). Washington, D.C.: World Bank.

Becker, G. (1962). Investment in Human Capital: A Theoretical Analysis. The Journal of Political Economy, 70 (5/2), 9-49.

Becker, G. (1993[1964]). Human Capital: A Theoretical and Empirical Analysis with Special Reference to Education, Third Edition. Chicago: The University of Chicago Press.

Becker, G. (2006), 'The Age of Human Capital by Gary S. Becker.' In H. Lauder, P. Brown, J. Dillabough \& A. Halsey, Education, Globalization and Social Change. Oxford: Oxford University Press.

Bernardo, A. (Jan 2002). International Higher Education: Models, Conditions and Issues (PASCN Discussion Paper No. 2001-12). Makati City, Philippines: Philippine APEC Study Center Network.

Bexley, E., Marginson, S. \& Wheelahan, L. (2007). Social Capital Theory and Practice: The contribution of Victorian tertiary education in the 'new economy' disciplines of business studies and IT. Melbourne: Centre for the Study of Higher Education, The University of Melbourne.

Biao, X. \& Shen, W. (2009). International student migration and social stratification in China. International Journal of Educational Development, 29(5), p.513-522.

Binsardi, A. \& Ekwulugo, F. (2003). International marketing of British education: research on the students' perception and the UK market penetration. Marketing Intelligence and Planning, 21(5): 318-327.

Bjornskov, C. (2006). The multiple facets of social capital, European Journal of Political Economy, $22,22-40$.

Bodycott, P. (2009). Choosing a higher education study abroad destination: What mainland Chinese parents and students rate as important. Journal of Research in International 
Education, 8(3): 349-373.

Böhm, A., Follari, M., Hewett, A., Jones, S., Kemp, N., Meares, D., Pearce, D. \& Van Cauter,K. (2004). Vision 2020: Forecasting international student mobility: a UK perspective (A joint study by the British Council and IDP-Education Australia). London: British Council.

Bollag, B., 2003. A Cuban scholar shut out. The Chronicle of Higher Education, 49 (31): A16.

Bollag, B. (2004a). Wanted: Foreign students. The Chronicle of Higher Education, 51 (7): A37.

Bollag, B. (Moderator) (2004b). Are foreign students turning away from American higher education? (Online chat with Maura Harty, Assistant U.S. Secretary of State). The Chronicle of Higher Education. Retrieved on Octo. 23, 2007 from http://chronicle.com/colloquylive/2004/10/foreign/.

Bollag, B. (2004c). Enrollment of foreign students drops in U.S., The Chronicle of Higher Education, 51 (13), A1. November 19.

Bollag, B. (2007). Financing for Higher Education Shifts to Private Sector Worldwide, by Burton Bollag. The Chronicle of Higher Education. Retrieved on Oct. 23, 2007 from http://chronicle.com/weekly/v53/i50/50a03601.htm.

Bolsmann, C. \& Miller, H. (2008a). International student recruitment to universities in England: discourse, rationales and globalisation. Globalisation, Societies and Education, 6: 1, 75 88.

Bolsmann, C \& Miller, H (2008b). International student recruitment: South African Rationales. Journal of Higher Education in Africa, 6 (2/3): 211-231.

Bonal, X. \& Rambla, X. (2009). 'In the Name of Globalisation': southern and northern paradigms of educational development.' In R. Dale and S. Robertson (Eds.), Globalisation and Europeanisation in Education. Oxford: Symposium Books.

Boucher, G. (1998), The Irish Are Friendly, But....: A Report on Racism and International Students in Ireland. Dublin: The Irish Council for International Students.

Bourdieu, P. (1971a). 'Systems of Education and Systems of Thought.' In E. Hooper, (Ed.), Readings in the Theory of Educational Systems. London: Hutchison and Co.

Bourdieu, P. (1971b). 'Intellectual Field and Creative Project.' In M. Young, (Ed.), Knowledge and Control: New directions for the Sociology of Education. London: Collier Macmillan.

Bourdieu, P. (1977a). 'Cultural Reproduction and Social Reproduction.' In J. Karabel. and A. Halsey (Eds.), Power and Ideology in Education. New York: Oxford University Press.

Bourdieu, P. (1977b). Outline of a Theory of Practice. Cambridge: Cambridge University Press.

Bourdieu, P. (1984). Distinction: a social critique of the judgment of taste. Cambridge, MA: Harvard University Press.

Bourdieu, P. (1986). 'The Forms of Capital.' In J.E. Richardson, (Ed.), Handbook of Theory of Research for the Sociology of Education. New York: Greenwood Press.

Bourdieu, P. and Passeron, J-C (1979[1964]). The Inheritors, French Students and their Relation Culture. Chicago, IL: University of Chicago Press.

Bourdieu, P. and Passeron, J-C (1990[1977]). Reproduction in Education, Society and Culture. London: Sage Publishing Ltd.

Bourke, A. (2000). A Model of the Determinants of International Trade in Higher Education. The Service Industries Journal, 20(1): 110-138.

Bowl, M. (2003). Non-traditional Entrants to Higher Education: 'They talk about people like me.' Stoke-on-Trent, UK: Trentham Books Ltd. 
Bray, M. (Ed.). (2003). Comparative Education: Continuing Traditions, New Challenges, and New Paradigms. Dordrecht: Kluwer Academic Publishers.

British Council (2011a). China Market Introduction. Education UK: Education Marketing Intelligence. Retrieved on August 25, 2011 from http://www.britishcouncil.org/eumdinformation-background-china.htm.

British Council (2011b). India Market Introduction. Education UK: Education Marketing Intelligence. Retrieved on August 25, 2011 from http://www.britishcouncil.org/eumdinformation-background-india.htm.

British Council (2011c). Korea Market Introduction. Education UK: Education Marketing Intelligence. Retrieved on August 25, 2011 from http://www.britishcouncil.org/eumdinformation-background-korea.htm.

British Council (2011d). Taiwan Market Introduction. Education UK: Education Marketing Intelligence. Retrieved on August 25, 2011 from http://www.britishcouncil.org/eumdinformation-background-taiwan.htm.

Brooks, R., \& Waters, J. (2009a). A Second Chance at 'Success': UK Students and Global Circuits of Higher Education. Sociology, 43(6), 1085-1102.

Brooks, R., \& Waters, J. (2009b). International higher education and mobility of UK students. Journal of Research in International Education, 8(2), 191-209.

Brooks, R., \& Waters, J. (2010). Social networks and educational mobility: the experiences of UK students. Globalisation, Societies and Education, 8(1), $143-157$.

Bryman, A. (2004). Social Research Methods, Second Edition. Oxford: Oxford University Press.

Burt, R. (2003). 'The Social Structure of Competition.' In E. Ostrom and TK Ahn (Ed.), Foundations of Social Capital. Bodmin, Cornwall: MPG Books Ltd.

Cammelli, A. (1991). Foreign Students in Italy. The International Journal of Higher Education and Educational Planning: Special Issue on Higher Education and the Flow of Foreign Students, 21(3):359-376.

Cantwell, B., Luca, S., \& Lee, J. (2009). Exploring the orientations of international students in Mexico: differences by region of origin. Higher Education, 57:335-354.

Casey, B. (2009). The economic contribution of PhDs. Journal of Higher Education Policy and Management, 31(3): 219-227.

Castells, M. (1998). The Information Age: Economy, Society and Culture, Volume 3: End of Millennium. Oxford: Blackwell.

Chadee, D. \& Naidoo, V. (2009). Higher educational services exports: sources of growth of Asian students in UK and UK. Service Business, 3: 173-187.

Chen, C-H. \& Zimitat, C. (2006). Understanding Taiwanese students' decision-making factors regarding Australian international higher education. International Journal of Educational Management, 20 (2): $91-100$.

Chen, L-H. (2007). Choosing Canadian graduate schools from afar: East Asian students' perspectives. Higher Education, 54 (5), 759-780.

Chishti, S. (1984). Economic Costs and Benefits of Educating Foreign Students in the United States. Research in Higher Education, 21 : 397-414.

Chol, L. and Green, R. T. (1991). Cross-Cultural Examination of the Fishbein Behavioral Intentions Model. Journal of International Business Studies, 22(2): 289-305.

Coffield, F. (1999) Breaking the consensus: Lifelong learning as social control. British Educational Research Journal, 25(4), 479-499. 
Coleman, J. (1988). Social Capital in the Creation of Human Capital. The American Journal of Sociology, 94, Supplement: Organizations and Institutions: Sociological and Economic Approaches to the Analysis of Social Structure: S95-S120.

Coleman, J. (1999). Social Capital: A Multifaceted Perspective. Washington, D.C.: World Bank Publications.

Commonwealth Consortium for Education (CCEM) (2006). No. 10 Commonwealth Student Mobility: Trends and Issues (Commonwealth Education Briefing Notes). London: CCEM.

Conway T, Mackay S. \& Yorke, D. (1994). Strategic planning in higher education: who are the customers? International Journal of Educational Management, 8(6): 29-36.

Cooper, L. (16 March 2009). Changes in visas to affect international students. The Badger Online. Retrieved on July 21, 2009 from http://www.thebadgeronline.co.uk/news/changes-invisas-to-affect-international-students/.

Coulby, D. (2005a). 'The Knowledge Economy: Technology and Characteristics.' In D. Coulby and E. Zambeta (Eds.), World Yearbook of Education 2005: Globalization and Nationalism in Education. London: Routledge Falmer.

Coulby, D. (2005b). 'The Knowledge Economy: Institutions.' In D. Coulby and E. Zambeta (Eds.), World Yearbook of Education 2005: Globalization and Nationalism in Education. London: Routledge Falmer.

Coulby, D. (2005c). 'Globalisation and the Narrative of Civilisation: Greece as Curricular.' In D. Coulby and E. Zambeta (Eds.), World Yearbook of Education 2005: Globalization and Nationalism in Education. London: Routledge Falmer.

Coulby, D. \& Zambeta, E. (2005). 'Trends in Globalisation.' In D. Coulby and E. Zambeta (Eds.), World Yearbook of Education 2005: Globalization and Nationalism in Education. London: Routledge Falmer.

Council for International Education and Council for the Education of the Commonwealth (CECUKCOSA) (2000). Student mobility on the map: Tertiary Education Interchange in the Commonwealth on the Threshold of the 21st Century (Joint Working Group Report). London: UKCOSA: The Council for International Education and Council for the Education of the Commonwealth.

Council of Graduate Schools (2004). Council of Graduate Schools survey finds widespread declines in international graduate student applications to U.S. graduate schools for Fall 2004 (Press Release). Washington, D.C.: Council of Graduate Schools.

Cox, W. (1997). 'ICOS and International Students'. In O. Egan (Ed.), Minority Ethnic Groups in Higher Education. Proceedings of Conference held in St. Patrick's College, Maynooth, 27 September 1996. Dublin: Higher Education Equality Unit.

Cummings, W. (1984). Going Overseas for Higher Education: The Asian Experience. Comparative Education Review, 28(2): 241-257.

Curry, D. (2001). Senator backs away from plan for moratorium on student visas. The Chronicle of Higher Education, 48(8), A20.

Dasgupta, P. (2000). 'Social Capital and Economic Performance: Analytics.' In P. Dasgupta and I. Serageldin (Eds.), Social Capital: A Multifaceted Perspective. Washington, DC: The World Bank.

Davey, G. (2005). Chinese Students' Motivations for Studying Abroad. International Journal of Private Higher Education, 2: 16-21.

Davis, T. (1995). Flows of International Students: Trends and Issues. International Higher Education, 1: 2-4.

de Wit, Hans (2002). Internationalization of Higher Education in the United States of America and 
Europe: A Historical, Comparative, and Conceptual Analysis. Westport CT: Greenwood Press.

de Wit, H. (2008a). 'The Internationalization of Higher Education in a Global Context.' In H. de Wit, P. Agarwal, M. Elhmady Said, M. Sehoole, M. Sirozi (Eds.), Global Perspectives on Higher Education: The Dynamics of International Student Circulation in a Global Context. Rotterdam: Sense Publishers.

de Wit, H. (2008b). 'Changing Dynamics in International Student Circulation: Meanings, Push and Pull Factors, Trends, and Data.' In H. de Wit, P. Agarwal, M. Elhmady Said, M. Sehoole, M. Sirozi (Eds.), Global Perspectives on Higher Education: The Dynamics of International Student Circulation in a Global Context. Rotterdam: Sense Publishers.

de Wit, H. \& Rumbley, L. (2008). 'The Role of American Higher Education in International Student Circulation.' In H. de Wit, P. Agarwal, M. Elhmady Said, M. Sehoole, M. Sirozi (Eds.), Global Perspectives on Higher Education: The Dynamics of International Student Circulation in a Global Context. Rotterdam: Sense Publishers.

de Wit, Hans, Agarwal, P., Elhmady Said, M., Sehoole, M.T., Sirozi, M. (2008). 'Introduction and Acknowledgements. ' In H. de Wit, P. Agarwal, M. Elhmady Said, M. Sehoole, M. Sirozi (Eds.), Global Perspectives on Higher Education: The Dynamics of International Student Circulation in a Global Context. Rotterdam: Sense Publishers.

DiMaggio, P. \& Mohr, J. (1985). Cultural Capital, Education Attainment, and Marital Selection. The American Journal of Sociology, 90(6), 1231-1261.

DiMaggio, P., Hargittai, E., Neuman, W.R. \& Robinson, J.P. (2001). Social Implications of the Internet. Annual Review of Sociology. 27, 307-36.

Dimmock, C. \& Soon Leong, J. (2010). Studying overseas: mainland Chinese students in Singapore. COMPARE, 40(1): 25-42.

Dorigo, G. \& Tobler, W. (1983). Push-Pull Migration Laws. Annals of the Association of American Geographers, 73(1):1-17.

Douglass, J. \& Edelstein, R. (2009). The Global Competition for Talent: The Rapidly Changing Market for International Students and the Need for a Strategic Approach in the U.S. (Research and Occasional Paper Series: CSHE.8.09). Berkeley: Center for Studies in Higher Education, University of California, Berkley.

Dustmann, C. (1999). Temporary Migration, Human Capital, and Language Fluency of Migrants. Scandinavian Journal of Economics, 101(2), 297-314.

Dyke, J. (10 Nov. 2008). New international student legislation "appalling." The Badger Online. Retrieved on July 21, 2009 from http://www.thebadgeronline.co.uk/news/newinternational-student-legislation-\%e2\%80\%9cappalling\%e2\%80\%9d/.

Egron-Polak, E. (2004). Comments by Eva Egron-Polak, IAU in response to paper by Karine Tremblay (OECD) on 'Links between academic mobility and immigration'. Proceedings from the WES Symposium: International Labor and Academic Mobility. Retrieved October 23, 2005, from http://www.wes.org/ewenr/symp/EvaEgronPolakResponseNote.pdf.

Egron-Polak, E. (2011): Monitoring Internationalization of Higher Education. International Higher Education, 63: 2-3.

Enever, J. (2009). 'Languages, Education and Europeanisation.' In R. Dale and S. Robertson (Eds.), Globalisation and Europeanisation in Education. Oxford: Symposium Books.

Enterprise Ireland (2010). Education Ireland: International Students in Higher Education in Ireland, 2009/2010. Dublin: Enterprise Ireland.

European Union Delegation to the United States of America (EU Delegation) (2010). Interactive Policy Making, Online Consultations, Public Consultation on the future EU Programme for 
international cooperation in higher education and human capital development. Retrieved on October 8, 2010 from http://ec.europa.eu/yourvoice/ipm/forms/dispatch.

Faggian, A., McCann, P. \& Sheppard, S. (2009). 'Higher Education, Graduate Migration and Regional Dynamism in Great Britain.' In A. Varga (Ed.), Universities, Knowledge Transfer, and Regional Development: Geography, Entrepreneurship and Policy. Cheltenham, UK: Edward Elgar Publishing Ltd.

Fairbrother, G. (2007). 'Quantitative and Qualitative Approaches to Comparative Education.' In M. Bray, B. Adamson and M. Mason (Eds.), Comparative Education Research: Approaches and Methods, CERC Studies in Comparative Education 19. Hong Kong: Comparative Education Research Centre, The University of Hong Kong.

Fearn, Hannah (24 July 2008). After the gold rush. Times Higher Education. Retrieved on August 6, 2011 from http://www.timeshighereducation.co.uk/story.asp?storycode $=402895$.

Feller, I. (2007). 'Higher Education, Then and Now - Internationalization and Globalization.' In C. King \& J. Douglass (Eds.), CSHE @ 50: A Reflection and Prospectus on Globalization and Higher Education (Results of a Symposium Organized by the Center for Studies in Higher Education University of California, Berkeley). Berkeley: Carnegie Corporation of New York and CSHE: Center for Studies in Higher Education.

Field, M. \& Fegan, J. (2005).' 'Globalization and Across-Border Education: Paradigms and Challenges.' In M. Field and J. Fegan (Eds.), Education Across Borders: Philosophy, Policy, Pedagogy - New Paradigms and Challenges. Tokyo: Waseda University Media-Mix Co., Ltd.

Findlay, A., King, R., Stam, A., \& Ruiz-Gelices, E. (2006). Ever Reluctant Europeans: The Changing Geographies of UK Students Studying and Working Abroad. European and Regional Studies, 13(4), 291-318.

Findlay, A. and Stam, A. (2006). International student migration to the UK: Training for the global economy or simply another form of global talent recruitment. Paper prepared for a meeting on 'International competition for S\&E students and workers', Institute for the Study of International Migration, Georgetown University, Washington, D.C., March 30-31. Dundee: Centre for Applied Population Research. Retrieved on May 15, 2011 from http://www12.georgetown.edu/sfs/isim/Event\%20Documents/Sloan\%20Global\%20Compe tition\%20Meeting/Findlay-UK.pdf .

Finkelstein, M. (2003). Japan's National Universities and Reform. International Higher Education, 33: $20-22$.

Finn, M. (2007). Stay Rates of Foreign Doctorate Recipients from U.S. Universities, 2005. Oak Ridge, TN: Oak Ridge Institute for Science and Education.

Fukuyama, F. (2003). 'Social Capital and Civil Society (International Monetary Fund Working Paper).' In E. Ostrom and TK Ahn (Ed.), Foundations of Social Capital. Bodmin, Cornwall: MPG Books Ltd.

Gibbons, M. (1998). 'A Commonwealth Perspective on the Globalization of Higher Education.' In P. Scott (Ed.), The Globalization of Higher Education, Buckingham, UK: The Society for Research into Higher Education \& Open University Press.

Glaeser, E. (2001). The formation of social capital. Canadian Journal of Public Policy, 2: 34-40.

Gomes, L. \& Murphy, J. (2003). An exploratory study of marketing international education online. International Journal of Education Management, 17(3): 116-125.

U.S. Government Accountability Office (GAO) (2004). Border Security: Improvements Needed to Reduce Time Taken to Adjudicate Visas for Science Students and Scholars (Report to the Chairman and Ranking Minority Member, Committee on Science, House of Representatives, GAO-04-371). Washington, D.C.: GAO.

U.S. Government Accountability Office (GAO) (2005). Border security: Streamlined Visas Mantis Program Has Lowered Burden on Foreign Science Students and Scholars, but Further 
Refinements Needed (Report to Congressional Requesters, GAO-05-198). Washington, D.C.: GAO.

U.S. Government Accountability Office (GAO) (2007). Global Competitiveness: Implications for the Nation's Higher Education System (Highlights of a GAO Forum, GAO-07-135SP). Washington, D.C.: GAO.

U.S. Government Accountability Office (GAO) (2009). Higher Education: Approaches to Attract and Fund International Students in the United States and Abroad (Report to the Chairman, Subcommittee on International Organizations, Human Rights, and Oversight, Committee on Foreign Affairs, House of Representative, GAO-09-379. Washington, D.C.: GAO.

Granovetter, Mark (1973). The Strength of Weak Ties. American Journal of Sociology, 78(6), p. 1360-80.

Gray, B., Fam, K., \& Llanes, V. (2003). Branding universities in Asian markets. Journal of Product and Brand Management, 12(2): 108-120.

Grbich, C. (2007). An introduction: Qualitative data analysis. London: Sage Publications Ltd.

Green, A. (2006). 'Education, Globalization and the Nation-State.' In H. Lauder, P. Brown, J-A. Dillabough, and A. Halsey (Eds.), Education, Globalization and Social Change. New York: Oxford University Press.

Gribble, C. (2008). Policy options for managing international student migration: the sending country's perspective. Journal of Higher Education Policy and Management, 30(1): 25-39.

Gunn, S. (2005). 'Introduction.' In C. Cullingford and S. Gunn (Eds.), Globalisation, Education, and Culture Shock. Aldershot: Ashgate Publishing Ltd.

Gürüz, K. (2008). Higher Education and International Student Mobility in the Global Knowledge Economy. Albany, NY: State University of New York Press.

Gutterman, L. (2003). Stalled at the border: Many research projects have been delayed or disabled by strict U. S. visa policies. The Chronicle of Higher Education, 49(31), A20.

Harker, R. (1990). 'Education and Reproduction.' In R. Harker, C. Mahar \& C. Wilkes, An Introduction to the Work of Pierre Bourdieu. Basingstoke, Hampshire: MacMillan Press Ltd.

Hawthorne, L. (2008). The Growing Global Demand for Students as Skilled Migrants. Washington, D.C.: The Migration Policy Institute.

Healy, T. \& Côté, S. (2001). The Well-Being of Nations: The Role of Human and Social Capital. Paris: Centre for Educational Research and Innovation, OECD.

Heath, S. (2007). Widening the gap: pre-university gap years and the 'economy of experience. British Journal of Sociology of Education, 28(1), 89-103.

Hemsley-Brown, J. \& Oplatka, I. (2006). Universities in a competitive global marketplace: A systematic review of the literature on higher education marketing. International Journal of Public Sector Management, 19(4): 316-338.

Home Office, UK Border Agency (UKBA) (July 2008). Students Under the Points Based System(Tier 4): Statement of Intent. Retrieved on January 30, 2009 from http://www.ukba.homeoffice.gov.uk/sitecontent/documents/managingourborders/pbsdocs /statementofintent/studentsunderthepointsbased.pdf?view=Binary.

Home Office, UK Border Agency (UKBA) (January 2012). Update for Tier 4 sponsors: educational oversight and other changes. Retrieved on January 10, 2012 from http://www.ukba.homeoffice.gov.uk/sitecontent/newsfragments/54-t4-sponsorseducation-over.

Huang, R. (2008). Mapping Educational Tourists' Experience in the UK: understanding international students. Third World Quarterly, 2(5): 1003-1020. 
Hugo, G. (2003). Circular migration: Keeping development rolling? Migration Information Source. Retrieved on July 2, 2006 from www.migrationinformation.org.

Hung, F. (2010). Intention of students in less developed cities in China to opt for undergraduate education abroad: Does this vary as their perceptions of the attractions of overseas study change? International Journal of Educational Development, 30, 213-223.

Institute of Higher Education, Shanghai Jiao Tong University, Academic Ranking of World Universities (ARWU) (2008). Retrieved on August 1, 2011 from http://ed.sjtu.edu.cn/ranking.htm.

Institute of International Education (IIE) (2009a). "Leading Places of Origin of International Students, 2007/08-2008/09." Open Doors Report on International Educational Exchange. Retrieved on August 13, 2011 from http://www.iie.org/opendoors.

Institute of International Education (IIE) (2009b). "Field of Study of International Students, 2007/08-2008/09." Open Doors Report on International Educational Exchange. Retrieved on August 16, 2011 from http://www.iie.org/opendoors.

Institute of International Education (IIE) (2009c). "International Students by Academic Level and Place of Origin, 2008/09." Open Doors Report on International Educational Exchange. Retrieved on August 28, 2011 from http://www.iie.org/opendoors.

International Education Board Ireland (IEBI) (2008). Education Ireland: International Students in Higher Education in Ireland, 2006/2007. Dublin: International Education Board Ireland.

International Student Guru (26 Jan 2010). Ireland drops the ball attracting International Students. International Student Blog: InternationalStudent.com. Retrieved on June 1, 2011 from http://blog.internationalstudent.com/2010/01/ireland-drops-the-ball-attractinginternational-students/ .

International Student and Scholar Services-Binghamton University (ISSS-BU), (15 March 2004). U.S. government report criticizes visa delays for international students and faculty. ISSSBU News [online newsletter]. Retrieved on Sept. 30, 2005 from http://www2.binghamton.edu/isss/regulatory-updates/2004/index.html.

Ivy, J. (2001). Higher education institution image: a correspondence analysis approach. International Journal of Educational Management, 15(6): 276-282.

Johnson, V. (2009). A Visa and Immigration Policy for the Brain-Circulation Era: Adjusting to What Happened in the World While We Were Making Other Plans. Washington, D.C.: NAFSA: Association of International Educators.

Kamibayashi, C. (2006). 'Current migration of IT engineers to Japan: Beyond immigration control and cultural barriers.' In C. Kuptsch and E. Pang (Eds.), Competing for Global Talent. Geneva: International Institute for Labour Studies, International Labour Office.

Keeley, B. (2007). Human Capital: How What You Know Shapes Your Life (OECD Insights Series). Paris: Organisation for Economic Co-operation and Development (OECD).

Khan, S. (2010). Highly educated emigration from low income countries: Turning pain to gain. Paper prepared for a conference on 'Crossing Borders: Migration, Transnationalism, and Citizenship', McCulloch Center for Global Initiatives, Mount Holyoke College, March 5-6, 2010. Retrieved on May 1, 2011 from https://www.amherst.edu/media/view/245071/original/Migration_Paper.pdf.

Kivinen, O. \& Ahola, S. (1999). Higher education as human risk capital: Reflections on changing labour markets. Higher Education, 38: 191-208.

Kless, S. H. (2004). We threaten national security by discouraging the best and brightest students from abroad. The Chronicle of Higher Education, 51(7), B9.

Knight, J. (2002). Trade in Higher Education Services: The Implications of GATS. Higher Education, 39(March): 1-25. 
Knight, J. (2004). Internationalization Remodeled: Definition, Approaches, and Rationales. Journal of Studies in International Education, 8(1): 5-31.

Knight, J. (2009). Collegial Conversations. Washington, D.C.: NAFSA: Association of International Educators. Retrieved on 18 Feb. 2009 from http://www.nafsa.org/resourcelibrary/Default.aspx?id=8434.

Labi, A. (2011a). Proposed Student Visa Changes in Britain Will Damage Universities, Report Warns. The Chronicle of Higher Education. Retrieved on January 30, 2012 from http://chronicle.com/blogs/global/proposed-student-visa-changes-in-britain-will-damageuniversities-report-warns/28952.

Labi, A. (2011b). Britain's New Student-Visa Policy Restricts Work Opportunities, but Not as Much as Feared. The Chronicle of Higher Education. Retrieved on January 30, 2012 from http://chronicle.com/article/Britains-New-Student-Visa/126862/.

Lamont, M. \& Lareau, A. (1988). Cultural Capital: Allusions, Gaps, Glissandos in Recent Theoretical Developments. Sociology, 6, 153-168.

Lange, T. (2009). Return migration of foreign students and the choice of non-resident tuition fees (IFO Working Paper No. 74: 1-32). Munich: Institute of Economic Research, University of Munich.

Lasanowski, V. (2009). International Student Mobility: Status Report 2009. London: The Observatory on Borderless Higher Education, International Strategic Information Service.

Lauder, H., Brown, P., Dillabough, J-A, \& Halsey, A. (2006). 'Introduction : The Prospects for Education: Individualization, Globalization, and Social Change.' In H. Lauder, P. Brown, JA. Dillabough, and A. Halsey (Eds.), Education, Globalization and Social Change. New York: Oxford University Press.

Lawley, M. \& Perry, C. (1997). Thai and Malaysian Students' Perceptions of Overseas Study Destinations: An Exploratory Review (Unpublished Management Papers, Faculty of Business, University of Southern Queensland). Retrieved on March 2, 2007 from http://smib.vuw.ac.nz:8081/www/ANZMAC1998/Cd_rom/Lawley90.pdf.

Leadbeater, C. \& Wilson, J. (2007). The Atlas of Ideas: How Asian innovation can benefit us all. London: Demos (www.demos.co.uk).

Lee, J. (2008). Beyond Borders: International Student Pathways to the United States. Journal of Studies in International Education, 12(3): 308-327.

Li, F., Findlay A.M., Jowett, A.J., Skeldon, R (1996). Migrating to learn and learning to migrate: a study of the experiences and intentions of international student migrants. International Journal of Population Geography, 2:51-68.

Li, F. \& Morgan, W. J. (2008). Private higher education in China: access to quality higher education and the acquisition of labour market by low-income students. Education, Knowledge, and Economy, 2(1): 27-37.

Li, F., Morgan, W. J. \& Ding, X. (2008). The expansion of higher education, employment and overeducation in China. International Journal of Educational Development, 28: 687-697.

Li, M. \& Bray, M. (2007). Cross border flows of students for Higher Education: Push-Pull Factors and Motivations of Mainland Chinese Students in Hong Kong and Macau. Higher Education, $53(6)$ : 791-818.

Loy, D. (2005).'Globalizing Education or Educating Globalisation?' In M. Field and J. Fegan (Eds.), Education Across Borders: Philosophy, Policy, Pedagogy - New Paradigms and Challenges. Tokyo: Waseda University Media-Mix Co., Ltd.

MacDonald, A. (8 Dec. 2008). U.K. cuts immigration as economy slows: Points-based system, raising hurdles for all but the most highly skilled, may decrease available positions $20 \%$. 
The Wall Street Journal, Economy and Politics Section: 9.

Maglen, L.R. (1990). Challenging the Human Capital Orthodoxy: The Education-Productivity Link Re-examined. The Economic Record, 66(195): 281-94.

Mahroum, S. (2000). Highly skilled globetrotters: mapping the international migration of human capital. R\&D Management, 30(1): 23-40.

Maier, G. (2009). 'Product Differentiation or Spatial Monopoly? The Market Areas of Austrian Universities in Business Education.' In A. Varga (Ed.), Universities, Knowledge Transfer, and Regional Development: Geography, Entrepreneurship and Policy. Cheltenham, UK: Edward Elgar Publishing Ltd.

Marginson, S. (2002). Nation-building universities in a global environment: The case of Australia. Higher Education, 43: 409-428.

Marginson, S. (2004a). Markets in higher education: National and global competition. AARE Radford Lecture [revised], NZARE/AARE Joint Conference: Auckland, New Zealand, Nov. 29-Dec.3, 2003, Revised 9 January 2004. Retrieved on December 1, 2006 from http://instruct1.cit.cornell.edu/courses/anthr362/Radford\%20lecture\%20final\%20revised. pdf.

Marginson, S. (2004b). National and Global Competition in Higher Education. The Australian Educational Researcher, 31(2): 1-28.

Marginson, Simon (2006). Dynamics of national and global competition in higher education. Higher Education, 52: 1-39.

Marginson, S. (2010). After globalization: emerging politics of education. Journal of Education Policy, 14(1): 19-31.

Maringe, F. \& Carter, S. (2007). International students' motivations for studying in UK HE: Insights into the choice and decision making of African students. International Journal of Educational Management, 21(6): 459-475.

Massey, D. \& García España, F. (1987). The Social Process of International Migration. Science, 237(4816): 733-738.

Massey, D. (1990).The Social and Economic Origins of Immigration. The Annals of the American Academy of Political and Social Science, 510(1): 60-72.

Mazzarol, T., Kemp, S. \& Savery, L. (1996). International Students Who Choose Not to Study in Australia: An Examination of Taiwan and Indonesia. Canberra: Australian International Education Foundation (AIEF).

Mazzarol, T., Choo, S. \& Nair V. (2001a). Australia and the Indian Postgraduate Science and Technology Market: Examining why Indian students choose to study in countries other than Australia. Canberra: Australian Education International, Department of Education, Training and Youth Affairs.

Mazzarol, T. \& Soutar, G. \& Thein, V. (2000). Critical Success Factors in the Marketing of an Educational Institution: A Comparison of Institutional and Student Perspectives. Journal for Marketing for Higher Education, 10(2): 39-57.

Mazzarol, T. \& Soutar, G. (2001). The Global Market for Higher Education: Sustainable Competitive Strategies for the New Millennium. Cheltenham, UK: Edward Elgar.

Mazzarol, T., \& Soutar, G. (2002). "PUSH-PULL" Factors Influencing International Student Destination Choice. The International Journal of Education Management, 16(2), 82-90.

Mazzarol, T., Soutar, G., Smart, D. \& Choo, S. (2001b). Perceptions, Information and Choice: Understanding How Chinese Students Select a Country for Overseas Study. Canberra: Australian Education International. 
McCracken, E. (15 Feb. 2009). £50m: Universities warn this is what new UK visa rules could cost them every year. Sunday Herald. Retrieved on Feb. 18, 2009 from http://www.sundayherald.com/misc/print.php?artid=2487771.

McDonough, P., Antonio, A. \& Horvat, E. (1996). College choice as capital conversion and investment: A New Model. Paper presented at the Annual Meeting of the Association for the Study of Higher Education, Memphis, TN, October 1996.

McGettigan, T. (31 May 2009). US: The business of higher education. University World News: The global window on higher education. Retrieved onAugust. 28, 2009 from http://www.universityworldnews.com/article.php?story=20090528172951762 .

McMahon, M. (1992). Higher Education in the World Market: A Historical Look at the Global Context of International Study. Higher Education, 24: 465-482.

Menon, S., \& Carspecken, P. (1990). Beyond "Push" and "Pull" Explanations, Asian-Indian Graduate Students in the United States. Paper presented at the Annual Meeting of the Comparative and International Education Society. Retrieved May 16, 2007 from http://search.ebscohost. com/login. aspx?direct=true\&db=eric\&AN=ED332888\&site=ehostlive.

Ministry of Education and Science (MES) (2004). Internationalisation of Irish Education Services (Report of Interdepartmental Working Group). Dublin: Ministry of Education and Science.

Mok, K. (2003). Globalisation and Higher Education Restructuring in Hong Kong, Taiwan and Mainland China. Higher Education Research and Development, 22(2): 117-129.

Moore, R. (2004). Cultural capital: objective probability and the cultural arbitrary. British Journal of Sociology of Education, 25(4), 445-456.

Mortimer, K. (1997). Recruiting Overseas Undergraduate Students: are their information requirements being satisfied? Higher Education Quarterly, 51(3): 225-238.

Moogan, Y.J., Baron, S., \& Harris, K. (1999). Decision-Making Behaviour of Potential Higher Education Students. Higher Education Quarterly, 53(3): 211-228.

Morgan, W. J. (14 November 2005). The Brain Drain: Who wins and who loses? Presentation to Commonwealth Scholarship Commission Welcome Day. Methodist Central Hall, London.

Morgan, W. J., Sives, A., Appleton, S. (2005). Managing the International Recruitment of Health Workers and Teachers: Do the Commonwealth Agreements Provide an Answer? The Round Table, 94(379): 225-238.

Morgan, W. J. (2008). Social capital, citizenship and continuing education: What are the connections? International Journal of Continuing Education and Lifelong Learning, 1(1): 35-45.

Motivans, A. (2009). Global trends in student mobility. UNESCO Education Sector Newsletter, June-July: $1-4$.

Murphy-Lejeune, E. (2002). Student Mobility and Narrative in Europe. New York: Routledge.

Murphy-Lejeune, E. (2003). 'An Experience of Interculturality: Student Travellers Abroad.' In G. Alred, M. Byram and M. Fleming (Ed.) Intercultural Experience and Education. Clevedon, UK: Multilingual Matters Ltd.

NAFSA: Association of International Educators (2003). In America's interest: Welcoming international students (Report of the Strategic Task Force on international student access). Washington, D.C.: NAFSA.

Naidoo, R. \& Jamieson, I. (2005). 'Knowledge in the Marketplace: The Global Commodification of Teaching and Learning in Higher Education.' In P. Ninnes and M. Hellstén (Eds.), Internationalizing Higher Education: Critical Explorations of Pedagogy and Policy, CERC Studies in Comparative Education, Series 1. Hong Kong: Comparative Education Research 
Centre, The University of Hong Kong.

Naidoo, V. (2010). From Ivory Towers to International Business: Are Universities Export Ready in Their Recruitment of International Students? Journal of Studies in International Education, 14(1): 5-28.

National Research Council (NRC) (U.S.) Staff (2005). Policy Implications of International Graduate Students and Postdoctoral Scholars in the United States. Washington, D.C.: National Academies Press.

Neice, D. \& Braun, P. (1977). A Patron for the World?: A Descriptive Report of the CBIE Survey of Foreign Students at Post-Secondary Institutions: Part One. Papers on Foreign Student Issues. Ottawa: Canadian Bureau for International Education.

Neri, F. \& Ville, S. (2006). The Social Capital Experience of International Students in Australia: The Wollongong Experience (Economics Working Paper Series 2006). Wollongong, Australia: University of Wollongong.

Neri, F. \& Ville, S. (2008). Social capital renewal and the academic performance of international students in Australia. The Journal of Socio-Economics, 37(4), 1515-1538.

Newman, Melanie (2009). A funny sort of welcome, Times Higher Education, 29 October 2009: 37-39.

Nicholls, R. \& Morgan, W.J. (2009). Integrating employment and skills policy: lessons from the United Kingdom's New Deal for Young People. Education, Knowledge and Economy, 3(2), 81-96.

Ninnes, P. \& Hellstén, M. (2005). 'Critical Engagements with the Internationalization of Higher Education.' In P. Ninnes and M. Hellstén (Eds.), Internationalizing Higher Education: Critical Explorations of Pedagogy and Policy, CERC Studies in Comparative Education, Series 1. Hong Kong: Comparative Education Research Centre, The University of Hong Kong.

Nora, A. (2004). The Role of Habitus and Cultural Capital in Choosing a College, Transitioning From High School to Higher Education, and Persisting in College Among Minority and Nonminority Students. Journal of Hispanic Higher Education, 3(2): 180-208.

Oliver, P. (2005). 'The concepts of globalisation and culture.' In C. Cullingford and S. Gunn (Eds.), Globalisation, Education, and Culture Shock. Aldershot: Ashgate Publishing Ltd.

Olssen, M. (2006). 'Neoliberalism, Globalization, Democracy: Challenges for Education.' In H. Lauder, P. Brown, J-A. Dillabough, and A. Halsey (Eds.), Education, Globalization and Social Change. New York: Oxford University Press.

Olssen, M., Codd, J., \& O'Neill, A.-M. (2004). Education Policy: Globalization, Citizenship and Democracy. London: Sage Publishing Ltd.

Ong, A. (1999). Flexible Citizenship: The Cultural Logics of Transnationality. Durham, NC: Duke University Press.

Organisation of Economic Cooperation and Development (OECD) (1998). Human Capital Investment: An International Comparison. Paris: Centre for Educational Research and Innovation, OECD.

Phelps, C. (2010). 'Bringing international students to campus: who, what, when, where, why and how?' In B. Johnstone, M. d'Ambrosio, and P. Yakoboski (Eds.), Higher Education in a Global Society. Cheltenham, UK: Edward Elgar.

Pimpa, N. (2003). The Influence of Family on Thai Students' Choices of International Education. The International Journal of Educational Management, 17(5): 211-219.

Pimpa, N. (2005). A family affair: The effect of family on Thai students' choices of international education. Higher Education, 49 (4): 431-448. 
Portes, A. \& Borocz, J. (1989). Contemporary Immigration: Theoretical Perspectives on Its Determinants and Modes of Incorporation. International Migration Review, 23(3), Special Silver Anniversary Issue: International Migration an Assessment for the 90's: 606-630.

Portes, A. (1998). Social Capital: Its Origins and Applications in Modern Sociology. Annual Review of Sociology, 24(1), 1-24.

Postgrad.com (2011a). Private Providers of postgraduate programmes. Retrieved on Sept. 3, 2011 from http://www.postgrad.com/editorial/uk_postgraduate_private_institutions/.

Postgrad.com (2011b). Postgrad universities in the UK. Retrieved on Sept. 3, 2011 from http://www.postgrad.com/editorial/uk_universities/.

Putnam, R. (2000). Bowling Alone: The Collapse and Revival of American Community. New York: Simon \& Schuster, Inc.

Putnam, R. (2001). Social capital: Measurement and consequences. Canadian Journal of Policy Research 2(1), 41-52.

Putnam, R., Leonardi, R. \& Nanetti, R. (2003). 'Social Capital and Institutional Success.' In E. Ostrom and TK Ahn (Eds.), Foundations of Social Capital. Bodmin, Cornwall: MPG Books Ltd.

Pye, L.W. (1999). Civility, Social Capital, and Civil Society: Three Powerful Concepts for Explaining Asia. Journal of Interdisciplinary History, 29(4): 763-782.

Reay, D. Davies, J., David, M., \& Ball, S. (2001). Choices of Degree or Degrees of Choice?: Class, 'Race' and the Higher Education Choice Process. Sociology, 35, 855-874.

Reay, D. (2004). Education and Cultural Capital: The Implications of Changing Trends in Education Policies. Cultural Trends, 13(2), 73-86.

Rizvi, F. (2004). Debating globalization and education after September 11. Comparative Education, 40(2): 157-171.

Robertson, S., Bonal, X. \& Dale, R. (2006). 'GATS and the Education Service Industry: The Politics of Scale and Global Reterritorialization.' In H. Lauder, P. Brown, J-A. Dillabough, and A. Halsey (Eds.), Education, Globalization and Social Change. New York: Oxford University Press.

Robertson, S., Novelli, M., Dale, R., Tikly, L., Dachi, H., Alphonce, N. (2007). Globalization, Education, And Development: Ideas Actors And Dynamics (Researching the Issues, 68). London: Department for International Development (DFID).

Rong, X. (2009). From the World to China, From China to the World: A Comparative Study Focusing on the Internationalization of China's Higher Education, The Impacts of the Economic Downturn on the Issues, Challenges and Opportunities (Beijing Forum 2009: Higher Education under the Financial Crisis: Strategies and Development, Collections of Papers and Abstracts). Beijing: Beijing Forum Organizing Committee: 294-308.

Ross, M., Heaney, J., Cooper, M. (2007). Institutional and managerial factors affecting international student recruitment management. International Journal of Educational Management, 21(7): 593-605.

Sadlak, J. (1998). 'Globalization and Concurrent Challenges for Higher Education.' In P. Scott (Ed.), The Globalization of Higher Education, Buckingham, UK: The Society for Research into Higher Education \& Open University Press.

Sahasrabudhe, U. (2008). Understanding Factors Guiding International Mobility Decisions: Perspectives of Graduate Engineering Students from India. wRAP Up: A Newsletter for the Recruitment, Admission and Preparation Knowledge Community, 5(1): 8-14.

Sakellaris, P. \& Spilimbergo, A. (2000). Business cycles and investment in human capital: 
international evidence on higher education. Carnegie-Rochester Conference Series on Public Policy 52: 221-256.

Schultz, T. (1961). Investment in Human Capital. The American Economic Review, 51 (1), 1-16.

Schuller, T. \& Field, J. (1998). Social capital, human capital and the learning society. International Journal of Lifelong Education, 17(4), 226-235.

Schuller, T. \& Bamford, C. (2000). A Social Capital Approach to the Analysis of Continuing Education: evidence from the UK Learning Society research programme. Oxford Review of Education, 26(1), pp. 5-19.

Schuller, T. (2001). The Complementary Roles of Human and Social Capital. Canadian Journal of Policy Research, 2, 18-24.

Seidel, H. (1991). Internationalisation: A New Challenge for Universities. The International Journal of Higher Education and Educational Planning: Special Issue on Higher Education and the Flow of Foreign Students, 21 (3): 289-296.

Sjaastad, L.A. (1962). The Costs and Returns of Human Migration. The Journal of Political Economy, 70(5), Part 2: Investment in Human Beings, 80-93.

Snook, I. (1990). 'Language, Truth and Power: Bourdieu's Ministerium.' In R. Harker, C. Mahar, and C. Wilkes (Eds.), An Introduction to the Work of Pierre Bourdieu. Basingstoke, Hampshire: MacMillan Press Ltd.

Somerville, W., Sriskandarajah, D., \& Latorre, M. (July 2009). United Kingdom: A Reluctant Country of Immigration. Migration Information Source. Retrieved on [need date] from http://www.migrationinformation.org/Profiles/print.cfm?ID-736.

Somerville, W., \& Sumption, M. (2009). Immigration in the United Kingdom: The recession and beyond. Washington, D.C.: Migration Policy Institute, Equality and Human Rights Commission.

Spence M. (1973). Job Market Signaling. Quarterly Journal of Economics, 87(3): 355-374.

Stachowski, C. (2011). Educational Marketing: A Review and Implications for Supporting Practice at Non-university Educational Institutions. Educational Management Administration and Leadership, published online 31 January 2011. Retrieved on May 1, 2011 from http://ema.sagepub.com/content/early/2011/01/13/1741143210390056.

Stark, O. and Wang, Y. (2002). Inducing Human Capital Formation: Migration as a Substitute for Subsidies. Journal of Public Economics, 86: 29-46.

Steadman, G.T. \& Dagwell, R.H. (1990). A Survey of Overseas Students in Queensland. Australian Universities' Review, 1 \& 2: 59-63.

Stiglitz, J. (2006). Making Globalization Work. New York: W.W. Norton \& Company, Inc.

Sullivan, A. (2001). Cultural Capital and Educational Achievement. Sociology, 35(4), 893-912.

Sullivan, A. (2006). Students as Rational Decision-Makers: the question of beliefs and attitudes. London Review of Education, 4(2), 271-290.

Sullivan, K. \& Enever, J. (2009). 'What if Language Europe?' In R. Dale and S. Robertson (Eds.), Globalisation and Europeanisation in Education. Oxford: Symposium Books.

Suter, B. \& Jandl, M. (2006). Comparative Study on Policies toward Foreign Graduates - Study on admission and retention policies towards foreign students in industrialized countries. Vienna: International Centre for Migration Policy Development.

Suter, B. \& Jandl, M. (2008). Train and Retrain: National and Regional Policies to Promote the Settlement of Foreign Graduates in Knowledge Economies. International Migration and Integration, 9: 401-418. 
Sweetland, S. (1996). Human Capital Theory: Foundations of a Field of Inquiry. Review of Education Research, 66(3), 341-359.

Szelényi, K.(2006). 'Students without Borders? Migratory Decision-making among International Graduate Students in the U.S.' In M. Smith and A. Favell (Eds.), The Human Face of Global Mobility, Comparative Urban and Community Research, Vol. 8. New Brunswick, NJ: Transaction Press.

Taiwanese Ministry of Education (2008). "Numbers of Students Obtaining Student Visas from Foreign Nations between 1998 and 2007." Summary of Education Statistics. Retrieved on January 5, 2012 from

http://english.moe.gov.tw/ct.asp?xItem $=9354 \& c t N o d e=1184 \& m p=1$.

Teichler, U \& Yaĝci, Y. (2009). 'Changing Challenges of Academic Work: Concepts and Observations.' In Meek, V.L., Teichler, U. \& Kearney, M-L. (Eds.), Higher Education, Research and Innovation: Changing Dynamics: Report on the UNESCO Forum on Higher Education, Research and Knowledge 2001-2009. Kassel: International Centre for Higher Education Research.

Throsby, C. (1991). The Financial Impact of Foreign Student Enrolments. The International Journal of Higher Education and Educational Planning: Special Issue on Higher Education and the Flow of Foreign Students, 21 (3): 351-358.

Throsby, D. \& Heaton, C. (1995). Postgraduate Education of Overseas Students in Australia (Economics Division Working Papers, Development Issues, 95/2). Canberra: Research School of Pacific and Asian Studies, Australian National University.

Times Higher Education, THE-QS World University Ranking (THES) (2008). Retrieved on August 1, 2011 from http://www.timeshighereducation.co.uk/hybrid.asp?typeCode=243.

Tremblay, K. (2002). Student Mobility between and towards OECD Countries: A Comparative Analysis Organisation for Economic Co-operation and Development (International Mobility of the Highly Skilled: OECD Proceedings). Paris: OECD Publishing.

Turner, Y. \& Robson, S. (2008). Internationalizing the University. London: Continuum International Publishing Group.

UK Council for International Student Affairs (UKCISA) (2008). Mobility matters: Forty years of international students, Forty years of UKCISA. London: UKCISA.

UK Council for International Student Affairs (UKCISA) (2010). "4. Top non-EU sending countries." International students in UK higher education: key statistics. Retrieved on August 16, 2011 from http://www.ukcisa.org.uk/about/statistics_he.php\#table4.

United Nations Education, Scientific, and Cultural Organization (UNESCO) (2006). Global education digest 2006: Comparing Education Statistics Across the World. Montreal: UNESCO Institute for Statistics.

United Nations Education, Scientific, and Cultural Organization (UNESCO) (2010). Global education digest 2010: Comparing Education Statistics Across the World. Montreal: UNESCO Institute for Statistics.

Universities UK (2010). Higher Education in Facts and Figures. Retrieved on Sept. 3, 2011 from http://www.universitiesuk.ac.uk/Publications/Documents/HigherEducationInFactsAndFigur esSummer2010.pdf.

van der Wende, M. (2001). Internationalisation policies: about new trends and contrasting paradigms. Higher Education Policy, 14 (3) 249-259.

Van der Werfhorst, H., Sullivan, A., \& Cheung, S-Y. (2003). Social Class, Ability and Choice of Subject in Secondary and Tertiary Education in Britain. British Educational Research Journal, 29(1): 41-62.

Varga, A. (2009). 'Introduction'. In A. Varga (Ed.), Universities, Knowledge Transfer, and Regional 
Development: Geography, Entrepreneurship and Policy. Cheltenham, UK: Edward Elgar Publishing Ltd.

Varghese, N. (2008). Globalization of higher education and cross-border student mobility. Research Paper Series. Paris: Institutional Institute for Educational Planning (IIEP)UNESCO.

Vickers, P. \& Bekhradnia, B. (2007). The Economic Costs and Benefits of International Students. Higher Education Policy Institute. Retrieved on July 12, 2007 from http://www.epi.soe.vt.edu/perspectives/policy_news/pdf/EconomicEffects.pdf.

Wagner, A. \& Schnitzer, K. (1991). Programmes and Policies for Foreign Student and Study Abroad: The Search for Effective Approaches in a New Global Setting. The International Journal of Higher Education and Educational Planning: Special Issue on Higher Education and the Flow of Foreign Students, 21 (3): 275-288.

Walker, I. \& Zhu, Y. (2003). Education, earnings and productivity: Recent UK evidence. Labour Market Trends, 111(3), 145-152.

Wallis, J. (2002). Human and social capital: ideological constructs to serve a new world order. Paper presented at the British Association of International and Comparative Education (BAICE) Conference, University of Nottingham, Sept. 2002.

Waters, J. (2006a). Geographies of cultural capital: education, international migration and family strategies between Hong Kong and Canada. Transactions of the Institute of British Geographers, 31(2): 179-192.

Waters, J. (2006b). Emergent Geographies of International Education and Social Exclusion. Antipode: 1046-1068.

Waters, J. (2007). Roundabout routes and sanctuary schools': the role of situated educational practices and habitus in the creation of transnational professionals. Global Networks, 7(4): 477-497.

Waters, J., \& Brooks, R. (2010). Accidental achievers? International higher education, class reproduction and privilege in the experiences of UK students overseas. British Journal of Sociology of Education, 31(2): 217-228.

Weiss, A. (1995). Human Capital vs. Signalling Explanations of Wages. The Journal of Economic Perspectives, 9(4): 133-154.

Wellington, J. (2000). Educational Research: Contemporary Issues and Practical Approaches. London: Continuum International Publishing Group.

Wellington, J. \& Szczerbinski, M. (2007). Research Methods for the Social Sciences. London: Continuum International Publishing Group.

Wiers-Jenssen, J. (2008). Does Higher Education Attained Abroad Lead to International Jobs? Journal of Studies in International Education, 12(2): 101-130.

Wilkins, S. \& Huisman, J. (2010). Student Recruitment at International Branch Campuses: Can They Compete in the Global Market? Journal of Studies in International Education, published online 6 December 2010. DOI: 10.1177/1028315310385461.

Woodhall, M. (1987). 'Human Capital Concepts.' In G. Psacharopoulos (Ed.), Economics of Education: Research and Studies. Oxford: Pergamon.

Woolcock, M. (1999). Social Capital: The State of the Notion. Paper presented at a multidisciplinary seminar on 'Social capital: Global and Local Perspectives', Helsinki, April 15.

Woolcock, M. (2001). 'The Place of Social capital in Understanding Social and Economic Outcomes.' In J. Helliwell (Ed), The Contribution of Human and Social Capital to Sustained Economic Growth and Well-being: International Symposium Report (Proceedings of an 
OECD/HRDC conference), Quebec, March 19-21, 2000). Ottawa: Human Resources Development Canada and OECD.

Yang, M. (2007). What attracts mainland Chinese students to Australian higher education? Studies in Learning, Evaluation Innovation and Development, 4(2): 1-12.

Yang, R. (2002). University internationalisation: its meanings, rationales and implications. Intercultural Education, 13(1): 81-95.

Yonezawa, A. \& Kim, T. (2006). The Future of Higher Education in a Context of Shrinking Student Population: Policy Challenges for Japan and Korea. Higher Education Management and Policy, 5 (2): 9-23.

Zha, Q. (2003). Internationalization of Higher Education: Towards a Conceptual Framework. Policy Futures in Education, 1(2), 248-270.

Ziguras, C. \& Law, S. (2006). Recruiting international students as skilled migrants: the global 'skills race' as viewed from Australia and Malaysia. Globalisation, Societies and Education, 4(1): 59-76.

Zimdars, A. Sullivan, A. \& Heath, A. (2009). Elite Higher Education Admissions in the Arts and Sciences: Is Cultural Capital the Key? Sociology, 43(4): 648-666. 


\section{Appendices}


Appendix A:

Questionnaire Information and Consent Forms 
Appendix B:

Interview Information and Consent Forms 


\section{ARTICIPANT INFORMATION}

Please read the following information prior to the interview.

The aim of this $\mathrm{PhD}$ research study is to understand how and why international students make decisions regarding where to study. This interview will take approximately 30-45 minutes.

All information provided by you will be solely used for the purpose of this research study and will be treated as confidential and with complete anonymity.

Your information will be stored securely by the researcher, with only the researcher and her supervisors having access to it for the sole purpose of this study.

Every effort will be made to prevent the identification of participants in any published material.

Participation in this research is completely voluntary, and you may withdraw at any stage without prejudice or negative consequences. Withdrawal or non-participation will not affect you now or in the future.

You may contact the researcher or her supervisors if you require further information about the research, and may also contact the Research Ethics Coordinator of the School of Education, University of Nottingham if you wish to make a complaint relating to your involvement in the research.

Contact details:

Researcher: Cheryl Rounsaville, ttxcar@nottingham.ac.uk

Supervisors: Professor W. John Morgan, john.morgan@nottingham.ac.uk

School of Education Research Ethics Coordinator: Professor Roger Murphy, roger.murphy@nottingham.ac.uk

\section{PARTICIPANT CONSENT FORM}

Please read the following information carefully.

- I have read the Participant Information above, understand the purpose of the research study, and am aware of what my participation involves.

- I understand that I may withdraw from the research study at any stage and that this will not affect my status now or in the future.

- I understand that while information gained during the study may be published, I will not be identified and my personal results will remain confidential.

- I understand that my participation in this interview is completely voluntary.

- I understand that my data will be stored securely by the researcher, with only the researcher and her supervisors to have access to it for the use of this study only.

- I understand that I may contact the researcher or her supervisors if I require further information about the research, and that I may contact the Research Ethics Coordinator of the School of Education if I wish to make a complaint relating to my involvement in the research.

- As with the questionnaire, my participation in this interview implies consent for my answers to the interview questions to be used as part of this research.

- I agree that the researcher may audio record and transcribe this interview, and understand that the transcription will be made available to me for comment or change prior to the completion of this research.

- All of my questions about the research have been satisfactorily answered. น N N N N N N N N N N N N N N N N N N N N N N N N N N N N N N N N N N N N N N N N I have read and understood the above and agree to participate.

Participant Signature Date

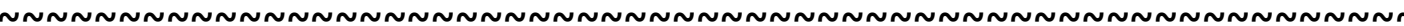

I have explained the above and answered all questions asked by the participant. 
Appendix C:

Questionnaire 
Appendix D:

Interview Schedule 


\section{INTERVIEW SCHEDULE}

Q2. Are you a post-graduate student?

Q13. At what level are you currently studying?

- Why did you decide to pursue PG education?

- Do you see PG education as an investment?

$\circ$ If no, why not?

- If yes, what are the benefits to you? Have you always thought this?

- What were you doing before starting your PG course?

- If working, why did you give up your job and salary to go to university?

- If not working but just continuing on with education from UG:

- Why?

- How will having a PG qualification help you more than just a UG qualification alone?

- Before deciding to study overseas, did you consider any options other than pursuing PG education?

$\circ$ Work, on-the-job training, apprenticeship

- Just want to ask a couple of background questions:

- What is your father's occupation?

- What is your mother's occupation?

- Did your parents go to uni?

Q6. Are you a completely or partially self-funded student?

F-U Q. If you are partially self-funded, were you able to make your own decision about where to study?

F-U Q. Although you have a full scholarship/grant OR your university fees are paid by your employer, government or other organization, were you able to make your own decision about where to study?

- I want to ask more about your funding:

- Fully/Partially Self-funded - where does money come from?

- Partial/Full scholarship/grant OR Fees paid by employer, government, other organization

- What is your obligation to them after graduation?

- Confirm with non-fully-self-funded participants that they could choose COUNTRY!

Q7. Are you pursuing a degree in one of the following disciplines: law, engineering, business/management, physical and life sciences, mathematics, OR computer science (IT)?

Q14. What is your area of study?

- Tell me more about your field of study within your major.

- Why were you interested in studying this area in general? 
- Why did you want to study it at the PG level?

- Was your course of study available in your home country?

Q24. How long have you been in the United States?

- If the student lived in the U.S. prior to starting their PG programme:

- Did anyone you know from your time in the U.S. provide advice or information regarding:

- Studying overseas?

- Choosing an institution/programme?

- Choosing a host country?

Q26. Have you studied in any other countries besides the U.S. and your home country?

Q27. Are any of your family members/friends currently studying overseas or have they studied overseas in the past?

- If the student studied in another country (besides the U.S. or their home country):

- Did anyone you know from your time in information regarding:

- Studying overseas?

- Choosing an institution/programme?

- Choosing a host country?

- Did your friends or family who had or are currently studying overseas have much influence on your:

- Decision to study overseas?

- Choice of an institution/programme?

$\circ$ Choice of host country?

- Were there other people you know besides family and friends who live(d) in the U.S.?

- Were there other people you know besides family and friends who studied overseas?

$>$ Co-workers, teachers, education agents, Internet

- Did they influence your decision to study in the U.S.?

- Did they provide advice or information regarding:

- Studying overseas?

- Choosing an institution/programme?

- Choosing a host country?

Q28. Did you consider studying at your current level of study in your home country?

- Did you consider studying at the PG level in your home country?

o If yes:

- In your opinion, what are the benefits of studying in your home country?

- As compared to studying overseas?

- As compared to the U.S.?

- Did you apply and get accepted to a university in your home country? 
○ If no:

- If yes, why didn't you study in your home country?

- If no, was your only option to study overseas?

- Why didn't you consider studying in your home country?

- Would you have studied in your home country if the economy there was the same as the U.S.? If yes, why? If no, why not?

- To make a decision about where to study, from whom and what information did you collect:

- About overseas study?

- About choosing an institution/programme?

- About choosing a host country?

$>$ Parents, friends, colleagues, education agents, Internet (on-line discussion groups, chat rooms, EM conversations, etc)...

- What information did these sources provide?

$>$ Suggest or provide details about best places to study, appropriate programmes, institution names...

- Did these contacts provide any other resources or help regarding:

- Your decision to study overseas?

- Your choice of an institution/programme?

- Your choice of host country?

Helped you to get admitted into a certain programme or institution, provided you with the contact information of a professor in your field...

- Did your family members have a lot of influence on your decisions to:

- Study overseas?

- Did your family members want you to study overseas?

- If yes, why? If no, why not?

- Study at a particular institution/programme?

- Study in the U.S.?

- Did your family members want you to study in the U.S.?

- If yes, why? If no, why not?

- Does your family think an overseas education is valuable? Why? Why not?

\section{Q29. What reasons were important to you in deciding to study} overseas in general?

- Why did you decide to study overseas? (Refer here to their answers from questionnaire.)

- In your opinion, what are the benefits of studying overseas?

$>$ Prompt for any missing capitals?

- How did you determine what the benefits are for you?

- Sources of information for this?

- In your opinion, what are the risks/costs of studying overseas?

$>$ Prompt for any missing capitals? 
- Do you think undertaking overseas study was a risk?

- If yes, in what way? If no, why not?

- How did you determine what the risks/costs are for you?

- Sources of information for this?

- Besides an educational qualification, what will you gain from an overseas study?

$>$ Economic/human capital gains - for your future career, for example?

$>$ Personal/cultural capital gains - ability to speak English, the pleasure of greater understanding of the surrounding world, etc.

$>$ Symbolic/cultural capital gains - prestige in community or among friends, etc.

$>$ Social capital gains - make some contacts to help get job after graduation

- Do you think that an overseas qualification will guarantee:

- A good job after graduation? In future career path?

- A good salary after graduation? In future career?

- Do you think you would be able to get a good job and good salary at home if you did not study overseas?

$\circ \quad$ If yes, in what way? If no, why not?

- Do you think an overseas qualification will be highly valued in your home country?

If yes, in what way? If no, why not?

- Do you think employers in your home country are more eager to hire someone with an overseas qualification rather than someone with a home degree?

If so, why? If not, why not?

- Besides proof that you have knowledge of a certain subject (engineering for example), what else does having a U.S. degree say about you to other people?

$>$ Future employers, friends, co-workers...

$>$ You are knowledgeable about Western culture; you are a very independent and mature person...

Q30. Please list, IN ORDER OF PREFERENCE, the names of the countries (up to 5) which you considered for study.

- Review answers to this question to see if 1 ) they make sense; 2) agree with what they put in matrix for Q.31.

Q31. According to your list of preferred countries in the previous question, please tick the action you took to pursue study in that country.

- Review answers to this question to see if 1 ) they make sense; 2) gave complete answers; 3 ) what other countries they considered and what stages of the process they went through. 
- If the student went through all the same stages of the process for 2 or more alternate host countries as they did for the U.S., then ask: What tipped you to finally choose the U.S. as your host country?

- For each country listed as having been considered, what are some of the main reasons:

- You considered that country for study

- You decided against that country for study

- You chose the U.S. over that country for study

- Besides education qualification, what did you hope to gain from study in the U.S.?

- How did you determine the benefits and risks of studying the U.S.?

- Sources of information for this?

- Would a degree from one of the other host countries you considered be as beneficial to you as a degree from the U.S.?

- Would a degree from your home country be as beneficial to you as a degree from the U.S.?

- The U.S. was one of the countries you considered for study, why didn't you choose to study there...

- Why did you choose the U.S. over the UK?

- Would study in the U.S. be of more benefit to you than study in the UK?

Q32. Do you still think study in the U.S. was a good choice for you?

- Why? Why not?

- If did not answer, prompt for explanation.

- How much did you know about the U.S. before you came here to study?

- Had you been to the U.S. before you came to study here?

\section{Q33. Was the U.S. your first choice for country of study?}

- Double check this against answers to Q30.

- Why? Why not?

- If did not answer, prompt for explanation..

Q34. What reasons were important to you in choosing a particular COUNTRY for study?

- Clarify given reasons if necessary.

- Other reasons?

Q35. Please give the THREE main reasons, IN ORDER OF IMPORTANCE, why you chose to study in the U.S.?

- Clarify given reasons if necessary.

- Other reasons? 
- Besides an educational qualification, what will you gain from studying in the U.S.?

Q36. Is there anything else you would like to add about your reasons for choosing to study overseas or choosing to study in the U.S.?

- Clarify given reasons if necessary.

- Other reasons?

Q37. Do you plan to return to your home country when you have completed your studies or do something else?

- For those who hope to return to their home country following graduation Why?

- Do you expect that your experiences in the U.S. will be useful to you at home?

- Do you think there will be problems when you return home?

- How will your experience in the U.S. benefit your home country?

- For those who said they were doing something else:

- What?

- Why do you not want to return home after graduation?

- If they said working abroad, do they plan to return home eventually?

\section{Global Economic Crisis}

- Has your opinion of the benefits of overseas study changed with the current global economic crisis?

- Have your 'after graduation' plans changed because of the current global economic crisis?

- Do you worry that the current global economic crisis will make it difficult to find a job?

- If you can't find a job what will you do? 


\section{Appendix E:}

Return and Response Rates 
Table 1: Questionnaires Return Rates

\begin{tabular}{|c|c|c|c|c|c|}
\hline Host Country & Total returned & Usable & \multicolumn{3}{|c|}{ Not usable } \\
\hline \multicolumn{4}{|c|}{ 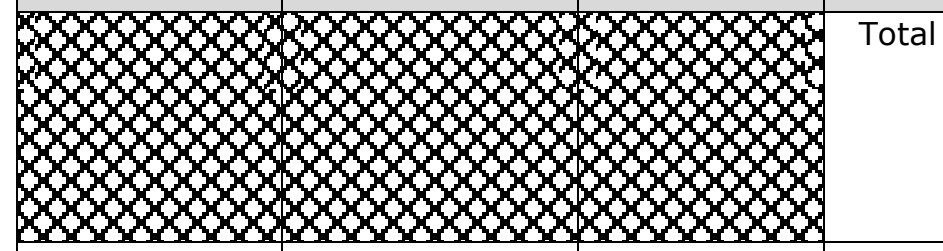 } & $\begin{array}{c}\text { Did not meet } \\
\text { screening criteria }\end{array}$ & $\begin{array}{l}\text { Eligible but did } \\
\text { not complete } \\
\text { questionnaire }\end{array}$ \\
\hline UK & 506 & $39(8 \%)$ & 467 & 433 & 34 \\
\hline U.S. & 165 & $22(13 \%)$ & 143 & 138 & 5 \\
\hline Ireland & 27 & $13(48 \%)$ & 14 & 13 & 1 \\
\hline TOTALS & 698 & $74(11 \%)$ & & & \\
\hline
\end{tabular}

Table 2: Interviewee Response Rates

\begin{tabular}{|l|c|c|c|}
\hline \multicolumn{1}{|c|}{ University } & Usable Questionnaires & Volunteers Total & Interviewed \\
\hline UK & 39 & 14 & 8 \\
\hline U.S. & 22 & 4 & 4 \\
\hline Ireland & 13 & 5 & 5 \\
\hline
\end{tabular}


Appendix F:

Participant Demographic Data 


\begin{tabular}{|c|c|c|c|c|c|}
\hline \multicolumn{6}{|c|}{ Table 3: Questionnaires - Demographic data for University UK } \\
\hline \multicolumn{6}{|c|}{ Total $=39$} \\
\hline \multirow{5}{*}{ Gender } & Male & 20 & \multirow{5}{*}{ Age } & $20-25$ & 31 \\
\hline & & & & $26-30$ & 6 \\
\hline & \multirow{3}{*}{ Female } & \multirow{3}{*}{19} & & $31-35$ & 1 \\
\hline & & & & $36-40$ & 0 \\
\hline & & & & $41-45$ & 1 \\
\hline \multirow{5}{*}{$\begin{array}{l}\text { Marital } \\
\text { Status }\end{array}$} & Single & 36 & \multirow{5}{*}{$\begin{array}{c}\text { Partner/ } \\
\text { Spouse } \\
\text { Living in UK }\end{array}$} & \multirow[t]{2}{*}{ Yes } & \multirow[t]{2}{*}{4} \\
\hline & Married & 3 & & & \\
\hline & Widowed & 0 & & & \\
\hline & Divorced & 0 & & No & 35 \\
\hline & Other & 0 & & & \\
\hline
\end{tabular}




\begin{tabular}{|c|c|c|c|c|c|}
\hline \multicolumn{6}{|c|}{ Table 4: Questionnaires - Participant data for University UK ${ }^{4}$} \\
\hline \multicolumn{6}{|c|}{ Total $=39$} \\
\hline \multirow{3}{*}{$\begin{array}{l}\text { Level of } \\
\text { study }\end{array}$} & Master's & 30 & \multirow{3}{*}{ Funding } & Completely self-funded & 27 \\
\hline & \multirow{2}{*}{$\mathrm{PhD}$} & \multirow{2}{*}{9} & & Partially self-funded & 8 \\
\hline & & & & Fully funded & 4 \\
\hline \multirow{6}{*}{$\begin{array}{l}\text { Country of } \\
\text { Origin }\end{array}$} & India & 20 & \multirow{6}{*}{$\begin{array}{l}\text { Field of } \\
\text { study }\end{array}$} & Law & 1 \\
\hline & China & 16 & & Engineering & 9 \\
\hline & Taiwan & 1 & & Business/Management & 18 \\
\hline & Korea & 1 & & Physical/Life Science & 10 \\
\hline & Japan & 0 & & Math/Computer Science & 1 \\
\hline & Other & 1 & & & \\
\hline
\end{tabular}

4 A comment should also be made here about the student who indicated 'Other' as country of origin. This student was from Malaysia, and although Malaysia was not one of the five countries chosen for the sample because it is not one of the top five source countries for international students in the U.S., after some discussion with my supervisor, I decided to include the responses from this student because they were informative, an already modest sample size, and the growing importance of Malaysia as both a source and host country (Lasanowski, 2009). Although not among the top five source countries, a significant number of Malaysian students still go to the U.S. for study making it twenty-first in the list of source countries for 2009 (IIE, 2009). In addition, the UK is one of the top study destinations for Malaysian students making the UK an important host country for these students (de Wit et al., 2008). 


\begin{tabular}{|c|c|c|c|c|c|}
\hline \multicolumn{6}{|c|}{ Table 5: Questionnaires - Demographic data for University U.S. } \\
\hline & & & $=22$ & & \\
\hline \multirow{5}{*}{ Gender } & Male & 14 & \multirow{5}{*}{ Age } & $20-25$ & 10 \\
\hline & & & & $26-30$ & 12 \\
\hline & \multirow{3}{*}{ Female } & \multirow{3}{*}{8} & & $31-35$ & 0 \\
\hline & & & & $36-40$ & 0 \\
\hline & & & & $41-45$ & 0 \\
\hline \multirow{5}{*}{$\begin{array}{l}\text { Marital } \\
\text { Status }\end{array}$} & Single & 21 & \multirow{5}{*}{$\begin{array}{c}\text { Partner/ } \\
\text { Spouse } \\
\text { Living in } \\
\text { U.S. }\end{array}$} & \multirow[t]{2}{*}{ Yes } & \multirow[t]{2}{*}{1} \\
\hline & Married & 1 & & & \\
\hline & Widowed & 0 & & \multirow{3}{*}{ No } & \multirow{3}{*}{21} \\
\hline & Divorced & 0 & & & \\
\hline & Other & 0 & & & \\
\hline
\end{tabular}




\begin{tabular}{|c|c|c|c|c|c|}
\hline \multicolumn{6}{|c|}{ Table 6: Questionnaires - Participant data for University U.S. } \\
\hline & & & $I=22$ & & \\
\hline \multirow{3}{*}{$\begin{array}{l}\text { Level of } \\
\text { study }\end{array}$} & Master's & 12 & \multirow{3}{*}{ Funding } & Completely self-funded & 6 \\
\hline & \multirow{2}{*}{$\mathrm{PhD}$} & \multirow{2}{*}{10} & & Partially self-funded & 3 \\
\hline & & & & Fully funded & 13 \\
\hline \multirow{5}{*}{$\begin{array}{l}\text { Country of } \\
\text { Origin }\end{array}$} & India & 12 & \multirow{5}{*}{$\begin{array}{l}\text { Field of } \\
\text { study }\end{array}$} & Law & 3 \\
\hline & China & 7 & & Engineering & 10 \\
\hline & Taiwan & 2 & & Business/Management & 5 \\
\hline & Korea & 1 & & Physical/Life Science & 3 \\
\hline & Japan & 0 & & Math/Computer Science & 1 \\
\hline
\end{tabular}




\begin{tabular}{|c|c|c|c|c|c|}
\hline \multicolumn{6}{|c|}{ Table 7: Questionnaires - Demographic data for University Ireland } \\
\hline \multicolumn{6}{|c|}{ Total $=13$} \\
\hline \multirow{5}{*}{ Gender } & Male & 8 & \multirow{5}{*}{ Age } & $20-25$ years & 9 \\
\hline & & & & $26-30$ years & 3 \\
\hline & \multirow{3}{*}{ Female } & \multirow{3}{*}{5} & & $31-35$ years & 1 \\
\hline & & & & $36-40$ years & 0 \\
\hline & & & & $41-45$ years & 0 \\
\hline \multirow{5}{*}{$\begin{array}{l}\text { Marital } \\
\text { Status }\end{array}$} & Single & 13 & \multirow{5}{*}{$\begin{array}{l}\text { Partner/ } \\
\text { Spouse } \\
\text { Living in } \\
\text { Ireland }\end{array}$} & \multirow[t]{2}{*}{ Yes } & \multirow[t]{2}{*}{1} \\
\hline & Married & 0 & & & \\
\hline & Widowed & 0 & & \multirow{3}{*}{ No } & \multirow[t]{3}{*}{12} \\
\hline & Divorced & 0 & & & \\
\hline & Other & 0 & & & \\
\hline
\end{tabular}




\begin{tabular}{|c|c|c|c|c|c|}
\hline \multicolumn{6}{|c|}{ Table 8: Questionnaires - Participant data for University Ireland } \\
\hline & & & $1=13$ & & \\
\hline \multirow{3}{*}{$\begin{array}{l}\text { Level of } \\
\text { study }\end{array}$} & Master's & 10 & \multirow{3}{*}{ Funding } & Completely self-funded & 9 \\
\hline & \multirow{2}{*}{$\mathrm{PhD}$} & \multirow{2}{*}{3} & & Partially self-funded & 1 \\
\hline & & & & Fully funded & 3 \\
\hline \multirow{5}{*}{$\begin{array}{l}\text { Country of } \\
\text { Origin }\end{array}$} & India & 3 & \multirow{5}{*}{$\begin{array}{l}\text { Field of } \\
\text { study }\end{array}$} & Law & 0 \\
\hline & China & 9 & & Engineering & 0 \\
\hline & Taiwan & 0 & & Business/Management & 7 \\
\hline & Korea & 0 & & Physical/Life Science & 4 \\
\hline & Japan & 1 & & Math/Computer Science & 2 \\
\hline
\end{tabular}




\begin{tabular}{|c|c|c|c|c|c|}
\hline \multicolumn{6}{|c|}{ Table 9: Interviews - Demographic data for University UK } \\
\hline \multicolumn{6}{|c|}{ Total $=8$} \\
\hline \multirow{5}{*}{ Gender } & Male & 6 & \multirow{5}{*}{ Age } & $20-25$ years & 7 \\
\hline & & & & $26-30$ years & 1 \\
\hline & \multirow{3}{*}{ Female } & \multirow{3}{*}{2} & & $31-35$ years & 0 \\
\hline & & & & $36-40$ years & 0 \\
\hline & & & & $41-45$ years & 0 \\
\hline \multirow{5}{*}{$\begin{array}{l}\text { Marital } \\
\text { Status }\end{array}$} & Single & 8 & \multirow{5}{*}{$\begin{array}{c}\text { Partner/ } \\
\text { Spouse } \\
\text { Living in UK }\end{array}$} & \multirow[t]{2}{*}{ Yes } & \multirow[t]{2}{*}{1} \\
\hline & Married & 0 & & & \\
\hline & Widowed & 0 & & & \\
\hline & Divorced & 0 & & No & 7 \\
\hline & Other & 0 & & & \\
\hline
\end{tabular}




\begin{tabular}{|c|c|c|c|c|c|}
\hline \multicolumn{6}{|c|}{ Table 10: Interviews - Participant data for University UK } \\
\hline & & & $1=8$ & & \\
\hline \multirow{3}{*}{$\begin{array}{l}\text { Level of } \\
\text { study }\end{array}$} & Master's & 5 & \multirow{3}{*}{ Funding } & Completely self-funded & 4 \\
\hline & \multirow{2}{*}{$\mathrm{PhD}$} & \multirow{2}{*}{3} & & Partially self-funded & 2 \\
\hline & & & & Fully funded & 2 \\
\hline \multirow{6}{*}{$\begin{array}{l}\text { Country of } \\
\text { Origin }\end{array}$} & India & 4 & \multirow{6}{*}{$\begin{array}{l}\text { Field of } \\
\text { study }\end{array}$} & Law & 0 \\
\hline & China & 4 & & Engineering & 5 \\
\hline & Taiwan & 0 & & Business/Management & 1 \\
\hline & Korea & 0 & & Physical/Life Science & 2 \\
\hline & Japan & 0 & & Math/Computer Science & 0 \\
\hline & Other & 0 & & & \\
\hline
\end{tabular}




\begin{tabular}{|c|c|c|c|c|c|}
\hline & & & $=4$ & & \\
\hline \multirow{5}{*}{ Gender } & Male & 3 & \multirow{5}{*}{ Age } & $20-25$ years & 2 \\
\hline & & & & $26-30$ years & 2 \\
\hline & \multirow{3}{*}{ Female } & \multirow{3}{*}{1} & & $31-35$ years & 0 \\
\hline & & & & $36-40$ years & 0 \\
\hline & & & & $41-45$ years & 0 \\
\hline \multirow{5}{*}{$\begin{array}{l}\text { Marital } \\
\text { Status }\end{array}$} & Single & 4 & \multirow{5}{*}{$\begin{array}{c}\text { Partner/ } \\
\text { Spouse } \\
\text { Living in } \\
\text { U.S. }\end{array}$} & \multirow[t]{2}{*}{ Yes } & \multirow[t]{2}{*}{ c } \\
\hline & Married & 0 & & & \\
\hline & Widowed & 0 & & \multirow{3}{*}{ No } & \multirow[t]{3}{*}{4} \\
\hline & Divorced & 0 & & & \\
\hline & Other & 0 & & & \\
\hline
\end{tabular}




\begin{tabular}{|c|c|c|c|c|c|}
\hline \multicolumn{6}{|c|}{ Table 12: Interviews - Participant data for University U.S. } \\
\hline & & & $=4$ & & \\
\hline \multirow{3}{*}{$\begin{array}{l}\text { Level of } \\
\text { study }\end{array}$} & Master's & 4 & \multirow{3}{*}{ Funding } & Completely self-funded & 0 \\
\hline & \multirow{2}{*}{$\mathrm{PhD}$} & \multirow{2}{*}{0} & & Partially self-funded & 1 \\
\hline & & & & Fully funded & 3 \\
\hline \multirow{5}{*}{$\begin{array}{l}\text { Country of } \\
\text { Origin }\end{array}$} & India & 1 & \multirow{5}{*}{$\begin{array}{l}\text { Field of } \\
\text { study }\end{array}$} & Law & 0 \\
\hline & China & 2 & & Engineering & 3 \\
\hline & Taiwan & 1 & & Business/Management & 1 \\
\hline & Korea & 0 & & Physical/Life Science & 0 \\
\hline & Japan & 0 & & Math/Computer Science & 0 \\
\hline
\end{tabular}




\begin{tabular}{|c|c|c|c|c|c|}
\hline & & & $=5$ & & \\
\hline \multirow{5}{*}{ Gender } & Male & 4 & \multirow{5}{*}{ Age } & $20-25$ years & 3 \\
\hline & & & & $26-30$ years & 2 \\
\hline & \multirow{3}{*}{ Female } & \multirow{3}{*}{1} & & $31-35$ years & 0 \\
\hline & & & & $36-40$ years & 0 \\
\hline & & & & $41-45$ years & 0 \\
\hline \multirow{5}{*}{$\begin{array}{l}\text { Marital } \\
\text { Status }\end{array}$} & Single & 5 & \multirow{5}{*}{$\begin{array}{l}\text { Partner/ } \\
\text { Spouse } \\
\text { Living in } \\
\text { Ireland }\end{array}$} & \multirow[t]{2}{*}{ Yes } & \multirow[t]{2}{*}{1} \\
\hline & Married & 0 & & & \\
\hline & Widowed & 0 & & \multirow{3}{*}{ No } & \multirow{3}{*}{4} \\
\hline & Divorced & 0 & & & \\
\hline & Other & 0 & & & \\
\hline
\end{tabular}




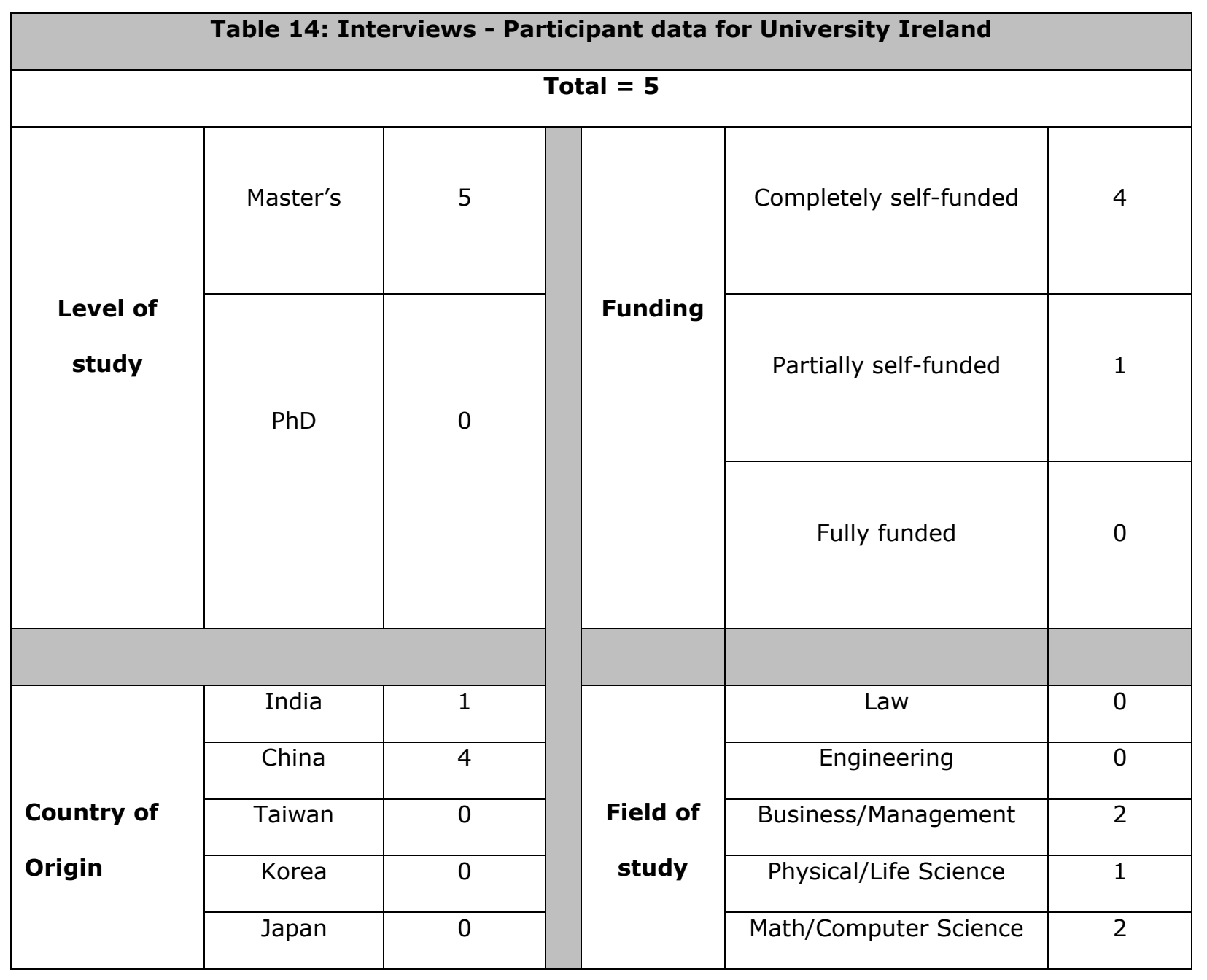


Appendix G:

Interviewee Information 


\section{Table 18: Interviewee Information}

\begin{tabular}{|c|c|c|c|c|c|c|c|c|}
\hline $\begin{array}{l}\text { Participant } \\
\text { no. }\end{array}$ & $\begin{array}{l}\text { Interview } \\
\text { Date }\end{array}$ & $\begin{array}{l}\text { Home } \\
\text { Country }\end{array}$ & $\begin{array}{l}\text { Host } \\
\text { Country }\end{array}$ & Gender & Age & $\begin{array}{l}\text { Level of } \\
\text { study }\end{array}$ & Field of study & $\begin{array}{c}\text { Which of the other two } \\
\text { host countries did } \\
\text { student consider as a } \\
\text { study destination } \\
(* \text { Ireland not listed })\end{array}$ \\
\hline UK\#11 & 26-03-09 & India & UK & Female & $20-25$ & PhD & Physical/Life Science & UK (\#1); U.S. (\#3);* \\
\hline UK\#37 & 26-03-09 & India & UK & Male & $20-25$ & Master's & Engineering & UK $(\# 1) ;$ U.S. $(\# 2) ; *$ \\
\hline UK\#28 & 27-03-09 & India & UK & Male & $26-30$ & PhD & Physical/Life Science & UK (\#1); U.S. (\#2); * \\
\hline UK\#14 & 27-03-09 & China & UK & Male & $20-25$ & Master's & Engineering & U.S. (\#1); UK (\#2); * \\
\hline U.S.\#20 & 13-04-09 & China & U.S. & Female & $20-25$ & Master's & Engineering & U.S. (\#1); UK (\#2);* \\
\hline U.S.\#21 & 13-04-09 & China & U.S. & Male & $26-30$ & Master's & Engineering & U.S. (\#1 - only choice) \\
\hline U.S.\#22 & 14-04-09 & Taiwan & U.S. & Male & $26-30$ & Master's & Business Mgmnt & U.S. (\#1); UK (\#2); * \\
\hline U.S.\#25 & 14-04-09 & India & U.S. & Male & $20-25$ & Master's & Engineering & U.S. (\#1); UK (\#2); * \\
\hline UK\#12 & 21-04-09 & China & UK & Female & $20-25$ & Master's & Engineering & UK (\#1); U.S. (\#2); * \\
\hline UK\#54 & 21-04-09 & China & UK & Male & $20-25$ & Master's & Engineering & U.S. (\#1); UK (\#2); * \\
\hline UK\#35 & 28-04-09 & India & UK & Male & $20-25$ & Master's & Business Mgmnt & UK (\#2); U.S. (\#3); * \\
\hline UK\#1 & $06-05-09$ & China & UK & Male & $20-25$ & PhD & Engineering & UK (\#2); U.S. (\#3); * \\
\hline IR\#2 & $19-05-09$ & India & Ireland & Male & $26-30$ & Master's & Business Mgmnt & $\begin{array}{l}\text { UK (\#1); U.S. (\#3); } \\
\text { Ireland (\#5) }\end{array}$ \\
\hline IR\# 5 & 19-05-09 & China & Ireland & Male & $20-25$ & Master's & Physical/Life Science & U.S. (\#1); UK (\#2); * \\
\hline IR\#1 & 20-05-09 & China & Ireland & Female & $20-25$ & Master's & Computer Science & U.S. (\#2); UK (\#3); * \\
\hline IR\#3 & 20-05-09 & China & Ireland & Male & $20-25$ & Master's & Computer Science & U.S. (\#1); UK (\#2); * \\
\hline IR\#4 & $20-05-09$ & China & Ireland & Male & $26-30$ & Master's & Finance & $\begin{array}{l}\text { Ireland (\#1); UK (\#2); } \\
\text { U.S. (\#3) }\end{array}$ \\
\hline
\end{tabular}


Appendix $\mathrm{H}$ :

Parents' Education and Occupations 


\begin{tabular}{|c|c|c|c|c|}
\hline \multicolumn{5}{|c|}{ Table 22: Parents' Education/Occupation } \\
\hline & \multicolumn{2}{|c|}{ Occupation } & \multicolumn{2}{|c|}{ Higher Education level achieved } \\
\hline $\begin{array}{l}\text { Student } \\
\text { ID }\end{array}$ & Father & Mother & Father & Mother \\
\hline UK\#2 & Civil Engineer & Accountant & Bachelor's & None \\
\hline UK\#62 & Bank Manager (ret.) & Homemaker & Master's & Master's \\
\hline UK\#101 & Company Manager & Accountant & None & Bachelor's \\
\hline UK\#133 & Medical Doctor & Medical Doctor & Medical degree & Medical degree \\
\hline UK\#278 & Railway Manager & Housewife & Master's & Bachelor's \\
\hline UK\#367 & Business Owner & Private tutor & None & None \\
\hline UK\#375 & $\begin{array}{c}\text { Head of College } \\
\text { Chemistry Lab (ret.) }\end{array}$ & $\begin{array}{c}\text { Head of College } \\
\text { Pharmaceutical Lab }\end{array}$ & Bachelor's & Bachelor's \\
\hline UK\#502 & Architectural Engineer & Assistant Accountant & Bachelor's & None \\
\hline U.S.\#149 & $\begin{array}{c}\text { College Staff (non- } \\
\text { teaching) }\end{array}$ & Dormitory Manager & None & None \\
\hline U.S.\#158 & Peasant Farmer & Peasant Farmer & None & None \\
\hline U.S.\#162 & Engineer & Factory Worker & $\begin{array}{l}\text { Vocational College } \\
\text { (two year degree) }\end{array}$ & $\begin{array}{l}\text { Vocational College } \\
\text { (two year degree) }\end{array}$ \\
\hline U.S.\#165 & $\begin{array}{c}\text { Company General } \\
\text { Manager }\end{array}$ & Housewife & $\begin{array}{c}\text { College } \\
\text { (two year diploma) }\end{array}$ & None \\
\hline IR\#6 & Engineer & College Teacher & $\mathrm{PhD}$ & PhD \\
\hline IR\#19 & Civil Engineer & Accounting Manager & Bachelor's & Bachelor's \\
\hline IR\#20 & Medical Doctor & Bank Staff & Medical degree & Bachelor's \\
\hline IR\#25 & Policeman & Primary School Teacher & $\begin{array}{c}\text { College } \\
\text { (two year diploma) }\end{array}$ & Bachelor's \\
\hline IR\#26 & Business Owner & $\begin{array}{c}\text { Works in husband's } \\
\text { company }\end{array}$ & None & None \\
\hline
\end{tabular}

